\title{
Impression Management in Consultancy: behavior tendencies, processes and effectiveness
}

Citation for published version (APA):

Safay, S. (2010). Impression Management in Consultancy: behavior tendencies, processes and effectiveness. [Doctoral Thesis, Maastricht University]. Océ Business Services. https://doi.org/10.26481/dis.20100219ss

Document status and date:

Published: 01/01/2010

DOI:

10.26481/dis.20100219ss

Document Version:

Publisher's PDF, also known as Version of record

\section{Please check the document version of this publication:}

- A submitted manuscript is the version of the article upon submission and before peer-review. There can be important differences between the submitted version and the official published version of record.

People interested in the research are advised to contact the author for the final version of the publication, or visit the DOI to the publisher's website.

- The final author version and the galley proof are versions of the publication after peer review.

- The final published version features the final layout of the paper including the volume, issue and page numbers.

Link to publication

\footnotetext{
General rights rights.

- You may freely distribute the URL identifying the publication in the public portal. please follow below link for the End User Agreement:

www.umlib.nl/taverne-license

Take down policy

If you believe that this document breaches copyright please contact us at:

repository@maastrichtuniversity.nl

providing details and we will investigate your claim.
}

Copyright and moral rights for the publications made accessible in the public portal are retained by the authors and/or other copyright owners and it is a condition of accessing publications that users recognise and abide by the legal requirements associated with these

- Users may download and print one copy of any publication from the public portal for the purpose of private study or research.

- You may not further distribute the material or use it for any profit-making activity or commercial gain

If the publication is distributed under the terms of Article $25 \mathrm{fa}$ of the Dutch Copyright Act, indicated by the "Taverne" license above, 
IMPRESSION MANAGEMENT IN CONSULTANCY:

Behavior tendencies, processes, and effectiveness

SARA SAFAY 
IMPRESSION MANAGEMENT IN CONSUlTANCY: Behavior tendencies, processes, and effectiveness

\author{
(C) S. Safay, Maastricht, 2009
}

All rights reserved. No part of this publication may be reprinted or utilized in any form by any electronic, mechanical or other means, now known, or hereafter invented, including photocopying and recording, or in any information storage or retrieval system, without permission from the copyright owner.

ISBN: 9789056813215 NUR: 801

Cover design: Sara Safay \& Axel Hüllenkremer

Photographer: Hans-Peter Hansen

Printed by: OCÉ Business Services 


\section{IMPRESSION MANAGEMENT IN CONSULTANCY:}

Behavior tendencies, processes, and effectiveness

\section{ProefsCHRIfT}

Ter verkrijging van de graad van doctor aan de Universiteit Maastricht, op gezag van de Rector magnificus, Prof. Mr. G.P.M.F. Mols volgens het besluit van het College van Decanen, in het openbaar te verdedigen op Vrijdag 19 februari 2010 om 14.00 uur

door

\section{SARA SAFAY}




\section{Promotor:}

Prof. dr. R. A. Roe

\section{Co-promotor:}

Dr. A. van Iterson

\section{Beoordelingscommissie:}

Prof. dr. M. A. Carree (voorzitter)

Prof. dr. M. G. Heijltjes

Dr. G. Odekerken-Schröder 


\section{IN MEMORY OF}

\section{Hasibe Gezduci}

Canim arkadaşım, bu senin için!

Seni gerçekten çok özlüyorum

...öteki maymun 


\section{ACKNOWLEDGEMENTS}

My PhD journey started with my work as a consultant at a well-known consulting firm. Working in the field and in direct interaction with the client I often wondered about colleagues' behaviors. Many times I asked myself: Why do they behave in certain ways even when clients might form unfavorable impressions? Are they not interested in how they appear to others? Are they not thinking of the result of their behaviors? In turn, others impressed me as well as their clients with great appearance and relationship binding actions. Acknowledging that sometimes consultants have to make the clients believe in capabilities that they may not actually have, I also asked myself what would be the effect on the consultant when he or she has to create the illusion of something they indeed are not. Would it make a difference to the client as well as to the consultant's performance if the behavior is authentic or artificially created? By resigning from my work as a consultant and by starting my $\mathrm{PhD}$ journey to investigate Impression Management in Consultancy I found the answers to these questions. However, during the time of my $\mathrm{PhD}$, life did not stand still or wait. Much has happened and changed in the time I've been involved with this project. Due to life's challenges my dissertation could not always be the number one priority. At any rate, I have finished! I could not have succeeded without the invaluable support, guidance, trust and efforts of a lot of people. Without these, especially the few I am about to mention, I may not have gotten to where I am today.

First, I want to express my deepest gratitude for my promoter, prof. dr. Robert Roe. Rob, I have been amazingly fortunate to have you as my supervisor and promoter. You gave me the freedom to explore on my own and at the same time the guidance to recover when my steps faltered. You experienced me in all emotional stages from sick at heart to sky high happiness. However, you managed it with a lot of patience and never lost your trust in me to finish the dissertation. Thank you for always given me inspiration, guidance, motivation and feedback in my own capabilities.

I would also like to thank my other promoter, dr. Ad van Iterson. Ad, thanks for your dedicated support and faith. We three had very interesting sessions and you often added another perspective on the issues at hand. From you I learned that it is sometimes better to take something with a pinch of salt - a lesson for life.

Further, I would also like to thank the members of the dissertation committee: prof. dr. Martin Carree, prof. dr. Marielle Heiltjes, and dr. Gaby Odekerken-Schröder. Thank you for the time, interest and energy that you devoted to reading this dissertation. 
My need for concrete help was met by a variety of people. Foremost, I would like to express my thankfulness to Rainer Heerling. Rainer, you started the journey with me by being my supervisor at the consulting firm. You mentored me and did not stop when I left the company to start my PhD. You always supported me, for example, by discussing ideas on consultants' behaviors towards their clients, but also in reaching a high group of participants for some of my studies. Thank you! Concerning the supply of information and data for my studies I have to thank many more people including the following: Akiko, thanks for sharing your expertise and knowledge with me and for creating contact with other interview partners; it was a pleasure meeting you and hope we can repeat it in whatever spot of the world. Johan, I enjoyed our talks, thanks for providing me with your insights and ideas. I also would like to thank among others Peter, Matthias, Michael, and Uta for talking with me about their role as a consultant and expressing honestly their personal viewpoints and opinions. Further, I would like to thank all persons who were involved in creating, testing, and filling in the questionnaires of the studies. I appreciate your help; without you this dissertation would not be what it finally is.

The best and worst moments of my dissertation journey have been shared with many more people, but I specially would like to thank my para nymphs, who have this role not without meaning. Adela and Fons, you were always there for me and helped me in any matter, you saw my laughing, you saw my crying, with you a problem shared was a problem halved, and felicity and enjoyment was doubled. I thank you for giving me your friendship, as deep and as rich as friendship can be. I am honored to have you both as my para nymphs.

Very special thanks go as well to Steffi, Simon, Vera, and Anneloes for your nice company: our walks in the park in the summer or winter, the exchange of scientific but also life knowledge and your help and support whenever I needed it. Thanks a lot!

The other current and former members of the department of Organization and Strategy and other departments also deserve a big thank you for maintaining an enjoyable and supportive work environment.

Moreover, I would like to thank my friends. Achim, Mel and Tine. Thanks for 25 years of friendship and support, you know me best and I am glad that I have you on my side. To my ex-neighbors, Claudia and Eric, we spent nearly the whole period of my $\mathrm{PhD}$ as neighbors, thanks for detracting me with great talks on the hallway. 
Further, my dear Hasibe, we went hand in hand through our PhD journeys, I miss you Hasibe, and with dedicating this book to you, I hope I can help to make one of your wishes come true.

The last, and surely the most, I would like to thank my family those living and those in heaven, for their love. My family has been a constant source of love, concern, support and strength all these years. My brothers, Sassan and Sandjar, are marvelous siblings; caring, funny and always there for me. My parents have instilled many good qualities in me and given me a good foundation with which to meet life. Ein besonderes Dankeschön geht an meine Mütter. Mama, danke für Dein Verständnis, Deinen Beistand, Deinen Rückhalt und Deine Liebe. Anna, danke für Deine unendliche Unterstützung. Wenn ich Zeit zum Arbeiten brauchte, hast Du von jetzt auf gleich auf Suri aufgepasst. Deine Ausdauer, Kraft, Flexibilität sind unvergleichlich und bewundernswert. Finally and most importantly my little family: Axel and Suri. Axel you know better than anybody else what I went through these last years and it was definitely not easy for you to understand or to help, but you did. You are the best man in the world; since I am not expressing this on a frequent basis I use this platform to do so. Thanks Baby! Suri, although you are not able to read this yet, you might do so in a couple of years. You, although you shorten my time during the day and night enormously since you came into this world, nothing can counter weigh what you give back to me. You are the best thing that has ever happened to me: ماما جان دوست دارم (Mama jan, duset daram). 


\section{CONTENTS}

ChAPTER $1 \quad$ INTRODUCTION.............................................................

Subject matter of research 3

Outline of this thesis $\quad 6$

Chapter 2 SETTINg THE SCENE For IMPRESSION MANAgEMENT .........................11

INTRODUCTION 12

An introduction and review of IM 12

$\begin{array}{ll}\text { Basic notions } & 13\end{array}$

IM IN THE WORK CONTEXT 16

IM in services 17

DifFERENCES AND VARIATIONS IN IM PERFORMANCE: SUCCESS AND FAILURE 20

IM performance from a differential perspective $\quad 22$

IM performance from a self-regulation perspective $\quad 26$

Methods to Measure IM

Measurement of IM in general social contexts $\quad 31$

Measurement of IM in organizational contexts $\quad 34$

CONCLUSION

Chapter 3 Impression Management in Consultancy SERVICEs: INTERVIEWS.......41

INTRODUCTION $\quad 42$

$\begin{array}{ll}\text { METHODS } & 42\end{array}$

$\begin{array}{ll}\text { Consultants } & 43\end{array}$

Experts/Trainers $\quad 43$

Analysis of interview content $\quad 44$

$\begin{array}{ll}\text { FINDINGS } & 45\end{array}$

Consultants 45

Experts/Trainers $\quad 58$

DISCUSSION 61

LimitATIONS AND FUtURE RESEARCH

$\begin{array}{ll}\text { CONCLUSION } & 64\end{array}$

Chapter 4 The Use of Impression Management Tactics by Consultants.........67

$\begin{array}{ll}\text { INTRODUCTION } & 68\end{array}$

CONSULTANTS' IM TACTICS

Consultants' IM tactics and performance 69

Effects of person and job-related characteristics on consultants' IM tactics $\quad 71$

$\begin{array}{ll}\text { METHODS } & 73\end{array}$

$\begin{array}{ll}\text { Participants and procedure } & 73\end{array}$

$\begin{array}{ll}\text { Scales } & 74\end{array}$ 
RESULTS

Factor analysis of consultants' IM tactics scales $\quad 76$

$\begin{array}{ll}\text { Descriptive statistics } & 77\end{array}$

$\begin{array}{ll}\text { IM tactics } & 79\end{array}$

IM tactics profiles $\quad 81$

DISCUSSION

IM tactics $\quad 86$

IM tactics profiles $\quad 86$

LIMITATIONS AND FUTURE RESEARCH

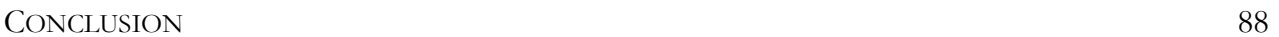

Chapter 5 To be, or ApPear to Be: How do Consultants' IM STYles Relate to

PERFORMANCE AND STRESS............................................91

INTRODUCTION 92

Part I: Styles of IM: AUthentic ACting And/OR Role ACting? 93

Authentic acting IM style 93

Role acting IM style $\quad 94$

Measure of IM styles $\quad 95$

METHOD 95

Participants and Procedure $\quad 96$

$\begin{array}{lr}\text { Scales } & 96\end{array}$

$\begin{array}{ll}\text { RESULTS } & 97\end{array}$

Principal component analysis $\quad 98$

$\begin{array}{lr}\text { Confirmatory factor analysis } & 99\end{array}$

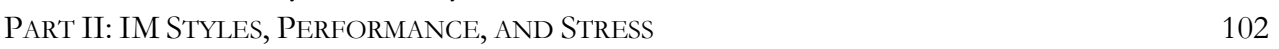

$\begin{array}{ll}\text { Performance } & 103\end{array}$

$\begin{array}{ll}\text { Stress } & 104\end{array}$

$\begin{array}{ll}\text { The role of IM competence } & 105\end{array}$

$\begin{array}{ll}\text { METHOD } & 107\end{array}$

$\begin{array}{ll}\text { Data } & 107\end{array}$

$\begin{array}{lr}\text { Scales } & 107\end{array}$

RESULTS 110

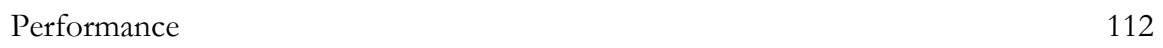

$\begin{array}{ll}\text { Stress } & 112\end{array}$

$\begin{array}{ll}\text { DisCUSSION } & 115\end{array}$

$\begin{array}{ll}\text { PART I } & 115\end{array}$

$\begin{array}{ll}\text { IM Styles: One- or two-dimensional? } & 115\end{array}$

$\begin{array}{ll}\text { PART II } & 117\end{array}$

$\begin{array}{ll}\text { The Main Effects of IM Styles } & 117\end{array}$

Direct and Moderating Effects of IM Competence 118

$\begin{array}{ll}\text { Effect of Age } & 118\end{array}$

LIMITATIONS AND FUTURE RESEARCH

$\begin{array}{ll}\text { CONCLUSION } & 120\end{array}$ 
CHAPTER 6 IMPRESSION MANAGEMENT OF BUSINESS STUdENTS OVER TIME.

$\begin{array}{ll}\text { INTRODUCTION } & 124 \\ \text { IM styles and tactics (over time) } & 126 \\ \text { METHOD } & 130 \\ \text { Participants } & 130 \\ \text { Procedure } & 131 \\ \text { Scales } & 132 \\ \text { RESULTS } & 134 \\ \text { Descriptive statistics } & 134 \\ \text { Re-test reliabilities } & 134 \\ \text { Correlations } & 135 \\ \text { Regression analyses } & 137 \\ \text { Multiple analysis of variance - repeated measures } & 139 \\ \text { DisCUSSION } & 141 \\ \text { LIMITATIONS AND FUTURE RESEARCH } & 142 \\ \text { CONCLUSION } & 142\end{array}$

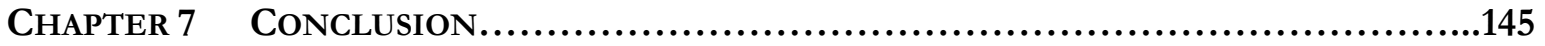

$\begin{array}{ll}\text { Subject matter and findings } & 145\end{array}$

Two Perspectives ON IM 146

Perspective 1: Differential 148

Perspective 2: Temporal (process) 151

Future RESEARCH DiRECTIONS 155

An Integral Model of IM 155

PRACTICAL IMPLICATIONS 160

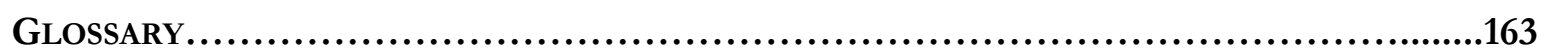

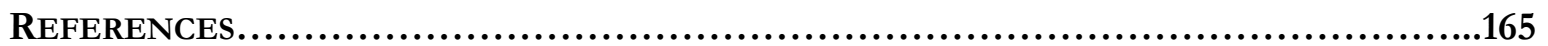

APPENDICES..........................................................................

APPENDIX A: CHAPTER 2 184

APPENDIX B: CHAPTER $3 \quad 185$

APPENDIX C: CHAPTER $4 \quad 196$

APPENDIX D: CHAPTER 5

APPENDIX E: CHAPTER $6 \quad 207$

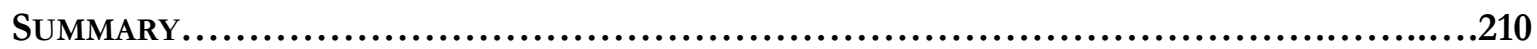

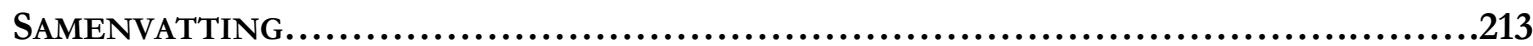

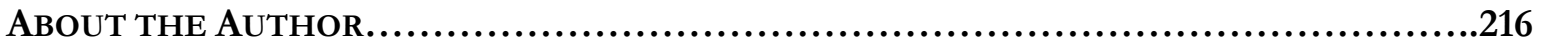



When an individual appears in the presence of others, there will usually be some reason for him to mobilize his activity so that it will convey an impression to others which it is in his interests to convey.

- Erving Goffman, The Presentation of Self in Everyday Life

In everyday life we experience again and again the effects of the impressions we make on other people. We might have realized it for the first time when we were a kid and our crocodile tears made our mother buy us a toy; in school, when we tried to appease our teacher with irreproachable behavior one week before a parent-teacher-evening; at our first date, when we only presented our best side, or at our first job application, recognizing that not only our expertise but also our appearance counts. These examples could be extended with many cases of day-to-day self-presentations, e.g. by sending emails at late hours to impress the boss with the portrayal of a hard-working employee, or by avoiding chewing gum at work so that one is not viewed as unprofessional and so on.

The presented situations illustrate that people are able to select the information they display to others in order to make a desired impression and thereby change others' thinking and subsequent behavior. This process is called impression management (IM). At first sight many people consider IM as manipulative, as a sign of insecurity or arrogance. However, examining one's own life reveals that IM is an important and omnipresent aspect of everyday interaction. In many social encounters we intentionally create a particular impression on our interaction partner. By the way we behave, i.e. look, talk, and move we are able to transmit selected information to others and thereby evoke certain images in others' eyes.

The impressions desired and the images presented are inter alia affected by the roles people play in social life (Goffman, 1959). Roles carry others' expectations and, typically, people want to convey impressions that are consistent with their roles and prevailing norms (Leary \& Kowalski, 1990). Work settings are known to prescribe roles to their organizational members (Katz \& Kahn, 1978). Consequentially, during the past twenty years, IM has found its way into organizational literature (e.g. Gardner \& Martinko, 1988; Giacalone \& Rosenfeld, 1989; 
Giacalone \& Rosenfeld, 1991). IM studies in organizational contexts have addressed for instance job interviews (e.g. Fletcher, 1989; Kacmar, Delery, \& Ferris, 1992; Levashina \& Campion, 2007), performance appraisals (e.g. Vilela, González, Ferrín, \& del Río Araújo, 2007; Wayne \& Kacmar, 1991), leadership (Leary, 1989), and careers (Ferris \& Judge, 1991; Judge \& Bretz, 1994).

This thesis aims to advance research on IM in organizations. The focus lies on studying IM's role at the edge of organizations - there where organizational members interact with customers - as in services. Unfortunately, to date, IM's function within service provider-customer relationships is rarely researched. For example, Vilela and colleagues (2007) argue that so far little is known about the situational, social and affective elements that are involved in a salesperson's performance appraisal. Although they consider IM as a potential impact factor, they unfortunately give solely attention to the effect of salespersons' IM on their supervisors but not on their customers. Other but few researchers have investigated service providers' IM hinting at its potential impact on customers. Here, for instance, attractiveness and standard accent were perceived more favorably by customers and created higher purchase intentions (DeShields, Kara, \& Kaynak, 1996). Moreover, the display of authenticity was found to positively affect customer satisfaction, regardless of task performance and busyness in the shop (Grandey, Fisk, Mattila, Jansen, \& Sideman, 2004).

Although many service settings might reveal the phenomenon of IM, this thesis intends to learn more about IM in a specific service area: consulting. Due to its enormous growth in the last past three decades the consultancy market has gained in importance (Ernst \& Kieser, 2002) and has become one of the most dynamic industries (Fincham \& Clark, 2002). The expansion is exemplary for the general shift to the service sector. A more and more turbulent environment and the need for knowledge transfer are given as reasons for the consultancy market explosion (Kieser, 2002).

Consulting is a so-called "pure" service (Solomon, Surprenant, Czepiel, \& Gutman, 1985) characterized by a high amount of person-to-person interaction. Here, "the service component of the total offering is a major element of that offering" (1985: 99), which encourages the emergence and even the need for IM. For example, because consultants mainly sell an intangible product based on their expertise and knowledge, clients a priori are not aware of what they buy. Consequently, there is room for consultants to influence the way clients will perceive the value and the quality of the service provided. It becomes indispensable for consultants to convince clients that they will benefit from the expertise, knowledge and skills offered. This implies that clients may reach a conclusion about the quality of consultancy services largely in terms of the 
images created by the consultant. As a result, the consulting industry provides an excellent scenery for studying IM (Alvesson, 1993; Clark, 1995; Clark \& Salaman, 1998; Starbuck, 1992).

However, "despite their increasing influence (...) the work of consultants is a fairly recent phenomenon and much remains to be done if we are to develop a broader and more detailed understanding of this activity" (Fincham et al., 2002: 1). This thesis aims to acquire more information about consultants' work and IM's relevance within consultant-client relationships.

To explore the concept of IM more thoroughly and to identify vital aspects of IM in consultancy, we have to take a look at essential research gaps. To date most studies on IM have dealt within the following topics: (1) specific behaviors resulting from people's desire to be seen by others in a particular way, (2) the motives underlying IM, (3) the kind of impressions people try to make and how others perceive these, and (4) consequences of IM (e.g. Leary, 1995; Leary et al., 1990; Schlenker, Britt, \& Pennington, 1996; Schlenker \& Weigold, 1992; Singh, Kumra, \& Vinnicombe, 2002; Wayne \& Liden, 1995). Although this has resulted in useful theoretical perspectives on IM (e.g. Gardner et al., 1988; Leary et al., 1990; Schlenker, 1980; Schlenker et al., 1996; Schlenker et al., 1992) the following issues related to IM in consultancy are still unresolved and open for research: (1) variations in IM performance levels; (2) behavior tendencies in IM; (3) competence in IM; and (4) IM processes over time. Insights gained may be of relevance for IM in general as well. In the following section these unresolved issues constituting the subject matter of our research will be explained in more detail.

\section{Subject matter of research}

\section{Variations in IM performance levels}

An individual's behavior in interaction with others has been described as performances constructed to provide the audience with impressions the actor wants them to develop (Goffman, 1959). Although the focus of IM is on creating an aimed for image in the eyes of others it is clear that IM performance varies and can also fail. Given that organizations select, train and give feedback to their employees concerning their expressions, success can be considered to be the norm and a deflection from the effective default status as problematic. For example, at times the (non-) application of IM may create undesirable impressions among others. Such as a consultant who makes a negative impression on a client because he or she is not appropriately dressed or one who overshoots with flattering the client so that the client considers him or her as a sycophant. Studies show that people who are poorly dressed are perceived as less competent (Rafaeli \& Pratt, 1993) as well as acknowledge that IM is not risk-free (Jones \& Pittman, 1982; Turnley \& Bolino, 2001). 
Theoretical and empirical explanations for variations in IM performance have primarily focused on inter-individual differences between impression managers. For example, Snyder's (1974) selfmonitoring characteristic of individuals has been examined and identified to relate to negative consequences of IM (Turnley et al., 2001). However to date, as far as known, only one line of systematic research has tried to establish which intra-individual factors prevent people at times to establish favorable images among others. Vohs and colleagues $(2005 ; 2004)$ found that depleted self-regulatory resources can result in unsuccessful IM performance. In accordance with these and others researchers (Bozeman \& Kacmar, 1997; Roberts, 2005; Vohs et al., 2005; Vohs et al., 2004) we think that a process orientation, particularly a self-regulation perspective on IM performance, is helpful in gaining a better understanding of IM and respective variations in its execution.

Furthermore, most research on IM focuses on its relationship with positive performance outcomes. We do not only investigate whether IM impacts positively on the performance of an individual, as was done before (e.g. Vilela et al., 2007; Wayne et al., 1991), but also regard the other side of the coin. Referring to the literature on emotional regulation in service settings and stress as a possible consequence (Grandey, 2003; Grandey, Fisk, \& Steiner, 2005b), we also examine whether IM relates to the experience of stress.

\section{Behavior tendencies in IM}

Various IM tactics and strategies are described and investigated in IM research (e.g. Leary, 1995; Schlenker et al., 1992; Thacker \& Wayne, 1995). For example, people are seen to use ingratiating behaviors to make the impression of a likeable person (Jones et al., 1982). However, limited knowledge exists about the styles with which people convey and perform IM. Until now IM behaviors are mainly linked to two different styles: an acquisitive (also called attributive and assertive) and a protective (also called repudiative and defensive) IM style (Arkin, 1981; Roth, Snyder, \& Pace, 1986; Schlenker, 1980; Tedeschi \& Melburg, 1984; Tedeschi \& Norman, 1985). Individuals with an acquisitive IM style attempt to gain social approval by communicating a favorable image. In contrast, people with a protective IM style try to evade social disapproval by disputing negative ascriptions.

Furthermore, different concepts (tactics, strategies, and styles) are used without clear distinctions and researchers use different labels to describe the same IM behaviors (Bolino, Kacmar, Turnley, \& Gilstrap, 2008). As a consequence, we decided to subsume them under two general labels - behavior tendencies in IM and IM behavior - and differentiate them later in the thesis. 
In this thesis, we aim to investigate behavior tendencies in IM that seem to be especially relevant in consultancy services. More precisely, we introduce three IM tactics specifically utilized by consultants to influence the impressions of their clients. We label them personal, professional and conforming IM tactics. Further, we propose that IM expressed in various IM tactics can be employed differently, somewhat akin to the distinction between honest and deceptive. For example, by complimenting clients consultant might try to achieve a likeable image in the eyes of the clients. However, the compliments could be sincerely given or just be played. We introduce two new IM styles: authentic acting and role acting IM styles, implying that individuals with an authentic acting IM style try to make certain impressions on others by presenting edited but real characteristics and behaviors of themselves, and individuals with a role acting style attempt to fulfill others' role based expectations irrespective of the personal truth.

Concerning behavior tendencies in IM, we intend to move the field of IM forward in two ways. First, we want to discover, test, and investigate specific consultants' IM tactics. The focus lies on the identification of IM tactics, their use, their relations to consultants' performance, and an investigation of various variables that might influence the use of IM tactics by consultants. Second, we plan to construct and test measures for two additional IM styles, identify their dimensionality and ascertain their relations with consultants' performance and experienced stress.

\section{Competence in IM}

Research suggesting that organizational actors can successfully employ IM has almost given exclusive attention to "typical" instead of "maximum" performance. Generally, typical performance is described as the behavior an individual displays over a period of time. In contrast, maximum performance is regarded as the level of performance reached when an individual devotes full effort to it (Sackett, 2007). The two concepts have been utilized to differentiate influences of personality from those of motivation and ability (Deadrick \& Gardner, 2008). While research on IM has focused on identifying typical behaviors of impression managers, as manifested in IM styles, strategies and tactics, no attention has been given to maximum performance in IM. To emphasize this aspect of IM, we introduce the notion of IM competence.

We aim to extend existing research on IM, first, by identifying elements of IM competence, second by developing and validating a measure that assesses the IM competence of consultants, and finally, by investigating how IM competence relates to consultants' IM tactics, IM styles, performance and experienced stress. 


\section{IM processes over time}

In spite of the fact that impression formation is described as a dynamic process (Bozeman et al., 1997; Jones, 1990; Roberts, 2005) there is almost no data available that describes changes in IM and its effectiveness over time. Wayne and Liden (1995) are, to our knowledge, the only scholars who have investigated the long-term effects of subordinates' IM on performance ratings given by their supervisors. The authors found that subordinates' use of IM in the beginning of the subordinate-supervisor relationship arouses liking and perceptions of similarity in supervisors' impressions, which in turn influence performance ratings made at a later point. However, more longitudinal studies on IM are needed to gain a better understanding of the IM process (Wayne et al., 1995).

We collect longitudinal data to explain how the management of impressions - expressed through individuals' IM styles and the employment of certain IM tactics - varies over time and how this affects their performance level.

\section{Outline of this thesis}

In the following we briefly present the chapters of this thesis. This introductory chapter finishes with a table (Table 1) displaying the outline of the thesis, including each study's purpose, research questions, added value, and design.

\section{Chapter 2}

We begin with a brief introduction and review of extant research literature on IM. Further, the potential impact of IM in work settings is discussed, emphasizing its importance in service settings. Here, we specifically point at the relevance of IM in consultancy claiming that it provides dramatic scenery for IM. Next, based on the argument that IM success can be considered to be the norm due to selection, training and feedback processes that employees and specifically consultants go through, we give attention to failure in IM performance and try to find explanations for it. One the one hand, we take a differential perspective on IM performance and study a personality characteristic often used in the IM literature to explain differences in IM performance, that is self-monitoring (Snyder, 1974), as well as IM styles, strategies, and tactics. On the other hand we take a self-regulation perspective, which is a novel approach, helping to explain intra-individual variations in IM performance. Hence, in addition to describing why some people are not successful in their IM attempts at all times, we also try to learn why others are 
sometimes not able to manage others' impressions. The chapter finishes with reviewing existing methods of IM measurement in general as well as in organizational settings.

\section{Chapter 3}

This chapter presents an interview-based study in which consultants and experts in the field of consultancy and/or IM give their view on what IM is about, how it is practiced and what makes it work or fail. It describes various differential and self-regulation notions that conform to existing views and inform further studies. The results of this study are an inventory of desired consultant images, specific behavior tendencies in IM shown by consultants, IM competences and self-regulation issues, and finally a personality characteristic implied in consultants' IM.

\section{Chapter 4}

This chapter describes an exploratory study among consultants $(\mathrm{N}=80)$ examining the use of IM tactics. Here, the three consultants' IM tactics identified in the previous study are analyzed (a) separately and (b) in combination. First, the study investigates the ways in which various person and job-related characteristics are related to IM tactics' use. Next, the research explores the relationship between consultants' IM tactics - employed one by one and in combination - and how consultants think that they are perceived by their clients.

\section{Chapter 5}

Based on an empirical study among consultants $(\mathrm{N}=233)$ this chapter introduces and operationalizes two new IM styles. The chapter is divided into two parts. In the first part we describe whether these styles represent opposite poles of a single dimension or rather two dimensions. In the second part, a differential design is used to establish relationships of the two styles with consultants' performance and stress. Additionally, direct and moderating roles for IM competence are examined.

\section{Chapter 6}

This chapter investigates the effects of differences in IM styles and tactics over time by means of a longitudinal study. For this purpose we use a sample of business students $(N=726)$. Here, the two IM styles tested in the previous study and five well-established IM tactics are related to the 
participating ratings that students receive from their teachers at two points in time. Thus, we are not only interested in IM's effectiveness but also its usage over time.

\section{Chapter 7}

The final chapter is cut in two parts. First, we integrate our findings in two related theoretical perspectives on IM taken in this thesis. The differential perspective focuses on the identification of individual differences in personality, behavioral tendencies, and competence in explaining differences in IM performance. The temporal approach on IM calls attention for processes rather than differences and helps to understands how it unfolds over time. Subsequently, we draw attention to factors potentially effecting IM, which, however, have neither been considered sufficiently in the IM literature nor in this thesis. Accordingly, we give future research suggestions leading to an integral model of IM. The chapter closes with discussing the practical implications.

For a clear distinction on various IM terms used in this thesis (as IM behaviors, styles, tactics and competence), please consider as well the glossary at the end of the thesis. 


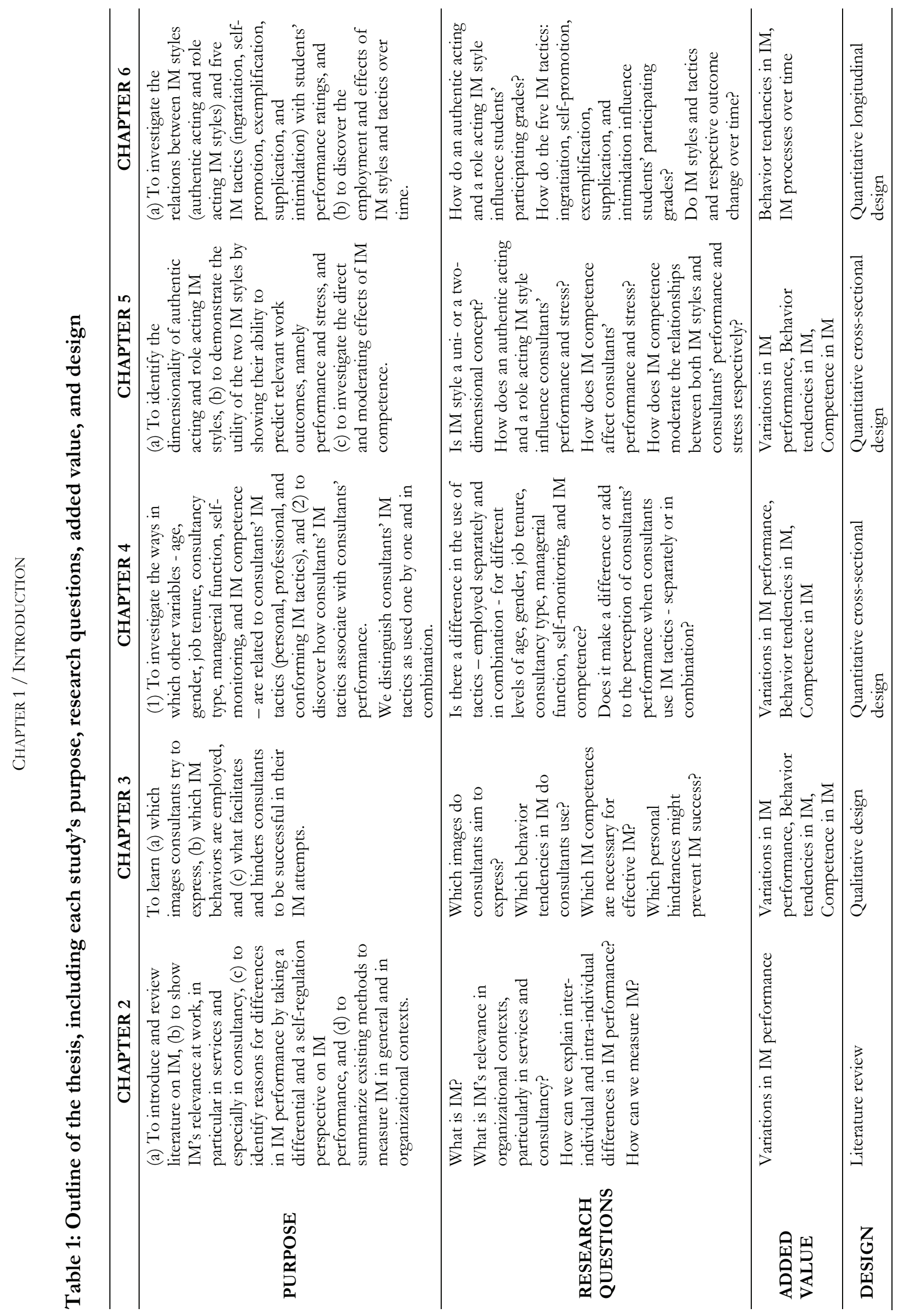




\section{SETTING THE SCENE FOR IMPRESSION MANAGEMENT}

It often happens that the performance serves mainly to express the characteristics of the task that is performed and not the characteristics of the performer. Thus one finds that service personnel, whether in profession, bureaucracy, business, or craft, enliven their manner with movements which express proficiency and integrity, but whatever this manner conveys about them, often its major purpose is to establish a favorable definition of their service or product.

(However,)... the performers may act in such a way as to give the impression that he is too much or too little concerned with the interaction. He may stutter, forget his lines, appear nervous, or guilty, or self-conscious; he may give way to inappropriate outbursts of langhter, anger, or other kinds of affect which momentarily incapacitate him as an interactant.

- Erving Goffman, The Presentation of Self in Everyday Life

Better be dumb than to have a tongue which is not under control.

- Persian proverb

IM is the process whereby people try to make a particular impression on other people in order to influence their future thinking and behavior. Organizational behavior researchers are recognizing the importance of IM in everyday work life. We show why IM can be seen as a crucial component of work performance in organizations, especially in a service area like consultancy. Further, assuming that IM success is the norm, due to selection, training and feedback processes that employees specifically consultants - run through, there are unquestionable inter- and intra-individual differences in IM performance. Hence, we take a dual perspective when reviewing the literature on IM. That is, a differential outlook and a self-regulation perspective on IM to explain why some people at all times and others at times fail in their IM attempts, respectively. The study finishes with a review that includes measures of IM in general and in organizational contexts. 


\section{INTRODUCTION}

The purpose of this chapter is to give an overview of IM theory and research. We focus on answering four questions: (1) What is IM? (2) What is IM's relevance in organizational contexts, particularly in services and consultancy? (3) How can we explain inter-individual and intra-individual differences in IM performance? (4) How can we measure IM?

We start the chapter with presenting background information, including historical views and basic notions on IM. Then, we highlight the linkage between IM and work performance, in services and consultancy. Subsequently, considering a differential and a self-regulation perspective on IM, we try to identify factors causing variations in IM performance levels. Finally, we summarize existing methods to measure IM in general and organizational contexts.

\section{An introduction and review of IM}

What people do, what they say, how they look and act, it all provides information to others. The view that individuals select the information they send to others in order to convey a certain image has been well supported (cf. Arkin, 1981; Baumeister, 1982; Leary, 1995; Schlenker, 1980). The goal is to influence others' thinking and behavior since "image is a mental picture or categorization of an individual" and it "affects the way one is evaluated" and "treated in social interaction" (Schlenker, 1980: 95). As the image develops, its effectiveness is examined and if necessary corrected. Each image must be continually legitimized because image is only "loan (...) from society" and it will be extracted from the individual if he or she does not behave accordingly (Goffman, 1967: 10).

From a sociological viewpoint IM is explained from social rules and processes. These are supposed to have an impact on people not as individuals, but as members of a group. Sociologists were the first to develop theory about people trying to shape the impressions held by others. Sociologist Erving Goffman's book “The Presentation of Self in Everyday Life" (1959) marks the beginning of conceptualizing the phenomenon of IM. According to Goffman, when behavior is public, there will usually be some reason for individuals to control their activities so that images are displayed to others that are in their interest to be expressed. It occurs at all stages of relationships, at first contact as well as over long-term relationships. He uses the metaphor of theatrical performance as a framework, where each individual plays different roles in everyday life. People prepare behind the drop curtain, not observable for their audiences, select the costumes suitable, and try to offer their public a convincing performance that is regarded as reality. (The Latin word "person" literally 
translates in an actor's mask). In his view, IM is a natural and omnipresent facet of social interaction. In the literature his and others' affirmative outlook on IM (Hogan \& Cheek, 1983; Schlenker, 1980, 1985) has been termed the expansive view (Schlenker et al., 1992). Goffman's approach has been criticized for mainly describing but not explaining IM (Grove \& Fisk, 1989). However, with his portrayal of social interactions and illustrations of the human tendency to steer other people's impressions in everyday life, Goffman did the groundwork for researching IM from other theoretical perspectives.

In contrast to Goffman's approach, the social psychological point of view emphasizes the individual and the individual's definition of the situation. Here, IM is characterized by people's concern about how they are perceived by others, sensitivity to the personal and others' expectations, and tailoring of behaviors as to create a desired image in the impression of others. This view implies that people have a choice in selecting the outward presented self; it depends on their interpersonal motives (Leary, 1995). In this perspective, IM is often described as something manipulative e.g. with the goal to deceive others in order maximize one's own power (Buss \& Briggs, 1984; Jones et al., 1982; Snyder, 1987). It stands in contrast to the expansive view on IM and has been called the restrictive approach (Schlenker et al., 1992).

Most research on IM emanates from a social psychological outlook on IM, which mainly started in the 1970s and focused on experimentally investigating subjects' IM (Jones et al., 1982; Jones \& Jones, 1964; Schlenker, 1980; Tedeschi \& Riess, 1981). Nevertheless, until the 1980s IM was regarded as a peripheral topic and not as a fundamental aspect of interpersonal behavior. Meanwhile IM has been identified to affect virtually all areas of social life (cf. Leary et al., 1990).

\section{Basic notions}

The extent to which people are imposed and motivated to manage others' impressions can vary across situations, implied audiences, and certainly from actor to actor ${ }^{1}$. For example, the situation and the audience stimulate or even dictate how people should present themselves. Additionally, through the process of interaction, the actor and the audience define the situation they find themselves in and thereby guide consequent behavior (Beard, 1996; Goffman, 1959). Furthermore, the actor can voluntarily decide for or against an image depending on personal preferences. Hence,

\footnotetext{
${ }^{1}$ In this thesis we call individuals who perform IM both actors and impression managers and use the terms: others, targets, audiences interchangeably to address those people whose impressions should be influenced.
} 


\section{CHAPTER 2}

IM can be a reaction to a current situation (including the audience) and/or present an individual's disposition to perform IM in a particular way (Schlenker et al., 1992).

\section{Situation}

Goffman (1959) distinguished between private and public situations. Referring to his theater metaphor of IM performance, he called public and private situations, front- and backstage. Backstage, people are freer in their behavioral choices since the audience is waiting frontstage for their performance and cannot see what they are doing behind the curtain. At the frontstage people are "on the scene", allowing audiences to judge and evaluate their performances. People are seen to be more motivated to manage others' impressions when their behavior is public (Schlenker et al., 1992).

Further, in public situations general and specific standards for self-presentational behaviors are given (Leary, 1995). These restrictions limit the choice of potential images. For example, consider yourself at a funeral, certain appearances - as a solemn face or dark clothing - are asked for irrespective of current personal feelings or proneness. Hence, "the role gives direction and purpose to the actor's behaviors, guiding them along a predetermined course" (1980: 66).

Due to the fact that social rules govern IM behavior, they can also affect its success or failure. For example, Rudman (1998) found that the gender of a person who "self-promotes", a well known IM tactic with which a person points at his or her ability and skills (Jones et al., 1982), has an impact on IM's effectiveness. She discovered that females perceive women who self-promote as competent but less socially attractive, causing a lower chance to get hired. The conclusion is that the perception by others that one is behaving atypically can result in detrimental impressions and consequent actions. This underlines that the social norms in a society or an organization determine the standards of social behavior and consequently of IM.

\section{Audience}

The audience is of significant importance for the IM process, because it is the target of IM; it is "them" who should be influenced. Audiences are not just a passive target of IM but also inform the potential impression manager about the image being desired (Schlenker et al., 1992). Without information about the targets, it becomes difficult for the actor to foresee their future reactions and to adapt behavior to their expectations (Bromley, 1993; DePaulo, 1992; Schlenker et al., 1996). Since 
audiences can differ, also different goals and the expression of different images condition human behavior (Schlenker, 2003).

Many authors acknowledge that audiences have to exhibit certain features in order to become the target of IM. Audiences should have desirable characteristics which are valued as important (Leary, 1995; Schlenker, 1980). For example, they should be powerful, influential, high in status, and attractive (Bromley, 1993; Leary et al., 1990; Schlenker \& Leary, 1982). They should have an influence on intended outcomes, as social approval and material rewards (Schlenker, 2003; Schlenker et al., 1996). Especially when the actor is dependent on others, he or she will be highly motivated to manage their impressions (Leary, 1995). Another aspect which has been taken into consideration is future interaction (Leary et al., 1990). That is, the impressions made on others are regarded as more important when the impression manager can expect to interact with them in the future (Gergen \& Wishnov, 1965; Leary, 1995).

\section{Actor}

As noted, Goffman (1959) representing the sociologist view, does not consider the roots of human behavior but rather its context. In his analysis of IM, the individual cannot be seen without the relationship to others. They all - actors and audiences - co-create a definition of the situation. It is not the actor who decides whether and which role to play. He or she is under compulsion to fulfill the duties of the social role and to present them to the audience. Therefore, IM is described to emerge from the occasion and not from the individual (Elliot, 2001).

Following the social psychological approach on IM (Jones et al., 1982; Jones \& Jones, 1964; Schlenker, 1980; Tedeschi \& Riess, 1981), we think it is important to include the "self" as the basis of individual performance. It is the actor who tries to "shape others' impressions of his personality" (Jones et al., 1982: 231). Hence, the situation and the audience clearly define a certain role for an individual, but the actor has a voice in playing the IM role yet constrained by his or her personal motivation and ability to manage others' impressions (Snyder, 1974; Turnley et al., 2001).

Since the impressions others develop have an impact on many aspects of persons' social lives, they also play an important role in everyday organizational behavior. In the following, we show that work organizations provide a stage for IM and that organizational members and customers can be regarded as important and influential audiences, asking for an adequate performance by organizational actors. 


\section{IM IN THE WORK CONTEXT}

The behavior of people in work settings is seen to be inter alia influenced by the intention to make particular impressions on others (Baumeister, Hutton, \& Tice, 1989; Bolino, 1999; Giacalone et al., 1991; Rosenfeld, Giacalone, \& Riordan, 1995). For example, IM in organizations has been associated with careers (Feldman \& Klich, 1991), performance appraisals (Bolino, Varela, Bande, \& Turnley, 2006; Vilela et al., 2007; Villanova \& Bernardin, 1991; Wayne et al., 1991), negotiations (Wall, 1991), job interviews (Fletcher, 1989; Levashina et al., 2007; van Iddekinge, McFarland, \& Raymark, 2007; Weiss \& Feldman, 2006), leadership (Leary, 1989), and many more (cf. Arkin \& Sheppard, 1989; Baumeister, 1989; Bozeman et al., 1997; Gardner et al., 1988; Giacalone et al., 1989; Giacalone et al., 1991; Rosenfeld et al., 1995; Rosenfeld, Giacalone, \& Riordan, 2002; Tedeschi et al., 1984).

Rosenfeld and colleagues (1995) describe organizational IM to comprehend strategic expressions of organizational members dedicated to establish, maintain or protect desired images. Due to the fact that all organizations have established norms and expect certain expressions from their members, the organization sets the standards and thereby the general set-up of member behavior. Any member has to satisfy these organizational requirements in order to be perceived as performing effectively. In our view IM is an essential and necessary tool to fulfill these demands.

It seems reasonable to assume that work performance requires some degree of IM. But to what degree is work performance influenced by IM? To find possible answers to this question, it is important to establish a clear terminology of performance at the outset. Arvey and Murphy (1998) stated that during the last decades not only task but also contextual performance gained in importance. Whereas task behaviors are needed to perform core technical activities, "contextual behaviors serve to facilitate communications, lubricate social communications, and reduce tension and/or disruptive emotional responses, and are viewed as important and contributing to organizational goals" (: 147). In our view, both are important. In addition to the performance of tasks, most jobs require interaction with other people, and often information, interest and cooperation from others is needed to perform successfully. The example of an employment interview demonstrates the importance of both performances and shows how IM is involved: the applicant needs a history of successful work performance, including the tasks fulfilled in former work places, and the applicant should be able to communicate clearly and apply effective IM, e.g. to bring his or her capabilities across or to make the interviewer like him or her. Consequently, work performance can be described to include IM. The importance, however, depends on the organizational setting and the extent to which task or contextual performance is required, valued and 
rewarded. Accordingly, the use of IM can vary from situation to situation, job to job, organization to organization, and industry to industry.

\section{IM in services}

In contrast to many other workplaces, a high degree of contact and sometimes also inter-dependence exists between employees and customers in service settings. This is due to the fact that most services are delivered through personal interactions, often face-to-face (Ashforth \& Humphrey, 1993; Bowen \& Schneider, 1988; Hochschild, 1983). In high contact services, customers have the possibility to notice and judge the actions of the service employee (Grove et al., 1989). Consequently, one important feature for service evaluation is the customer's impression of the service provider. Further, for the reason that services are intangible customers often use impressions to evaluate the service provided (Bowen et al., 1988), including the appearance of service providers (Bessom \& Jackson, 1975). The service providers in turn can use this knowledge to influence a customer's impression of a service in a predetermined direction.

Moreover, service encounters often comprise emotional labor, which is the expression of organizationally desired emotions (Hochschild, 1983). The impressions formed through observation of employee's expressed emotions are an important aspect in the evaluation of service performance. For example, an enraged service provider and consequent performance like yelling at the customer will create a negative impression in the customer and will most likely result in a cancellation of customer's buying intention. However, a friendly employee smiling at the customer can create customer satisfaction, which ultimately can lead to a potential sale. As a result, in services the emotional expression in accordance with display rules increases the likelihood of more effective workplace interaction and task accomplishment (Grandey, 2000); but the emotions have to be perceived as genuine by the customers (Rafaeli \& Sutton, 1989). In order to succeed in emotional labor, emotional management is a prerequisite. Hochschild (1983: 7) defined emotional management as the "management of feeling to create a publicly observable facial and bodily display". She emphasized how employees are required to manage or shape their own feelings in interaction with others in order to be able to manage their appearance and thereby other people's perceptions. Selfpresentation skills of employees are viewed to influence the outcome of emotional labor (Ashforth et al., 1993; Wharton, 1993). This illustrates the strong catenation between emotional management and IM, as acknowledged by various authors (Friedman \& Miller-Herringer, 1991; Grandey, 2000). 


\section{CHAPTER 2}

Hence services, in particular those including emotional labor, offer good examples for describing and examining IM.

However, in spite of the awareness on IM's importance in services and emotional labor, specifically in the interaction between service providers and customers, it is surprisingly seldom investigated.

\section{IM in consultancy}

IM is regarded as especially important in service encounters like consultancy (Clark, 1995). It appears that various consultancy service characteristics make the concept of IM particularly relevant for this type of work. For example, the significance of a favorable interaction between consultants and clients is important due to clients' interest to have consultants join a client team. Formerly, consultants did most of the work together with a client representative. Today, consultants are in the role of assisting client employees and work together in and with client teams. As a consequence the outcome depends on the quality of interaction and this is also the process where consultants can convince clients of their value and quality. However, due to the reason that clients' own interaction and effort contributes to project work, it is difficult for them to objectively measure consultants' performance at the end of a project.

Furthermore, consultancy is depicted as a knowledge intensive service featuring the transfer of knowledge (Ernst et al., 2002). Since knowledge is intangible, it is difficult for clients to determine the quality of consultants' service beforehand and afterwards. Consultants can rely only on thirdparty reports or direct experience of past service to prove their expertise. Nevertheless, it is not easy to evaluate whether a consultant is actually knowledgeable or only knows how to manage impressions. According to Starbuck (1992: 731) we must "pay attention to their symbolic outputs" if we want to apprehend consultancies' success. That is how they create impressions of their quality and convince clients of their value. "Being perceived as an expert is (...) more crucial than being one" (Alvesson, 1993: 1004). To that effect, consultants are described to make use of the "systems of persuasion" to claim that they have expertise and knowledge (Alvesson, 1993: 1011). Further, the different requirements of clients' business solutions, clients' company characteristics and consequently provided solutions are heterogeneous and perishable, thereby contributing to clients' susceptibility for IM. Table 1 lists the above mentioned service characteristics paving the way for IM and corresponding implications for consultants and clients. 
Table 1: Implications of service characteristics for management consultants and their clients

\begin{tabular}{|c|c|c|}
\hline $\begin{array}{c}\text { SERVICE } \\
\text { CHARACTERISTICS }\end{array}$ & $\begin{array}{c}\text { IMPLICATIONS FOR } \\
\text { MANAGEMENT CONSULTANTS }\end{array}$ & IMPLICATIONS FOR CLIENTS \\
\hline \multirow{3}{*}{ INTERACTION } & $\begin{array}{l}\text { Outcome dependent upon quality of } \\
\text { interaction with clients. }\end{array}$ & $\begin{array}{l}\text { Outcome dependent upon quality of } \\
\text { interaction with consultants. }\end{array}$ \\
\hline & \multirow{2}{*}{$\begin{array}{l}\text { Management of interaction process offers } \\
\text { possibility of convincing clients of value } \\
\text { and quality. }\end{array}$} & $\begin{array}{l}\text { Experience of interaction informs pre- and } \\
\text { post-purchase evaluations of quality. }\end{array}$ \\
\hline & & Quality difficult to determine ex ante. \\
\hline \multirow{2}{*}{ INTANGIBILITY } & $\begin{array}{l}\text { Nothing to show clients ex ante except } \\
\text { third-party reports, or direct experience of } \\
\text { past service. }\end{array}$ & $\begin{array}{l}\text { Quality difficult to determine ex ante and } \\
\text { ex post. }\end{array}$ \\
\hline & $\begin{array}{l}\text { IM important since possibility of creating a } \\
\text { reality which persuades clients of value and } \\
\text { quality. }\end{array}$ & \\
\hline HETEROGENEITY & $\begin{array}{l}\text { Considerable discretion over delivery of } \\
\text { the service. }\end{array}$ & Quality variable \\
\hline Perishability & $\begin{array}{l}\text { Service destroyed during consumption. } \\
\text { Therefore difficult to replicate; hold stocks } \\
\text { and expand output during periods of high } \\
\text { demands. }\end{array}$ & $\begin{array}{l}\text { Unable to purchase the same service at } \\
\text { later points. }\end{array}$ \\
\hline
\end{tabular}

Source: Clark, T. \& Salaman, G. 1998. Creating the "Right" Impression: Towards a Dramaturgy of Management Consultancy. The Service Industries Journal, 18(1): 18-38.

On the basis of these service characteristics a range of ways are open by which consultants can create an impression of themselves and their service that clients will regard favorably. For example, the physical appearance of the consultant, the image and reputation of consultants and consultancy firms, and references are identified as major criteria used by clients to select and evaluate consultants (Clark, 1993; Dawes, Dowling, \& Patterson, 1992; Selchert, 1997).

Thus, for consultants managing impressions turns into an important task. We even argue that IM is an intrinsic part of service performance and a job-relevant tool for consultants since the creation, regulation and management of impressions and images are central to the makeup and evaluation of consultants' work performance. For example, consultants' performance ratings are partially determined by the extent to which the clients believe that the consultants possess the necessary technical and social skills (Clark, 1995). It is not to say that impressions are more important than substance in regarding consultant's performance, but consultant's success requires amongst others the ability to present oneself and to offer and deliver recommendations or results in an appropriate way. "Not only to give the right advice, but also the give it in the right way (...) is considered to be part of the basic skills set of the consultant" (Alvesson \& Johansson, 2002:230). 


\section{CHAPTER 2}

Further, having a good relationship with the client and respective employees and making a favorable impression on them will improve cooperation, increasing the chance for project's success. Favorable impressions will positively influence consultants' reputation and increase the likeliness of follow-up projects, two factors which have been identified to be vital importance in the consultancy business (Dawes et al., 1992; Patterson, 1995). As a result, consultancy services and respective consultants are well suited for exploring the IM process. The relevance of IM in consultancy is supported by several scholars (Alvesson, 1993; Huczynski, 1996; Kieser, 1998; Starbuck, 1992). For instance, the main message in Timothy Clark's (1995) book "Managing consultants: Consultancy as the Management of Impressions" is that persuasion is at the core of consultancy. The author describes the activities of executive recruitment consultants and management gurus and relates their activities to the distinction of Goffman in front- and backstage performances, respectively. However, empirical studies on IM in consultancy are rare.

Having shown that IM is relevant in work settings as services and important for performance in consultancy, we continue this chapter with presenting literature on differences and variations in IM performance. Although successful IM is desired by an individual and by his or her organization, IM performances can differ from individual to individual and at times also vary in effectiveness for the same person. To find explanations, we draw on two types of outlooks: a differential and a self-regulation perspective, respectively.

\section{DIFFERENCES AND VARIATIONS IN IM PERFORMANCE: SUCCESS AND FAILURE ${ }^{2}$}

IM can be considered successful when the image offered is accepted by the audience. IM can be said to fail when an individual's behavior does not arouse the desired impressions. For example, actors might be not aware of others' expectations regarding how they dress, they forget to say things they would like to say, they stutter or lose their temper when getting emotionally upset, and so on. When individual's performance is viewed as out of place by others unwanted attributions are likely (Ferris, Judge, Rowland, \& Fitzgibbons, 1994; Gardner et al., 1988). People might for example be perceived as inattentive, unintelligent or ill-tempered, and evoke reactions that are substantially unlike from those aimed for. Additionally, IM carries risks (Jones et al., 1982). That is, for every aimed

\footnotetext{
${ }^{2}$ While we acknowledge that IM can differ and vary on various levels in its performance, we prefer for reasons of simplicity to focus mainly on its success or failure.
} 
impression there is at least one undesired image that could be evoked. For instance, a person who self-promotes in order to be seen as a competent person might rather be perceived as a bragger (Turnley et al., 2001).

Failure in IM can be destructive for individual work performance and have negative effects on organizational effectiveness (Giacalone et al., 1989; Grove et al., 1989). For example, a consultant who is not able to create beneficial impressions in clients' eyes will not be very effective in fulfilling his or her service tasks and in the last resort, is not tolerable for the employing organization. Additionally, IM failure and consequent reactions of others may become a source of frustration for the impression manager and undermine his or her performance and self-esteem (Schlenker et al., 1992).

In contrast, successful IM supposedly translates into positive consequences for the individual and the organization. It "(1) facilitates positive interpersonal relationships and increases harmony within and outside the company; (2) accurately portrays positive persons, events, or products to those in or out of the organization; and (3) facilitates decision-making regarding persons, events, or products, and leads management and/or consumers to successful decisions" (Rosenfeld et al., 1995: 133).

In spite of its relevance for organizational effectiveness and individual well-being, very little research has been done to identify causes for differences and variations in IM performance. Some researchers have acknowledged that IM attempts can go awry (Crant, 1996; Jones et al., 1982; Turnley et al., 2001). Others suggested individual differences in the success of IM (Leary et al., 1990; Snyder, 1987; Turnley et al., 2001). However, the amount of research on variations of IM performance including its failure and on psychological factors that control the successfulness of IM has remained very small. Turnley and Bolino (2001) and Vohs and colleagues (2005; 2004) are, to our knowledge, the only scholars who have examined potential individual sources for IM failure. Turnley and Bolino (2001) addressed both the positive images that are desired as well as the negative images that are risked when individuals use IM. They argued that inter-individual differences expressed by Snyder's (1974) self-monitoring theory determine whether IM has desired or undesired consequences. According to Snyder (1974) there are two distinct types of individuals: (a) high selfmonitoring individuals, who are able to read social cues and adapt their behavior accordingly and (b) low self-monitoring individuals, who show less concern about the appropriateness of their social behavior and focus on their current affective state and on personal attitudes. Bolino and Turnley 


\section{CHAPTER 2}

(2001) found that in contrast to low self-monitoring individuals, high self-monitoring individuals have greater success in IM.

We acknowledge the influence of personality characteristics on individual's ability to manage other's impressions, but also agree with recent studies that begun to explore determinants of IM failure based on intra-individual differences, specifically arguing from a self-regulation perspective. "Linking self-regulation with self-presentation helps explain the perplexing question of why people fail at self-presentation"(Vohs et al., 2005: 4). Unfortunately, Vohs and colleagues mainly concentrate on depleted self-regulatory resources as a cause for varying IM performances. In our view, the psychological self-regulation perspective has more to offer and can help to identify other possible factors that intrude upon a person's ability to succeed in IM. By recognizing grounds for IM failure, prerequisites for IM achieving success are identified as well. The chapter will continue with reviewing literature representing a differential approach on IM performance and subsequently introduce a selfregulation outlook on the IM process including its potential failure.

\section{IM performance from a differential perspective}

Literature argues and proves that individuals differ in the execution and effectiveness of IM attempts based on varying characteristics, as machiavellism (Christie \& Geis, 1970; Schlenker, 1980), locus of control (Schlenker, 1980; Tedeschi et al., 1985), self-consciousness (Fenigstein, Scheier, \& Buss, 1975; Filipp \& Freudenberg, 1989), and self-monitoring (Snyder, 1974). In this thesis, we focus on the factor that has most often been found to influence the effectiveness with which people employ IM: Snyder's self-monitoring (1974). In addition, we report on different "behavior tendencies" in IM expressed in styles, strategies and tactics.

\section{Personality: Snyder's self-monitoring}

As mentioned before, Snyder (1974) developed the theory of self-monitoring and described it in relation to the motivational orientations of the public and private facets of the self. "According to self-monitoring theory, a person in a social setting actively attempts to construct a pattern of behavior appropriate to that context, drawing on two primary sources of information: information about situational and interpersonal specifications of behavioral appropriateness, and information about inner feelings, attitudes, dispositions, and other personal attributes". Correspondingly, there are stable individual differences in the degree to which people "rely on either source of information" 
(Snyder, 1987: 33). Hence, the self-monitoring tendency is regarded as a personality trait. The question for high self-monitoring individuals is "how would somebody (an image) act in this situation" and for low self-monitoring individuals "how would I act in this situation". An individual is supposed to fall into one discrete class or the other (Snyder, 1987). Further, it is assumed that low self-monitors are more concerned with establishing long-term identities and high self-monitors are more interested in tactical maneuvers that will allow them immediate situational advantages (Tedeschi et al., 1985). Snyder and Cantor (1980) found that high self-monitoring individuals gain the knowledge for managing others' impressions due to studious interest and concentration on other people. The authors were able to identify significant evidence for proposed relationships between self-monitoring and social knowledge and knowledge of the self or as the authors termed it: "prototype-oriented" and "self-oriented" knowledge. Webb and colleagues (1989) attempted to understand the situational factors that mediate different self-monitoring orientations, e.g. the focus of attention, and tried to discover private and public factors that delimit the expression of those orientations. In their research they addressed their questions with the theory of objective selfawareness (Duval \& Wicklund, 1972), which is controlled by external stimuli. The authors found that high self-monitoring individuals, whose flexibility in attending to different situational cues is known, are also able to change their behavior to satisfy inner conditions when the focus is on the self. However, low self-monitoring individuals are in comparison to high self-monitoring individuals more able to access information about themselves and their inner processes.

Next to investigating self-monitoring in general social settings, as college women's use of cosmetics (Cash \& Wunderle, 1987) or the expression of prejudices (Klein, Snyder, \& Livingston, 2004), various researchers utilized self-monitoring to address differences in individual IM outcomes in organizational settings (Day, Schleiber, Unckless, \& Hiller, 2002; Gangestad \& Snyder, 2000; Jordon \& Roloff, 1997). There, high self-monitoring individuals have been found to have an advantage. For example, they achieve more internal promotions than low self-monitoring individuals (Kilduff \& Day, 1994) and are more effective in boundary spanning positions which call for varying personal approaches and interpersonal skills (Caldwell \& O'Reilly, 1982). Other studies suggest that high self-monitoring individuals are adept at influencing performance ratings of themselves through the use of IM tactics (Day et al., 2002; Gangestad et al., 2000). In their meta-analysis on the impact of self-monitoring on work-related performance, Day and colleagues (2002) found a significant overall relationship. In short, the self-monitoring characteristic is often applied to explain differences in IM 


\section{CHAPTER 2}

performance between individuals both in general social and in work settings. Its measurement - the Self-Monitoring Scale - is described at a later stage of this chapter.

\section{Behavior tendencies: Styles, Strategies, Tactics}

Researchers have referred to individual differences in IM in a variety of terms such as styles, strategies and tactics. For example, Arkin (1981) speaks about IM styles. He regards individual differences in IM behaviors as style variations, also calling them IM strategies. A distinction is made between the acquisitive - to acquire social approval by presenting a favorable image - and the protective IM style - to avoid social disapproval by denying negative attributions. The two selfpresentation styles are described as distinct and independent (Arkin, Lake, \& Baumgardner, 1986). Other authors agree on this distinction, however with giving them different names. For instance, Roth and colleagues (1986) differentiate between self-presentation behaviors that attempt to convey that a person possesses certain characteristics or is a particular kind of person (attributive tactics) and tactics that deny the possession of characteristics (repudiative tactics). Other authors term them assertive and defensive tactics of IM (Schlenker, 1980; Tedeschi et al., 1984; Tedeschi et al., 1985). Not only different labels are used for the same IM tactics, some authors call IM behaviors styles or strategies (e.g. Arkin, 1981; Jones et al., 1982) and others term them tactics (e.g. Bolino et al., 2006; Kacmar \& Carlson, 1999; Kacmar et al., 1992; Kipnis, Schmidt, \& Wilkinson, 1980; Roth et al., 1986).

The best known and most studied IM behaviors were first described by Jones and Pittman (1982) and later empirically validated by Bolino and Turnley (1999). According to them, people typically use five types of behaviors, also called IM tactics. These are: (1) ingratiation, where individuals use flattery or favor-doing in an attempt to be seen as likable; (2) self-promotion, where individuals play up their abilities or accomplishments to be seen as competent; (3) exemplification, where individuals go above and beyond the call of duty to appear dedicated; (4) supplication, where individuals advertise their shortcomings in an attempt to be viewed as needy and (5) intimidation, where individuals seek to appear intimidating or threatening to have others view them as dangerous. Other examples of IM behaviors are blasting (blaring) and basking (blurring) (Andrews \& Kacmar, 2001; Cialdini \& Richardson, 1980), apologies and excuses (Arkin, 1981; Schlenker, 1980), selfhandicapping (Jones \& Berglas, 1978), and many more. A list of frequently studied IM behaviors can be found in Appendix A. 
Although Arkin (1981) and Jones and Pittman (1982) refer to individual differences in IM, they stress also that individuals' ways of self-presentation - as in the sense of personal styles - might form a habit. For example, Jones and Pittman (1982) suggest there may be individual differences in preferences for one strategy over another. They noted: "it would not be altogether surprising to find that certain experiences and certain personal resources would make one strategy much more prominent than others in a particular actor's repertory" (: 260). For example, some individuals might prefer to be perceived as friendly and likeable, whereas others might prefer to be perceived as intelligent and competent. As a consequence, given the same situation, people who want to be seen as friendly would probably use the IM tactic of ingratiation, and people who want to be perceived as competent would be likely to apply the IM tactic of self-promotion.

Tedeschi and Melburg (1984) further theoretically distinguish IM behaviors into tactical and strategic IM. According to them tactical IM has short-term objectives and strategic IM behaviors have long-range consequences over time and situations. For example, a person who uses selfpromotion as an IM behavior in an employment interview is oriented to the short-term goal of obtaining a job offer. The specificity of the goal and the audience, as well as its short-term nature, characterizes this IM behavior as tactical. The created image, e.g. a competent image, results from strategic considerations. Then, strategic IM typically involves a variety of tactical behaviors cumulatively directed toward establishing a desired identity in the eyes of others. Strategic outcomes may be associated with repeated or habitual use of IM tactics and should apply in different situations, whereas tactical IM should have a situation specific effect (Tedeschi et al., 1985).

According to Mummendy (1995) the classification of IM behaviors both into strategies and tactics and in assertive and defensive IM is in some points not clearly defined. He gives the following example to defend his viewpoint. "How would you classify a student who swots in his book under the sunlamp? This student eventually wants to suggest that he is not always studying but also enjoys open air activities to the same degree. Therefore, he places a sunlamp over his desk, which tans him during studying. This behavior can be considered as assertive (the student wants to make a particular impression), as defensive (the student wants to avoid a certain impression), as tactical (as preparation for a specific exam), and as strategic (in the sense of a permanent image building)" (: 140). Referring to the ambiguity of IM terms, in the thesis we utilize the words IM behavior and behavior tendencies as umbrella terms for all names existing in extant theory. On a more specific level, we employ the term IM style to represent an individual tendency to perform IM in a certain way, and IM tactics to 


\section{CHAPTER 2}

correspond with more or less specific behaviors as e.g. self-promotion but we are aware that these could be used in various ways, e.g. in an acquisitive or protective way.

\section{IM performance from a self-regulation perspective}

A differential perspective on IM performance is useful in explaining inter-individual differences in IM performance and in distinguishing between successful and unsuccessful impression managers. However, it does not explain why persons who are generally able to form desired impressions on others as well fail at times. To study such intra-individual variations in IM performance we need a temporal perspective and theories that focus on processes rather than on differences (Roe, 2008). A most promising approach is that of self-regulation theory, which depicts IM as unfolding over time.

\section{Self-regulation processes: goal-setting, self-monitoring and evaluation, self-efficacy}

Psychological self-regulation theory focuses exclusively on the internal processes by which people can influence their behavior (Carver \& Scheier, 1998; Goldfried \& Merbaum, 1973). Baumeister and others (1994: 7) described self-regulation as "any endeavor by an individual to adjust its own responses, including actions, thoughts, feelings, desires, and performances". In the process of selfregulation people design a mental representation of the desired behavior, impose on themselves behavioral standards, monitor their own actions, evaluate these actions by comparing them with the standards, and try to correct themselves to stay as close to the standard as possible (Baumeister et al., 1994; Kanfer, 1977; Karoly, 1993). In this sense, human behavior is portrayed as a continual goaloriented behavioral process, regulated by the process of feedback control that provides individuals with the capacity to adjust their action and goals to achieve desired results (Carver \& Scheier, 1990a). In addition, individuals' self-efficacy beliefs, also significantly affect the process. People who are capable and believe in their abilities are able to influence the variables of which their behavior is a consequence (Bandura, 1977).

Although self-regulation aims to be successful, it can also fail (Baumeister et al., 1994). Failure can occur for various reasons e.g. when goal-setting has been inappropriately implemented, 
when conflicting standards exist, when self-monitoring ${ }^{3}$ has been insufficiently utilized, or when the person does not believe in his or her abilities to handle the situation (Baumeister, 1999).

Since human behavior occurs within social settings a major influence factor for selfregulation resides in the social and interpersonal domain. This leads us from general self-regulation to self-regulation within an IM framework. According to Carver and Scheier (1998) most individuals have the self-regulatory potential to manage the impressions formed by others. Their focus of selfregulation is the relationship with another (Baldwin, 1992). In order to regulate others' impressions, they first must regulate themselves (Karoly, 1993). That is, self-presentation requires self-regulation (Vohs et al., 2005; Zeidner, Boekaerts, \& Pintrich, 2000).

In the following, we describe each of the three self-regulation processes: (1) goal-setting, (2) self-monitoring and evaluation, and (3) self-efficacy (Karoly, 1993). First, we review general knowledge on each process. Then, we utilize existing theories to understand failures in IM performance. Here, we portray IM performance as an outcome of these three general self-regulation processes. These are illustrated to result in specific behaviors, eventually determining IM performance.

\section{Goal-Setting}

In general, self-regulation is defined as a set of behavioral processes that involve goal-setting and guides behavior in order to attain the goal (Zeidner et al., 2000; Zimmermann, 2000). Given that selfregulation is viewed as a process of discrepancy detection by monitoring the results of current behavior and comparing it with the standard (Hull, 2002), goals can be described as standards of

\footnotetext{
${ }^{3}$ Self-monitoring as a self-regulation process should not be confused with Snyder's (1974) concept of self-monitoring. The term from Snyder's theory indicates a personality trait and refers to the monitoring of individual behavior in interaction with the social context. The self-regulation process of self-monitoring, however, focuses on the inner processes of an individual concerned with IM. The difference between the two can be seen in the following. According to Snyder, high self-monitoring individuals have more public awareness than low self-monitoring individuals, but low self-monitoring individuals have more private awareness than high self-monitoring individuals. When self-monitoring in self-regulation terms means the ability to observe oneself, then high self-monitoring individuals according to Snyder are actually low self-monitors and low self-monitoring individuals are high self-monitors. So, using Goffman's metaphor, Snyder's self-monitoring refers to the self-on-stage.
} 


\section{CHAPTER 2}

comparison (Carver \& Scheier, 1981). In the case of salient differences, discrepancy reduction is achieved by making adjustments, either by adapting behavior or the standard (Carver et al., 1998). It is important to recognize that people's reference values are not static but adjustable; for example, a goal can be changed to be more challenging or less threatening, depending on the demand of the situation and the abilities of the person (Carver \& Scheier, 1990b). Furthermore, self-discrepancy theory states that standards can vary across people (Higgins, 1999).

In reference to IM, which is presented as a goal-directed behavior (Schlenker et al., 1992), the amount of withdrawal should be a direct function of the importance of relevant goals and standards (Schlenker, 1985). Since people have the capacity to choose among multiple action alternatives, including the choice to take no action at all (Locke \& Latham, 1990), people might also not have the desire to manage their expressions in order to influence others (Bromley, 1993). As a consequence, their IM performance can vary. If the goal for IM is not present or not considered as important enough, IM might be ineffective; "with no standard, the system cannot begin to function" (Carver et al., 1981: 169). For example, consultants who do not intend to make positive impressions on prospective clients and are e.g. careless with their outward appearance might end up with negative impressions eventually resulting in project rejections.

Another cause for IM failure stems from a person's inability to put a goal into practice because the person does not know how (Carver et al., 1990a). For example, uncertain social contexts make it very difficult for people to find out what is expected from them (Deci, 1995). As a result, a person might be unable to identify appropriate IM behavior potentially causing IM failure. For example, consultants who are new and untrained in their jobs might have problems acting in an appropriate manner with clients' employees.

In addition, people can have multiple goals at the same time (Pintrich, 2000). That is no problem when the goals are not conflicting (Carver et al., 1998; Locke et al., 1990). Much more important is when goals involve competing demands/conflicting standards. When there are more options than can be performed or there is more information than can be processed, choices have to be made and these are not always appropriate. For example, people are often challenged by situations where they have to choose between IM concerns and task activities (Goffman, 1959). However, task regulation can shift attention from the self to the task and as a result, people in situations of high task engagement are less affected by the presence of others and therefore less interested in IM (Duval et al., 1972; Jones et al., 1982; Schlenker, 1980). Consider a consultant who has to fulfill a demanding task and uses all of his or her attention and effort to perform the task satisfactorily. The consultant 
might forget everything around him or her and also the demand of making a positive impression on the client.

\section{Self-Monitoring and Self-Evaluation}

Self-regulation is described in terms of the principles of feedback control (Carver et al., 1998). In the case of discrepancy detection the person receives feedback that current behavior is not leading to the goal and that changes either in the goal or in behavior are required. Bandura (1986) stated that through effective self-monitoring, people can recognize the constraints which govern their behavior and adapt their behavior accordingly. There is consensus among researchers that self-regulation involves a cognitive direction that requires permanent adjustments and decisions, awareness to interpret situations, and an ability to reflect past, current, and future performances (Zimmermann, 2000). Self-monitoring, implying a reflective capability, is viewed as crucial for successful selfregulation (Baumeister et al., 1994; Carver \& Scheier, 1985; Kanfer, 1973). The interplay of selfmonitoring and self-evaluation is important, since only observing will not suffice to evoke changes in goal-setting or behavior. An evaluation is needed to decide whether self-directed reactions are needed (Bandura, 1982). Consequently, the final outcome of self-monitoring always depends on the result of self-evaluation.

Applying general self-regulation theory to the context of IM, self-monitoring and selfevaluation can be considered successful, when "feedback indicates that an undesired impression has been created, controlled processes are activated, and people take corrective action to restore the desired impression" (Schlenker, 2003: 8). However, when people do not monitor or evaluate their behavior and audience feedback, they might fail in making a good impression (Schlenker, 2003). A reason for not monitoring one's own behavior in reference to IM might be absence of a goal to impress another.

Further, self-monitoring can only be effective if the appropriate behavior is monitored, otherwise self-regulation will be defective (Carver et al., 1998). However, sometimes successful selfmonitoring and the identification of appropriate behaviors is a complicated act due to a wide variety of possibilities (Kanfer, 1973). People might misread the situation (Schlenker, 2003) or be unaware of how they are perceived by other people. For example, a consultant who just started working at the clients' place tries to identify, i.e. by observing colleagues, which behavior is expected from him or 


\section{CHAPTER 2}

her. However, the consultant might monitor inappropriate behaviors, but evaluate them as adequate and hence fail in IM.

Further, although people are generally able to inhibit their impulses and to choose how to behave, strong emotions may stop people from approaching their goal (Deci, 1995). People may show an immediate reaction to an event, without taking future consequences into account. This socalled transcendence failure (Baumeister et al., 1994), which is often emotionally steered can result in varying IM performances, as immediate desires win over long-term IM concerns. According to Jones and Pittman (1982: 234) "some emotions apparently overwhelm the concerns of IM, if only for a brief moment before we start to worry whether our reactions are appropriate to the occasion". Then all attention is concentrated on the relevant stimuli. For example, a consultant who is upset with clients' employees might decide to stop working with them. In that case current emotions keep the consultant focused on the immediate desire to vent his or her anger instead of thinking on the impression he or she is forming in the clients, which can have negative consequences on clients' satisfaction and future performance evaluations. In such powerful states people often say and do things that they later regret, partly because they did not consider others' reactions beforehand. Other authors confirm that emotions that are hard to control probably subdue IM concerns (Tedeschi et al., 1981).

\section{Self-Efficacy}

Self-efficacy affects goal-setting; the more people belief in themselves the higher the set goals will be (Locke et al., 1990). People may know that a certain behavior produces certain outcomes, but at the same time not be sure whether they can perform these actions. A greater discrepancy between the goal and the current situation (Hull, 2002) and the perception of individual self-efficacy motivate the person to spend more effort to the reduction of mismatch; in the case of success self-efficacy increases (Bronson, 2000). However, negative feedback lessens efforts to attain the goal and people will stop any effort when they do not belief in a successful discrepancy reduction. Hence, people's expectancies about their ability to change behavior in the direction of the goal are seen as critical factors that influence whether a person continues the attempt to reach the set goal and how much endeavor is invested or gives up the effort (Bandura, 1986; Kanfer, 1977). Research has also discovered that people who expect to perform poorly on a task for which they are publicly 
accountable do much worse than those who either anticipate success or perform in private situations (Schlenker, 1975).

With regard to IM, research describes that people experience social anxiety when they aim to influence other people's impressions, but lack the necessary self-confidence or self-efficacy (Schlenker et al., 1982). This can cause an avoidance of the situation, forgoing of certain goals, a low investment of endeavor and/or an ease to give up effort which eventually result in varying IM performances. Since confidence about successful IM is seen as a major determinant for effective IM performance (DePaulo, 1992; Schlenker et al., 1996) a lack of self-efficacy in one's personal IM ability can be considered as a decisive factor for IM failure.

\section{METHODS TO MEASURE IM}

The literature on IM also provides information on the operationalization of IM concepts and on methods of measurement. Below, we will review these methods, making a distinction between inventory methods developed for general social contexts and other methods constructed for application in organizational contexts. It will appear that methods developed for general social contexts, i.e. self-monitoring scale (Snyder, 1974), can also be used to study organizational behavior (e.g. Caldwell et al., 1982; Snyder \& Campbell, 1982).

\section{Measurement of IM in general social contexts}

As argued by Goffman (1959) conditions of privacy and publicity are important in studying IM. Duval and Wicklund (1972) manipulated the public-private dimension in laboratories and found that objective self-awareness develops or increases by a stimulus that reminds an individual of himself or herself (e.g. mirrors, or tape recorder) and subjective self-awareness increases by stimuli that distract attention from the self (e.g. a challenging task). Some years later, Fenigstein and others (1975) developed a 23-items scale, called Self-Consciousness Scale that measures private and public selfconsciousness and social anxiety. The authors stated that "public and private self-consciousness refer to a process of self-focused attention; social anxiety refers to a reaction to this process" (1975: 523). In an empirical study they found that private self-consciousness and social anxiety have a very low correlation, in contrast to public self-consciousness and social anxiety - which is in line with the theory of social anxiety described by Schlenker and Leary (1982). They assumed among other things that high IM concerns (caused by public self-consciousness) in combination with personal doubts on 


\section{CHAPTER 2}

effectiveness can cause social anxiety. Contrary to Duval and Wicklund, Fenigstein and others focused on individual differences in self-consciousness. For them self-consciousness was, in fact, more of a trait than a situationally induced state. Nevertheless, the authors assumed that selfawareness as defined by Duval and Wicklund has the same implications for behavior as their definition of self-consciousness. Statements in the scale are for example: "I'm generally attentive to my inner feelings" and "I am concerned about what other people think of me".

Filipp and Freudenberg (1989) modified the Self-consciousness Scale compiled by Fenigstein and others (1975). Their questionnaire includes 27 items and measures dispositional self-consciousness/selfawareness. Like these authors, Filipp and Freudenberg (1989) focused on the dispositional rather than situationally induced self-awareness. The scale does not include social anxiousness anymore, and some items were added to the subscales of private and public self-consciousness/self-awareness. Questions included in the questionnaire are for example "I feel uncomfortable if other people observe me" and "I think about my current facial expression".

As mentioned earlier, the most popular method to measure IM behavior conditioned by individual differences is Snyder's Self-Monitoring Scale (1974). The original Self-Monitoring Scale consisted of 25 true-false descriptive statements; an improved version includes 18 items (Snyder \& Gangestad, 1986). The scale focuses on an individual's motivation to engage in IM and how skilled a person is at it. Statements like: "I find it hard to imitate the behavior of other people" and "I guess I put on a show to impress or entertain people" are used to indicate low or high self-monitoring individuals, respectively. However, the Self-Monitoring Scale and its application are not free of criticism. First, it is often used to indirectly measure IM. "In this way, we are confronted with the oddity, that personality variables, whose relationships with IM would be worthwhile to be investigated, are utilized by many researchers to measure IM" (Mummendy, 1995: 212). Second, Briggs, Cheek and Buss (1980) tested Snyder's Self-Monitoring Scale and distinguished the items into three groups: acting (like to entertain), extraversion (outwards directed interest), and otherdirectedness (adapt behavior to align with others). Other-directness and extraversion were found to have contrary patterns of correlations with other personality dimensions, as for example shyness. They found that "at least on some occasions, self-monitors and extraverts appear to behave in the same way" (: 684). Therefore, the authors recommended that scores for each group of items should be preferred to full scale scores. Unfortunately, the use of the subscales (acting, extraversion and other-directedness) is not without problems either. Briggs and colleagues (1980) argued that for instance the acting subscale is rather adequate to measure skills of "real" actors, extraversion is 
irrelevant to self-monitoring, and other-directedness relates positively with shyness and neuroticism. Furthermore, Gangestad and Snyder (2000) examined the self-monitoring literature and suggested that not all forms of IM tactics should be addressed when discussing self-monitoring abilities. They proposed that defensive tactics should not be included because "this mode of adaptation presents a restrained, appeasing social self that, unlike that of the high self-monitor, may be relatively invariant across many social circumstances, relationships and roles" (: 546).

Roth, Snyder and Pace (1986) developed the Self-Presentation Scale (SPS) comprehending two subscales with in total 60 true-false statements. The subscales measure whether people tend to use IM behaviors to display the possession of positive characteristics (attributive tactics), or to disclaim negative characteristics (repudiative tactics). The self-deception scale includes 30 items describing positive statements which are unlikely to be realistic and the social-desirability scale consists of 30 items, which contain undesirable characteristics for almost each individual. People answering true for the positive statements ("My childhood was always happy") are seen to engage in attributive IM and those answering false to the negative characteristics ("The success of others makes me jealous") are viewed to employ repudiative IM tactics. The authors found some proof that the process of attributing positive characteristics to the self is different from the process of denying negative traits, because individual differences on the subscales were correlated with different personality variables. For example, self-consciousness (public and private) was negatively correlated with the denial subscale, however not with the attribution subscale.

Riggio (1986) developed a 105 item scale based on seven basic dimensions of social skills. He called the instrument the Social Skills Inventory (SSI). The basic skills on which the framework is built are sensitivity to communication, communication expressivity, and monitoring or control of communication. These are divided into the following seven social skills dimensions: emotional expressivity (ability to express actual emotions; "When I get depressed, I tend to bring down those around me"), emotional sensitivity (ability to receive and decode nonverbal communication of others; "It is nearly impossible for people to hide their true feelings from me"), emotional control (ability to control emotions and their expressions; "I am very good at maintaining a calm exterior, even when upset"), social expressivity (ability to start a discussion or a talk; "At parties I enjoy speaking to a great number of different people"), social sensitivity (ability to identify norms of the social situation; "While growing up, my parents were always stressing the importance of good manners"), social control (ability to act and adjust behavior to the social situation; "I find it very easy to play different roles at different times"), and social manipulation (ability or orientation to influence others; "If I really have to, 


\section{CHAPTER 2}

I can 'use' other people to get what I want"). The author proposed that people, who have better social skills, make more positive impressions on others.

Mielke (1990) developed the Efficacy of Self-presentation Questionnaire. It is an inventory method to measure the expectations and beliefs participants have about being effective in IM or not. According to the author and e.g. in contrast to the self-monitoring scale by Snyder (1974), IM should be measured directly through an individual's perception of his or her self-efficacy beliefs on self-presentational behavior. The questionnaire consists of 33 items, which are divided into three subscales: social approval ("In a lot of situations I am able to express my positive sides"), intellectual approval ("In work-shop discussions I often display an unfortunate character"), and material goals ("It is no problem for me to appear ambitious and capable in an interview for a job"). The scale includes only assertive IM tactics.

Paulhus' (1991) Balanced Inventory of Desirable Responding consists of 40 items measuring two forms of socially desirable responses: self-deception and IM. On the one hand, the selfdeception subscale intends to measure an individual's tendency to give positive self-evaluations and actually believes them ("I always know why I like things"). On the other hand, the IM subscale measures the tendency to present oneself deliberately favorable to others ("I always declare everything at customs").

\section{Measurement of IM in organizational contexts}

In addition to the inventory methods investigating IM in general social contexts, some measures were developed specifically for assessing IM in organizations. Wayne and Ferris (1990) developed a 24 item IM scale that attempts to measure the amount of employees' use of IM behavior. IM behavior is distinguished into supervisor-focused, self-focused, and job-focused IM tactics. The authors tried to find evidence for their hypothesis that both objective performance and IM influence "exchange quality", that is e.g. supervisor support, better subordinate satisfaction and performance. They assumed that exchange quality is increased through the impact of IM on supervisor's sympathy for his or her subordinate and on the supervisor's performance rating of the subordinate. To confirm their hypothesis, they first tested the scale in a laboratory experiment. The result was that participants, who played the role of subordinates and applied supervisor-focused IM behaviors, were liked more and evaluated as more productive and positively than the participants who did not use IM. Self-focused IM behavior was found to have no effect on performance ratings and job-focused 
IM tactics were negatively related to supervisor's evaluation of employee's performance. Next to the experimental setting, the authors also conducted a field study. Questionnaires were sent to bank employees asking them how often they behaved in a particular way (supervisor-focused, self-focused, and job-focused IM behavior) over the last three months. Furthermore, employees' supervisors were asked to evaluate them. The result was that employees who used supervisor-focused IM were liked more than employees who applied self-focused or job-focused IM behavior, supporting their first study. However, an impact on performance evaluation could not be identified. The explanation is that in new situations, as in the laboratory setting, there might be more potential for successful IM behavior, since the participants, who played the supervisor, did not have other information than the perception of the actual performance about the other. Literature acknowledges that IM behavior in situations with expected verity check-up is rather constrained (Schlenker, 1975). These are situations, where the potential impression manager believes that the audience already has information about him or her, and consequently bears for a higher risk of being identified as a liar or a dazzler. Moreover, liking was identified to highly influence exchange quality.

Kumar and Beyerlein (1991) developed the Measure of Ingratiatory Behaviors in

Organizations Settings Scale (MIBOS), which focuses on the extent to which individuals use various tactics of ingratiation in supervisors-subordinate relationships. The 24 items on the scale measure the extent to which people ingratiate others in various forms. The authors describe four IM tactics which can be categorized as ingratiation tactics. These are other-enhancement ("Impress upon your supervisor that only he/she can help you in a given situation mainly to make him/her feel good about himself/herself"), opinion conformity ("Express work attitudes that are similar to your supervisor's as a way of letting him/her know that the two of you are alike"), self-enhancement ("Look for opportunities to let the supervisor know your virtues/strengths"), and favor rendering ("Volunteer to help your supervisor in his/her work even if it means extra work for you"). According to Rosenfeld and others (2002: 131) "administering the MIBOS could tell us about the tactics employees use to manage images for themselves, and, by comparing them to scale norms, whether they were being used excessively".

Both above presented scales were criticized by Bolino and Turnley (1999). They question the reliability of the scale developed by Wayne and Ferris and therefore mistrust it as a measure for testing causes and consequences of various IM strategies. Further, they criticize Kumar's and Beyerlein's MIBOS for an overlap of the construct with organizational citizenship behavior. In order to develop a scale that overcomes these limitations, Bolino and Turnley (1999) used and validated the 


\section{CHAPTER 2}

taxonomy of IM tactics proposed by Jones and Pittman (1982) in an organizational setting. The provided organizational IM scale includes 22 items, which can be distinguished into five IM tactics: ingratiation ("Compliment your colleagues so they will see you as likeable"), self-promotion ("Make people aware of your accomplishments"), exemplification ("Stay at work late so people will know you are hard working"), supplication ("Pretend to know less than you do so you can avoid an unpleasant assignment"), and intimidation ("Let others know that you can make things difficult for them if they push you too far"). A recent assessment on the factor structure of the scale, the reliability of the subscales and their convergent and discriminant validity provide additional support for the scale (Kacmar, Harris, \& Nagy, 2007).

Another IM scale was developed by Moss, Valenzi and Taggart (2003). They focused on IM behaviors that aim to influence the feedback exchange process. The authors viewed the process of feedback management as one dimension of IM; "to the extent that an employee can intervene at the beginning of the feedback $\rightarrow$ impression $\rightarrow$ evaluation process, they have some control over the type of feedback they receive (or don't receive), the impressions they make, and ultimately, the outcomes they achieve" (: 506). Therefore, they constructed a taxonomy that describes three different types of feedback strategies. The developed scale includes 17 items, which measure the following constructs: Feedback seeking behavior (“After performing well, I would ask my supervisor about my performance to draw his/her attention to my success"), feedback mitigating behavior ("I would inform my boss that I wasn't able to complete my assignment on time but that I would stay late that night to finish it"), and feedback avoiding behavior ("After performing poorly, I would go the other way when I saw my supervisor coming"). Each construct was measured by a separate scale. Moss and others found that feedback seeking behavior is related to good performance, while feedback mitigating and feedback avoiding behaviors indicate poor performers.

The different inventory methods for investigating IM behaviors in general as well as in organizational settings are summarized in Table 2. 
Table 2: Methods to measure IM

\begin{tabular}{|c|c|c|c|}
\hline MEASUREMENT & AUTHOR(S) & YEAR & FOCUS \\
\hline \multicolumn{4}{|l|}{ GENERAL SOCIAL SETTINGS } \\
\hline $\begin{array}{l}\text { Laboratory experimental } \\
\text { methods to arouse } \\
\text { objective and/or subjective } \\
\text { self-awareness }\end{array}$ & $\begin{array}{l}\text { Duval and } \\
\text { Wicklund }\end{array}$ & 1972 & $\begin{array}{l}\text { Emergence of objective self-awareness: situationally } \\
\text { induced state of attending to oneself (challenging task), and } \\
\text { of subjective self-awareness: situationally induced state of } \\
\text { attending to the environment (e.g. mirrors or tape } \\
\text { recorder). }\end{array}$ \\
\hline Self-Consciousness Scale & $\begin{array}{l}\text { Fenigstein, } \\
\text { Scheier and } \\
\text { Buss }\end{array}$ & 1975 & $\begin{array}{l}\text { Scale that measures private and public self-consciousness } \\
\text { and social anxiety. }\end{array}$ \\
\hline $\begin{array}{l}\text { Scale to measure self- } \\
\text { consciousness/self- } \\
\text { awareness }\end{array}$ & $\begin{array}{l}\text { Filipp and } \\
\text { Freudenberg }\end{array}$ & 1989 & $\begin{array}{l}\text { Scale that measures levels of private and public self- } \\
\text { consciousness/self-awareness. }\end{array}$ \\
\hline Self-Monitoring Scale & Snyder & $\begin{array}{l}1974 \\
1986\end{array}$ & $\begin{array}{l}\text { Scale that measures individual's motivation and ability to } \\
\text { attend and respond to social cues. }\end{array}$ \\
\hline $\begin{array}{l}\text { Self-Presentation Scale } \\
\text { (SPS) }\end{array}$ & $\begin{array}{l}\text { Roth, Snyder } \\
\text { and Pace }\end{array}$ & 1986 & $\begin{array}{l}\text { Scale that measures whether people tend to use IM to } \\
\text { display the possession of positive characteristics (attributive } \\
\text { tactics), or to disclaim negative characteristics (repudiative } \\
\text { tactics). }\end{array}$ \\
\hline $\begin{array}{l}\text { Social Skills Inventory } \\
\text { (SSI) }\end{array}$ & Riggio & 1986 & $\begin{array}{l}\text { Scale that measures an inventory of seven social skills: } \\
\text { emotional expressivity, emotional sensitivity, emotional } \\
\text { control, social expressivity, social sensitivity, social control, } \\
\text { and social manipulation. }\end{array}$ \\
\hline $\begin{array}{l}\text { Efficacy of Self- } \\
\text { presentation Questionnaire }\end{array}$ & Mielke & 1990 & $\begin{array}{l}\text { Scale that measures whether people believe in their own } \\
\text { abilities to be effective in IM behaviors. Includes three } \\
\text { subscales: social approval, intellectual approval, and } \\
\text { material goals. }\end{array}$ \\
\hline $\begin{array}{l}\text { Balanced Inventory of } \\
\text { Desirable Responding } \\
\text { (BIDR) }\end{array}$ & Paulhus & 1991 & $\begin{array}{l}\text { Scale that measures on the one hand the extent to which } \\
\text { people exaggeratedly give positive statements about } \\
\text { themselves that they actually believe. On the other hand, } \\
\text { people's inclination to intentionally express a distorted } \\
\text { image of themselves. }\end{array}$ \\
\hline \multicolumn{4}{|l|}{ ORGANIZATIONAL SETTINGS } \\
\hline $\begin{array}{l}\text { Scale to measure three } \\
\text { types of IM behaviors }\end{array}$ & $\begin{array}{l}\text { Wayne and } \\
\text { Ferris }\end{array}$ & 1990 & $\begin{array}{l}\text { Scale that measures the amount of employees' use of IM } \\
\text { behavior. Three types: supervisor-focused, self-focused and } \\
\text { job-focused IM behavior. }\end{array}$ \\
\hline $\begin{array}{l}\text { Measure of Ingratiatory } \\
\text { Behaviors in Organizations } \\
\text { Settings Scale (MIBOS) }\end{array}$ & $\begin{array}{l}\text { Kumar and } \\
\text { Beyerlein }\end{array}$ & 1991 & $\begin{array}{l}\text { Scale that measures the extent to which employees use } \\
\text { various tactics of ingratiation in supervisors-subordinate } \\
\text { relationships. Four ingratiation tactics: other-enhancement, } \\
\text { opinion conformity, self-enhancement, and favor } \\
\text { rendering. }\end{array}$ \\
\hline $\begin{array}{l}\text { Scale based on the } \\
\text { taxonomy of IM tactics } \\
\text { proposed by Jones and } \\
\text { Pittman (1982) }\end{array}$ & $\begin{array}{l}\text { Bolino and } \\
\text { Turnley }\end{array}$ & 1999 & $\begin{array}{l}\text { Scale that measures the use of five IM tactics in an } \\
\text { organizational context. These are: ingratiation, self- } \\
\text { promotion, exemplification, supplication, and intimidation. }\end{array}$ \\
\hline $\begin{array}{l}\text { Scale to measure IM tactics } \\
\text { in the feedback exchange } \\
\text { process }\end{array}$ & $\begin{array}{l}\text { Moss, Valenzi } \\
\text { and Taggart }\end{array}$ & 2003 & $\begin{array}{l}\text { Scale that measures the implications of feedback oriented } \\
\text { IM tactics. These are: feedback seeking behavior, feedback } \\
\text { mitigating behavior, and feedback avoiding behavior. }\end{array}$ \\
\hline
\end{tabular}




\section{CONCLUSION}

This literature review has highlighted a number of issues with regard to IM that are important for subsequent chapters of this thesis: (1) What is IM? (2) What is IM's relevance in organizational contexts, particularly in services and consultancy? (3) How can we explain inter-individual and intraindividual differences in IM performance? (4) How can we measure IM?

To answer these questions, the chapter started with a brief review of IM theory and history describing where it comes from and where it stands now. Additionally, we described basic notions on IM, thereby contributing to a better understanding of IM in the situation-audience-actor interplay. Subsequently, by defining IM as an integral part of work performance we highlighted its relevance for services, particularly consultancy, and drew attention to our view that it should be recognized as an intrinsic part of consulting performance. Furthermore, whereas most investigations of IM seek to understand how it may help individuals to create favorable images, the chapter continued with another important objective of the study: the identification of potential causes for differences and variations in IM performance. Based on a description of IM success and failure, we first took a differential approach to IM performance reviewing extant literature. Here, we acknowledged that an individual's self-monitoring level is important to understand what types of goals are attractive and why certain performances are possible and credible to some human beings but not to others. Further, we discussed different behavior tendencies in IM expressed in IM styles, strategies, and tactics. Individual differences in personality and in utilization of behavior tendencies took us further in comprehending why some people fail in their IM attempts. However, since even people with favorable individual IM characteristics sometimes fail in IM, not only inter-individual but also intraindividual differences should be considered as determinants of IM failure and success. Consequently, we additionally called to regard psychological self-regulation effects and provided an in-depth analysis of well-known psychological self-regulation processes both in general and in reference to IM, which pointed at factors that have escaped the attention of previous researchers. The psychological self-regulation perspective on IM with a specific focus on three self-regulation processes - (1) goal-setting, (2) self-monitoring and self-evaluation, and (3) self-efficacy - was helpful in identifying when and why people might fail to manage other people's impressions. That is, each self-regulation process can go awry, like people can monitor the wrong aspects of behavior or do not believe in their ability to successfully manage the impressions of other people. As a consequence, IM might vary. Hence, IM performance can be predicted from the degree to which people match and cope with the enactment of the self-regulation processes involved in IM performance. As evident, 
our approach should not be interpreted as a rejection of individual differences causing IM success and failure but rather as complementary. The chapter finished with an elaboration on methods to measure IM in general social and in organizational contexts. 


\section{IMPRESSiON MANAgEMENT IN CONSUltanCy SERVICES: INTERVIEWS}

"You play a role. I play it in a working setting more pronounced than in a private situation. At work you consciously use impression management. I would even call it a weapon, which is employed with a certain goal I have in mind. I mean we are equipped with certain tricks, e.g. you know how to influence the audience at a presentation, and hence you use them".

Interview excerpt - Consultant

To explore IM behaviors of consultants, a small-scale study is conducted. The aim is to learn which images consultants try to express, which IM behaviors are employed and what facilitates and hinders them to be effective in their IM attempts. We interviewed two groups of subjects. First, a small group of consultants $(\mathrm{N}=5)$ was interviewed about IM behavior in consultancy services. Second, some experts and trainers in the field of IM and/or consultancy $(N=5)$ were questioned with the aim to identify personal requirements for IM success as well as common personal hindrances potentially causing IM failure in consultancy. Although evidently based on heuristics derived from the literature, the study design was open-ended so as to allow new information to emerge from the data.

The results of this study are an inventory of aspired images, prevalent IM tactics and styles, IM competence, self-regulation issues, and a personality characteristic implied in consultants' IM behaviors, which are to guide subsequent studies. 


\section{INTRODUCTION}

The quote at the beginning of this chapter shows how a consultant thinks about his behavior at work. It conforms to descriptions in the literature saying that IM lies "at the core of consultancy work" (Clark et al., 1998: 19). Despite all theoretical work on IM, we still have a limited understanding on IM in consultancy. In this chapter we aim to answer the following questions: What sort of images consultants aim for, how they try to manage clients' impressions, and what helps or prevents them to be effective in their IM efforts? To find answers to these questions, we believe that it is important to go to the field and to talk to people who are confronted with IM in reality. We therefore decided to turn our attention to "real" consultants. In doing so our main goal was to inductively define IM in consultancy based on an interview-investigation. For the issue of variations in IM performance and what possibly hinders consultants to succeed in their IM attempts, we built upon a conceptual model of the IM process derived from literature on selfregulation and IM (Chapter 2). Here we want to see whether the theoretical concepts are useful and how they can be complemented.

In addition to asking consultants questions about their views on their work of a consultant, we interviewed a second group of interviewees consisting of experts and trainers familiar with consultancy and IM. The information given by the second group was considered to shed a different light on the matter, with a specific focus on individual requirements and obstacles for IM success.

The chapter is structured as follows. We start with describing the research method. Thereafter, we present our findings. The research method and consequent results will be presented separately for the two samples. The paper will finish with a discussion of the findings, limitations and future research directions, and a conclusion.

\section{METHODS}

We conducted ten semi-structured interviews, five with consultants and five with experts and trainers in the field of IM and/or consultancy. Our sample is not random, but was chosen according to its adequacy for the research question pursued. The small number of subjects $(\mathrm{N}=5)$ in each group is considered adequate because of the ability of subjects to provide qualitative information about IM in consultancy.

In the following the interviewees and respective findings will be presented per group. Detailed information on the interviewees ${ }^{4}$ and questions asked can be found in Appendix B.

\footnotetext{
${ }^{4}$ We call the five consultants in our sample C1 to C5 and the interviewees from the expert group E1 to E5.
} 


\section{Consultants}

As consultants are assumed to be using IM in their daily work activities, they should be able to provide real-life information on IM in consultancy. Due to the fact that the author worked as a consultant in her former career, we relied on captive sampling (Tashakkori \& Teddlie, 1998). In total, five consultants were interviewed (one female; four males). They had all at least two years of consultancy experience and were currently employed. In their projects they had direct and high level contact to clients and respective employees. The average age was 40.7 years (range: 33 to 53) and they had on average a job tenure of 10 years (range: 2 to 24). All consultants were German.

First, the consultants were contacted and asked for their cooperation in a research project. Having the assurance of their willingness to participate an appointment was scheduled. Interviewees were visited either at their work place or the interviews were conducted at a neutral place, e.g. a hotel.

Right before the beginning of the interview, it was explained to them that they had been selected on the basis of their work as a consultant. We stressed that we aimed to hear about their views and experiences on consultancy in general; they should not perceive it as a test of their knowledge. Further, the approximate time needed for the interview was indicated. The actual interview duration for the group of consultants was on average 78 minutes (range: 72 to 90). In addition, we assured subjects' anonymity, if desired. Then, consultants were asked some personspecific questions, such as age, educational level, current job and work tenure.

To prevent influencing the consultants at the beginning of the interviews and to encourage a free talk about their work, the interviewer did not reveal the true objective of this study but simply told them that it is about the "Work of a consultant". Accordingly, the interview scheme was designed in such a way that the consultants were encouraged to first talk about issues that they thought were important under very general categories, e.g. "What does it take to be successful as a consultant?'. This allowed consultants to spontaneously discuss topics that were important to them. The topic of IM was introduced by the interviewer at a later time, to uncover information being expected on theoretical grounds but not yet provided by the consultant. For example, if a consultant did not mention potential reasons for IM failure more specific questions were asked. All interviews were audio-recorded, and complete transcriptions were made.

\section{Experts/Trainers}

After having interviewed the consultants, we started with interviewing the second group of interviewees which was made up of three experts in the area of consultancy (two females; one male) and two trainers in the field of IM (two males). This so-called expert-group was expected 
to be knowledgeable about the importance of IM in consultancy and be familiar with how individuals can manage the impressions of others. Their judgment was perceived as crucial in identifying personal requirements and potential hindrances for effective IM due to more objective information. Subjects of this group were identified through personal contacts and through recommendations of already interviewed experts in the group.

In the beginning, the interviewees from the expert-group were asked for a depiction of their current job in order to verify expertise in the topic of interest. The interviews lasted on average 56 minutes (range: 20 to 150).

Contrary to the consultants, the expert-group was provided with all necessary information prior conducting the interview in order to probe their views on all aspects of IM in consultancy. Therefore, the questions were more specific and targeted. All interviews were audiorecorded as well and full transcriptions were made.

\section{Analysis of interview content}

We coded for occurrence and not for frequency, since the overall purpose of this study was to gain as much qualitative information as possible. We neither aimed to test existing theories nor to generalize our findings. Rather, we wanted to see whether our findings conform to what is already known, if they are a specification or an elaboration, or a genuine addition to extant knowledge. The comparison of emerging concepts with existing literature is described as an essential facet of theory building (Eisenhardt, 1989).

The verbatim transcripts of conducted interviews provided the basis for our analysis. The analysis aimed at a rich description of the entire data set by means of presenting the major themes and categories (Krippendorff, 2004). The themes were mainly derived from the research aims, being the identification of images desired by consultants, IM behaviors used, and personal requirements and obstacles for effective IM. A priori specification of constructs is not common but nevertheless regarded as beneficial in the initial design of theory building investigations (Eisenhardt, 1989). The more specific categories were derived from multiple readings of raw data. We formulated them in respect to theory and material, completed step by step, and revised with the process of analysis. Hence, this allowed for a data display structured by themes and categories, both in tables and larger collections of quotes which served as a basis for interpretation and support emerging concepts (Miles \& Huberman, 1984) that can be used in our further research. 


\section{FINDINGS}

The following discussion of the themes and categories is designed to highlight major findings per group. The presented quotations in the subsequent text are extracts from the interviews and used to illustrate our findings. Please find all relevant quotes in the appendix to this chapter (Appendix B).

\section{Consultants}

First of all, the perceived importance of IM was indicated by the fact that all consultants raised the topic on their own initiative, not necessarily calling it IM but expressing the same purpose and outcome, as can be seen below:

"Much is decided because of appearance, it is sometimes more crucial than expertise".

"A typical consultant must have a disposition for self-presentation. He sells; be has to sell himself". [C4]

In addition, all consultants attached more importance to a positive consultant-client relationship than to a mere analysis and solution of the client's problem. For example, the following quote came from one consultant:

"I would add more value on the client relationship, since that is what finally accounts for the success of a project; a lot of people have knowledge". [C3]

These statements show that the interviewees consider IM as essential in their work environment.

The further analysis of the data allowed us to extract four themes: desired consultant-images, IM behaviors employed, and requirements and obstacles for effective IM.

\section{Theme 1: Desired Consultant-Images}

IM in consultancy is concerned with public displays of images that yield favorable potential. Tedeschi and Melburg (1984: 43) called the expressed images, "strategic considerations of reputational characteristics". The images consultants choose to present are assumed to be influenced by their individual perceptions of what an appropriate consultant image should look like and from an effort to present images that they think will be expected and rewarded by the 
client. The qualitative analysis of interview accounts resulted in an identification of three desired images: the honest/authentic consultant, the competent consultant, and the likeable consultant.

\section{Honest/ authentic consultant}

The image mentioned by all our interviewees was related to honesty/authenticity:

"I want to be perceived as honest". [C1]

Rosenfeld and colleagues (2002) suggest that IM is valuable when it involves a true and favorably regarded portrayal. Literature on services shows that being perceived as sincere is important to make a favorable impression. For example, Grandey and others (2005a) found that authenticity had a direct effect on customer satisfaction.

\section{Competent consultant}

The image of a competent consultant is also considered as crucial by the consultants in our sample in order to positively influence clients' impressions. Clients should recognize them as experts in the field they should consult the client:

\section{"I want to be known as an expert". [C4]}

From literature is known that consultants have a particular need to convince clients that they are "competent, expert, knowledgeable, skilled and can deliver a quality service" (Clark, 1995: 93). Staute (1998: 106) stated that in order "to maintain individual and companies' reputation, the consultant has to express competence. The consultant has the impress the client by the way he or she defines and tackles problems, presents solutions with support of graphical displays and rhetoric. The successfulness of this 'staging' is highly linked to the person him- or herself, to his or her dress, his or her accouterment (as status attributes), his or her individual language, as rhetoric and so on."

\section{Likeable consultant}

A likeable image is perceived as favorable by one interviewed consultant:

"How the clients like the consultants, how they appeal to them. Not the expertise but really how you get along with the client is important". [C1] 
This desired consultant-image can be linked to the perceived importance of a good consultantclient relationship; here likeability might be an issue as well. IM is found to induce liking which in turn relates positively to performance ratings (Wayne et al., 1995). Furthermore, the finding is in accordance with the theory that consultants should evoke images that are sympathetically perceived and cause clients to positively evaluate the service being offered and delivered (Clark, 1995).

These findings conform to and complement literature. We knew beforehand that consultants want to be perceived as competent (Clark, 1995). However, besides knowing from the literature that authenticity and likeability are favorable images, the view of consultants on these points is new and genuinely adds to the current literature on IM in consultancy.

\section{Theme 2: IM Behavior}

Another aim of this study was to learn with what kind of behaviors consultants try to influence their clients' impressions.

\section{Consultants' IM tactics}

From literature we know that there are various IM tactics, which are specific behaviors aiming for concrete impressions in others (Bolino et al., 1999; Giacalone et al., 1991; Jones et al., 1982; Rosenfeld et al., 1995). In our interviews we were able to identify behaviors which are comparable to well-known IM tactics in addition to actions which seem to specifically be used by consultants.

To avoid confusion with already existing IM tactics, we name our findings, which are restricted to consultants: consultants' IM tactics. The analysis of interview accounts resulted in an identification of three consultants' IM tactics: personal, professional, and conforming IM tactics.

\section{Consultants' personal IM tactic}

This consultants' IM tactic consists of personal behaviors. The consultant wants to appear likeable to the client by using a personal approach of IM. The following behaviors of consultants are identified attempting to promote personal attraction: get personal, share information, act as a partner, flatter, be nice, smile, please the client, and be honest. These are expressed in the following quotations: 
"I try to get on a personal level. That helps a lot". [C2]

From literature is known that personal stories are often used to convey a positive image (Stevens \& Kristof, 1995). Another approach of making a favorable impression mentioned was to share information:

"I give them information from which they think they normally do not get that kind of information. Then they think, hey, be is telling me something, and then I will do so too. That is a good method, when you try to elicit them by given them information they normally do not get and thereby express: I trust you". [C2]

The disclosure of appropriate information about the self is an important determinant of likeability and interpersonal perceptions (Vohs et al., 2005). For example, Schneider and Eustis (1972) found that subjects were more positive to a revealing than to a non-revealing person. Further, acting like a partner is seen to help tighten the relationship between consultants and clients:

"You have to give the client the feeling, to have you as a partner on his side that you specifically stand up for him”. [C3]

With flattery, being nice, smiling and pleasing the client, the consultant praises the client:

"To be nice is just a part of the game". [C2]

Moreover, to be honest is seen as a part of the personal IM tactic because authenticity often attains a positive and personal impression in the audience.

"To create trust, you bave to be honest, do not exaggerate and do not put your knowledge in the background, but also admit that there are others which are better than I’. [C3]

All the above mentioned behaviors fall into the category of what we call consultants' personal IM tactic. The personal IM tactic is similar to the IM tactic "ingratiation" (Bolino et al., 1999), which intends to make an individual more appealing to another by influencing the perception of attractiveness and eliciting an attribution of likeability (Jones et al., 1982). Ingratiation is the most extensively studied tactic in IM research. For example, interpersonal attraction (i.e. liking) was found to have large direct effects on subjective impressions and indirect effects on interviewers' 
evaluations (Graves \& Powell, 1988). It operates on the principle of reciprocal attraction - people are attracted to others who seem to be attracted to them (Byrne, 1961).

Consultants' professional IM tactic

This consultants' IM tactic consists of professional, rather than personal-related, behaviors. The professional IM tactic is found to be pursued by the following behaviors: self-promote, rely on references and/or third parties, prepare, and be reliable.

"In (...) discussions I try to specifically express what I have done. You point at: I am awesome”. [C2]

IM provides a means for actively communicating qualities and abilities (Frink \& Ferris, 1998). By self-promotion, consultants give positive statements to describe themselves, their future plans, or past accomplishments (Jones et al., 1982). Further, by relying on references and/or third parties consultants associate themselves with successful events or others and thereby sanitize their own public image:

"Through a number of various projects I made experiences in different areas, which I can point out and thereby make a competent impression". [C5]

"When you know that a contract depends on central persons who can report to others: these are good boys, than it is even more important for the significance of a project". [C2]

Cialdini and Richardson (1980) called this IM behavior: "IM by association”. Moreover, preparation is viewed as crucial to make a favorable impression.

"When I want to consult a company (...) I have to prepare for it, what kind of people are there, how do they proceed, how do they think, according to which criteria do they decide, that is the essential thing: I have to prepare. Through this preparation I unconsciously adjust to the situation. So, the first essential information is information over the other, this you have to collect, and then adjust the impression you want to achieve". [C5]

Only by knowing whom they would like to impress, consultants can be effective in IM. This can be related to Goffman's (1959) thought on "dramaturgical circumspection", which describes the need to prepare prior a performance. 
Finally, reliability is seen as very decisive for a positive impression, as e.g. expressed in the following quote.

"Starting on time, I think is important, and finishing on time is also important. Because these are things that people remember". [C5]

In contrast to the consultants' personal IM tactic, which is used to elicit liking/sympathy, the professional tactic is used to allure the attribution of competence and is similar to the IM tactic “self-promotion" (Bolino et al., 1999; Jones et al., 1982).

Consultants' conforming IM tactic

Organizational norms and informal rules define which behaviors are appropriate and these in turn influence the desired image (Roberts, 2005). This experience is also reported by our consultants. Therefore, the last identified consultants' IM tactic is described to consist of conforming behaviors. Here, the consultants want to appear favorable by conforming to role requirements and general conventions as attached to clothing, communication and behavior. Four consultants mentioned clothing as an important instrument in leaving a favorable impression. Here one example:

"We are also in a system, where bow you appear counts. Obviously when you come in jeans or shorts that will shape very negative impressions in the beginning. There is a minimum in the demand that we have, so the way you appear and the initial message that you convey, these are the ingredients that construct or make an impression, a good or bad one". [C4]

For the outfit of consultants is recommended: " 1 . Dress elegant, conservative, neatly and clean. 2. Try, as far as possible to adjust to the client" (Niedereichholz, 1996: 90). Studies show that people who are poorly dressed are perceived as less competent and less capable of fitting into the organization's culture, which detracts from the construction of a viable professional image (Rafaeli et al., 1993). Another important aspect in conforming mentioned by our interviewees lies in communication.

"You choose the language differently. Of course, I speak different with friends. Then I speak in my dialect. I also speak different with an area manager than with the CEO or with a colleague of the client who is in my project". [C3] 
There is considerable evidence that people tailor their message to suit their audience's attitude or opinion about the subject of the message (Higgins, 1992). Literature on speech accommodation shows that communicators will shift their speech style to converge with the speech style of their audience (Giles, Mulac, Bradac, \& Johnson, 1987). Finally, a consultant mentioned that he adapts his behavior in order to make a positive impression on the client:

"I behave more politely and reticent at the client's place". [C2]

The politeness phenomena (Brown \& Levinson, 1978) shows that people base their behavior on their interaction partner for saving their own face but also the one of others. A well-researched example of IM conformity is the matching effect, in which people match the self-presentation level of others by becoming more self-enhancing when interacting with egoistical others and more modest when interacting with self-deprecating ones (Baumeister et al., 1989).

For the conforming IM tactic it seems difficult to connect it only with a single desired impression, as done with consultants' personal tactics and a likeable image and with consultants' professional tactics and a competent image. According to Jones (1964) conformity in opinion, judgment, and behaviors are tactical variations of ingratiation, because the probability of likeability is increased when a person believes another person has similar values and beliefs (Schneider et al., 1972). That is, by conforming people can create a likeable image. However, by applying conforming tactics also a competent image can be created, e.g. appropriate clothing can give the impression of a competent consultant. As a consequence, we decided for defining conforming tactics separate from personal and professional tactics, since both strategic objectives - namely that of likeability and competence - could be addressed.

Our findings conform to existing knowledge on IM tactics by identifying two consultants' IM tactics which are very similar to well-known general IM tactics: ingratiation and self-promotion (Bolino et al., 1999; Jones et al., 1982). However, by discovering specific behaviors employed by consultants to manage clients' impressions, we genuinely add to the current knowledge on IM in consultancy. Furthermore, consultants' statements made it possible to classify some of their behaviors into a conforming tactic. Our categorization of conforming as a separate IM tactic is in contrast to existing theory, saying that conforming behavior is used within the context of ingratiation (Jones, 1964; Schneider et al., 1972). 
IM styles

Authentic acting IM style

All interviewed consultants seem to have a tendency to present an authentic portrait to clients.

The focus is on presenting a favorable consultant image with real personal elements. An illustration is offered below:

"I try to influence the impressions of the client; however I am relatively sure, that I have the right qualifications to do so. Therefore, I count on what and how I am. (...) Really successful you can only be, when you bring authenticity for yourself and optimize the means you have". [C5]

Role acting IM style

In contrast to the behavior described above consultants also mentioned tendencies to conform to role expectations in order to fulfill clients' expectations. These can be described as actorbehaviors which are used to favorably influence clients' impressions irrespective of the truth. A consultant reporting on behaviors of colleagues gives an example:

"I observe insincere behaviors by colleagues, in particular by those, which I know on a private basis. They jump into a consultant-costume, which they disrobe after the end of work, and then they are fully normal". [C4]

Further, interviewed consultants pointed to the fact that there are certain situations that ask for inauthentic behaviors, as described below:

"There are often topics, about which I have not clue. However, it is expected from you, that you can talk about these, even though I have no or little knowledge about it. Then you inevitably bave to play act and thereby conceal my lack of knowledge". [C4]

Based on these interview accounts, we can distinguish between two types of IM behaviors attempting to influence clients' impressions. Given that these behaviors at large show general individual tendencies to act in particular ways, we call them IM styles. In particular, we term the authentic behavior: "authentic acting IM style" and the inauthentic behavior with a major focus on role conformity: "role acting IM style". Similar views on IM and whether it is authentic or inauthentic are present in the IM literature. One is the expansive approach viewing IM as natural manners and in essence as authentic and true and the other is the restrictive view associating IM 
with deceptive and manipulative behavior (Ashforth et al., 1993; Schlenker, 1980, 1985; Schlenker et al., 1982). Though, the distinction into two different IM styles is original and our definitions also slightly diverge from the two views on the nature of IM. In particular, in our conception individuals with an authentic acting IM style try to make a favorable impression e.g. by presenting beneficial but authentic aspects of themselves and people with a role acting IM style want to fulfill others' expectations regardless whether they are actually able to satisfy them or not. The focus on the presentation of personal pros or on role fulfillment is a specification to extant knowledge. For this reason, the view of interviewed consultants can be seen to specify current knowledge on IM in general and expands the knowledge of IM in consultancy.

\section{Theme 3: Requirements and obstacles for effective IM}

In the following we report what the consultants considered as requirements and obstacles for effective IM. They reported on certain personal competences, self-regulation issues and a personality characteristic.

\section{IM competence}

Based on the interpretations of the interview transcripts, we were able to identify three IM competences: (a) communication, (b) relationship management, and (3) adaptiveness/flexibility.

\section{Communication}

Communication seems a major competence needed for successful IM. It should include listening ability, and verbal as well as nonverbal communication, as described below:

$$
\begin{aligned}
& \text { "An ability to communicate is a crucial base, which you should have. Active listening is } \\
& \text { also a component of it". [C5] } \\
& \text { "I worked with a colleague; he manipulated others with his face. Very strong with his } \\
& \text { eyes and the way he looked at others. He rewarded people with a smile or penalized them } \\
& \text { with a harsh expression". [C4] }
\end{aligned}
$$

Carver and Scheier (1985: 169) indicated that individuals require communications skills in order to "create a coherent self-presentation". Especially consultants need to be able to communicate in a highly effective manner with clients, colleagues, and others in the business environment. They must inform, persuade, convince, educate and train various individuals all within the 
context of and simultaneous with their work. In addition, consultants must be active and attentive listeners. Since much communication is non-verbal, a good consultant must also be able to display appropriate body language.

\section{Relationship management}

Another crucial IM competence in the eyes of our consultants is the ability to manage relationships and to make and keep social contact with other people. According to our interviewees, consultants should be able to put themselves in the position of another in order to manage relationships with the clients.

"That you are an attentive partner, that you recognize the situation of the other, and that you draw the right conclusion for the client out of this perception, that is an essential thing." [C5]

That aspect is also used to define empathy. Salovey and Mayer (1990: 194-195) defined empathy as “the ability to comprehend another's feelings and to re-experience them oneself'. Empathy is given, when the perspective of another is taken to understand his or her reactions. Hence, effective IM requires role-taking skill in anticipating how an audience is likely to react and communication skill in tailoring one's communications to produce the desired effect.

\section{Adaptiveness/flexibility}

Consultants face many different situations and people and therefore there seems to be a continuous demand for adaptiveness and flexibility as the following quotation shows:

\footnotetext{
"To create confidence in the client's mind (...) they have not only to show that they understand the topic matter, but also that they have the wisdom and the judgment to understand that the formula doesn't necessarily work in all circumstances, that they are flexible enough to understand what the client wants (...)". [C5]
}

Competence refers to the capacity of an individual to show particular behaviors in order to successfully handle certain situations or complete a certain task or job (Ford, 1985; Roe, 2002). IM seems to be effective when people are motivated to make a desired impression on an audience and are relatively confident they will be able to do so (Schlenker et al. 1996). Confidence could come from the knowledge of possessing adequate IM competence. Hence, in the context of IM, we define IM competence as being qualified to manage favorable impressions in the client. 
We consider them as basic, because they are not specific in terms of particular situations or persons. In the literature, the three identified competences are often described as ingredients of social competence: "social competence consists of relationship skills. It involves responsiveness, especially the ability to elicit positive responses from others; flexibility, (...); empathy, communication skills, and a sense of humor" (Benard, 1995: 67). It is important to note that the term IM competence is one aspect of social competence that stands for the combined effects of various social skills - of which the ability to make a good impression on others is only one. Individual differences in social competence are identified as reasons for less IM effectiveness (Riggio, 1986; Schlenker et al., 1982). Knowledge about necessary IM competences, however, is new to the field of IM in general and particularly to IM in consultancy.

\section{Self-regulation processes}

In Chapter 2 we argued that the topic of self-regulation might help to find an answer to the question why consultants are sometimes not effective in their IM attempts. In this section we describe interview accounts about potential reasons for IM failure that correspond to this theoretical notion.

\section{Goal setting}

Goal setting in the IM context says that an individual has to set the goal of influencing another in order to pursue future action. One consultant reported that she does not have the aim to influence the impressions of the client.

"I act as I am. Here I have a person, and I want to influence him/ her in this or that direction; that is not how I calculate". [C1]

Because the consultant does not have the goal to influence clients' impressions, it is obvious that IM can not be a success. A different problem is described by another consultant; he does not know what to do in a certain situation.

"During a presentation I recognize that I have my hands in my pocket, but I do not take it out, because I do not know what I should do with it". [C2]

Therefore, it will be difficult for him to succeed in his IM efforts. Another consultant reported of problems when he does not like somebody. In that case, he describes problems to stay focused due to extra effort and reduced motivation. 
"When I do not like somebody the limits are quickly achieved and I retreat. Behaving against that is exhausting and I have no interest in it". [C4]

As a consequence, his initial IM attempts might fail. He also mentioned situations in which his attention is diverted and therefore making impressions only plays a secondary role:

"Sometimes you are so occupied with a topic that you have no time left to think about your own behavior." [C4]

In Chapter 2 we describe all the above mentioned reasons as potential grounds for IM failure. To recapitulate, first, IM might fail in case that the goal for IM is not existent or not important enough (Bromley, 1993; Karoly, 1993). Second, it is detrimental for IM success if an individual does not know how to act in a certain situation (Carver et al., 1990a). The third reason, conflicting goals, is as well described in theory as one reason for self-regulation failure (Carver et al., 1981) potentially resulting in IM ineffectiveness. Conflicting goals occur when for instance habitual inclinations come in conflict with the demands of the situation. Also the last situation portrayed by the consultant is in accordance with theory saying in situations of high task engagement people are less affected by the presence of others (Duval et al., 1972; Jones et al., 1982; Schlenker, 1980) and therefore the behavioral control needed to manage others' impressions might suffer. As a consequence, we can say that the real-life experiences of our consultants conform to what is described in the literature on goal-setting.

Self-monitoring and self-evaluation

IM requires from an individual to monitor and to reflect his or her own behavior in interaction with others, as described by one consultant:

"My own behavior is monitored and tested, what I can do, e.g. to mitigate a situation. The behavior of the other is also monitored e.g. why is he now moping, or so aggressive, or also so openminded, what did I wrong or well, in order to countersteer and reach a good communicative result". $[C 57$

Another consultant described and disapproved his own behavior:

"My behaviors are rather spontaneous, and often, unfortunately, emotionally directed." [C3]

All described situations correspond with extant knowledge. For example, in the literature on selfregulation the importance of monitoring and evaluation is stressed (e.g. Bandura, 1982; Carver et 
al., 1985; Kanfer, 1973). Further, it is acknowledged that when monitoring and evaluation do not take place or in the event that the wrong aspects are monitored, self-regulation might fail (Carver \& Scheier, 1998). The portrayed behavior in the last quote in this paragraph can be compared to a behavior termed transcendence failure in the literature on self-regulation. Hereby individuals give in to immediate desires and simultaneously forget about long-term consequences (Baumeister et al., 1994). As for goal-setting, the reports of our consultants correspond to what self-regulation literature with respect to self-monitoring and self-evaluation describes in detail.

\section{Self-efficacy}

In the context of IM failure, one consultant described why she has problems with IM, specifically with selling herself to the client:

"My weaknesses lie in the point that I find it difficult to sell. That is not really my nature; it is a weakness, because it belongs to the job, that you can display your performance and that you display yourself as sellable. But I always give in that weakness, because I act on the assumption, that I am not good in it". [C1]

This description conforms to current knowledge, saying that individuals stop any IM attempts when then do not believe in their abilities to influence others' impressions. As a result, a lack in self-efficacy is seen by theory as a reason why IM might not succeed (e.g. Bandura, 1982; Kanfer, 1973; Karoly, 1993; Schlenker et al., 1996; Schlenker et al., 1982).

To summarize, concerning self-regulation issues all from theory derived notions were present in consultants' descriptions of personal experiences. There was no supplemental information or genuine additions on the topics in interest.

\section{Self-monitoring}

Regarding personality, interview statements of the consultants showed that different personality types were present in our sample:

"I can press a button and say: Show-time!" [C4]

"I act as I am". [C1] 
These descriptions can be compared to the personality characteristic of self-monitoring (Snyder, 1974). As learned in the previous chapter, a high self-monitoring individual adjusts his or her actions to situational and interpersonal conditions of behavioral suitability. In contrast, a low selfmonitoring individual is concerned with his or her inner feelings and personal attributes and does not take outer demands into consideration. Here "real-life" seems to agree with literature as well.

\section{Experts/Trainers}

In the following we will present the results for the second sample: the expert-group. This sample was interviewed with a focus on the identification of consultants' personal requirements and obstacles for effective IM.

\section{Theme 3: Requirements and obstacles for effective IM}

The interview accounts of the expert-group could be distinguished as well into IM competence, self-regulation issues, and self-monitoring.

\section{IM competence}

The experts mentioned the same three aspects of IM competence as the consultants.

\section{Communication}

Communication was considered by the expert group as the most important facet of IM competence. This is well expressed in the following quote:

"Obviously it is the way you talk. You have to know what you are talking about. That is the first step. The way of talking is extremely important, it is even more important in the context like ours, because how convincing your are in the way you state what your are saying; so this is one factor that I consider as important in shaping the impressions that people have”. [E3]

\section{Relationship management}

One expert mentioned the ability to manage relationships as eminent in the context of IM effectiveness. She referred to her experience with people having relationship management competence and how it affects one personally: 
"Some people have the ability, because they are able to create a relationship all over sudden and you feel really good at it." [E4]

Adaptiveness/flexibility

The competence of adaptiveness was mentioned by the experts as well:

"When somebody comes in dressed looking really good, really well, very much in line with our standard it is like an automatic 20\% buying versus if somebody comes in not in line with our standards or with something that is totally different from our image, we get the feeling they do not understand our business. So a lot of it, you must understand what is the client's business, what is the client's environment like, and then create your visual image." [E4]

With regard to IM competence for many the next question is: is it possible to train consultants to be better impression managers? The answer is probably "yes", but little work has been done in this area. We discussed with the expert-group whether they think IM is trainable. In general, they all agreed on the fact that it is trainable to a certain level. For instance:

"Some people (...) have better communication abilities than others. But may be with a training people can improve their communication competence, and usually nowadays most of the organizations have some training on communication. I think that helps. I mean each person knows his weakness. When I have a weakness in communication skills I will attend training, read books. I always say you can improve in life, you cannot change 100\%, but you can always improve. Some people learn how to control themselves a bit more, other people learn how to be more extraverts, and other people learn how to address an audience, learn how to talk in front of people. You know this comes with training". [E2]

\section{Self-regulation processes}

With reference to self-regulation issues, experts mentioned some events that overlap with those mentioned by the consultants. 
Goal-setting

Concerning goal-setting an expert mentioned that when an individual is not interested enough in IM it correspondingly will fail:

"I have a consultant friend, and I have been able to see him now and then. I know him as very personal, and he is such a sweet and nice person and I have seen him in situations where is he like under the gun, where all over of a sudden be is different. Everybody understands that he acts different, but I think that impression is how you react when other people try to disturb you. People understand when you are busy, you can go like: "oh I am sorry, sorry" or you can go: "don't bother me". I think it depends on your behavior. Your true personality comes up, if your value system on how you want to relate to others is not important. (...). In situations where people have to be, they don't want to be (...) it depends on their value system, how important is impression management and how important is your relationship with others." [E4]

Self-monitoring and self-evaluation

One expert described a situation in an interaction with a consultant. Here the consultant showed unfavorable behavior due to his inability to monitor and evaluate his own behavior:

"I had one person one day, and he kept moving on his chair, (...) but they do not recognize, because for them it is automatic, impulsive, it is from inside, they feel it inside, it is reflected outside, but they do not realize it." [E2]

\section{Self-efficacy}

Most interviewees from the expert-group stated when persons doubt their ability to succeed in IM the probability is high that they really fail.

"When you are going into consultancy and you have a problem of self-efficacy it does not belp to form a good impression. That is lack of self-control, and a lack of confidence is not positive for forming positive impressions. It can lead to an impression of instability and that does not help". [E3] 


\section{Self-monitoring}

Experts and trainers acknowledged that there are individuals who are naturally able to succeed in $\mathrm{IM}$ and others not.

"I mean some people are gifted, they are born like this. They have it (the ability to influence impressions)”. [E2]

The interpretations of interview accounts of the expert-group conform to most findings from the consultant group. Further, since we learned that the views of the consultants on personal requirements and hindrances to effective IM fit well to findings in the literature; these match up with the interview accounts of the expert-group as well.

\section{DISCUSSION}

The main goal of this study was to gain real-life information about IM, specifically about consultants' IM by asking the subjects of research themselves. In particular, we wanted to learn about images consultants try to get across, how they do so and what they need and what prevents them from being successful in their IM attempts. Some issues were already theoretically discussed in Chapter 2 and here further illustrated. It is important to realize that we did not intend to test existing theories or to generalize our results. Rather, we compared the findings to established theories to see whether they conform to what is already known, specify or elaborate, or genuinely add to existing knowledge. Table 1 summarizes our findings; it presents the various themes and categories and how these compare to extant literature on IM in general and in consultancy in particular.

Table 1: Overview - Summary of findings in comparison to extant literature

\begin{tabular}{|c|c|c|c|}
\hline THEMES AND CATEGORIES & CONFORMITY & $\begin{array}{l}\text { SPECIFICATION/ } \\
\text { ELABORATION }\end{array}$ & GENUINE ADDITION \\
\hline \multicolumn{4}{|c|}{ THEME 1: DESIRED CONSULTANT-IMAGES (Interviewees: Consultants) } \\
\hline Honest/authentic consultant & & $\begin{array}{l}\text { of IM in general (e.g. } \\
\text { Grandey et al., 2005a; } \\
\text { Rosenfeld et al., 2002) }\end{array}$ & to IM in consultancy \\
\hline Competent consultant & $\begin{array}{l}\text { with IM in consultancy } \\
\text { (Clark, 1995; Staute, } \\
\text { 1998) }\end{array}$ & & \\
\hline Likeable consultant & & $\begin{array}{l}\text { of IM in general } \\
\text { (e.g. Clark, 1995; Wayne } \\
\text { et al., 1995) }\end{array}$ & to IM in consultancy \\
\hline
\end{tabular}




\begin{tabular}{|c|c|c|c|}
\hline THEMES AND CATEGORIES & CONFORMITY & $\begin{array}{l}\text { SPECIFICATION/ } \\
\text { ELABORATION }\end{array}$ & GENUINE ADDITION \\
\hline \multicolumn{4}{|c|}{ THEME 2: IM BEHAVIOR (Interviewees: Consultants) } \\
\hline \multicolumn{4}{|l|}{ IM STYLES } \\
\hline Authentic acting IM style & & $\begin{array}{l}\text { of IM in general; similar } \\
\text { to expansive view of IM } \\
\text { (e.g. Briggs et al., 1980; } \\
\text { Jones et al., 1982; } \\
\text { Snyder, 1974) }\end{array}$ & to IM in consultancy \\
\hline Role acting IM style & & $\begin{array}{l}\text { of IM in general; similar } \\
\text { to restrictive view of IM } \\
\text { (e.g. Goffman, 1959; } \\
\text { Schlenker, 1980) }\end{array}$ & to IM in consultancy \\
\hline \multicolumn{4}{|l|}{ CONSULTANTS' IM TACTICS } \\
\hline Consultants' personal IM tactic & $\begin{array}{l}\text { with IM in general, } \\
\text { similar to ingratiation } \\
\text { (e.g. Bolino et al., 1999; } \\
\text { Jones et al., 1982) }\end{array}$ & & to IM in consultancy \\
\hline Consultants' professional IM tactic & $\begin{array}{l}\text { with IM in general, } \\
\text { similar to self-promotion } \\
\text { (e.g. Bolino et al., 1999; } \\
\text { Jones et al., 1982) }\end{array}$ & & to IM in consultancy \\
\hline Consultants' conforming IM tactic & & & $\begin{array}{l}\text { to IM in general and in } \\
\text { consultancy }\end{array}$ \\
\hline \multicolumn{4}{|c|}{ THEME 3: REQUIREMENT AND OBSTACLES FOR EFFECTIVE IM (Interviewees: Consultants \& Experts) } \\
\hline \multicolumn{4}{|l|}{ IM COMPETENCE } \\
\hline Communication & & & $\begin{array}{l}\text { to IM in general and in } \\
\text { consultancy }\end{array}$ \\
\hline Relationship management & & & $\begin{array}{l}\text { to IM in general and in } \\
\text { consultancy }\end{array}$ \\
\hline Adaptiveness/flexibility & & & $\begin{array}{l}\text { to IM in general and in } \\
\text { consultancy }\end{array}$ \\
\hline \multicolumn{4}{|l|}{ SELF-REGULATION PROCESSES } \\
\hline Goal-setting & $\begin{array}{l}\text { With goal-setting } \\
\text { (e.g. Baumeister, 1999; } \\
\text { Carver et al., 1981, } \\
\text { 1990a, 1998; Karoly, } \\
\text { 1993) }\end{array}$ & & \\
\hline Self-monitoring and self-evaluation & $\begin{array}{l}\text { With self-monitoring } \\
\text { and self-evaluation (e.g. } \\
\text { Bandura, 1982; } \\
\text { Baumeister et al., 1994; } \\
\text { Carver et al., 1985, } \\
\text { 1998; Kanfer, 1973) }\end{array}$ & & \\
\hline Self-efficacy & $\begin{array}{l}\text { With self-efficacy (e.g. } \\
\text { Bandura, 1997; Kanfer, } \\
\text { 1973; Karoly, 1993; } \\
\text { Schlenker et al., 1996; } \\
\text { Schlenker et al., 1982) }\end{array}$ & & \\
\hline \multicolumn{4}{|l|}{ PERSONALITY CHARACTERISTIC } \\
\hline Self-monitoring tendency & $\begin{array}{l}\text { With self-monitoring } \\
\text { (Snyder, 1974) }\end{array}$ & & \\
\hline
\end{tabular}


Starting with theme 1 - the desired consultant-images - interview accounts conform to theory in stating that competence is a major image desired to be presented by consultants (Clark, 1995). The identified images of honesty/authenticity (e.g. Clark, 1995; Grandey et al., 2005a; Rosenfeld et al., 2002; Wayne et al., 1995) and likeability (e.g. Clark, 1995; Wayne et al., 1995) are known to yield beneficial outcomes but did not yet express the personal preference of the impression manager him- or herself - here the consultant. As a consequence, we consider these findings as an elaboration of established IM knowledge by adding the impression manager's view. Further, the findings of an honest/authentic and a likeable consultant image can be seen as genuine additions to the literature on IM in consultancy because almost all knowledge on IM evolved from other sources than consultancy.

Concerning theme 2 - IM behavior - the consultants described behavior tendencies in IM which are already described in the IM literature but helped us also to discover specifications and even genuine additions to theory. For instance, consultants reported three IM tactics they use to elicit favorable impressions in the clients. The personal and professional IM tactics are very similar to the well-established IM tactics termed ingratiation and self-promotion (e.g. Bolino et al., 1999; Jones et al., 1982) and therefore conform to theory on general IM. In addition, we were able to identify a third consultants' IM tactic - conforming. Since all three IM tactics are seen to be specifically valid for consultants, these truly add to IM theory on consultancy. Furthermore, we discerned two IM styles - authentic acting and role acting IM styles - and these could be linked to two different conceptions of how IM is seen in the literature. Some researchers attach a negative connotation to it, e.g. by saying that it is used to deceive in order to serve oneself (restrictive approach). The other approach considers IM as an omnipresent feature of social behavior and describes IM behavior e.g. as the "packaging of information" but not as manipulative and flagitious (expansive approach) (Schlenker et al., 1992: 137). We are able to specify current knowledge on IM by offering slightly different conceptions of the two IM styles and further add to it by linking it to the field of consultancy.

Regarding theme 3 and potential requirements and obstacles for effective IM both interview samples mentioned various aspects of IM competence as prerequisites for effective IM. Since this aspect has yet not been tackled in research on IM, particular on IM in consultancy, it is new and innovative. Referring to self-regulation processes the descriptions of our interviewees correspond to all aspects of consulted literature to explain IM failure in Chapter 2. Concerning the personality characteristic of self-monitoring, which is often used to distinguish between successful and unsuccessful impression managers, answers of our respondents also conform to what is described in the literature. 
In conclusion we believe that our qualitative study has yielded a broader and deeper understanding of IM in consultancy due to the fact that our findings (a) agree with current knowledge, (b) specify and elaborate, or (c) add to existing theory. Besides, the conformed, specified and newly identified concepts can be used to further research in this important area.

\section{LIMITATIONS AND FUTURE RESEARCH}

First of all, the research does not give generalizable results on IM in consultancy. However, generalization to other individuals and settings was not attempted in this phase of investigation. In our opinion, the disadvantage of choosing a qualitative methodology - such as a smaller sample size and a lack of statistical representativeness - were outweighed by the advantage of gaining additional in-depth knowledge on the topic of interests as was intended at this stage of the overall project.

Further, while the lack of a client perspective may raise concern, the focus of this study was on how consultants apply IM, what do they need for doing it successfully and what prevents them from making favorable impressions. Therefore, the negligence of clients' opinions seems acceptable. In addition, we tried to countersteer the potential impact of lacking a client perspective in our findings by interviewing experts and trainers in the area of IM and/or consultancy to account for more objective information. However, future work should involve clients' perspective. Thereby, it could e.g. be identified whether the images desired to be expressed by consultant actually are in accordance with what clients wish.

Most importantly, current findings should be tested in empirical studies. Thereby, the "real" influence of particular desired consultancy images, consultants' IM tactics and styles and potential reasons for IM success or failure could be verified or eliminated. Future research, including this $\mathrm{PhD}$-project, can use the results of this study to develop more complex and precise measures of IM that will allow broader based empirical studies to be conducted.

\section{CONCLUSION}

With this study we were able to identify the images that consultants consider as appropriate for making a favorable impression on the client. These are the images of an authentic/honest, a competent, and a likeable consultant. In order to achieve these images particular IM tactics and styles were reported by interviewed consultants. Consultants' personal, professional and conforming IM tactics in addition to an authentic acting and a role acting IM style are seen to facilitate the making of favorable impression on the client. Moreover, we were able to learn that 
IM competence is seen as necessity for successful IM. Component parts are communication, relationship management, and adaptiveness/flexibility. Further, the interview accounts showed the usefulness of our theoretical findings presented in Chapter 2, saying that the self-regulation processes: goal setting, self-monitoring and self-evaluation, and self-efficacy can go awry and interfere with successful IM. Finally, we learned that low and high self-monitoring individuals were present in our sample. The expert-group emphasized the distinction of people in either having or not having the ability to influence others' impressions, but also indicated the possibility of improvement by means of training. In general, interpretations of consultants' and expertgroup interview accounts showed great overlap underlining the significance of statements. On the whole, results of the study point to the importance of examining IM in consultancy. At this stage, the study aimed to generate fresh ideas that steer subsequent studies by which we aim to discover more about IM in consultancy and prove current results on an empirical basis. 


\section{The Use of IMPRESSION MANAGEMENT TACTICS By CONSUltants}

"Every buman in this world counts as much as he presents bimself". (Jeder Mensch gilt in dieser Welt nur so viel, als wozu er sich selbst macht.) - Freiherr von Knigge, Über den Umgang mit Menschen

A pleasant owner can sell his merchandise.

- Persian proverb

This chapter describes an exploratory study among consultants $(\mathrm{N}=80)$ examining the use of three specific IM tactics (personal, professional, and conforming IM tactics) identified in the previous study (Chapter 3). The major objectives were to investigate the ways in which various person and job-related characteristics relate to consultants' use of IM tactics and to identify whether the tactics contribute to the prediction of consultants' perceived performance. We differentiate between consultants' IM tactics used one by one and in combination.

Concerning consultants' IM tactics used separately, the results indicate an effect of age, job tenure and IM competence. That is, (a) consultants in the age between 31 and 40 use the professional IM tactic less than their older colleagues ( $>51$ years); (b) job tenure, namely over 21 years, is associated with a more frequent employment of the conforming IM tactic; and (c) IM competence is related to a more frequent use of all three consultants' IM tactics. Pertaining to the question whether IM tactics use relates to consultants' perceived performance, the findings show that the personal and the professional IM tactics have positive relationships with consultants' performance when used separately.

With regard to consultants' IM tactics used in combination the study discovered three profiles. One group of consultants makes use of all three IM tactics above average (versatile profile), another group employs all three IM tactics below average specifically the personal IM tactic (impersonal profile), and consultants in a third group (naive profile) use the personal IM tactic above and the professional and the conforming tactics just lower than average. The results further suggest that consultants with a versatile profile typically have high IM competence. They also self-report better performance evaluations than consultants in the others two groups. 


\section{INTRODUCTION}

In the previous chapter consultants provided real-life information concerning the images they aim to express and the IM tactics they use to attain these and thereby influence clients' impressions. They reported the use of three IM tactics. With the personal IM tactic consultants aim to evoke impressions of sympathy - they flatter the client. The professional tactic, which implies promoting oneself, is employed to display the image of a competent professional. The conforming tactic, which includes behaviors showing conformance to roles and customs, is used to create general favorable impressions in the client.

In this chapter, we want to delve deeper into the topic of consultants' IM tactics by asking the following questions. First, who uses the different IM tactics? In particular, are there differences between men and women, younger and older consultants? Does it matter whether consultants have a short or long job tenure, or whether they work e.g. as an IT or a management consultant, or have managerial functions or not? Are there differences between low and high self-monitoring consultants and those with low or high IM competence? Second, and perhaps more important, does consultants' use of IM tactics actually add to their performance?

Furthermore, although it is obvious that people can combine IM tactics to influence others' impressions, research has mainly investigated IM tactics in isolation. Only a few researchers studied different IM tactics in terms of profiles (Bolino \& Turnley, 2003b; Falbe \& Yukl, 1992). For example, Bolino and Turnley (2003b) found that individuals who either refrain from using IM or who make only use of positive tactics are seen more positively than those who use relatively high levels of IM tactics. We agree with these authors in that by concentrating on separate IM tactics one may overlook patterns that predict consultants' performances. Therefore, we consider the comprehension of IM tactics used in combination as an important issue.

Hence, to gain further knowledge on consultants' IM tactics, two objectives guide this study. First, we investigate consultants' IM tactics one by one. That is, we explore the ways in which other variables (age, gender, job tenure, consultancy type, managerial function, selfmonitoring, and IM competence) are related to the one of each IM tactic and study whether the use of these tactics associate with consultants' performance. Second, we repeat the same analysis with consultants' IM tactics used in combination. However, we start with identifying groups of consultants who employ similar combinations of personal, professional, and conforming IM tactics. Then, we explore whether diverse factors influence the ways of using IM in combination and whether different profiles of consultants' IM tactics associate with consultants' performance. 
The chapter is organized in the following way. First, we describe IM tactics and list studies that have found a relationship between IM tactics and individual performance. After that, we introduce various person and job-related variables and discuss why they might relate to consultants' IM tactics. Next, we describe the methods of the study, followed by the presentation of the findings. In the final part of the chapter we discuss the results, address limitations and give recommendations for future research. The chapter finishes with the conclusion.

\section{CONSULTANTS' IM TACTICS}

\section{Consultants' IM tactics and performance}

There are a number of ways by which individuals can present particular images of themselves in order to manage others' impressions. The focus in this chapter is on IM tactics, which are described as specific behaviors aiming for concrete impressions in others (Bolino et al., 1999; Giacalone et al., 1991; Jones et al., 1982; Rosenfeld et al., 1995). Ingratiation, self-promotion, exemplification, supplication, intimidation compose the most popular taxonomy of IM tactics (Jones et al., 1982). The first, ingratiation, involves e.g. flattery to gain affection by others. With self-promotion individuals highlight their abilities to express a competent image. Exemplification is used to display the image of an exemplary person, e.g. by going beyond the call of duty. With supplication, individuals try to advertise their limitations to evoke impressions of neediness. Finally, it is suggested that people can employ intimidation to appear threatening.

On the basis of the interviews reported in the previous chapter, we decided to investigate three newly identified consultants' IM tactics: personal, professional, and conforming IM tactics. Our decision to focus on these tactics is based on the fact that IM tactics are job specific. For example, "the display of friendliness and good cheer are expected in an array of service occupations including flight attendants, servants, and sales clerks. In contrast, bill collectors and bouncers are paid to convey hostility. Funeral directors express sadness. Other roles call for the suppression of emotion, 'good' academic deans display neutrality, especially around budget time" (Rafaeli \& Sutton, 1987: 23). Although the IM tactics from the Jones and Pittman taxonomy were used by Bolino and Turnley (1999) to develop a measure of employee IM behavior, we think that they might not be applicable or rather not so well suited to study consultants' IM. Consultancy is a setting with its own prescribed roles specifying certain expectations of consultants and respective behaviors. For example, the consultant-client relationship is not comparable to other service relationships, as i.e. between doctors, hairdressers, etc. and their customers and therefore defines a substantial part of the consultant role. 
Furthermore, the Jones and Pittman IM taxonomy includes the IM tactics supplication and intimidation. However, as described before, with these tactics individuals do not aim to establish positive images in others' eyes. In contrast, all of our consultants' IM tactics are assertive, which means that consultants can proactively use them to convey favorable images to clients. For example, by utilizing the personal IM tactic, which is comparable to ingratiation, the consultant aims to appear likeable to the client. He or she does i.e. by flattering, pleasing the client and by being honest. A consultant employing the professional IM tactic, which is very much alike selfpromotion, rather aims to make a competent impression on the client. Behaviors like promoting one's qualifications and relying on references should help in achieving that goal. The conforming IM tactic is not so clear-cut on the image desired. By conforming to role requirements and general conventions as attached to clothing, communication and behavior, the consultant tries to appear favorable to the client, which could include a likeable and/or a competent consultant image.

Additionally, some IM tactics might work together (Jones et al., 1982). For example, an individual might first try to evoke others' sympathy by flattering, and then switches over to present his or her own amenities. However, other IM tactics, like self-promotion and supplication, are rather incompatible in that it is unlikely to evoke plausible images of neediness and competence at the same time. Although literature and common sense point at the topic of IM tactics used in combination, it is remarkable that almost all research refrained from investigating it. With regard to the three consultants' IM tactics all combinations are thinkable. First of all and in difference to some of the IM tactics from the Jones and Pittman taxonomy, they are not mutually exclusive, which opens a range of possible combinations. Varying situational requirements as well as individual characteristics might influence consultants' use of IM tactics. For example, in the bidding phase of a consultancy project, consultants might avoid eliciting attributions of likeability with the help of the personal IM tactic, but rather use the professional and the conforming IM tactics in order to appear competent and to prevent any risk of early rejection e.g. by not being adequately dressed. The major aim is to satisfactorily show that one is competent. Then again, one could also imagine that consultants employ all three IM tactics since every one of them can help in establishing a favorable image in clients' eyes. Besides, there might also be consultants who do not want to influence clients' impressions via IM and therefore do without the use of any of the three consultants' IM tactics.

Concerning the effectiveness of IM tactics several studies have suggested that individuals use IM to enhance their performance evaluations and diverse IM tactics have indeed been shown to positively influence these (Bolino et al., 2006; Harris, Kacmar, Zivnuska, \& Shaw, 2007; Vilela 
et al., 2007; Villanova et al., 1991e.g.; Wayne et al., 1991; Zivnuska, Kacmar, Witt, Carlson, \& Bratton, 2004). For example, Wayne and Ferris (1995) found that subordinates' use of IM tactics provoked supervisors to perceive their subordinates as likeable and similar, which in turn positively influenced given performance ratings. The findings of a study conducted by Harris and colleagues (2007) showed that individuals who were high in IM use and in political skill received higher performance evaluations.

In this regard, we want to investigate whether the three consultants' IM tactics, alone and in combination, have an effect on consultants' performance. In particular, we aim to discover whether the use of consultants' IM tactics, increases consultants' perceptions on how they think their performance is evaluated by their clients.

\section{Effects of person and job-related characteristics on consultants' IM tactics}

Before we investigate the question whether consultants' IM tactics - used alone or in combination - have an effect on consultants' performance, we are interested in identifying who uses the IM tactics. That is, what determines consultants' IM tactics use?

People differ in how they can and want to present themselves and the literature proposes many factors that influence the use of IM (for a review see Bolino et al., 2008). The present research includes seven variables that cover a broad range of person and job-related issues. We describe in the following why these might be decisive for consultants' use of IM tactics and thus should be included in coming analyses.

\section{Gender}

The literature acknowledges a special use and different effects of IM among men and women (Singh \& Vinnicombe, 2001). For example, in comparison to men, women are found to behave in a less aggressive manner and to be rather passive in their use of IM (Bolino et al., 2003b; Fletcher, 1981). Furthermore, knowing that a behavior was performed by a man or a woman can lead to different evaluations of that behavior (Deaux and Taynore, 1973). For example, Rudman (1998) found that self-promotion is instrumental for women in creating a competent impression; however, in interactions with other females it might evoke social reprisals for violating the gender norms of being modest. Bolino and Turnley (2001) found that the use of intimidation had little effect on the performance evaluations of female employees but had a positive impact on the performance appraisal of male employees. Further, female managers utilizing ingratiation received higher performance ratings than male managers using the same IM behavior (Kipnis \& 
Schmidt, 1988). As a result, female consultants might e.g. employ different IM tactics compared to their male colleagues.

\section{Age and job tenure}

Other variables likely to influence how consultants utilize IM are age and job tenure. With age experience grows and so does ability and practice in IM behavior (DePaulo, 1992). The same can be assumed for job tenure, since longer job tenure often equates with an older age. It can be expected that older people and people with longer job tenure are more effective in their IM attempts due to more available knowledge and experience gained on how to behave in various situations and with different interaction partners. Research also noticed age as a significant predictor of the frequency with which IM tactics are applied. For instance, Singh and others (2002) found that younger females seemed to employ less ingratiation then their older colleagues. Consequently, consultants' age and job tenure might influence their way of using IM tactics.

\section{Consultancy type and managerial function}

The consultancy type might also relate to consultants' use of IM tactics. For example, IT consultants might employ less or different IM tactics in their everyday job activities due to a smaller amount of face-to-face interaction with clients. Further, there might be differences between consultants with and without managerial functions as the former group wants or has to establish images in the eyes of the clients that differentiate them from the latter group. For example, supervisors need to insure they have credibility with subordinates (Huber, Latham, \& Locke, 1989). As a result, consultancy type and managerial function might determine which consultants' IM tactics are employed.

\section{Self-monitoring}

Some individuals are described as more likely to engage in IM because their traits predispose them to engage in such behavior (Ferris et al., 1991). As mentioned in Chapter 2, such interindividual differences are largely captured by Snyder's construct of self-monitoring, which refers to the motivation and ability to monitor and modify one's expressive behavior (Gangestad et al., 2000; Snyder, 1974, 1987). The prototypical high self-monitor "treats interactions with others as dramatic performances designed to gain attention, make impressions, and at times entertain" and the prototypical low self-monitor "is someone who is unable or unwilling to engage in histrionics in social situations and who typically does not use dramatic performances to impress others or 
gain their attention" (Snyder, 1987: 178). It has been suggested that self-monitoring encompasses both the tendency to use IM and the skill to successfully execute such behaviors (Caldwell et al., 1982). That is, high self-monitors frequently engage in IM and are more effective than low selfmonitoring individuals in using IM tactics to achieve favorable images while avoiding undesired ones (Turnley et al., 2001). Furthermore, high self-monitoring individuals are more likely to utilize a variety of strategies to manipulate the impressions they make during negotiations (Jordan \& Roloff, 1997). As a consequence, consultants' self-monitoring level might impact on their utilization of IM tactics.

\section{IM competence}

In contrast to self-monitoring, which has received a lot of attention in previous studies on IM, IM competence is a novel concept, which emerged as a crucial topic in our interviews. We defined IM competence, consisting of aptitudes in communication, relationship management, and adaptiveness/flexibility, as the proficiency to create favorable impressions in others. Due to the fact that the possession of IM competence can result in higher confidence, which in turn is seen as a key determinant of effective IM performance (Schlenker et al., 1996), we expect that IM competence relates to consultants' use of IM tactics.

\section{METHODS}

\section{Participants and procedure}

The sample consists of 80 consultants being members of the $\mathrm{BDU}^{5}$ (Bundesverband Deutscher Unternehmensberater). Prior to the beginning of the data collection, the chief executive officer of the BDU sent an e-mail to contact persons of member companies asking for their support in forwarding the request for research participation to their consultants. The email included a project description for participating companies (see Appendix C) and a link to an onlinequestionnaire. Respondents were asked to follow the link and complete the survey at their earliest convenience, but before the end of the four-week window.

It appeared that 69 percent of respondents are male. Most consultants (54\%) are younger than 41 years (14\% up to 30 years, 39\% between 31 and 40 years, 26\% between 41 and 50 years,

\footnotetext{
${ }^{5}$ The Federal Association of German Management Consultants BDU e.V. is the industrial and professional association of management consultants and executive search consultants in Germany. It is the biggest association of management consultants in Europe.
} 
$21 \%$ over 51 years). 69 percent of the consultants have a job tenure up to 10 years ( $36 \%$ up to 5 years, 33\% between 6 and 10 years, 25\% between 11 and 20 years, and 6 percent more than 21 years). 23 percent of them work as management consultants, 24 percent as HR consultants, 34 percent as IT consultants, and 19 percent in other consultancy fields. Most consultants (54\%) do have managerial functions.

\section{Scales}

Due to the fact that the consultants' IM tactics (personal, professional, and conforming IM tactics) and the construct of IM competence are new to the IM literature we had to develop new scales. We applied a two-step procedure: first, when feasible, we adopted items from existing scales that show great overlap with given definitions, second, we developed and added new items based on the results of the interview study.

The complete survey instrument was initially constructed in English but translated into German. To validate the German version, the survey was translated back into English in order to check the accuracy of the translation (Brislin, 1980). Further, we pre-tested the German version of the survey instrument on 20 consultants. They were requested to comment on the clarity of the wording of the items. Their comments led to only minor changes in the wording.

Most scales used a 5-point Likert response format ranging from 1 (totally disagree) to 5 (totally agree). However, to measure consultants' IM tactics we focused on how frequently each IM tactic is used, as other researchers have also done (Kumar et al., 1991; McFarland, 2003; Wayne et al., 1990). The Likert scales range from 1 (never) to 5 (very often). The items in each scale were summed and then averaged to arrive at an overall value for the scale. Higher scores represent higher levels of each of the constructs. A detailed description per scale follows.

\section{Personal IM tactic}

The personal IM tactic scale consists of ten items and combines existing and newly developed questions. Due to similarities in the definitions of the personal IM tactic and ingratiation, we made use of the ingratiation subscale of the IM Scale developed by Bolino and Turnley (1999). All four existing items were adopted but modified to establish consistency in tone and perspective across all of the items (consultant perspective). We added six new items to account for findings in the interview data and thereby to better capture the nature of IM in the context of consultancy. A sample item for the personal IM tactic - following the question: "As a consultant I 
perform the following behavior in order to make a likeable impression on the client:" - is: "I try to convey to the client that I stand behind him or her."

\section{Professional IM tactic}

The professional IM tactic was measured using eight items, four from an existing scale and four new items. The professional IM tactic shows great overlap with the concept of self-promotion. Consequently, we adopted all four items of the self-promotion subscale from the Bolino and Turnley (1999) IM scale. The consultancy context was emphasized by adding the consultancy perspective to existing items and by including four new items based on interview results. All items of the professional IM tactics scale follow the question: "As a consultant I perform the following behavior in order to make a competent impression on the client"? A sample item is: "I make my client aware of my accomplishments."

\section{Conforming IM tactic}

We measured the conforming IM tactic with nine items - all based on findings in the interview data. Here, consultants are asked to indicate which of the listed behaviors they use to make a favorable impression on clients. A sample item is "I try to adjust my outward appearance to my client and my task”.

All scales can be found in the appendix to this chapter (Appendix C). Their Cronbach's alpha will be shown at a later stage in connection with item analyses.

\section{Self-monitoring}

Self-monitoring was measured using the 18 item revised version of The Self-monitoring Scale (Snyder et al., 1986). As recommended by Briggs and Cheek (1986), a 5-point scale was used rather than the True-False format. Sample items include: "I find it hard to imitate the behavior of other people" (reverse scored) and "I am not always the person I appear to be." Cronbach's alpha for the scale is .85 .

\section{IM competence}

The scale consists of 15 items and combines existing and newly developed items relating to three competence factors: communication, relationship management, and adaptiveness/flexibility. Five 
newly developed questions ask about consultant's proficiency in communication, e.g. “ $M y$ communication with the client is comprehensible and clear." To measure competence in relationship management and adaptiveness/flexibility, we adopted in total five items of two subscales from the Social Skills Inventory (Riggio, 1986) - the Emotional Sensitivity (3 items) and the Social Control (2 items) subscales. The Social Skills Inventory is a 105-item self-report measure designed to assess adult's social and emotional communication skills of expressivity, sensitivity and control. The items are adapted for the consultancy context. For the competence of relationship management, a sample item is: "It is nearly impossible for clients to bide their true feelings from me." We add three newly developed items to account for other aspects of relationship management. For the IM competence of adaptiveness/flexibility, a sample item is: "I find it very easy to play different roles at different times". Here two new items were added. With a Cronbach's alpha of .88 the scale demonstrates acceptable internal consistency.

\section{Performance evaluations}

We used four items developed by Wayne and Liden (1995) to measure the performance of employees and added one item. The existing items were modified to match the consultancy context. A sample item is: "The client considers me as highly effective." With a Cronbach's alpha of .89 these items make up an internally consistent scale.

Performance evaluations are given by self-reports filled in by consultants. Therefore, the performance evaluation scale does not represent consultants' actual performance level as seen by their clients, but rather, how they think their performance is perceived by their clients.

\section{RESULTS}

In the following, we will distinguish the results concerning (a) what determines consultants' IM tactics use and (b) how do these tactics relate to consultants' performance, into two parts: (1) for separate tactics and (2) for consultants' IM tactics profiles. But first we present the results of a factor analysis on the three tactics and show the relevant descriptive statistics.

\section{Factor analysis of consultants' IM tactics scales}

We started with a factor analysis to see whether the three IM tactics represent distinct constructs. In a principal component analysis specifying a single factor it appeared that 17 of the 27 items load on a single factor (>.45). The entire factor explained 28 percent of the variance. Then, we extracted three factors. In this case 11 of the 27 items loaded on three separate factors which 
accounted for 48 percent of the total variance. Noting that neither solution was satisfactory, we proceeded with an analysis of the items. As advised by Flynn and Pearcy (2001), we examined the factor structure as well as the item level contribution to alpha. To get an acceptable solution, which we define as positive loading of .45 or higher on each factor and reasonable reliabilities of the scales (i.e., alpha of .70 or higher) we reduced the scales. As a result only 11 items remained (personal IM tactic $=4$ items; professional IM tactic $=3$ items; conforming IM tactic $=4$ items). Thus, we obtained pure scales. This complies with our aim to focus on the heart of the constructs in particular in view of subsequent analysis.

Next, the same factor analysis was performed with 11 instead of 27 items. The solution of a varimax rotation on the overall 11 items revealed three factors, which clearly represent the different IM tactics. The personal IM tactic factor accounted for 27.0, the professional for 24.3, and the conforming for 21.5 percent of the item variance. Hence, in total these three factors accounted for 72.8 percent of total item variance.

To verify the factor structure from the exploratory analysis, we conducted a confirmatory factor analysis (CFA). The results supported the 3 -factor structure $\left(\chi^{2}=39.01, d f=41, p=0.55\right)$. The key fit indices for the 3-factor model were as follows: the standardized root-mean square error of approximation $($ RMSEA $)=0.00$; the non normed-fit index $($ NNFI $)=0.99$ and the root mean square residual $(\mathrm{SRMR})=0.066$. Besides the RMSEA all other fit indexes were acceptable: the NNFI is higher than 90 (Bentler, 1990; Bentler \& Bonett, 1980; Vandenberg \& Lance, 2000) and the SRMR is below .08 (Browne \& Cudeck, 1993; Hu \& Bentler, 1998). The fit of this 3factor model was also compared with the fit of 1-factor model. Results indicated that the fit of the 3-factor model was significantly better than the fit of the 1-factor model. Further, it showed that each of the IM tactics items loaded significantly on its specified factor. Cronbach's alphas for each IM tactic showed good internal consistencies: personal IM tactic: .86; professional IM tactic: .87 ; and conforming IM tactic: .82.

To conclude, it was found that the personal IM tactic scale with four items, the professional IM tactic scale with three items, and the conforming IM tactic scale with four items show sufficient internal consistency and have the best model fit. Therefore, these are used in the following analyses.

\section{Descriptive statistics}

A correlation matrix of all the variables used in this study, as well as the means and standard deviations for the scales, are provided in Table 1. 


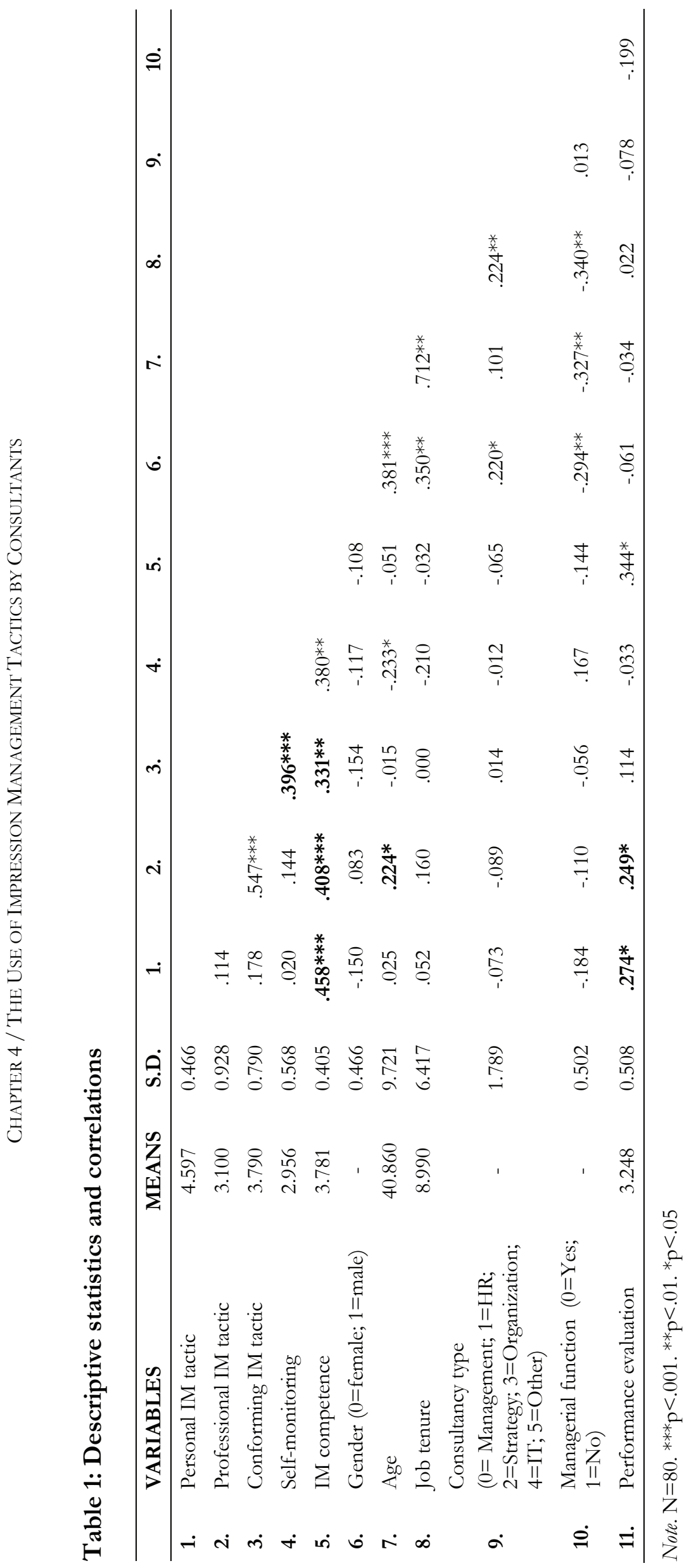




\section{IM tactics}

\section{What determines consultants' use of separate IM tactics?}

An objective of the study was to examine whether various person and job-related variables can be considered as determinants of consultants' use of IM tactics. These variables are: gender, age, job tenure, consultancy type, managerial function, self-monitoring and IM competence.

A multivariate analysis of variance (MANOVA) was conducted to determine the effect of these variables on each of the three consultants' IM tactics. As can be seen in Table 2, significant differences were found for age (Pillai's Trace $=.257, \mathrm{~F}(9,192)=2.001, \mathrm{p}<.05$ ), job tenure (Pillai's Trace $=.308, \mathrm{~F}(9,192)=2.441, \mathrm{p}<.05)$, and IM competence (Pillai's Trace $=.340, \mathrm{~F}(3,62)=$ $10.630, \mathrm{p}<.01)$. The result for IM competence was foreseeable because of strong correlations between all three IM tactics and IM competence.

Table 2: Results of MANOVA analysis per consultant characteristic

\begin{tabular}{lccc} 
& \multicolumn{3}{c}{ PILLAI'S TRACE } \\
\cline { 2 - 4 } CONSULTANTS' CHARACTERISTICS & F & Sign. & Partial Eta Squared \\
\hline Sex & 1.186 & .322 & .054 \\
Age & 2.001 & .041 & .086 \\
Job tenure & 2.441 & .012 & .103 \\
Consultancy type & .658 & .823 & .049 \\
Managerial function & .791 & .503 & .037 \\
Self-monitoring & 1.528 & .216 & .069 \\
IM competence & 10.630 & .000 & .340 \\
\hline
\end{tabular}

Note. $\mathrm{N}=80$.

Analyses of variances (ANOVAs) on each dependent variable were conducted as follow-up tests to the MANOVA. The ANOVA was significant for all three consultants' IM tactics: personal IM tactic, $\mathrm{F}(16,64)=2.573, \mathrm{p}<.01, \eta^{2}=.391$, professional IM tactic $\mathrm{F}(16,64)=1.965, \mathrm{p}<.05, \eta^{2}=.329$, and the conforming IM tactic, $\mathrm{F}(16,64)=2.016, \mathrm{p}<.05, \eta^{2}=.335$. Post hoc analyses consisted of pairwise comparisons to find which variable affected consultants' use of IM tactics most strongly. Age and job tenure were found to have an impact on consultants' use of the professional and the conforming IM tactic, respectively. More precisely, it was discovered that consultants in the age between 31 and 40 seem to make much less use of the professional IM tactic than their older 


\section{CHAPTER 4}

colleagues $(>51$ years $)(\mathrm{p}<.05)$. Furthermore, long job tenure, namely over 21 years, was related to a more frequent utilization of the conforming IM tactic than a tenure of 6 to 10 years $(p<.05)$.

Concerning IM competence, we first classified consultants in this sample as having high or low IM competence using a median-split. Then we calculated the means of consultants' IM tactics on each split of the file. As can be seen in Figure 1, we found that consultants with low IM competence generally make less use of all three IM tactics in comparison to consultants with a high IM competence. Further, consultants with high IM competence use in descending order mostly the personal, the professional, and least the conforming IM tactics. For consultants with low IM competence it is exactly is the other way around.

\section{Figure 1: Separate IM tactics use per IM competence}

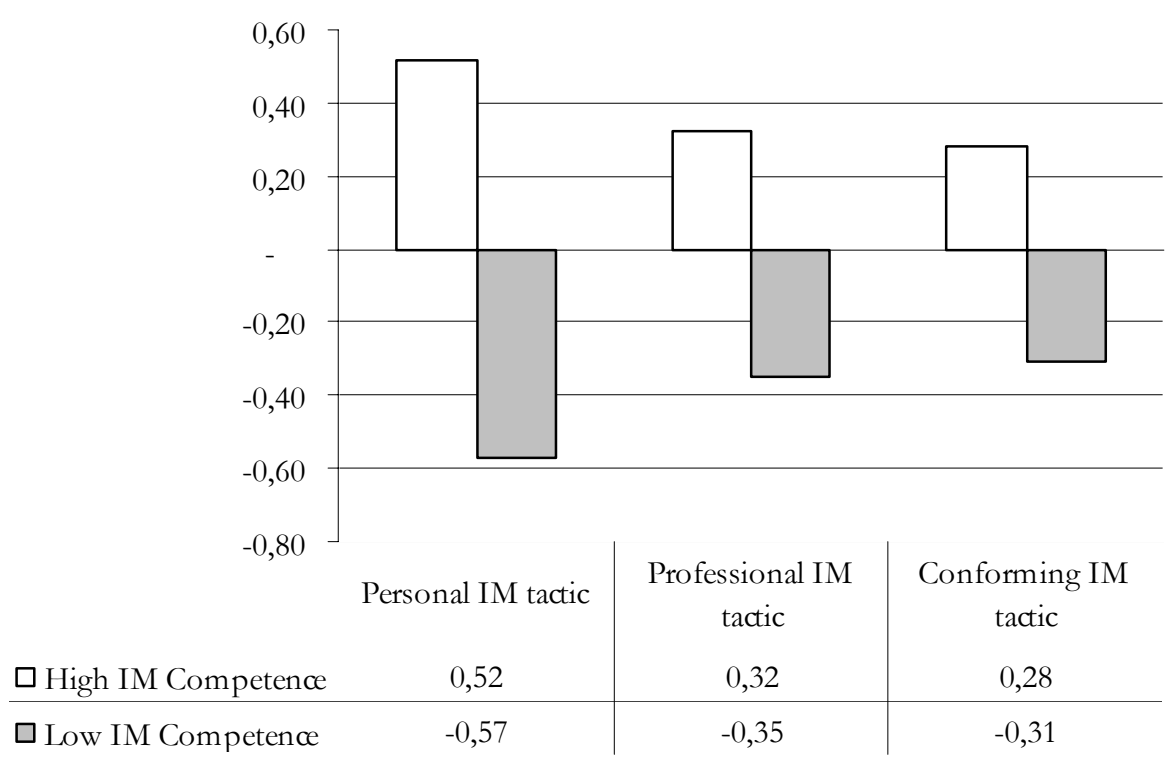

Consultants' IM Tactics

\section{Relation of separate IM tactics with performance}

The most direct way to evaluate the relative effectiveness of the three consultants' IM tactics is to examine consultants' performance with simple regression analysis using only a single IM tactic, since there will be no confounding effects based on the simultaneous use of another tactic. In Table 3, we display the results of all three IM tactics and their relations to performance. The overall models with the personal IM tactic $\left(\mathrm{R}^{2}=.075, F=6.308, \mathrm{p}<.05\right)$, the professional IM tactic $\left(\mathrm{R}^{2}=.062, \mathrm{~F}=5.176\right.$, $\mathrm{p}<.05)$ and performance as the dependent variable fitted well. Further, both IM tactics were 
significantly positively related to consultants' performance (personal IM tactic: $\beta=.274, p<.05$ and professional IM tactic: $\beta=.249, \mathrm{p}<.05)$. The conforming IM tactic showed no significant result. Hence, the most effective consultants' IM tactic when used alone was the personal IM tactic followed by the professional IM tactic.

Table 3: Regression analyses for each consultants' IM tactic

\begin{tabular}{lllll} 
& PERFORMANCE & $\mathbf{R}^{\mathbf{2}}$ & F & Sign. \\
\hline IM TACTICS & & & & \\
\hline Personal IM tactic & $.274^{*}$ & .075 & 6.308 & .014 \\
Professional IM tactic & $.249^{*}$ & .062 & 5.176 & .026 \\
Conforming IM tactic & .114 & .013 & 1.025 & .314 \\
\hline
\end{tabular}

Note. $\mathrm{N}=80 .{ }^{* * *} \mathrm{p}<.001 .{ }^{* *} \mathrm{p}<.01 .{ }^{*} \mathrm{p}<.05$. Values for independent variables are $\beta$ coefficients.

\section{IM tactics profiles}

Before being able to answer (1) what determines consultants' use of IM tactics in combination and (b) how do profiles of consultants' IM tactics relate to consultants' performance, we first had to identify groups of consultants who make similar use of IM tactics in combination.

\section{Identification of consultants' IM tactics profiles}

Cluster analysis was employed to identify specific patterns of consultants' IM tactics use in this study. We used standardized scores of the three IM tactics variables - personal, professional, and conforming - to ensure that differences in variability in the scales would not influence the classification obtained. To provide the greatest flexibility in determining the appropriate number of clusters, we examined the data using a hierarchical cluster analysis method (i.e. Ward's method using squared Euclidean distances). We considered two- to five-cluster solutions. The agglomeration coefficients acted as indicators of the suitable number of clusters and pointed at the selection of a three-cluster solution. To fine-tune identified results, we performed nonhierarchical clustering (i.e. kmeans cluster analysis) to obtain the final three-cluster solution. A combination of hierarchical with non-hierarchical methods is recommended by Hair and colleagues (1998).

An examination of cluster means (graphically presented in Figure 2) suggested the following groups: (a) Cluster 1 ( $\mathrm{n}=31,38.8 \%)$ was labeled versatile profile, due to consultants' high scores on all three IM tactics, (b) Cluster 2 ( $\mathrm{n}=19,23.8 \%$ ) was termed impersonal profile, since these consultants 


\section{CHAPTER 4}

have especially low scores for the personal IM tactic in addition to scores below average for the professional and the conforming IM tactics, and (c) Cluster 3 ( $\mathrm{n}=30,37.4 \%$ ) was called naive profile, because consultants in this group had scores above average for the personal IM tactic but below the mean for the professional and the conforming IM tactics, indicating that they mainly try to display a likeable image by using a personal approach. Since this group of consultants seems to think that the personal approach is sufficient to influence clients' impressions in a favorable way, we called them naive. The results further suggested that to a certain degree all consultants in this sample make use of IM tactics, since no cluster revealed a non-utilization of any consultants' IM tactic.

Figure 2: Use of consultants' IM tactics (personal, professional, conforming) by three types of impression managers

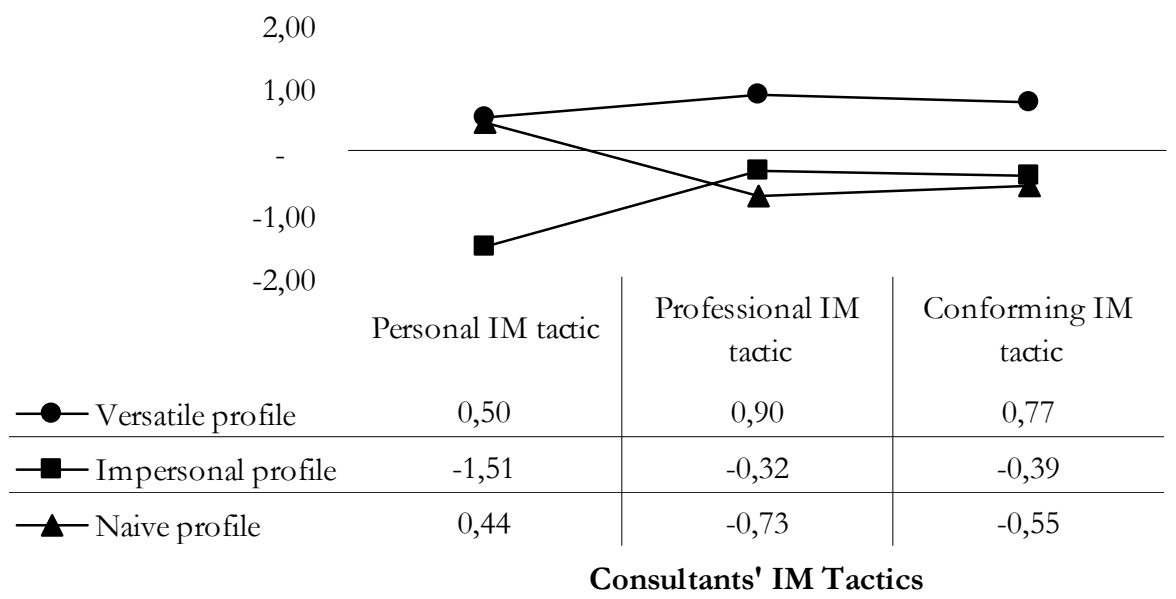

Cluster membership was retained as a single categorical variable, and in the final step examined as a predictor of consultants' performance. However, first, we examined various variables and their relationships with consultants' use of IM tactics.

\section{What determines consultants' use of IM tactics in combination?}

As with separate consultants' IM tactics, we investigated whether various characteristics of the consultants and their jobs are associated with consultants' use of IM tactics in combination. Frequency tables were developed in order to determine the nature of the relationships between gender, age, job tenure, consultancy type, managerial function, self-monitoring, IM competence and 
the consultants' IM tactics clusters. As can be seen in Table 4, the results revealed no significant differences between the clusters regarding consultants' gender, age, job tenure consultancy type, managerial function, and self-monitoring. However, an examination of the relationship between IM competence and IM tactics profiles revealed a difference in usage of IM tactics between consultants with low and high IM competence $\left(\chi^{2}=26.856, \mathrm{p}<.000\right)$.

Table 4: Results of chi-square tests per consultants' characteristics

\begin{tabular}{lcc} 
& \multicolumn{2}{c}{ PEARSON'S CHI-SQUARE } \\
\cline { 2 - 3 } CONSULTANTS' CHARACTERISTICS & $\boldsymbol{\chi}^{\mathbf{2}}$ & \multicolumn{1}{c}{ Sign.* } \\
\hline Sex & 2.060 & 0.357 \\
Age & 8.736 & 0.365 \\
Job tenure & 5.362 & 0.520 \\
Consultancy type & 8.061 & 0.653 \\
Managerial function & 5.305 & 0.071 \\
Self-monitoring & 2.139 & 0.343 \\
IM competence & 26.856 & 0.000 \\
\hline
\end{tabular}

Note. $\mathrm{N}=80 .{ }^{*}$ Exact Sig. (Two-sided)

In Figure 3, we display the distribution of consultants with low and high competence per cluster. The findings show that a large percentage of consultants with a versatile profile (81\%) possessed high IM competence. That is, consultants with high IM competence, those who have the proficiency to utilize IM in an effective manner, tended to utilize all three IM tactics above average. For consultants with an impersonal profile, it was the other way around; here most consultants $(95 \%)$ had low levels of IM competence. Cluster 3, consultants with a naive profile, showed a nearly equal division of low and high IM competence. Thus, the results suggest that in comparison to consultants with low IM competence, consultants with high IM competence engage in a frequent utilization of all three IM tactics. 


\section{CHAPTER 4}

Figure 3: Profiles of IM tactics per IM competence

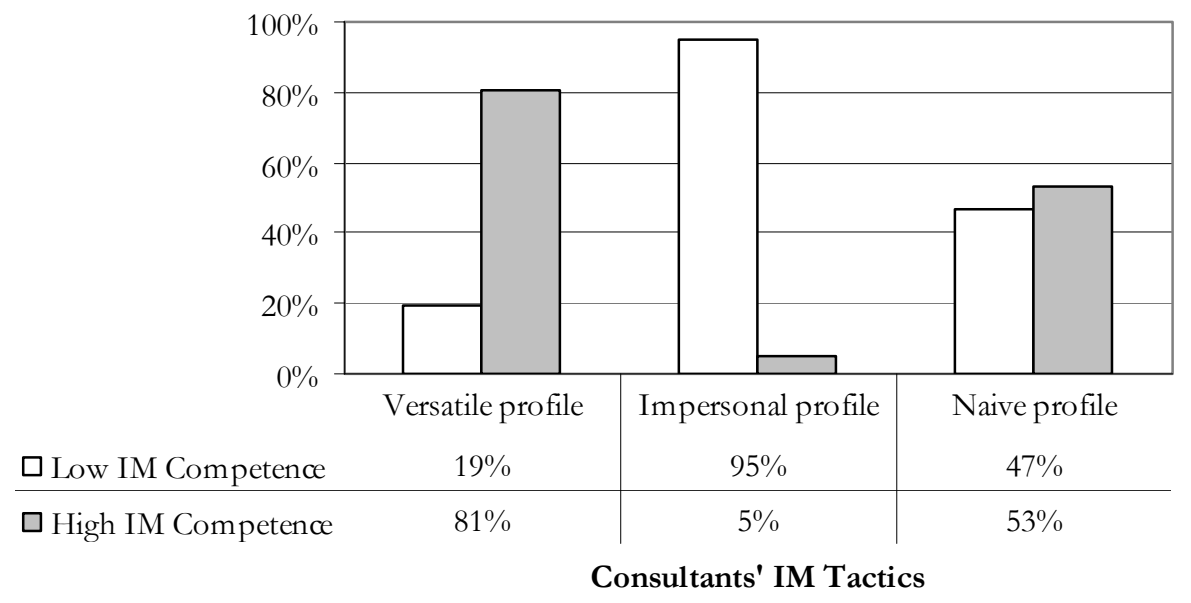

\section{Relation of consultants' IM tactics profiles with performance}

Using the cluster memberships derived by from the preceding analysis as between-subjects factor, a univariate ANOVA was conducted using performance as the outcome variable. At this final stage the aim was to determine whether consultants' use of IM tactics in combination relate to consultants' performance evaluations.

The result of the ANOVA was significant, $\mathrm{F}(2,77)=5.442, \mathrm{p}=.006$. The strength of relationship between the profiles of IM tactics and performance, as assessed by $\eta^{2}$, was relatively strong, with consultants' IM tactics profile accounting for $12 \%$ of the variance of the dependent variable. These results further indicate that there were significant differences in the evaluation by clients as perceived by the consultants. As shown in Table 5 , consultants with a versatile profile reported the highest perceived performance evaluations, the naive were second, and the consultant group with an impersonal profile thought they received the lowest performance evaluations.

Table 5: Means of consultants' IM tactics profiles in relation to performance

\begin{tabular}{lcc} 
& \multicolumn{2}{c}{ PERFORMANCE } \\
\cline { 2 - 3 } PROFILES OF IM TACTICS & Mean & s.d. \\
\hline Versatile profile & $\mathbf{2 0 . 6 7 7 4}$ & 2.66317 \\
Impersonal profile & 17.9474 & 3.34122 \\
Naïve profile & 19.2333 & 2.81233 \\
Overall model $\left(\mathrm{F}=5.442 / \mathrm{df}=2 / \mathrm{R}^{2}=.124\right)$ & 19.4875 & 3.04811 \\
\hline
\end{tabular}

Note. $\mathrm{N}=80$. Bold: Highest mean. 
For a more precise analysis, post-hoc tests were conducted to evaluate pairwise differences among the means. A Dunnett t-test revealed that there was a significant difference between cluster 1 (versatile profile) and cluster 2 (impersonal profile). The difference between cluster 2 (impersonal profile) and cluster 3 (naive profile) was not significant. Hence, cluster 1 (versatile profile) and cluster 3 (naive profile) are as well not significantly different. Thus, consultants in this sample thought their clients give them better performance evaluations when the use high levels of all three IM tactics. When consultants used relatively low levels of all three IM tactics, in particular of the personal IM tactic, they assessed their performance evaluations as lower.

\section{DISCUSSION}

The overall purpose of this research was to take a first empirical step into identifying the role IM plays in consultancy. Literature shows that IM predicts performance evaluations (Bolino et al., 2006; Gordon, 1996; Vilela et al., 2007); we aimed to know whether the same is true in a consultancy context. Since we were able to identify specific consultants' IM tactics in the previous study, we decided to complement current literature by learning more about these tactics than studying general IM tactics already known to the IM literature. As a result this study is exploratory and descriptive in nature.

The study's objectives have been summarized in two research questions: (1) Is there a difference in consultants' use of IM tactics for different levels of age, gender, job tenure, consultancy type, managerial function, self-monitoring and IM competence? (2) Do consultants' IM tactics relate to their perception of clients' view on their performance?

Concerning what determines consultants' IM tactics use we called attention to the impact of IM competence in addition to other person- and job-related factors (self-monitoring, age, gender, job tenure, consultancy type and managerial function). While research has examined individual traits like self-monitoring, other variables, including IM competence, have been neglected. This is particular unfortunate given the possibility to train competences, while it is impossible to change e.g. a person's trait or gender. Further, we differentiated the two questions between IM tactics used separately and in combination, which is rarely done in current research. The findings regarding separate consultants' IM tactics and consultants' IM tactics profiles are discussed below. 


\section{CHAPTER 4}

\section{IM tactics}

As for consultants' IM tactics used separately we found that age, job tenure and IM competence have an effect. The findings point out that older consultants (above 51) use the professional IM tactic more frequently than their younger colleagues (between 31 and 40). This is in line with research, indicating that age predicts the frequency with which certain IM tactics are used (Singh et al., 2002). In a similar manner, job tenure seems to be a differentiating factor in consultants' use of IM tactics such that consultants with longer job tenure (over 21 years) employ the conforming IM tactic more frequently than consultants with shorter job tenure (6 to 10 years). Apparently, advanced age and longer job tenure facilitate a higher utilization of certain IM tactics. Due to the fact that these consultants had more time to gain the knowledge for managing clients' impressions they seem to be more willing to make use of IM. IM competence was found to be a significant predictor of consultants' use of all three IM tactics. More precisely, consultants with high IM competence appear to use all IM tactics more frequently than their colleagues with low IM competence. The effects of age, job tenure and IM competence are interesting in that they hint at the trainability of IM, which has already been indicated by the expert-group in our interview study (Chapter 3).

With regard to the second question, we found that the personal and the professional IM tactics have significant relationships with consultants' performance, such that their use seems to improve consultants' performance.

\section{IM tactics profiles}

Concerning consultants' use of IM tactics in combination, we found that the data from the current sample were most appropriately divided into three distinct profiles of consultants' IM tactics, being labeled versatile profile, impersonal profile, and naive profile.

First of all, the IM tactics profiles underline the fact that IM tactics are used in combination and not one by one. No consultant in our sample refrained from using any of the three IM tactics, they differed in the frequency of IM tactics' usage but they employed them all. This indicates the importance of studying IM tactics in combination instead of looking at them in isolation.

Regarding the first question, the results indicated that gender, age, job tenure, consultancy type, managerial function and self-monitoring do not significantly relate to consultants' IM tactics profiles. In reference to the findings concerning IM tactics used alone, this is not too surprising since 
there we found only significant results for some IM tactics and the relationships seem not strong enough to persist when we look at consultants' IM tactics in combination.

Though as for the separate use of IM tactics, IM competence was found to play a role for the IM tactics profiles as well. Consistent with common sense, consultants with high IM competence are most likely those with a versatile profile. The highest percentage of consultants with low IM competence can be found in the group of the impersonal profile consultants.

With regard to the second question, the results showed that having a versatile profile rather than the naive profile or even the impersonal profile improves consultants' performance. That is, in contrast to consultants who use all three in particular the personal IM tactic less frequently (impersonal profile) or to consultants who seem to think they can make favorable impressions by simply "being nice" to the client (naive profile), consultants who use all three IM tactics quite frequently (versatile profile) have the best perception of their own performance.

Both, the results of consultants' IM tactics used one by one and in combination point at the potential impact of IM on the process of evaluating consultants' performance. It shows that a frequent utilization of personal and professional IM tactics alone, of all three consultants' IM tactics (versatile profile), and even mostly of the personal IM tactic (naive profile), might be more beneficial than a marginal use of the three IM tactics, in particular of the personal IM tactic (impersonal profile). Thus, the more frequent use of consultants' IM tactics seems to translate into "better performance".

Moreover, it seems that especially IM competence determines the frequency with which consultants employ IM tactics - separately and in combination. This information suggests that consultants and their employing organizations should focus on consultants' IM competence and concentrate their efforts on training it.

\section{LIMITATIONS AND FUTURE RESEARCH}

There are a number of limitations evident in our research. One limitation of the study is related to the sample. First, the sample size is small, which raises issues of sample representativeness. For instance, one could have more confidence in the cluster solution that emerged if data had been collected form a larger number of respondents. In order to demonstrate the validity of the cluster solution it should be replicated in another sample. 


\section{CHAPTER 4}

Second, future research is needed that assesses IM behaviors and potential effects from independent sources; most suitable from the target of consultants' IM - the client. In our study all variables were assessed based on consultants' self-reports. This was a convenience decision but potentially can introduce distortion through self-serving bias. To prevent common method bias future research would do well to draw from multiple methods (e.g. client reports) to assess consultants' performance outcomes.

Furthermore, causality could not be determined due to the cross-sectional nature of the data. The findings should not be interpreted as implying a causal relation between using certain IM tactics and consultants' performance. In this exploratory study, we asked merely whether a relation exists. Hence, while it is indicated that there are relationships, their exact nature cannot be established. Given that there are other models that may fit the data just as well, it is important to carry out additional research that can help exclude these alternative models.

Moreover, the exploratory nature of the study and the lack of longitudinal data from the current sample render the data obtained from the current study largely descriptive. Since IM is regarded as a process, it is essential to conduct longitudinal studies to gain a better understanding on IM and to identify casual linkages, such as between consultants' IM tactics and performance. Also other questions could be answered. For example, does individual's use of IM tactics differ over time? Or in reference to IM tactics used in combination: do individuals perhaps start with one IM tactic and continue with another? Future research is needed to address these interesting questions.

Finally, although desired, the consultancy sample is fairly unique in comparison to former studies on IM. Nonetheless, we expect that the relationships found in the study will generalize to other samples and work settings where IM is likely, as other service industries. Even so, we hope that future research will replicate our study in other samples and contexts to ensure the external validity of our results.

\section{CONCLUSION}

As noted in previous chapters, the role demands of a consultant point at the relevance of IM for consultancy and the findings of this study underline its crucial role.

We found that the personal and the professional IM tactics used one by one relate positively to consultants' performance, and identified age, job tenure and IM competence as variables significantly related to consultants' separate use of IM tactics. Older consultants ( $>51$ years) use the 
professional IM tactic more frequently than their younger colleagues, and consultants with longer job tenure ( $>21$ years) tend to use the conforming IM tactic more than their colleagues with shorter job tenure. A high IM competence relates to a more frequent employment of all three consultants' IM tactics.

Further, we identified three profiles of consultants' IM tactics, discovered a contribution of IM competence, and showed their relevance in the prediction of consultant's performance. We determined that consultants who have high IM competence are most likely those who utilize all three consultants' IM tactics on a frequent basis (versatile profile). These consultants also expect better performance evaluations than their colleagues who use the personal IM tactic barely above and the professional and the conforming IM tactics below average (naive profile), and unlike colleagues who employ all IM tactics below average, specifically the personal IM tactic (impersonal profile).

We regard this study as an explorative start off for more exhaustive future research. In concert with the larger IM literature, our preliminary results on IM tactics in consultancy suggest that research should continue to look upon IM as a valuable tool of consultants and further investigate IM tactics, one by one and in combination since it is likely that IM tactics interact in consequential ways. 


\section{5 'To be, or Appear to BE: How Do CONSUltants' IM STYLES Relate to PerformanCE AND Stress?}

We know that in service occupations practitioners who may otherwise be sincere are sometimes forced to delude their customers because their customers show such a beartfelt demand for it. Some performances are carried off successfully with complete dishonesty, others with complete honesty; but for performances in general neither of these extremes is essential and neither, perhaps, is dramaturgically advisable. - Erving Goffman, The Presentation of Self in Everyday Life

The purpose of this study ( $=233)$ was to investigate IM styles among consultants. First, we aimed to determine whether two newly identified consultants' IM styles represent the opposite poles of a single dimension or rather two dimensions. Exploratory and confirmatory factor analyses showed that a two-factor model had best fit. Additionally the results validated our scale developed to measure an authentic acting IM style and a role acting IM style.

Second, we intended to identify how the authentic acting and role acting IM styles of consultants relate to ratings of their perceived performance and stress, and how IM competence associates with these outcomes as well as moderates proposed relationships. A series of hierarchical multiple regressions revealed a negative main effect for the authentic acting IM style on consultants' stress, and a negative main effect for the role acting IM style on performance and a positive effect on stress. IM competence is found to directly relate to performance and stress as expected: positively and negatively respectively. Its moderating effect in interaction with a role acting IM style was as supposed; it resulted in improved performance. However, the result of IM competence in interaction with the authentic acting IM style was opposite to what was expected. An authentic acting IM style combined with greater IM competence is associated with lower performance. An additional finding was that age is significantly related to stress. Older consultants $(>41)$ experience less stress. 


\section{INTRODUCTION}

With IM people aim to control the attributions and impressions formed by others (Tedeschi et al., 1981). What is known to be valid for IM in general and on the work floor is also found in consultancy. The results of the two preceding studies and the research literature point to the importance of IM for successful consultancy and depict consultants' behaviors as being deliberate and effective in managing clients' impressions (Clark, 1995; Clark et al., 1998).

In Chapter 3 we identified two IM styles and three IM tactics employed by consultants to influence the impressions of their clients. Consultants' IM tactics were further examined in Chapter 4 and generally found to associate with consultants' performance. In this study, we focus on consultants' IM styles - the authentic acting and role acting IM styles. Since we do not yet know whether these are one- or two-dimensional, the first question in this study is: Are the consultants' IM styles each others opposite or rather independent styles? Moreover, until today, there is no research on the development of instruments to measure these constructs. The first part of the present study addresses this problem with the development of an IM styles scale that is designed to assess consultants' perceptions of their IM style at work.

The authentic acting and role acting IM styles seem to fit an organizational context like consultancy better than the IM styles described in the literature. That is, the assertive and the defensive IM styles (Arkin, 1981; Roth et al., 1986; Schlenker, 1980; Tedeschi et al., 1984) correspond very well to IM behaviors at work; however, they neglect important aspects of external relationships, as represented by consultants and clients. We base our argument on research concentrating on the issue of authenticity/inauthenticity in service settings (Grandey et al., 2004; Grove et al., 1989; Rafaeli et al., 1987; Schaefer \& Pettijohn, 2006) as well as on the emerging field of research on authentic leadership (cf. Avolio \& Gardner, 2005; Avolio, Gardner, Walumbwa, Luthans, \& May, 2004; Gardner, Avolio, Luthans, May, \& Walumbwa, 2005; Walumbwa, Avolio, Gardner, Wernsing, \& Peterson, 2008). Here authenticity is regarded as the decisive factor for success, e.g. for customer satisfaction or leading of followers.

Further, thinking of IM in terms of authentic acting and of role acting IM styles opens new opportunities for research taken up in the second part of this study; as these styles may not have uniformly positive and negative outcomes. For example, next to the beneficial possibility of improving performance evaluations (Bolino \& Turnley, 2003a; Ferris et al., 1994; Higgins, Judge, \& Ferris, 2003; Wayne et al., 1990; Wayne et al., 1995), consultants may experience stress from the process of creating and maintaining false impressions to elicit favorable client responses. That is, the 
regulation of expression can not only be linked to expedient results but also to negative outcomes such as stress (Grandey, 2003). Hence, by examining authentic acting and role acting IM styles, we can find an answer to the question: whether and how the two IM styles relate to consultants' performance and stress?

Moreover, authentic acting and role acting IM styles may interact differently with IM competence. IM competence emerged from the interviews presented in Chapter 3 and was empirically investigated in Chapter 4. It is seen as proficiency in displaying a desired image successfully to others, regardless whether it is true or not. By and large, it was found to associate with a more frequent utilization of the three consultants' IM tactics. In this chapter we aim to identify: how IM competence relates to consultants' performance and stress, and how it behaves in connection with an authentic acting IM style and with a role acting IM style.

To summarize, in part I of this study we will investigate the dimensionality of IM styles and test developed scales. In part II, we will study possible relationships of both IM styles - as well as of IM competence - with consultants' performance and stress and thereby describe an initial examination of the scale's construct validity by exploring the relationships with two IM related outcomes.

\section{PART I: STYLES OF IM: AUTHENTIC ACTING AND/OR ROLE ACTING?}

In the IM literature there exists an unresolved debate about the nature of IM (Schlenker, 1985). Some researchers argue that the presented self is designed to fit the appropriate circumstances, but that it nevertheless tends to represent an individual's genuine or true self (Schlenker, 1980; Schlenker et al., 1992). Others view IM as manipulative or even deceptive and question the truthfulness of certain behaviors (Ashforth et al., 1993).

In this study IM style is assumed to be a relatively stable, individual-difference variable describing an individual habitus, a tendency to perform IM either with an authentic approach or a way that satisfies role expectations regardless of the truth.

\section{Authentic acting IM style}

A definition of IM should not exclude the possibility that people actually present internal states (Kirouac \& Hess, 1999). In accordance with this view an authentic acting IM style involves attempts to convey to audiences a portrait that is a slightly polished and glorified conception of the self, but 


\section{CHAPTER 5}

one that is genuinely believed by the actor to be true (Baumeister, 1982; Cheek \& Hogan, 1983; Greenwald \& Breckler, 1985; Leary, 1995; Schlenker, 1980). This is done by presenting information on personal experiences, thoughts, emotions, needs and wants (Harter, 2002) that are believed in and are in accordance with the true self, but aligned to the situation, including the actor's goals and the audience's expectations and values (Schlenker et al., 1992). With an authentic acting IM style the individual forgoes to mask or to deny real emotions and thoughts, and does not pretend to be phony. The impression manager's internal state and external expressions are congruent. Consultants having an authentic acting IM style represent themselves to clients no differently than they view their actual selves. Their major aim is to present true aspects of themselves in order to impress the client.

Most researchers emphasize that IM is employed to accurately communicate emotional states or habitual traits (Leary et al., 1990; Schlenker, 1980). "It may take a considerable amount of careful staging to display one's true beliefs and feelings in order to create a social world conducive to one's own personality and sense of self" (Snyder, 1987: 172). According to Goffman (1959) there is nothing inherently unreal about the roles individuals perform, that they in fact reflect real aspects of people's complex selves and are not false masks that hide the true parts of a person. Peterson (1997) called this process "fabricating authenticity" and described it with the example of country music performers. To make the audience believe in the authenticity of country performers - to think of them as "real country persons" - various aspect in their appearance are adapted, as for instance their accent, their hairstyle and so on.

\section{Role acting IM style}

A role acting IM style stands opposed to an authentic acting IM style and is merely performed to meet the social requirements of a particular situation. With a role acting IM style individuals tend to display a socially desirable portrait that is not consistent with the actual self (Leary, 1995). The expression of conformity to role expectations is intended to result in beneficial impressions in others. This is done by pretending certain characteristics, feelings, needs and thoughts; if necessary by masking one's authentic self - including current emotions and the like. Hence, consultants employing role acting IM can produce effective displays on demand irrespective of their inner self.

Roles are described to evoke desired behaviors irrespective of personal needs (cf. Katz et al., 1978). Given that societal pressures and not internal cues are the determining factors for consequent behavior inauthenticity results (Deci \& Ryan, 1995; Ryan \& Deci, 2003). "In those instances where 
one deliberately enacts an identity opposed to one's true self, role experimentation is likely to be inauthentic" (Kernis, 2003: 14). A reason for performing role acting IM is that one's authentic selfportrayal is inconsistent with external standards of professional competence and character and in order to gain certain social and professional benefits, individuals often display untrue personal characteristics for the sake of meeting societal expectations (Hewlin, 2003). In the context of emotional labor this behavior is called "surface acting". It involves the masking or manipulation of expressing naturally occurring emotions (Hochschild, 1983). For example, service providers may show concern by asking customers how they are doing when, in actuality, they care little about the customers' welfare (Ashforth and Humphrey, 1993).

\section{Measure of IM styles}

To date no instrument was developed designed to tap constructs like an authentic acting or a role acting IM style. Most instruments measure the amount of employees' use of IM behavior (Bolino et al., 1999; Kumar et al., 1991; Wayne et al., 1990) but not whether it is authentic or artificially created. Other instruments, such as the Balanced Inventory of Desirable Responding (BIDR) assume that IM is deceptive by definition (Paulhus, 1986) and neglect the possibility of an authentic acting IM style. To address the lack of a reliable and valid measure of IM styles, we developed the "Maastricht Impression Management Styles Scales” (MIMSS).

In this regard, one intention of this study is to identify whether IM styles is a one- or twodimensional phenomenon. On the one hand, there might be a single bipolar IM dimension with the two styles of IM being represented by opposite poles. This implies that an individual can take any position, either having an authentic acting IM style, a role acting IM style, or an IM style that has elements of both. On the other hand, the two IM styles might actually be separate, representing independent dimensions. Here people can display any combination of IM style, e.g. present a high authentic acting IM style in combination with a low role acting IM style.

\section{METHOD}

In the following we will describe the participants and procedure of the research, which also pertain to part II of the study. Furthermore, we present the original two IM styles scales - being the authentic acting and the role acting IM styles scales - and report on their factor structure (one- or 


\section{CHAPTER 5}

two-dimensional) and on the scaling of items (number of items) by illustrating the results of exploratory and confirmatory factor analyses.

\section{Participants and Procedure}

The sample of this study consists of 233 consultants, acquired by combining a snowball-sampling $(\mathrm{N}=130)$ with a company-oriented sampling $(\mathrm{N}=103)$ procedure. Snowball-sampling is based on volunteers solicited by the author of the study to participate in the study and being encouraged to recruit people in their professional consultancy network. The volunteers are consultants or people knowing individuals from the consultancy industry. Most of them work in the Netherlands, Germany, and the US. Company-oriented sampling was done through six consultancy companies who agreed to participate in this research ${ }^{6}$. One company sample is from Germany, one from the UK, and the others from the Netherlands. Prior to the beginning of the data collection, sponsors of the research within the companies sent an e-mail to the consultants introducing the study and requesting their participation. Data was collected over a four-week period. The link to an onlinequestionnaire was provided and respondents were asked to follow the link and complete the survey at their earliest convenience, but before the end of the four-week window. After two weeks a reminder was sent to increase the response rate.

The two samples were kept separate in our initial analyses and were merged after it was shown that no systematic differences exist. It appeared that 62 percent of respondents are male. Most consultants (68\%) are younger than 41 years (27\% between 20 and 30 years, $41 \%$ between 31 and 40 years, $21 \%$ between 41 and 50 years, and 11\% were over 51 years). 70 percent of the consultants have a job tenure up to 10 years (36\% up to 5 years, 34\% between 6 and 10 years, 23\% between 11 and 20 years, and 7 percent more than 20 years). 38 percent of them work as management consultants, 22 percent as HR consultants, 21 percent as IT consultants, and 19 percent as consultants in other fields. Most consultants (57\%) do not have managerial functions.

\section{Scales}

In principle there are two ways to measure consultants' IM styles. The targets - here the clients themselves could be asked to indicate their perception of the IM style of a consultant. However,

\footnotetext{
${ }^{6}$ A project description for participating companies can be found in Appendix D.
} 
since people's accuracy in detecting deception in others is found to be low (Goffman, 1959; Toris \& DePaulo, 1985; Zuckerman, DePaulo, \& Rosenthal, 1981) clients might not be able to identify whether consultants show authentic or insincere behavior. As a result, it seems adequate to ask the consultants instead of the clients about the "real" nature of their IM style.

The authentic acting IM style and the role acting IM style scales can be found in the appendix to this chapter (Appendix D). In connection with item analyses we will present their Cronbach's alpha at a later stage.

\section{Authentic acting IM style}

The scale created to tap the authentic acting IM style of consultants consists of thirteen questions assessing whether the consultants typically perform behaviors with the aim to convey a positive impression on the client but in consonance with their inner feelings, thoughts and needs. A sample item is: "My behavior towards the client is genuine."

\section{Role acting IM style}

To measure role acting IM style another scale is created. Thirteen items assess whether the consultants "play" certain behaviors in order to favorably manage their clients" impressions independent of how they actually feel and think about it. For example: "At work I talk about topics on which I have almost no information."

\section{RESULTS}

To identify whether IM styles is a one- or two-dimensional phenomenon we conducted a series of analyses. We always started with analyzing the data per sample - "snowball" and "companies"- in order to identify whether these samples can be merged and in case that they could we conducted the same analysis on the combined sample.

We began with an exploratory factor analysis, using the principal component method for each sample separately, followed by the same analysis carried out for the combined sample. Next, we conducted a confirmatory factor analysis, using LISREL to investigate the issue of dimensionality (DeVellis, 1991). We started with a multi-sample analysis to see whether the proposed models perform equally well in both samples and to discover the best-fitting model of the MIMSS 


\section{CHAPTER 5}

(Maastricht Impression Management Styles Scales). To verify these results we did a confirmatory factor analysis after merging the samples.

\section{Principal component analysis}

We started with principal component analysis performed on each sample separately. The results are ambiguous in that a clear support for a one- or a two-factor solution is not given. However the twofactor solution showed greater adequacy than the one-factor solution in both samples. For example, the percentage of total variance explained from one factor to two factors improved for the snowballsample from 27.3 percent to 35.4 percent and for the companies-sample from 24.4 percent to 32.9 percent. Since the samples demonstrated comparable results we combined them and repeated the analysis with the original 26 items developed for this study.

First, we performed a principal component analysis specifying a single factor. It appeared that 17 items load strongly on a single factor (>.45), of which seven items of the authentic acting scale had negative loadings ranging from -.515 to -.691 and ten items of the role acting scale had positive loadings with a range from .481 to .648 . The entire factor explained 26 percent of the variance. The alpha coefficient of reliability for the 26 items was quite disappointing with .43. Then, we extracted two factors. In this case 20 of the 26 items loaded on two factors which accounted for 33.5 percent of the total variance.

Due to the fact that these results did not unequivocally support a two-factor solution, we continued with an analysis of the items in the two scales. We examined the factor structure as well as the item level contribution to alpha (Flynn et al., 2001). To obtain an acceptable solution, which we defined as positive loading of .45 or higher on each factor and reasonable reliabilities of the scales (i.e., alpha of .70 or higher) we reduced the scales. As a result, seven authentic acting IM style items and eight role acting IM style items remained.

Thereafter, the same factor analysis was performed with 15 instead of 26 items. The final solution employing varimax rotation on the overall 15 items revealed two factors, which can be interpreted as authentic acting and role acting IM styles. The authentic acting IM style accounted for 22.2 percent of the item variance, and the role acting IM style accounted for 22.0 percent of the item variance. Hence, in total these two factors accounted for 44.2 percent of total item variance ${ }^{7}$

\footnotetext{
${ }^{7}$ We performed the analysis with 15 instead of 26 items as well on each of the two samples "snowball" and "companies". The result was also much clearer for the two separate samples. A two-factor solution was supported. The percentage of
} 
The coefficient alpha reliabilities were adequate with .78 for Factor 1 (authentic acting IM style), and .80 for Factor 2 (role acting IM style). As Table 1 shows, the factor matrix indicates that all items load on the intended factor and have acceptable loadings. An oblimin rotation of the two-factor solution was performed and here as well all items load on the corresponding factors.

\section{Table 1: Rotated factors and loadings for the MIMSS items on total sample}

\begin{tabular}{|c|c|c|c|}
\hline & ITEMS & $\begin{array}{c}\text { FACTOR } 1 \\
\text { (authentic } \\
\text { acting IM } \\
\text { style) }\end{array}$ & $\begin{array}{c}\text { FACTOR } 2 \\
\text { (role acting } \\
\text { IM style) }\end{array}$ \\
\hline 1. & In dealing with clients I rarely mask my true thoughts and feelings. & .488 & -.073 \\
\hline 2. & As a consultant I express my true self. & .696 & -.134 \\
\hline 3. & I express what I feel when I am excited about something at work. & .628 & .124 \\
\hline 4. & I do not pretend to be someone else at work. & .600 & -.296 \\
\hline 5. & My behavior towards the client is genuine. & .731 & -.227 \\
\hline 6. & $\begin{array}{l}\text { My behavior as a consultant is usually an expression of my true feelings, attitudes } \\
\text { and beliefs. }\end{array}$ & .790 & -.238 \\
\hline 7. & At work I do not lie even if I am unlikely to be caught. & .506 & -.208 \\
\hline 1. & At work I talk about topics on which I have almost no information. & -.103 & .589 \\
\hline 2. & In situations with different clients I act like different persons. & -.271 & .600 \\
\hline 3. & I deceive clients by acting friendly when I actually dislike them. & -.256 & .636 \\
\hline 4. & I flatter clients even when they do not deserve it. & -.078 & .744 \\
\hline 5. & I do personal favors for the client even when I do not feel like. & .119 & .714 \\
\hline 6. & $\begin{array}{l}\text { What I say or do as a consultant is not necessarily a reflection of what I really } \\
\text { think or feel. }\end{array}$ & -.429 & .518 \\
\hline 7. & I smile to the client even when I am bad-tempered. & -.166 & .553 \\
\hline 8. & I tell clients what they want to hear. & -.171 & .554 \\
\hline
\end{tabular}

Note. $\mathrm{N}=233$

\section{Confirmatory factor analysis}

To verify the factor structure from the exploratory analysis, we conducted a confirmatory factor analysis. We start with reporting the global goodness of fit statistics of a multi-sample confirmatory

cumulative variance explained with 15 instead of 26 items improved for the snowball-sample from 35 to 46 percent and for the companies-sample from 33 to 44 percent. The improvement was also obvious in the loadings on the intended factors (Appendix D). 


\section{CHAPTER 5}

factor analysis to see whether a one- or two-factor model with either 26 or 15 items had best fit over both samples. Next, we did this for the combined sample.

\section{Multi-sample analysis}

To compare the factor solutions for the original 26 items and the selected 15 items with one or two latent factors we performed a multi-sample confirmatory factor analysis. We specified a structural model with one and with two IM styles dimensions as latent variables and 26 and 15 items as the observed variables (Byrne, 1998). Hence we utilized four proposed models. These models were fitted to consultants' responses from the "snowball" $(\mathrm{N}=130)$ and from the "companies" sample $(\mathrm{N}=103)$.

The multi-sample method allowed us to keep parameters equal across the two samples and to compare models with and without equality constraints. If the chi-square value for the model with equality constraints is significantly larger than the chi-square value for the baseline model, this points at a between-group difference. This appeared not to be the case. For example, for the two factor model with 15 items; the Chi-square value for the model with equality constraints was approximately equal $\left(\chi^{2}=352.85, d f=191, p<0.000\right)$ to the Chi-square for the model without equality constraints $\left(\chi^{2}=331.16, d f=178, p<0.000\right)$.

While the Chi-square test for the goodness of fit and the root mean square error of approximation $($ RMSEA $=.86)$ indicated an unsatisfactory fit $($ RMSEA $<.08)$, other fit indices as the non-normed fit index $(\mathrm{NNFI})=.91$, and the comparative fit index $(\mathrm{CFI})=.91(\mathrm{NNFI}$ and $\mathrm{CFI}>.90)$ showed that the two-factor model with 15-items fits the data best (Bentler et al., 1980; Hu and Bentler, 1998;Vandenberg et al., 2000) (Table 2a).

The results support the idea that the two IM styles represent two distinct phenomena and these can be adequately measured by the reduced scales. 
Table 2a: Results of LISREL analyses: Global goodness of fit statistics

\begin{tabular}{|c|c|c|c|c|c|}
\hline MODEL DESCRIPTION & $\chi^{2}$ & df & RMSEA & NNFI & CFI \\
\hline 1-Factor model with 26 indicators & $\begin{array}{c}1255.58 \\
(1230.36)\end{array}$ & $\begin{array}{c}623 \\
(598)\end{array}$ & $\begin{array}{c}.094 \\
(.096)\end{array}$ & $\begin{array}{l}.85 \\
(.84)\end{array}$ & $\begin{array}{c}.86 \\
(.86)\end{array}$ \\
\hline 1-Factor model with 15 indicators & $\begin{array}{c}578.23 \\
(561.94)\end{array}$ & $\begin{array}{c}194 \\
(180)\end{array}$ & $\begin{array}{l}.132 \\
.(137)\end{array}$ & $\begin{array}{c}.83 \\
(.82)\end{array}$ & $\begin{array}{c}.84 \\
(.84)\end{array}$ \\
\hline 2-Factor model with 26 indicators & $\begin{array}{c}1200.77 \\
(1115.52)\end{array}$ & $\begin{array}{c}620 \\
(596)\end{array}$ & $\begin{array}{c}.090 \\
(.087)\end{array}$ & $\begin{array}{c}.86 \\
(.87)\end{array}$ & $\begin{array}{c}.86 \\
(.88)\end{array}$ \\
\hline 2-Factor model with 15 indicators & $\begin{array}{c}352.85 \\
(331.16)\end{array}$ & $\begin{array}{c}191 \\
(178)\end{array}$ & $\begin{array}{c}.086 \\
(.086)\end{array}$ & $\begin{array}{c}.91 \\
(.90)\end{array}$ & $\begin{array}{c}.91 \\
(.92)\end{array}$ \\
\hline
\end{tabular}

Note. $\mathrm{N}=233$. RMSEA $\Rightarrow$ Root Mean Square Error of Approximation; NNFI $\Rightarrow$ Non-Normed Fit Index; CFI $\Rightarrow$ Comparative Fit Index. In brackets: analysis without equality constraints. Bold: Best model.

\section{One-sample analysis}

The fact that the solutions with equality constraints fitted equally well or better, suggests that the two samples are comparable. Hence, we proceeded with confirmatory factor analysis in the combined sample, again utilizing the four proposed models. Three indexes were examined in order to evaluate model fit: the standardized root-mean square error of approximation (RMSEA); the non normed-fit index (NNFI); and the root mean square residual (SRMR). First, we tested for a one-factor model, in which all items (26 and 15) were specified to load on a single factor. These one-factor models were compared to the two-factor models of the 26- and 15-items scales (Table 2b).

Table 2b: Results of LISREL analyses on combined sample

\begin{tabular}{lccccc}
\hline \multicolumn{1}{c}{ MODEL DESCRIPTION } & $\boldsymbol{\chi}^{2}$ & $\boldsymbol{d} \boldsymbol{f}$ & RMSEA & NNFI & SRMR \\
\hline 1-Factor model with 26 indicators & 789.21 & 299 & .093 & .87 & .081 \\
1-Factor model with 15 indicators & 354.61 & 90 & .132 & .84 & .092 \\
2-Factor model with 26 indicators & 680.06 & 298 & .083 & .90 & .076 \\
2-Factor model with 15 indicators & $\mathbf{2 0 8 . 4 9}$ & $\mathbf{8 9}$ & $\mathbf{. 0 7 5}$ & $\mathbf{. 9 3}$ & $\mathbf{. 0 7 0}$ \\
\hline
\end{tabular}

Note. $N=233$. RMSEA $\Rightarrow$ Root Mean Square Error of Approximation; NNFI $\Rightarrow$ Non-Normed Fit Index; SRMR $\Rightarrow$ Standardized Root Mean Square Residual. Bold: Best model.

It appeared that in both cases (the 15- and the 26-items IM styles scales) the two-factor model fits better than the one-factor model. Moreover, the best fitting model was the two-factor model for the 


\section{CHAPTER 5}

15-items that comprises seven authentic acting IM style items and eight role acting IM style items. The fit for the two-factor measurement model of the 15-items IM styles scale was as follows: $\chi^{2}=$ $208.49(d f=89, p<0.000), \mathrm{RMSEA}=.075, \mathrm{NNFI}=.93$ and $\mathrm{SRMR}=.07$. All these fit indexes are acceptable: although the RMSEA is higher than .06 (Hu and Bentler, 1998) it is still below .08, which should be seen as an upper limit (Vandenberg et al., 2000); NNFI is higher than .90 (Bentler et al., 1980; Vandenberg et al., 2000) and SRMR is below .08 (Hu et al., 1998).

We conclude that IM styles is two-dimensional, represented by authentic acting and role acting IM styles. Further, since the 15-items scale, that is the authentic acting IM scale with seven items $(\alpha=.78)$ and the role acting IM scale with eight items $(\alpha=.80)$, showed sufficient internal consistency and had the best model fit these are used in the following analyses.

\section{PART II: IM STYLES, PERFORMANCE AND STRESS}

Research has suggested that performance (Ferris et al., 1994; Wayne et al., 1990; Wayne et al., 1995) and stress (Grandey, 2003; Hochschild, 1983) are two critical outcomes of IM. We propose the models shown in Figure $1 \mathrm{a}$ and $1 \mathrm{~b}$ to posit that the two styles of IM may have different associations with performance and stress. These two outcomes are assumed to be further influenced by IM competence, both in a direct way and as a potential moderator of the proposed relationships with IM styles. The two models are further used to generate hypotheses that will be presented in the following paragraphs.

Figure 1a: Proposed models of IM styles, IM competence, and performance

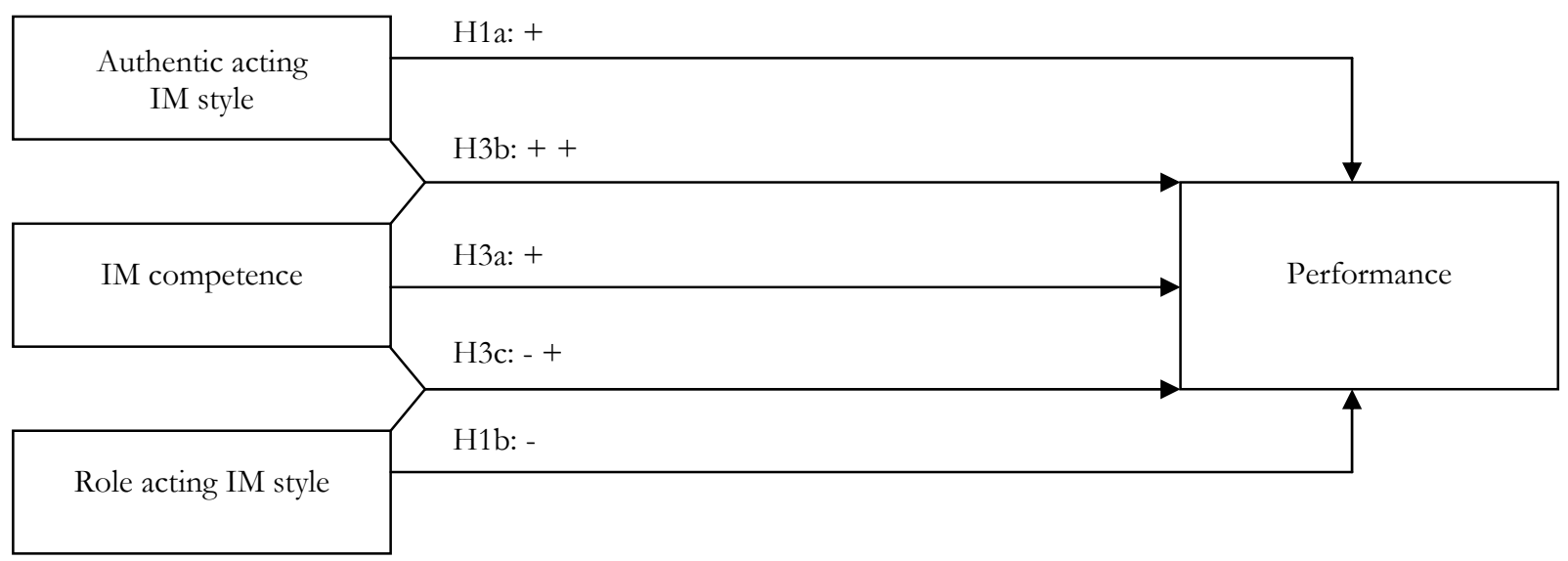


Figure 1b: Proposed models of IM styles, IM competence, and stress

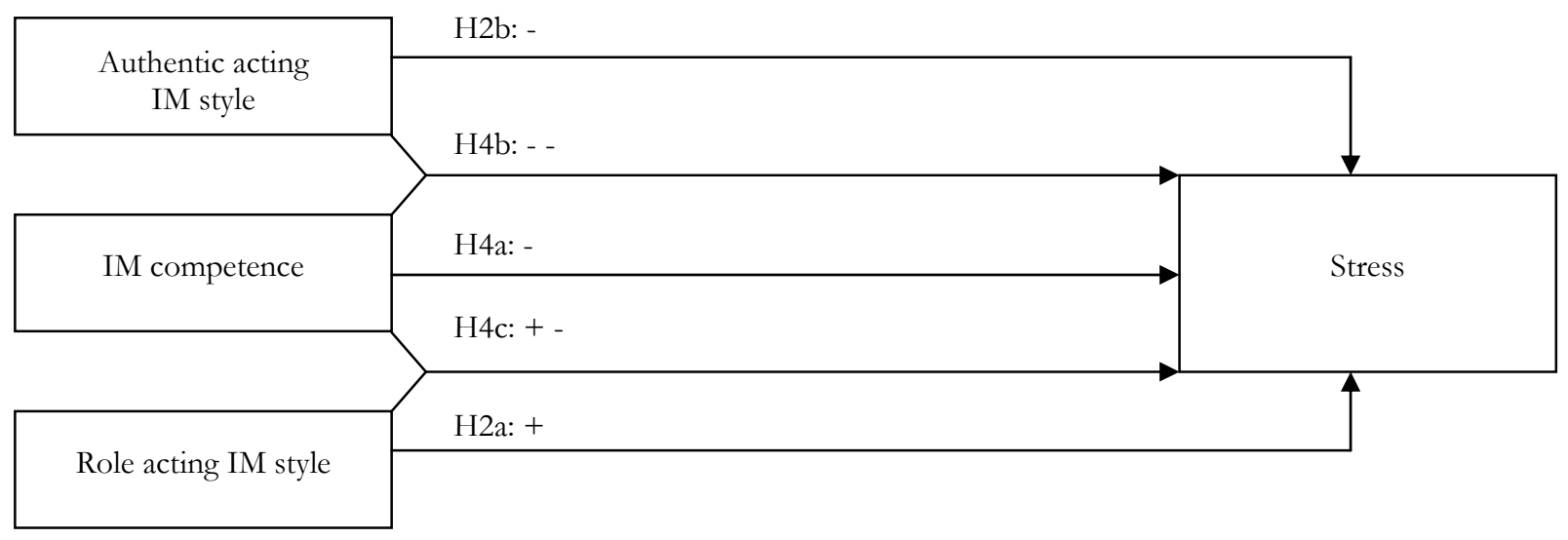

\section{Performance}

There is general agreement about the relationship between IM and performance evaluations (Schlenker, 1980). For example, research found that IM is often a decisive factor in appraisals an employee receives (Ferris et al., 1994; Wayne et al., 1990; Wayne et al., 1995). This indicates that employees are not passive elements in the performance evaluation process, but active agents who engage in efforts to influence the process and outcomes by managing the impressions they seek to communicate.

However, there may be differences depending on which IM style is applied. Trilling (1971) and Taylor (1991) stated that in Western cultures people prefer honest feelings even when they are negative. For example, genuine emotional displays are seen as very important, as is apparent from their positive impact on performance evaluations (Ashforth et al., 1993; Hochschild, 1983; Rafaeli et al., 1987). Grayson (1998: 148) stated that in marketing exchanges "managers will prefer employees who are genuinely nice and who are good actors when needed". He found that Western consumers do in fact prefer consumption of the authentic or genuine, but in accordance with display rules. Czepiel (1990) also noted the value of sincere communications in service exchanges in particular when service and client interactions have a lengthy character - as in consultancy. Furthermore, evidence suggests that people who defend their own beliefs contrary to social pressure are sometimes liked better than those who conform to others' values, and liking is found to have a positive impact on performance evaluations (Cardy \& Dobbins, 1986; Wayne et al., 1995). Therefore, we propose the following hypothesis: 


\section{CHAPTER 5}

Hypothesis 1a: Consultants' authentic acting IM style has a positive relationship with consultants' performance.

On the contrary, when the audience does take the impression as "calculated" rather than a true representation of feeling and does not "belief in the part one is playing" (Goffman, 1959: 17) a negative impression can result. In a service context, it was found that emotional expressions perceived as insincere can have a negative impact on customer service (Grove et al., 1989; Rafaeli et al., 1987). Another reason for the proposed negative relationship between a role acting IM style and performance is that untrue self-presentations are mostly less persuasive than those which are sincere (DePaulo et al., 2003). Hence, while consultants use role acting IM because they aim for beneficial outcomes in interaction with their clients, negative results might occur. That leads us to:

Hypothesis 1b: Consultants' role acting IM style has a negative relationship with consultants' performance.

Thus, although both IM styles are intended to favorably influence clients' impressions, there may be a difference between them in the sense that an authentic acting IM style is associated with higher performance and a role acting IM style with lower performance.

\section{Stress}

"One of the most common and personally troubling self-presentational dilemmas occurs when the image that would have the desired effect on a target is discrepant from the person's own selfconcept" (Leary, 1995:168). For example, consider a service provider who got annoyed with a customer but has to suppress this feeling and behave friendly to confirm to job rules. In a case like this, role acting IM as part of one's work role may create stress (Price, Arnould, \& Deibler, 1994). Two reasons can be called to account for this effect: (1) the experience of tension from emotional dissonances and (2) the draining of resources while effortful acting (Hochschild, 1983; Vohs et al., 2005). The first reason goes back to cognitive dissonance theory (Festinger, 1957) stating that negative emotional arousal and stress occur when individuals' behaviors are inconsistent with their personal beliefs or attitudes. Further, stress may arise when role acting individuals must be constantly alert for signals that their performance is being revealed and discredited (Elliott, 1979). Vohs and colleagues (2005) found that IM consumes self-regulatory resources, in particular when it runs contrary to habitual patterns. In emotional labor, the negative outcome of regulating expressions, in 
particular emotions, is well known and has been linked to stress outcomes (Grandey, 2003; Hochschild, 1983). As a consequence, the following is proposed:

Hypothesis 2a: Consultants' role acting IM style has a positive relationship with consultants' stress.

Generally speaking individuals conveying an authentic impression during an interaction should feel less stress. They have more or less only to be themselves to keep the interaction proceeding smoothly. Therefore, they may be concerned about the way in which audience perceives their impression, but they will not suffer from dissonance or effortful role acting.

Hypothesis 2b: Consultants' authentic acting IM style has a negative relationship with consultants' stress.

\section{The role of IM competence}

We consider IM competence as proficiency in transmitting a particular image successfully to others; regardless whether it is authentic or played. The focus is on maximum performance aspects of IM. We assume that communication, relationship management, and adaptiveness/flexibility are the most important competence factors. These are also described as components of social competence (Benard, 1995). Riggio and Friedman (1986) found that social skills dimensions accounted for significant proportions of variance in impression ratings. Individual with high social skills were rated as more successful in interpersonal interaction and were liked more than unskilled people (Riggio, 1986; Riggio and Throckmorton, 1988). In this context, we propose:

Hypothesis 3a: IM competence has a positive relationship with consultants' performance.

Regarding the presentation of a true or an untrue portrait of self, the literature states that it takes as much IM proficiency to present one or the other (Cheek et al., 1983; Grandey et al., 2005a; Schlenker, 2003). That is, people with poor self-presentation abilities are less effective in convincing others of what they are feeling even when they are telling the truth (DePaulo, 1992). Consequently, we propose: 


\section{CHAPTER 5}

Hypothesis 3b: IM competence will strengthen the positive relationship between an authentic acting IM style and performance.

Invalid presentations are very hard to detect by the audience when impression managers are experienced and able to control behavioral cues that could otherwise create doubts on their authenticity (Riggio \& Friedman, 1983; Schaefer et al., 2006). For example, Mehrabian and Williams (1969) found that individuals deliberately keep eye contact with others to make them believe in the sincerity of their behaviors. A pleasant face or a smile may also help to disguise the discomfort that might come with pretending the untruth (Kraut, 1978, Mehrabian, 1971). As a result:

Hypothesis 3c: IM competence will weaken the negative relationship between a role acting IM style and performance.

Furthermore, a lack of IM competence could lead to more stress and anxiety in social situations. It is known that people will experience social anxiety to the degree that they have the goal of creating a preferred impression on others but doubt they will able to do so (Schlenker et al., 1982). Therefore, we additionally propose that greater IM competence reduces the experience of stress.

Hypothesis 4a: IM competence has a negative relationship with consultants' stress.

Apart from these direct effects, one would also expect interactions to occur. Thus, the relationships between the two IM styles and stress that are hypothesized above may be moderated by IM competence. That is, the better the IM competence the less stress a consultant may experience when having an authentic acting IM or a role acting IM style.

Hypothesis 4b: IM competence will strengthen the negative relationship between an authentic acting IM style and stress.

Hypothesis 4c: IM competence will weaken the positive relationship between a role acting IM style and stress. 


\section{METHOD}

In the following, we describe the measures needed to test our hypotheses, the analysis and consequent results.

\section{Data}

The data used are the same as described before. We perform the analysis in the combined sample of 233 consultants after having checked for differences between the snowball-sample $(N=130)$ and the company sample $(\mathrm{N}=103)$. This was done by using the sample as a control variable in the regression analysis as illustrated at a later point.

\section{Scales}

Unless stated otherwise, all of the scales are measured on 5-point Likert scales ranging from 1 (totally disagree) to 5 (totally agree). The items in each scale are summed and then averaged to arrive at an overall value for the scale. Higher scores correspond to higher levels of each of the constructs. Furthermore, to avoid confusion on the measures of our dependent variables, it has to be stated that both - performance and stress - are assessed with self-reported measures and therefore represent the consultants' perceptions of their performance and stress level. All scales can be found in Appendix D.

\section{Authentic acting IM style}

The scale developed to tap the authentic acting IM style of consultants consists of seven questions. With a Cronbach's alpha ${ }^{8}$ of .78 the scale demonstrates acceptable internal consistency.

\section{Role acting IM style}

To measure the role acting IM style eight items are used. The reliability based on internal consistency is confirmed with a Cronbach's alpha of .80 .

\footnotetext{
${ }^{8}$ The values of Cronbach's alpha mentioned here are based on an analysis in the combined sample.
} 


\section{CHAPTER 5}

\section{IM competence}

To measure the IM competence of consultants we use a 15 -item scale that has already been employed in the previous study. The scale combines new items with existing items from other scales to measure three competence factors: communication, relationship management, and adaptiveness/flexibility. A sample item for the IM competence communication is: "I keep eye contact when I talk to the client." To measure the other two identified components of IM competence: relationship management and adaptiveness/flexibility, we inherited five items of two subscales of the Social Skills Inventory (Riggio, 1986) - the emotional sensitivity (three of 15 items) and the social control (two of 15 items) subscales in addition to newly developed items. Existent items are modified for the consultancy context. A sample items for the IM competence relationship management is: "It is nearly impossible for clients to bide their true feelings from me." An item representing the competence of adaptiveness/flexibility is: "I find it very easy to play different roles at different times." With a Cronbach's alpha coefficient of .74 the items demonstrate adequate internal consistency.

\section{Performance}

Performance is measured using the same five-item scale applied in the preceding study. Four items were taken from Wayne and Liden's (1995) performance scale and adapted to the consultancy context. Items include: "The client considers me as highly effective." We added one item: "The client will spread positive words about me." The construct of interest is not respondents' actual performance level but, rather, how they think their performance is perceived by the clients. Responses for all five items are summed and with a Cronbach's alpha of .85 these items make up an internally consistent scale.

\section{Stress}

Stress is measured with a subscale (6-items) of the Perceived Stress Scale (Cohen, Kamarck, \& Mermelstein, 1983). The Perceived Stress Scale is a 14-item self-report measure assessing the degree to which situations in one's life are appraised as stressful. Hewitt and colleagues (1992) argue for a two-factor model of the Perceived Stress Scale: one scale measuring perceived coping, that is how individuals perceive their coping ability in stressful situations, and the other scale measuring perceived distress, that are global feelings of discomfort arising from perceptions that one's life is stressful, unpredictable, uncontrollable, and overloading. Given that we are interested in how the 
experience of stress relates to IM styles, only the items of the perceived distress subscale are used in this study and adapted to the consultancy context. Items include: "In the last month, how often have you felt nervous and stressed'. Responses are recorded on a 5-point Likert scale with the following anchors: very often (5), often (4), sometimes (3), rarely (2), and never (1). With a Cronbach's alpha of .84 the measure displays good internal consistency.

\section{Control variables}

All regressions control for gender, age, job tenure, consultancy type and managerial function.

\section{Gender}

As already mentioned in Chapter 4, women and men are recognized to employ IM differently and also its outcome can differ (Singh et al., 2001). For example, women seem to have a less aggressive approach in interview situations (Fletcher, 1981). Further, Westphal and Stern (2006) found that IM influences board appointments; however IM has a less positive relation to board appointments when employed by women instead of men. As a consequence, gender is often found to moderate relationships between IM and performance (Gordon, 1996).

\section{Age and job tenure}

Hogan and Cheek (1983) proposed that maturity involves being able to recognize and deal with bother inner (e.g. personal principles) and outer concerns (e.g. expectations and preferences of others). Research found that when given the opportunity, the use of deception in organizational life is sooner used by older and more experienced persons. Further, they appeared less revealing nonverbally when they were lying than younger persons (Parham, Feldman, Oster, \& Popoola, 1981). Hence, with increased experience in social interaction the elderly seem to become more cognizant of the necessity to control nonverbal behavior and exercise their abilities accordingly.

Moreover, since consultants are recognized for their IM behavior, it can be assumed that having longer job tenure in consultancy will have produced more proficiency in IM. Hence, in general for job tenure similar effects as for age could be assumed. 


\section{CHAPTER 5}

\section{Consultancy type and managerial function}

Consultancy type is included as another control variable. One can imagine that e.g. HR consultants approach their clients in a different way than IT consultants. This can result from the circumstance that IT consultants often face their clients to a much lesser extent. Further, we asked whether consultants fulfill managerial functions. Consultants with managerial functions have to supervise people and may therefore have developed another IM style than consultants without managerial functions.

\section{RESULTS}

The second aim of this study was to identify the relationships of the two IM styles to performance and stress as well as a main and a moderating effect of IM competence on these outcomes. Due to the fact that we rely on two samples, we have inspected the data set for differences between the "snowball" and "companies" samples before testing the hypotheses. A hierarchical regression analysis was conducted with sample entered first, followed by the independent variables and the interactions between sample and each independent variable - the dependent variables being performance and stress. As recommended by Aiken and West (1991), the sample score was centered in this analysis. The results revealed no significant main effect for sample and no significant interaction terms. In addition, we conducted independent t-tests to identify similarities between the two samples. Although reaching statistical significance for age, gender, consultancy type and managerial function, the actual difference in mean scores between the two samples was not large. The results supported our decision to use the combined sample when testing the hypotheses.

Means, standard deviations and correlations for all variables are presented in Table 3. As shown there, authentic acting and role acting IM styles were significantly and as expected related to performance and to stress. The authentic acting IM style had a positive correlation with performance $(\mathrm{r}=.153, \mathrm{p}<.05)$ and a negative with stress $(\mathrm{r}=-.319, \mathrm{p}<.001)$. For a role acting IM style it is the other way around: here we found a negative relationship with performance $(r=-.185, p<.01)$ and a positive with stress $(\mathrm{r}=.295, \mathrm{p}<.001)$. The correlations with stress appeared to be stronger than with performance. IM competence also correlated as predicted. It had a positive relationship with performance $(r=.400, \mathrm{p}<.001)$ and a negative but not significant one with stress. Furthermore, IM 
competence had non-significant correlations with authentic acting and with role acting IM styles, pointing at the discriminant validity of the measurement.

Table 3: Descriptive statistics and correlations

\begin{tabular}{|c|c|c|c|c|c|c|c|}
\hline & VARIABLE & MEAN & s.d. & 1. & 2. & 3. & 4. \\
\hline 1. & Authentic acting IM style & 3.96 & .66 & & & & \\
\hline 2. & Role acting IM style & 2.55 & .73 & $-.465 * * *$ & & & \\
\hline 3. & IM competence & 3.96 & .37 & .030 & .063 & & \\
\hline 4. & Performance & 4.09 & .57 & $.153 *$ & $-.185^{* *}$ & $.400 * * *$ & \\
\hline 5. & Stress & 2.54 & .73 & $-.319 * * *$ & $.295 * * *$ & -.125 & -.124 \\
\hline
\end{tabular}

Note. $\mathrm{N}=233 .{ }^{* * *} \mathrm{p}<.001 .{ }^{* *} \mathrm{p}<.01 .{ }^{*} \mathrm{p}<.05$

In testing the hypotheses we conducted hierarchical regression analyses for performance and stress separately (see Table 4). In case that the control variables were insignificant they were left out of the analysis.

Table 4: Hierarchical regression analyses

\begin{tabular}{lcc} 
& \multicolumn{1}{l}{ PERFORMANCE } & STRESS \\
\hline CONTROLS & & $-.165^{*}$ \\
\hline Age & n.a. & \\
\hline IM STYLES & & $\underline{-.207^{* *}}$ \\
\hline Authentic acting IM Style & $\underline{.077}$ & $\underline{.140^{*}}$ \\
Role acting IM Style & $\underline{-.172^{*}}$ & \\
\hline IM COMPETENCE & & $\underline{-.129^{*}}$ \\
\hline IM Competence & $\underline{.416^{* * *}}$ & $\underline{-.031}$ \\
IM Competence $*$ Authentic acting IM Style & $-.154^{*}$ & .049 \\
IM Competence $*$ Role acting IM Style & $-.131^{*}$ & .176 \\
\hline R for total equation & .232 & .000 \\
F for total equation & .000 & \\
\hline
\end{tabular}

Note. $\mathrm{N}=233 .{ }^{* * *} \mathrm{p}<.001 .{ }^{*} \mathrm{p}<.01 .{ }^{*} \mathrm{p}<.05$.

Values for independent variables are $\beta$ coefficients, with all variables and interaction terms included in the regression equation. Underlined coefficients indicate relationships in the hypothesized direction. 


\section{CHAPTER 5}

\section{Performance}

The overall model with performance as the dependent variable fitted well $\left(\mathrm{R}^{2}=.232, \Delta \mathrm{R}^{2}=.215\right.$, $F=13.709, p<.000)$. Referring to the proposed hypotheses, we expected in Hypothesis $1 \mathrm{a}$ that an authentic acting IM style relates positively to performance. As can be seen in Table 4 the result was in the anticipated directed, however not significant. Accordingly, Hypothesis 1a was not supported. In Hypothesis $1 \mathrm{~b}$ we expected that a role acting IM style has a negative relationship with performance. This hypothesis was supported $(\beta=-.172, \mathrm{p}<.05)$. In Hypothesis 3 a we stated that IM competence associates positively with performance and the results conformed to this prediction ( $\beta$ $=.416, \mathrm{p}<.000)$. Thus, Hypothesis 3 a can be considered to be supported as well. In addition, we suggested that the relationships between the two IM styles and performance may differ at different levels of IM competence. IM styles may positively or adversely affect performance under conditions of low or high IM competence. More specifically, in Hypothesis $3 \mathrm{~b}$ we proposed an interaction between authentic acting IM and IM competence such that consultants who have high IM competence and an authentic acting IM style may be evaluated more positively than consultants with less IM competence. Surprisingly, the interaction between an authentic acting IM style and IM competence significantly attenuated rather than strengthened the positive relation of an authentic acting IM style on consultants' performance $(\beta=-.154, \mathrm{p}<.05)$. That means that a high IM competence in combination with an authentic acting IM style seems to potentially reduce the good performance of a consultant. It changes the direction of the relation between an authentic acting IM style and performance from positive to negative. Thus, Hypothesis $3 \mathrm{~b}$ was not supported. Hypothesis $3 \mathrm{c}$ proposed an interaction between a role acting IM style and IM competence in such a way that consultants who have high IM competence and apply role acting IM receive less negative performance evaluations than do consultants with low IM competence. The interaction of role acting IM style and IM competence produced a significant interaction effect as expected. Subjects high on the role acting IM style scale and high on the IM competence scale showed a less negative relation with performance $(\beta=-.131, \mathrm{p}<.05)$ than role acting IM by its own. Thus, we did find support for Hypothesis 3c.

\section{Stress}

For stress as the dependent variable the control variable age $(\beta=-.266, \mathrm{p}<.000)$ had a significant negative effect and significantly explained unique variance $\left(\mathrm{R}^{2}=.266, \Delta \mathrm{R}^{2}=.067, F=17.622, p<.000\right)$. 
That is, older consultants seem to experience less stress in their work as a consultant $(\beta=-.165$, $\mathrm{p}<.05)$. In the statistical analyses a linear increase could be identified per age group till the age of $60^{\circ}$. Therefore, age was included as a control variable in the stress model. It was entered in the first step; authentic acting and role acting IM styles and IM competence were entered in the second step, and the interaction terms were entered in the final step of the regression analysis. The overall regression effect was significant $\left(\mathrm{R}^{2}=.176, \Delta \mathrm{R}^{2}=.154, \mathrm{~F}=8.048, p<.000\right)$.

Hypothesis 2 a proposed that consultants with a role acting IM style will experience more stress and Hypothesis $2 \mathrm{~b}$ suggested that consultants with an authentic acting IM style will undergo less stress. Both hypotheses were supported $(\beta=.140, \mathrm{p}<.05 ; \beta=-.207, \mathrm{p}<.01)$. Further, it was hypothesized that IM competence has a negative relationship with consultants' stress, which was the case $(\beta=.-129, \mathrm{p}<.05)$. That is, consultants with high IM competence appear to feel less stress. IM competence was also suggested to be a moderator of the relationships between an authentic acting IM style and stress (Hypothesis 4b), as well between a role acting IM style and stress (Hypothesis 4c). Neither of these hypotheses was supported. In Table 5 all hypotheses and their corresponding results are listed.

\section{Table 5: Hypotheses - Supported and not supported}

\begin{tabular}{llc}
\hline HYPOTHESES & \multicolumn{1}{c}{ RESULTS } \\
\hline Hypothesis 1a: & $\begin{array}{l}\text { Consultants' authentic acting IM style has a positive relationship with } \\
\text { consultants' performance. }\end{array}$ & - \\
Hypothesis 1b: & $\begin{array}{l}\text { Consultants' role acting IM style has a negative relationship with consultants' } \\
\text { performance } \\
\text { Consultants' role acting IM style has a positive relationship with consultants' } \\
\text { Hypothesis 2a: }\end{array}$ & $\checkmark$ \\
stress. & $\checkmark$ \\
Hypothesis 2b: & $\begin{array}{l}\text { Consultants' authentic acting IM style has a negative relationship with } \\
\text { consultants' stress. }\end{array}$ & $\checkmark$ \\
Hypothesis 3b: & $\begin{array}{l}\text { IM competence has a positive relationship with consultants' performance. } \\
\text { acting IM style and performance. }\end{array}$ & - \\
Hypothesis 3c: & $\begin{array}{l}\text { IM competence will buffer the negative relationship between a role acting IM } \\
\text { style and performance. }\end{array}$ & $\checkmark$ \\
Hypothesis 4a: & IM competence has a negative relationship with consultants' stress. & $\checkmark$ \\
\hline
\end{tabular}

\footnotetext{
${ }^{9}$ This conclusion is based on an extra regression analysis performed with different age-groups as independent variables and their relationships with role acting IM style as the dependent variable. The results showed a significant positive relationship for consultants between 20-30 year and a role acting IM style $(\beta=.27, \mathrm{p}<.000)$. The other age-groups $(31-40$; 41-50; 51-60; >61) were not significantly related to a role acting IM style.
} 
CHAPTER 5

\begin{tabular}{llc}
\hline HYPOTHESES & \multicolumn{2}{c}{ RESULTS } \\
\hline Hypothesis 4b: & $\begin{array}{l}\text { IM competence will strengthen the negative relationship between an authentic } \\
\text { acting IM style and stress. }\end{array}$ & - \\
Hypothesis 4c: & $\begin{array}{l}\text { IM competence will buffer the positive relationship between a role acting IM } \\
\text { style and stress. }\end{array}$ & - \\
\hline
\end{tabular}

Figure $2 \mathrm{a}$ and $2 \mathrm{~b}$ show the results in a graphical form.

Figure 2a: Revised models of IM styles, IM competence, and performance

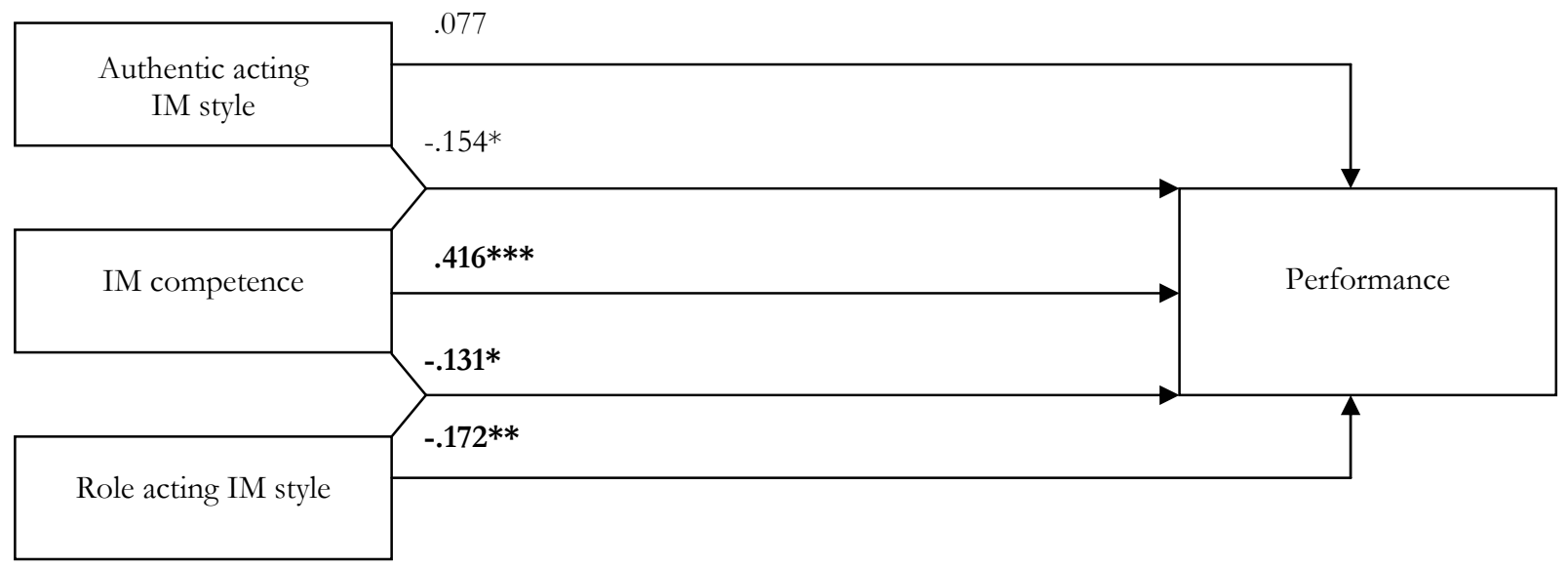

Note. $\mathrm{N}=233$. Bold values present supported hypotheses.

Figure 2b: Revised models of IM styles, IM competence, and stress

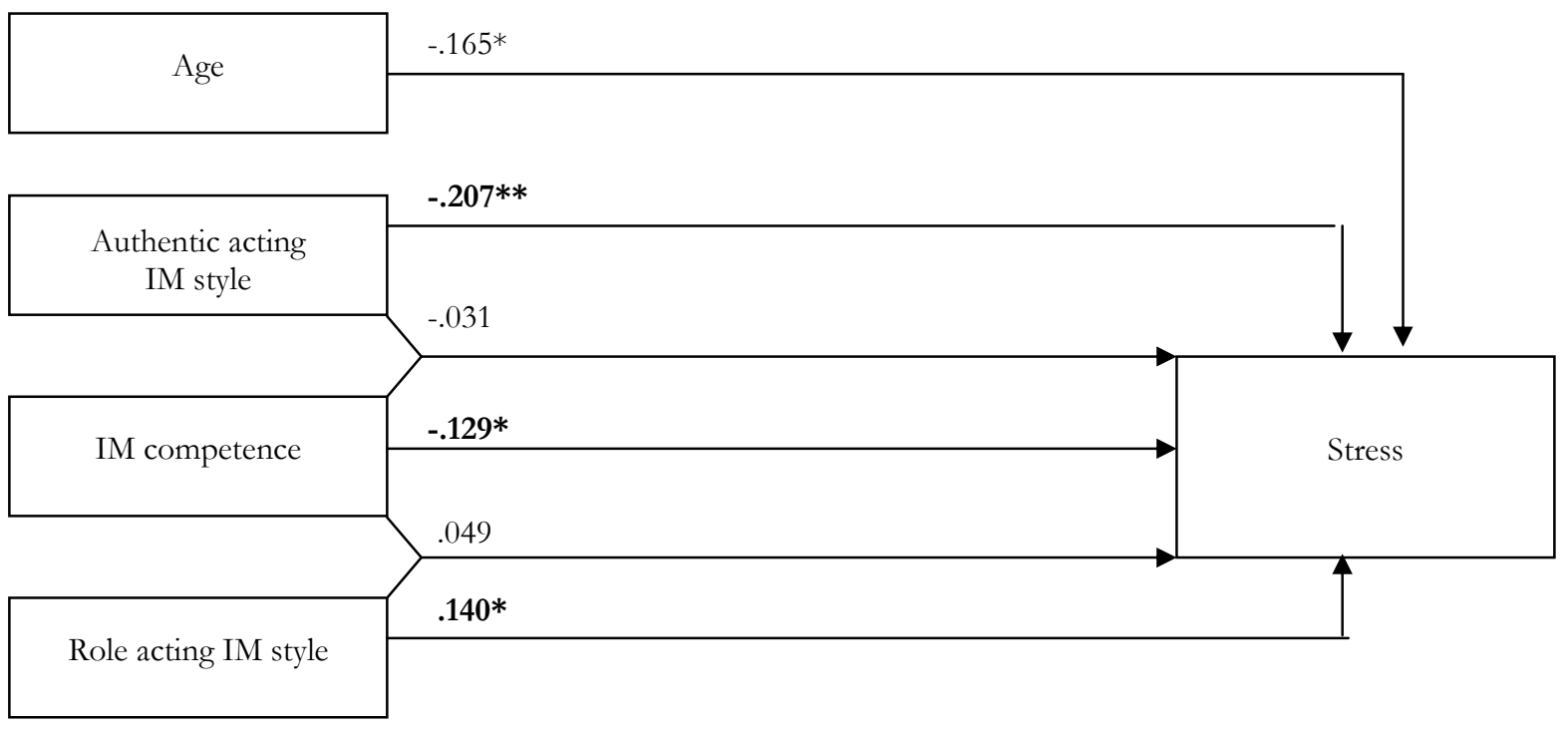

Note. $\mathrm{N}=233$. Bold values present supported hypotheses. 


\section{DISCUSSION}

\section{PART I}

\section{IM Styles: One- or two-dimensional?}

Goffman (1959) described two models of IM. In one model, the impression manager gives a "real, sincere, or honest performance", in the other model the performance is a "false one that thorough fabricators assemble for us" (Goffman, 1959: 70).

Our definition of the two possible IM styles can be illustrated as follows. The approach of individuals with an authentic acting IM style is "I express myself to impress others". Here, the individual tries to make a favorable impression on another by presenting personal and authentic facets of him or herself. In difference, people with a role acting IM style might rather say "I conform to role expectations to impress others". They try to influence the impressions of others by complying with role expectations regardless of whether they are actually able to satisfy these or not.

The study contributes to the IM literature by leading us to a new and original articulation of two IM styles, that of an authentic acting and a role acting IM style. In part I of this study we have tested whether these two types of IM styles represent bipolar opposites of single dimensions or rather two different dimensions. The study reported here supports a two-factor theory and suggests that people's IM style is defined to encompass two broad factors or dimensions of IM behavior. In particular, it can vary to the extent to which behavior is authentic and with an intention to express oneself to impress another or untrue and mainly employed to satisfy others' role expectations. The two constructs are clearly different from each other, even though they show a negative relationship.

It is essential to note that all levels and all combinations of an authentic acting and a role acting IM style on both dimensions are possible (see Figure 3). That is, IM styles can range from low authentic acting to high authentic acting IM and from low role acting to high role acting IM and e.g. combine a high authentic acting IM style with a low role acting IM style. People with a high authentic acting IM style and a low role acting IM style tend more to frame, choose and present real but positively biased information about them. They abstain from behaving in a way that presents an image that they know is not consistent with the truth but conforms to the consultant role. Reverse behavior is likely for individuals with a low authentic acting IM style and a high role acting IM style. Furthermore, it is also possible that a person is high in both IM styles. Here an individual shows honest aspects of him or herself and is also unhesitant to deceive when necessary to fulfill others' expectations. The combination of a low authentic acting and a low role acting IM style is as well 


\section{CHAPTER 5}

probable. This mixture presents an individual that uses IM on a low basis and therefore it is unlikely that he or she attempts to impress others neither with an honest nor with a false staging of him or herself.

Figure 3: Authentic acting and role acting IM styles dimensions

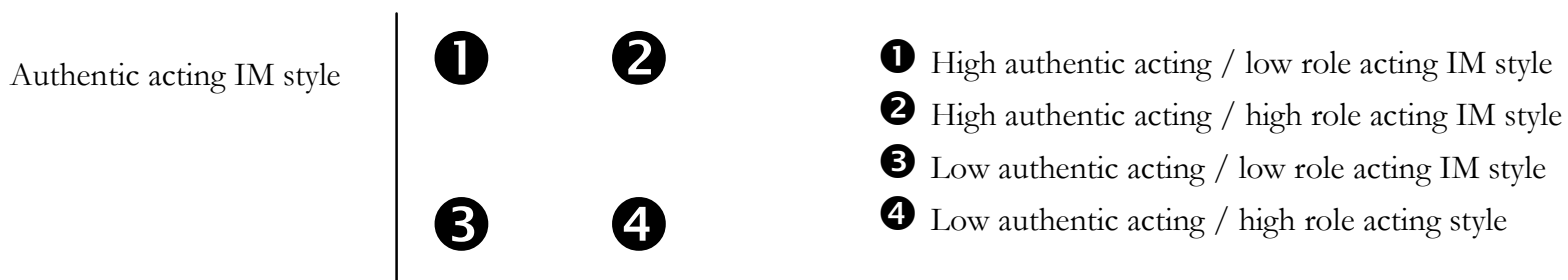

Role acting IM style

To illustrate the described combinations of an authentic acting IM style and a role acting IM style and to see whether these are lifelike representations of human beings we advise the following. For each combination think of people in your circle of friends or colleagues and try to categorize them in one of the four quadrants. For simplification consider extreme cases. For example, can you think of somebody who tries to manage others' impressions just by fulfilling their expectations instead of presenting real facets of him- or herself and vice versa? And, do you know somebody who attempts to leave a positive mark both with being as he or she is and by fulfilling others' expectations when necessary with insincere behaviors? Do you also recognize somebody in your circle of acquaintances who rarely tries to manage others' impressions neither with a true nor with a faked image of him- or herself?

Concerning authentic and faked behaviors, our finding is consistent with theory saying that authenticity is not an either/or condition. People are depicted as being more or less authentic or inauthentic (Erickson, 1995). The literature on authentic leadership (cf. Avolio et al., 2005; Avolio et al., 2004; Gardner et al., 2005; Walumbwa et al., 2008) adopts this definition and describes authenticity to exist on a continuum. The more individuals stay true to their core values, identities, preferences and emotions, the more they are seen as authentic.

Moreover, acknowledging that individuals have either a tendency to engage in authentic acting or role acting IM, we also have to take into account that certain roles and situations ask for 
role acting IM even when an individual rather tends to employ an authentic acting IM style (cf. Katz et al., 1978); (Chapter 3, consultants' interview account on a role acting IM style).

Furthermore, the study enriches IM research by contributing to measurements of IM. We verified the superior fit of the two-factor model with in total 15-items and accepted it as the basis for studying its relationships to various outcomes, as in our study on performance and stress.

\section{PART II}

\section{The Main Effects of IM Style}

The development of the MIMSS (Maastricht Impression Management Styles Scales) provides further insight in the potential outcomes of the two IM styles. In particular, we have contributed to a deeper knowledge of IM by investigating whether and how the two IM styles - authentic acting and role acting - relate to consultants' performance and stress. In addition, this study goes beyond existing research on IM by focusing not solely on the mostly considered outcome - performance - but also takes a potential negative result, that of stress, into account.

We have shown that an authentic acting IM style is positively related to performance, however not significantly. As expected, the application of authentic acting IM is associated with lower stress. Furthermore, both results on role acting IM support our hypotheses, in that a role acting IM style has a negative association with performance and a positive with stress. Hence, excluding the nonsignificant effect of authentic acting IM on performance, all our hypotheses of the main effects of the two IM styles are supported.

It is important to realize that IM can have different effects. First, it adds to the current literature on IM, by establishing two new IM styles and potential relationships with performance and stress. Second, it is essential knowledge for consultants and their organizations. The results show that due to role acting IM, even if used to achieve a positive outcome, consultants' performance, at least the perception of it, will suffer. Furthermore, the study shows that role acting IM might enhance the experience of stress supporting previous research saying that when people deviate from habitual behavior they will require more self-regulation costs in terms of effort and energy (Vohs et al., 2005). Therefore, consultants relying on an authentic acting IM style instead of a role acting IM style seem to perform better, in that role acting IM might result in a lower performance perception and furthermore associates with the experience of more stress. Nevertheless, we acknowledge that in 


\section{CHAPTER 5}

real-life both IM styles have their entitlement. Therefore, a synthesis between the two might be realistic and feasible, and in the end optimal for the company and for the individual employing IM.

\section{Direct and Moderating Effects of IM Competence}

Another purpose of part II of this study was to examine one boundary condition of the effect of consultants' IM styles. As expected, we find that IM competence has a positive relation to consultants' performance and a negative association with consultants' experience of stress. That means that consultants with a high IM competence may have a good performance or succeed in managing clients' impressions of their performance while suffering less from stress. Furthermore, as expected we find that IM competence has a moderating effect on the relation between a role acting IM style and performance in that the negative relation is weakened. Contrary to our original thought that IM competence will be helpful in any case - when IM is untrue but also true - the most surprising finding of this study is that IM competence in interaction with an authentic acting IM style relates negatively to consultants' performance.

For the moment, we have no answer to explain the unexpected result. We examined possible reasons; however none was satisfying in the end. For example, from a statistical outlook we assumed that a suppressor effect could be responsible for the unforeseen result. However, since there is no correlation between the authentic acting IM style and competence a suppressor effect could be excluded. Further, we assumed that consultants who normally tend to give honest impressions may seem insincere when they consciously use their IM competence. For example, being attentive in a conversation with a client could be an automatic and true behavior for a consultant with an authentic acting IM style but when he or she deliberately concentrates e.g. on keeping eye contact with the client the habitual behavior might get disrupted and performance could deteriorate, or the audience might recognize the deliberateness and interpret it as artificial behavior. Nonetheless, not any of the described reasons seems to adequately answer the unexpected outcome.

\section{Effect of Age}

Another interesting finding is the fact that older consultants appeared not to experience as much stress as younger consultants do. In particular, consultants over 41 years but not older than 60 years did experience less stress than their younger colleagues. The reason seems to be that younger consultants make more use of role acting but less of authentic acting IM, while for older consultants 
it is just the other way around. From our analyses we learned that authentic acting and role acting IM styles have differential and significant associations with stress, therefore the reasoning used to explain the lower stress level of older consultants appears logical. This result is contrary to other research which found that when the possibility is given to deceive in organizational life it is rather done by older persons (Parham et al., 1981). However, in our study it seems that older consultants do not experience the necessity of artificially impressing their clients as much as their younger colleagues. A motivation for younger consultants could be that they feel sooner insecure, worry more about satisfying clients' expectations and therefore rely more on a role acting IM style. The lower use of a role acting IM style and the undergoing of less stress speak clearly against the current trend of disposing older consultants and replacing them with younger ones.

\section{LIMITATIONS AND FUTURE RESEARCH}

As with most research, the present study has its limitations. First, findings presented here are based on self-report measures and require replication with different methodologies. Since all data comes from a cross-sectional self-report design one cannot draw causal conclusions, and there is ground for concern about possible perception bias. The results may differ when we would have clients' performance evaluations of consultants available. Therefore, the study should be repeated in future research with clients' assessments of consultants instead of relying on consultants' self-reported measures. An additional interesting way of measuring IM could be to ask a third and neutral observer to rate consultants' IM behavior, as e.g. a colleague.

Besides, we measured the data at one point in time. Due to the fact that impression formation is known to be a dynamic process, it is important that future studies on IM utilize longitudinal research designs and seek to explain how the management of impressions and its outcomes might vary over time.

Another limitation is that we have done two studies on a single data set and tested the hypotheses using data from the same sample utilized for validating our scales. Therefore, the scales might suffer from lower reliability and validity in future samples. In addition, we cannot directly compare our results with those of other studies since the differentiation between an authentic acting and a role acting IM style has not yet been performed empirically. Further, the two IM scales show intercorrelation. As with any new measure, further research is needed to refine the construct, as scale 


\section{CHAPTER 5}

development is an iterative process. Therefore and due to the fact that the fit indices are moderate, we hope for model improvement by replicating our findings in future research.

Further, unfortunately we could not explain the surprising effect of the moderator IM competence in interaction with an authentic acting IM style on performance. Research on this aspect is needed to learn more about IM competence in general and its impact as a moderator in the IM process in particular.

Moreover, in this study we speak only about IM styles. However, research on IM identified various IM tactics (Turnley et al., 2001) and it would be interesting to see which of these in addition to our consultants' IM tactics associate with stress instead of just focusing on performance. Further, future research could investigate whether and how IM tactics and styles relate to each other.

Finally, the sample examined in the present study was fairly unique in comparison to former studies. However, we believe the relationships found in the study will generalize to other samples with similar characteristics, e.g. other service industries. Even so, we encourage future research to replicate our findings in other samples and contexts to ensure the external validity of our results.

In the next chapter of this thesis we will take most of above remarks into consideration. We will conduct a longitudinal study on IM as well as examine various IM tactics in addition to the authentic acting and the role acting IM styles. Further, we will try to identify a potential outcome of IM by asking the targets of IM directly instead of relying on self-reported data.

\section{CONCLUSION}

This study extends previous research on IM by investigating two novel IM styles: the authentic acting and the role acting IM styles. Results showed that these represent distinct dimensions. Further, the study contributes to the literature on IM by providing results for a particular business: consultancy. Results demonstrated that consultants having an authentic acting IM style seem to experience less stress, while consultants with a role acting IM style appear to undergo more stress and perform less successfully. Further we found that IM competence associates positively with performance and negatively with stress. Moreover, it is interesting to see that IM competence in combination with role acting IM associates with better performance than role acting IM by its own. In interaction with an authentic acting IM style, competence shows a negative relation with performance. That is, consultants high in IM competence and with an authentic acting IM style demonstrate a negative relationship with performance. 
Taken together, these results empirically show that IM - here demonstrated through consultants' IM style - is a central point in the consultancy context and that positive as well as negative outcomes are possible. Finally, it is worth noting that consultants between 41-60 years seem to experience less stress than their younger colleagues. 
- 122 - 
In addition to reckoning with what can be seen, the performer will also have to take into consideration the information the audience already possesses about him. The more information the audience has about the performer, the less likely it is that anything they learn during the interaction will radically influence them. On the other hand, where no prior information is possessed, it may be expected that the information gleaned during the interaction will be relatively crucial.

- Erving Goffman, The Presentation of Self in Everyday Life

In a previous study we added to the literature on IM by proposing a distinction between an authentic acting and a role acting IM style. In this study we used the authentic acting and the role acting IM styles in addition to various general IM tactics to investigate business students' IM $(\mathrm{N}=726)$ in interaction with their teachers and potential effects on their participation grades. Furthermore, we tested whether both students' IM behavior and its effectiveness change over time.

We collected data over the period of a university course (seven weeks) with two points in time (beginning and end of a course). A series of hierarchical multiple regressions revealed the following relationships with business students' participation grades at the beginning of a course: (a) a positive relationship for an authentic acting IM style; (b) a positive relationship for the IM tactic selfpromotion and (c) a negative relationship for the IM tactic supplication. At the end of a course no effects were observable anymore. Further, by applying a general linear model with repeated measures we discovered that students seem not to substantially change their IM behavior - neither their IM styles nor their IM tactics - over the period of a course. In addition, we found that gender, educational experience, nationality and exam grading had a significant relation with IM behavior employed. 


\section{INTRODUCTION}

As learned in preceding studies, with IM individuals aim to positively influence others' perceptions and reactions by displaying certain behaviors (Baumeister, 1982; Schlenker \& Weigold, 1990; Schlenker, 1980; Schlenker et al., 1982; Tedeschi et al., 1985; Tedeschi et al., 1981). Due to the fact that the images presented are affected by the roles people play in social life (Goffman, 1959) and by the expectations of the audience they are currently dealing with (Thomas \& Al-Maskati, 1997) it is necessary to take the context in which people's IM is constructed into consideration (Kipnis et al., 1988).

IM has been studied in a variety of contexts, in recent years in particular in work settings (Giacalone et al., 1989; Rosenfeld et al., 1995) and here with a focus on upward-directed IM. Research found i.e. that IM has a positive impact on performance evaluations, getting hired, building a career, carrying out negotiations, establishing sales transactions etc. (Feldman \& Klich, 1991; Wall, 1991; Wayne \& Ferris, 1990; Wayne \& Liden, 1995).

In this study we give attention to IM in a pre-employment setting: a business university. University courses in which teachers and students interact can be viewed as what Goffman (1961) has called "situated activity systems". These are rather closed systems, as they are not open for outsiders and bound to specific time-frames in which activities go on with students and teachers being put together. Many IM studies have used students as participants; but research on students' actual IM behavior in university settings is rare. In regard to studies conducted with students representing the research sample, Juvonen and Murdock (1993a) discovered that students adapted justifications for their failures in reference to the audience. In this context, Bohra and Pandey (1984) found that students are more likely to try to control how they are perceived by their teachers than by their friends. Other studies analyzed mainly students' self-handicapping strategies. These are used by students to make the circumstances instead of their abilities responsible for their low performance (Urdan, Midgley, \& Anderman, 1998; Weiner, 2003). However, most studies on IM conducted in a university setting focus on teachers' IM (Colvin, 2007; Olds \& Crumbley, 2003; Tetlock, 1980). That is surprising, since the center of attention in organizational studies is on upward-directed IM.

In this study, we focus on IM employed by business students in order to influence their teachers. We claim that university students do not only learn the expertise needed for their future organizational careers but also how to present a favorable picture of themselves to people of higher ranks. 
To examine the usage and effects of business students' IM we consider their IM styles and tactics. In regard to IM styles, we look at the two IM styles investigated in the previous study. That is, the authentic acting IM style which is sincere and the role acting IM style which is artificially created to influence audience's impressions. Further, since the focus is on students' instead of consultants' IM behaviors we do not examine the three consultants' IM tactics investigated in Chapter 4, but rather draw on five well-known IM tactics which attempt to manage others' impression by presenting the following images: friendly, competent, dedicated, needy, and tough.

In general, we assume that students who have an authentic acting IM style instead of a role acting IM style will receive better performance evaluations expressed in higher participation grades ${ }^{10}$ and that students who tend to be rather passive in their use of IM tactics should be receiving lower participation grades by their teachers than those who use IM to some degree; however conditioned by which tactic of IM is utilized.

Moreover, although literature gives proof of IM's effectiveness (Bolino et al., 2006; Wayne, Liden, Graf, \& Ferris, 1997) and acknowledges its process character (Bozeman et al., 1997; Jones, 1990) there is almost no data available that describes changes of IM use and its effectiveness over time. To our knowledge, the only study which has implemented time as an aspect of research was conducted by Wayne and Liden (1995). The authors found that employee's employment of IM early in the relationship with the supervisor made the supervisor perceive similarities with the subordinate and like him or her, which affected performance ratings made at a later point. However, since one study is by far not enough to explain how the management of impressions and its outcome might vary over time, we decided to collect longitudinal data.

In short, we aim to learn more about IM styles and tactics and primarily intend to find out whether business students' use of these and respective outcomes differ over a certain period. Therefore, we ask the following questions: (a) Which IM styles and tactics are mostly applied by business students in order to influence their teachers? (b) Do students' IM styles and tactics influence business students' participation grades at Time1 and at Time2? And which are effective and which not? (c) Do business students' IM styles and tactics change from Time1 to Time2?

\footnotetext{
10 The university in which the research has been conducted expects students to participate actively during tutorial sessions. Tutorial sessions consist of up to 14 students, take place twice a week and last up to two hours. A teacher invigilates the tutorial sessions and is responsible for grading students' participation which is generally a component in the overall grading of a course.
} 


\section{CHAPTER 6}

\section{IM styles and tactics (over time)}

Regarding the style of presenting a favorable image, one can either present oneself in an authentic way or display unreal characteristics (Goffman, 1959). In most cases IM is based on actual and accurate information (Schlenker et al., 1992) but people also utilize IM behavior that produce untrue and fabricated images just to meet the attempted goal (Leary, 1995). Thereby the IM styles can vary in the extent to which the behavior is authentic or played as, although they are seen to represent an individual tendency to perform IM in a particular way.

The specificity of the goal and the audience, as well as its short-term nature, characterizes IM behavior as tactical (Tedeschi et al., 1984). In this study, we focus on five well-researched IM tactics: ingratiation, self-promotion, exemplification, supplication and intimidation. These are behaviors used to make specific impressions on others as being likable, competent, moral, in need of assistance or intimidating (Bolino et al., 1999; Jones et al., 1982; Schlenker, 1980).

In the following we will portray each IM style and tactic in more detail and explore hypothesized relationships between them and students' participation grades. We start with a description why time could have an additional influence on proposed associations.

\section{IM over time}

According to Thorndike (1920) particular characteristics of a person can create a general impression that overtakes further impressions of that person. A typical example for the so-called halo effect would be a teacher who assumes that a friendly student will also show good performance.

However, general impressions are likely to be a stronger basis of performance evaluations when the evaluator is unfamiliar with the individual (Kozlowski \& Kirsch, 1987) and misses performance-relevant information (Thorndike \& Hagen, 1961) as at the beginning of an interaction. At the end of a course a teacher has more proficiency related knowledge on the student and therefore might not be so susceptible for IM behavior.

As a consequence, it can be expected that the various IM styles and tactics may differ in their effectiveness over time. In this study, we hypothesize that a relation between IM and business students' participation grades at Time1 (beginning of course) is likely; however, that association might not persist over time; that it is not existent at Time2 (end of course) anymore. This aspect will be covered by all hypotheses following below. 


\section{IM styles}

In our view authentic acting and role acting IM styles are distinct and independent IM styles representing relatively stable, individual-difference variables.

\section{Authentic acting IM style}

In case that an individual tends to show to the audience a portrait that he or she honestly believes is true the individual has an authentic acting IM style. Hereby, the individual does not hide from nor plays for the audience but rather tries to impress the other with presenting actual facets of him- or herself.

There is evidence that IM has an effect on work outcomes such as performance ratings (Ferris et al., 1994; Wayne et al., 1990; Wayne et al., 1995). However, as already mentioned in Chapter 5, displays have to be perceived as sincere (Ashforth et al., 1993; Hochschild, 1983; Rafaeli et al., 1987). Taking into account what was said about time, we propose the following hypothesis:

Hypothesis 1a: Students' use of an authentic acting IM style has a positive relationship with their participation grade at Time 1 but not at Time2.

Role acting IM style

In contrast to an authentic acting IM style, a role acting IM style is defined as a tendency to influence other's impressions by deflecting from what the individual believes to be the truth. It is employed to meet the social requirements of a specific situation independent of the real characteristics of the person employing IM.

As also discussed in the previous chapter, quite the opposite outcomes are possible for a role acting IM style in comparison to an authentic acting IM style. When the audience recognizes that the impression manager plays to them and that his or her behavior is not based on the truth negative consequences might occur (Grove et al., 1989). The results of the preceding study conform to this in that a role acting IM style was found to relate negatively with consultant's performance. Hence, while students employ a role acting IM style because they attempt advantageous outcomes in interaction with their teacher, negative results might occur. That leads us to: 


\section{CHAPTER 6}

Hypothesis 1b: Students' use of a role acting IM style has a negative relationship with their participation grade at Time1 but not at Time2.

\section{IM tactics}

Tactical IM addresses a specific target audience - here the teachers - and is intended at achieving concrete, short term goals (Rafaeli \& Harness, 2002). According to the Jones and Pittman taxonomy (1982) individuals typically use five IM tactics. These are: (1) ingratiation, where they use flattery or favor-doing in an attempt to be seen as likable; (2) self-promotion, where they play up their abilities or accomplishments to be seen as competent; (3) exemplification, where they go above and beyond the call of duty to appear dedicated; (4) supplication, where they advertise their shortcomings in an attempt to be viewed as needy and (5) intimidation, where they seek to appear intimidating or threatening to have others view them as dangerous. We emphasize that IM tactics can be used independently of IM styles since true but also untrue events can serve as the basis for IM tactics.

\section{Ingratiation}

Ingratiation is an IM tactic employed by individuals in an attempt to make a positive impression on others (Turnley et al., 2001). Individuals using ingratiation want to be perceived as likable. Gordon (1996) found in a meta-analytic investigation of ingratiation studies that ingratiation was positively related to performance evaluations. Watt (1993) discovered that a higher frequency of ingratiation lead to a more favorable judgment by supervisors, employees were perceived as more competent, motivated, possessing greater leadership ability and promotion potential. As such, one would expect that business students use ingratiation in order to make a likeable impression on their teachers and thereby influence them to evaluate them more positively. As a result, we hypothesize:

Hypothesis 2a: Students' use of ingratiation has a positive relationship with their participation grade at Time1 but not at Time2.

\section{Self-promotion}

Self-promotion is also utilized by individuals to display a positive image to others, particularly a competent one. In the context of our study, it is evident that students want to make a competent 
impression to receive better participation grades. Self-enhancing strategies that convey to others that one is competent may work best in situations in which one desires to impress a person in a position of authority such as teachers. Evidence is among others found in studies on employment interviews (Gilmore \& Ferris, 1989; Kacmar et al., 1992; Kristof-Brown, Barrick, \& Franke, 2002; McFarland, 2003). Consequently, we propose the following:

Hypothesis 2b: Students' use of self-promotion has a positive relationship with their participation grade at Time1 but not at Time2.

\section{Exemplification}

Exemplification tactics are aimed at making the individual who uses them appear hardworking (Jones et al., 1982; Turnley et al., 2001). Jagacinski and Nicolls (1990) reported that when college students were instructed to make a positive impression on a hypothetical instructor, they preferred to convey the impression that they worked hard rather than creating the impression that they did not need to work hard because of high ability. Students who use exemplification tactics were found to be perceived as highly dedicated (Turnley et al., 2001). Therefore, it is expected that students who use exemplification may receive better participation grades.

Hypothesis 2c: Students' use of exemplification has a positive relationship with their participation grade at Time 1 but not at Time2.

\section{Supplication}

With supplication an individual advertises personal weakness and tries to be perceived as needy to get sympathy and help from others. By attributing failure to low ability and thus eliciting sympathy, students may be able to receive supportive reactions instead of punishment (Juvonen et al., 1993a). However, the desired image is likely to have negative repercussions (Turnley et al., 2001). Although students may gain assistance from the teachers by appearing needy they may also be seen less favorably as a result of this kind of behavior. As a result, we hypothesize that:

Hypothesis 2d: Students' use of supplication has a negative relationship with their participation grade at Time1 but not at Time2. 


\section{CHAPTER 6}

\section{Intimidation}

Intimidation is an IM tactic by which individuals let others know that they can make things difficult for them if they are pushed too far, deal aggressively with individuals who get in their way, or use forceful behavior to get others to behave appropriately (Jones et al., 1982). Here individuals want to be perceived as tenacious and forceful. Intimidation is most likely to occur in non voluntary relationships such as supervisor and subordinate, families or student and teacher (Jones et al., 1982). As it is for supplication, intimidation is also an IM tactic for which the desired images is likely to have negative implications (Turnley et al., 2001). Thus, although students may achieve their own ends through intimidation, they may also be seen less beneficially due to this behavior and thereby negatively impact on their participation grades. Accordingly, we propose that:

Hypothesis 2e: Students' use of intimidation has a negative relationship with their participation grade at Time1 but not at Time2.

\section{METHOD}

\section{Participants}

The participants in this study were on the one hand (1) business students enrolled in nine regularlyscheduled business courses at a university in the Netherlands and on the other hand (2) teachers who taught these students over a period of seven weeks. The teachers served as raters of their students. The numbers of students participating in the two rating periods were 875 and 818 respectively, and the number of teachers was 26. Finally, we received data at both times of 726 students situated in 86 groups across nine different courses. The students were at the junior (31\%) and the senior levels $(69 \%)$ in their studies. 44 percent of the students were female and 56 percent were male students. Most students were German (42\%), followed by Dutch students (37.5\%), and 20.5 percent had another national background. On average they had an exam grade ${ }^{11}$ for the attended courses of 6.9 with a standard deviation of 1.5 .

The main reasons to use business students instead of consultants as the participating group in this study were the wider possibilities given with this sample (extension motive). As we wanted to involve audience to see whether IM has the attempted outcome, but at the same time consultants' clients are a difficult group to study, we asked business students instead of consultants to participate

${ }^{11}$ Grades can lie between 1 and 10, with 10 indicating the highest possible grade. 
in our last study. Further, in spite of general differences, the consultant-client and the student-teacher relationships are similar in many facets. For instance, the consultancy and the university setting can be described as places for knowledge exchange. Both relationships are of temporary nature and imply a clear definition of the terms, content, and duration of the relationship. A requisite for IM likelihood existing in both relationships is dependency (Leary, 1995); based on the fact that teachers and clients retain control over the reward process. For example, teachers grade the students for their active participation in class and clients have the capacity to hire and fire the consultant. Moreover, the consultant is dependent on repeat business; therefore the consultant's position is illustrated as a subordinate position in reference to the client (Maister, 1993). Research has shown that lower-status actors often employ IM to influence higher status actors (Gardner \& Martinko, 1988; Leary \& Kowalski, 1990; Yukl \& Tracey, 1992). In reward terms the student-teacher relationship can also be compared to the one of consultants and clients, since consultants receive money and students a grade as a compensation for their performance - "grades are tokens of exchange that are earned like currency" (Beatty, 2004: 188). Finally, both consultants' and students' IM are subject to the corrective role of performance and their audience. That is, they depend on the willingness of the others to believe what is performed and to appreciate the impression they make. By investigating student-teacher relationships, we are better capable to measure IM from the impression manager and from the audience side and additionally research IM over time.

\section{Procedure}

Over the seven-week period of a course, two questionnaires were distributed to students and teachers. Students and teachers completed the questionnaires in week 2 (Time1) and in week 7 (Time2). Both surveys were administered to students in their classrooms. First, they were informed that participating in the study was voluntary and that the information would be kept confidential. In their questionnaires they were asked to indicate their IM styles and tactics used to make a particular impression on their teachers. The retrieval of demographic items was done by the initial survey. A student from the group delivered the filled-in questionnaires in closed envelops to the author of this study. The effect of students' reported IM styles and tactics was measured by asking teachers to fill in a survey with evaluations of their students' participation in tutorial meetings. Audience's view of IM is crucial to identify if IM has the desired effect. Students whose teacher did not fill out one of the two surveys were dropped form the study. 


\section{CHAPTER 6}

\section{Scales}

Most scales were measured on 5-point Likert scales ranging from 1 (totally disagree) to 5 (totally agree). To be consistent with previous work on IM (Kumar et al., 1991; McFarland, 2003; Wayne et al., 1990), we used different terms for IM tactics to take into account how frequent each tactic is used. Therefore the Likert scales range from 1 (never) to 5 (very often). The items in each scale were summed and then averaged to arrive at an overall value for the scale. Higher scores represent higher levels of each of the constructs. All scales are given in the appendix to the chapter (Appendix E).

\section{Scales for students}

MIMSS (Maastricht Impression Management Styles Scales)

Authentic acting IM style

The seven-item scale developed and tested in the last study (Chapter $5 ; \alpha=.78$ ) is used to tap the authentic acting IM style of students. Items are adapted to the student-teacher situation. A sample item is: "My behavior towards the teacher is genuine." With a Cronbach's alpha of .64 at Time1 and of .62 at Time 2 the scale demonstrated low, but acceptable internal consistency. In the present study, internal test-retest reliability after five weeks was .6, showing that the authentic acting IM style remains rather consistent over time.

Role acting IM style

The eight item scale from the previous study (Chapter $5 ; \alpha=.80)$ is used to measure a role acting IM style. It is adapted to the student-teacher context. A sample item is: "What I say or do as a student is not necessarily a reflection of what I really think or feel." The reliability based on internal consistency was confirmed with a Cronbach's alpha of .72 at Time1 and of .76 at Time2. Test-retest reliability showed consistency with a value of 64 .

\section{IM tactics}

Bolino and Turnley's (1999) 23 item measure of IM was used to capture students' usage of five IM tactics. The advantages of this scale are that it is well-developed and representative of the full field of IM tactics. The items were reworded to make them more amenable for students. The items for all 
five of the IM tactics used the same opening phrase, "Please indicate how often you perform the following behaviors in order to make a particular impression on the teacher." Ingratiation was measured with four items (Cronbach's alpha at Time1=.66; Time2=.68). A sample behavior is "I do personal favors for the teacher to show him/ her that I am friendly." Self-promotion was also measured with four items (Cronbach's alpha at Time1=.82; Time2=.84). For example, with "I make the teacher aware of my talents or qualifications." We measured exemplification with five items (Cronbach's alpha at Time1=.70; Time2=.76). A sample item is "I take on more than my fair share of course work so that the teacher will see that I am dedicated." Supplication was measured with five items (Cronbach's alpha at Time1=.81; Time2=.84). Such as, " $I$ act like I know less than I really do so that he teacher will help me out." Intimidation was also measured with five items (Cronbach's alpha at Time1=.80; Time2=.83). A sample behavior is "I use intimidation to get the teacher to do bis/ her work."

\section{Control variables}

Participants voluntarily indicated their gender, nationality, and educational experience. We used all three as control variables based on their ability to influence individual's IM and to account for variance in teacher's impressions of his or her students (Bolino et al., 2003a; Juvonen \& Weiner, 1993b; Lalwani, Shavitt, \& Johnson, 2006; Thacker et al., 1995). The inclusion of gender is based on recognized differences between women and men in their ways and effectiveness in managing others' impressions (Deaux \& Taynor, 1973; Gardner et al., 1988; Rudman, 1998; Singh et al., 2001). With regard to national background, Lalwani and others (2006) found that European Americans in comparison with Asian Americans scored lower on IM which shows that the national background of a person can have an influence on how he or she utilizes IM and eventually also on how it is perceived by others. Further, we asked students to indicate their study year. Young students often want to gratify their teachers; older students focus more on pleasing their peers (Juvonen et al., 1993b). As a result, there might be differences in IM employment and effectiveness for junior students in comparison to senior students. Another control variable is the exam grade of participating students. The reason to include this variable is that students' participation grades are with the utmost probability not only influenced by students' IM behavior but also by their course comprehension which among other things exhibits in students' exam grade. 


\section{CHAPTER 6}

\section{Scales for teachers}

Participation grade

Teachers were asked to indicate a participation grade for their students at Time1 and Time2 - being the final participation grade for the course.

\section{RESULTS}

\section{Descriptive statistics}

The means and standard deviations for each IM style and tactic at Time1 and at Time2 are provided in Table 1. Our first research question is: Which IM styles and tactics are mostly applied by business students in order to influence their teachers? At both times, an authentic acting IM style was the predominant IM style and self-promotion the most used IM tactic students reported in order to influence their teachers. In descending order the most employed IM tactics were: self-promotion, exemplification, ingratiation, intimidation and supplication.

Table 1: Means and standard deviations of the IM styles and tactics at Time1 (beginning of a course) and Time2 (end of a course)

\begin{tabular}{|c|c|c|c|c|}
\hline \multirow[t]{2}{*}{ VARIABLE } & \multicolumn{2}{|c|}{$\begin{array}{c}\text { TIME1 } \\
\text { (BEGINNING OF A COURSE) }\end{array}$} & \multicolumn{2}{|c|}{$\begin{array}{c}\text { TIME2 } \\
\text { (END OF A COURSE) }\end{array}$} \\
\hline & $\mathbf{M}$ & s.d. & $\mathbf{M}$ & s.d. \\
\hline \multicolumn{5}{|l|}{ IM STYLES } \\
\hline Authentic acting IM style & 3.98 & 0.63 & 4.01 & 0.63 \\
\hline Role acting IM style & 2.20 & 0.64 & 2.19 & 0.65 \\
\hline \multicolumn{5}{|l|}{ IM TACTICS } \\
\hline Ingratiation & 1.87 & 0.68 & 1.92 & 0.70 \\
\hline Self-promotion & 2.76 & 0.81 & 2.74 & 0.80 \\
\hline Exemplification & 2.42 & 0.72 & 2.58 & 0.73 \\
\hline Supplication & 1.58 & 0.60 & 1.62 & 0.63 \\
\hline Intimidation & 1.61 & 0.62 & 1.66 & 0.66 \\
\hline
\end{tabular}

Note. $\mathrm{N}=726$. Bold: highest mean.

\section{Re-test reliabilities}

Table 2 presents comparable same-form correlations between Time1 and Time2. The results suggest that styles and tactics were equally stable with levels of $.55-.69$ over the 7 -week period. 
Table 2: Re-test reliabilities for the IM styles and IM tactics scales

\begin{tabular}{lc}
\hline IM STYLES AND TACTICS & $\begin{array}{c}\text { FROM TIME1 (BEGINNING OF A COURSE) } \\
\text { TO TIME2 (END OF A COURSE) }\end{array}$ \\
\hline Authentic acting IM style & .59 \\
Role acting IM style & .64 \\
Ingratiation & .55 \\
Self-promotion & .69 \\
Exemplification & .63 \\
Supplication & .61 \\
Intimidation & .58 \\
\hline
\end{tabular}

Note. $\mathrm{N}=726$. All correlation coefficients are significantly different from 0 at $\mathrm{p}<.01$.

\section{Correlations}

Correlations among the variables were examined separately for Time1 and Time2. As can be seen in Table 3, the hypothesized associations for an authentic acting IM style and a role acting IM style were generally supported at Time1 but not at Time2. That is, an authentic acting IM style had a positive correlation and a role acting IM style had a negative correlation with students' participation grades. For the five IM tactics, only self-promotion (positive) and supplication (negative) had a significant correlation with students' participation grades at Time1 but again not at Time2.

Moreover, in order to examine the unique contribution of the IM styles and tactics to the prediction of students' participation grades, we calculated semi-partial correlations for each independent variable controlling for students' exam grades. We used students' exam grades as an objective measure of their course comprehension which most likely has a high influence on students' participation performance in tutorials. In Table 3 the correlations and semi-partial correlations are displayed. Squared semi-partial correlations, reflecting the percentage of unique variance in students' participation grades that is predicted when the contributions of the exam grade have been partialled out showed that when taken separately neither IM styles nor IM tactics made significant contributions to students' participation grades. 


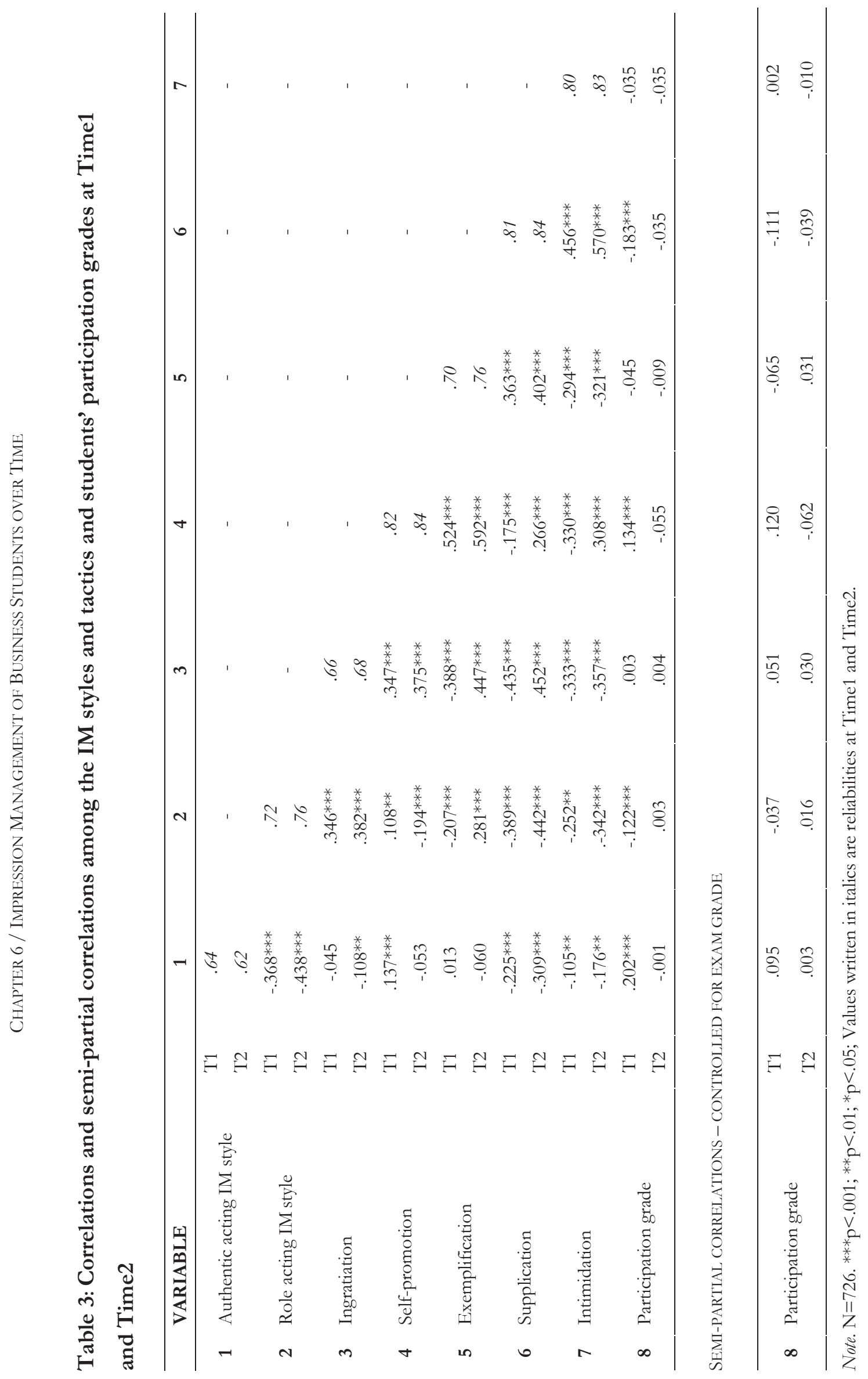




\section{Regression Analyses}

Do students' IM styles and tactics influence their participation grades at Time1 and at Time2? And which are effective and which not? In order to answer these questions and to test the hypotheses hierarchical regressions were computed for students' participation grades at Time1 and at Time2.

As a first step the control variables were entered. For Time1 the analysis indicated that the control variables - educational experience, student nationality and exam grade - significantly explained unique variance $\left(\mathrm{R}^{2}=.068, \Delta \mathrm{R}^{2}=.064, \mathrm{~F}=15.770, p=.000\right)$. It showed that students' nationality had a significant relation with students' participation grade. Specifically, German students had better participation grades than students with other nationalities $(\beta=.084, \mathrm{p}<.05)$. Moreover, educational experience showed a relation with the dependent variable. Junior students appeared to receive lower participation grades than their senior student colleagues $(\beta=-.118, \mathrm{p}<.000)$. Finally, the results indicated that the exam grade of a student had a positive relationship with student's participation grade $(\beta=.167, \mathrm{p}<.000)$ which underlines our argumentation given before in the thesis.

In the second step all independent variables - being IM styles (authentic acting and role acting IM styles) and IM tactics (ingratiation, self-promotion, exemplification, supplication and intimidation) - were entered in the regression and significantly added to model explanation $\left(\mathrm{R}^{2}=.124\right.$, $\left.\Delta \mathrm{R}^{2}=.113, F=11.053, p=.000\right)$.

For Time2, the analysis showed a different picture. Neither the control variables significantly explained unique variance $\left(\mathrm{R}^{2}=.004, \Delta \mathrm{R}^{2}=-.001, F=.790, p=.532\right)$ nor the independent variables entered in the second step $\left(\mathrm{R}^{2}=.010, \Delta \mathrm{R}^{2}=-.004, F=.692, p=.747\right)$.

With regard to the hypotheses, it can be seen in Table 4 that the result for Hypothesis 1a was in the expected direction and significant. This hypothesis was supported in that an authentic acting IM style had a positive relation with student's participation grade at Time1 and not at Time2 ( $\beta$ $=.107, \mathrm{p}<.01)$. In Hypothesis $1 \mathrm{~b}$ we expected that a role acting IM style has a contrary sign that is a negative relationship with student's participation grade. The result was in the projected direction, however not significant. Therefore, Hypothesis $1 \mathrm{~b}$ was not supported. Concerning IM tactics, we hypothesized in Hypothesis 2a, that ingratiation relates positively to student's participation grade, it was positive however not significant. Self-promotion had a positive significant relationship with the dependent variable as expected at Time1 and not at Time2 $(\beta=.127, \mathrm{p}<.01)$. Therefore, Hypothesis $2 \mathrm{~b}$ was supported. In Hypothesis $2 \mathrm{c}$ we stated that exemplification relates positively to student's participation grade. This hypothesis was not supported. In Hypothesis $2 \mathrm{~d}$, supplication is assumed to 


\section{CHAPTER 6}

negatively associate with students' performance measured in their participation grading and it significantly did at Time1 $(\beta=.-129, \mathrm{p}<.01)$ but not at Time2. Consequently, Hypothesis $2 \mathrm{~d}$ was supported. Finally, intimidation was not found to have a negative relationship with student's participation grade. Therefore, Hypothesis 2e was not supported.

Table 4: Hierarchical regression analyses

\begin{tabular}{|c|c|c|}
\hline & \multicolumn{2}{|c|}{ PARTICIPATION GRADE } \\
\hline & TIME1 & TIME2 \\
\hline \multicolumn{3}{|l|}{ CONTROLS } \\
\hline Gender (Female/Male) & .040 & -.037 \\
\hline Nationality (German/Dutch/Other) & $.084 *$ & -.019 \\
\hline Educational experience (Junior/Senior) & $-.118 * * *$ & -.016 \\
\hline Exam grade & $.167 * * *$ & -.033 \\
\hline \multicolumn{3}{|l|}{ IM STYLES } \\
\hline Authentic acting IM Style (H1a) $\checkmark$ & $.107 * *$ & .001 \\
\hline Role acting IM Style (H1b) & $\underline{-.052}$ & .021 \\
\hline \multicolumn{3}{|l|}{ IM TACTICS } \\
\hline Ingratiation $(\mathrm{H} 2 \mathrm{a})$ & .066 & .040 \\
\hline Self-promotion (H2b) $\checkmark$ & $.127 * *$ & -.077 \\
\hline Exemplification (H2c) & -.067 & .039 \\
\hline Supplication (H2d) $\checkmark$ & $\underline{-.129 * *}$ & $\underline{-.053}$ \\
\hline Intimidation $(\mathrm{H} 2 \mathrm{e})$ & .002 & -.005 \\
\hline $\mathrm{R}^{2}$ for total equation & .124 & .010 \\
\hline F for total equation & $11.053 * * *$ & .692 \\
\hline
\end{tabular}

Note. $\mathrm{N}=726 .{ }^{* * *} \mathrm{p}<.001 .{ }^{* *} \mathrm{p}<.01 .{ }^{*} \mathrm{p}<.05$. Values for independent variables are $\beta$ coefficients, with all variables included in the regression equation. Underlined coefficients indicate relationships in the hypothesized direction.

To summarize, it showed that some of students' IM styles and tactics had a relationship with students' participation grades at Time1 but not at Time2. These are specifically the authentic acting IM style and the two IM tactics self-promotion and supplication. An authentic acting IM style and self-promotion related positively to students' participation grades and supplication showed a negative relationship. 


\section{Multiple analysis of variance - repeated measures}

Do students' IM styles and tactics change from Time1 to Time2? In order to discover a change in IM use over time and to acknowledge potential associations with various demographic variables the study went on with a multiple analysis of variance (MANOVA) using a 2 (Time: 1 and 2) x 2 (gender: female and male) x 2 (study experience: junior and senior) x 3 (nationality: German, Dutch, and other) design with time as a repeated variable and gender, study experience, and nationality as between-subjects factors. Student's exam grade was used as a covariate. IM styles (authentic acting and role acting) and tactics (ingratiation, self-promotion, exemplification, supplication, and intimidation) served as dependent variables.

The results revealed no main effect of the time variable within-subjects $(F=.442 ; \mathrm{p}=.876)$, effect size (partial eta squared) $=.004$. That is, neither IM styles nor IM tactics did change systematically over time that is from the beginning till the end of a course.

The between-groups test indicated that the variables gender, educational experience, nationality and student's exam grade all had a significant impact. Hence, they all seemed to influence student's IM. With IM styles and tactics being the dependent variables, the main effect of gender (female versus male) was significant $(\mathrm{F}=8.1, p=0.000$ ), effect size (partial eta squared) $=.071$. The main effect of educational experience (junior versus senior student) was also significant ( $F=3.111$, $p=0.003$ ), effect size (partial eta squared) $=.028$. The same goes for students' nationality (German, Dutch, and others) $(\mathrm{F}=4.999, p=0.000)$, effect size (partial eta squared $)=.045$ and for students' exam grades $(\mathrm{F}=2.664, p=0.01)$ effect size (partial eta squared $)=.024$. According to the criteria proposed by Cohen (1988) effect sizes ranging from .059 to .137 are considered moderate, and those greater than .137 are regarded as large. Thus, gender comparatively appeared to have the highest impact on student's IM. The tests of between-subjects effects in combination with estimated marginal means (see Table 5) showed that female students had a low role acting IM style in comparison to their male student colleagues. Further they used less ingratiation, less self-promotion, less supplication, and less intimidation in order to influence the impressions of their teachers. Hence, in general, they seemed to employ IM tactics to a less frequent amount than male students do. In regard to educational experience, we found that junior students had a lower authentic acting IM style than senior students and used more supplication and intimidation than seniors. Moreover, Dutch students in comparison to German students and students from other nationalities performed most authentically in their IM and applied ingratiation on the most frequent basis. German students employed mostly the self-promotion and the intimidation tactic and less the supplication tactic in 


\section{CHAPTER 6}

comparison to other nationalities in our sample. Further, students with high exam grades - between 8.1 and 10 - had rather an authentic acting IM style than students with lower grades and students who failed the course with grades between 0 and 5.4 employed in comparison to students with better grades mostly the IM tactic supplication.

Table 5: Significant results of tests between-subjects effects and estimated marginal means

\begin{tabular}{|c|c|c|c|c|c|c|}
\hline \multirow{2}{*}{ SOURCE } & \multirow{2}{*}{ MEASURE } & \multirow{2}{*}{$\mathbf{F}$} & \multirow{2}{*}{ Sig. } & \multicolumn{3}{|c|}{ MEAN } \\
\hline & & & & & FEMALE & MALE \\
\hline \multirow{5}{*}{ GENDER } & Role acting IM style & 16.001 & .000 & & 16.933 & 18.280 \\
\hline & Ingratiation & 15.145 & .000 & & 7.175 & 7.843 \\
\hline & Self-Promotion & 5.401 & .020 & & 10.535 & 11.037 \\
\hline & Supplication & 27.569 & .000 & & 7.572 & 8.591 \\
\hline & Intimidation & 37.502 & .000 & & 7.511 & 8.737 \\
\hline \multirow{2}{*}{ SOURCE } & \multirow{2}{*}{ MEASURE } & \multirow{2}{*}{ F } & \multirow{2}{*}{ Sig. } & \multicolumn{3}{|c|}{ MEAN } \\
\hline & & & & & JUNIOR & SENIOR \\
\hline \multirow{3}{*}{$\begin{array}{l}\text { EDUCATIONAL } \\
\text { EXPERIENCE }\end{array}$} & Authentic acting IM style & 10.650 & .001 & & 27.304 & 28.287 \\
\hline & Supplication & 11.281 & .001 & & 8.427 & 7.736 \\
\hline & Intimidation & 4.076 & .044 & & 8.338 & 7.910 \\
\hline \multirow{2}{*}{ SOURCE } & \multirow{2}{*}{ MEASURE } & \multirow{2}{*}{$\mathbf{F}$} & \multirow{2}{*}{ Sig. } & \multicolumn{3}{|c|}{ MEAN } \\
\hline & & & & GERMAN & DUTCH & OTHER \\
\hline \multirow{5}{*}{ NATIONALITY } & Authentic acting IM style & 9.021 & .000 & 27.600 & 28.647 & 27.140 \\
\hline & Ingratiation & 3.241 & .040 & 7.476 & 7.815 & 7.237 \\
\hline & Self-promotion & 5.777 & .003 & 11.276 & 10.801 & 10.281 \\
\hline & Supplication & 3.086 & .046 & 7.746 & 8.177 & 8.321 \\
\hline & Intimidation & 3.186 & .042 & 8.416 & 7.855 & 8.102 \\
\hline \multirow{2}{*}{ SOURCE } & \multirow{2}{*}{ MEASURE } & \multirow{2}{*}{ F } & \multirow{2}{*}{ Sig. } & \multicolumn{3}{|c|}{ MEAN } \\
\hline & & & & \multicolumn{3}{|c|}{ GRADES } \\
\hline \multirow{3}{*}{ EXAM GRADE } & \multirow{3}{*}{$\begin{array}{l}\text { Authentic acting IM style } \\
\text { Supplication }\end{array}$} & & & $0-5.4$ & $5.5-8$ & $8.1-10$ \\
\hline & & 3.636 & .027 & 27.4851 & 27.9191 & 28.8492 \\
\hline & & 4.450 & .012 & 8.5374 & 8.0436 & 7.4048 \\
\hline
\end{tabular}

Note. $\mathrm{N}=726$. Bold: Highest mean.

Apart from the general steadiness of IM styles and tactics over the period of a course, there was a significant interaction between the two variables time and study year $(F=2.181 ; \mathrm{p}=.034)$. The withinsubject test indicated that the interaction of time and study year for a role acting IM style was significant $(\mathrm{F}=4.466 ; \mathrm{p}=.035)$. Senior students were decreasing (Mean: Time1=17.581;

Time2=17.173) and junior students were increasing their role acting IM style over the period of a 
course (Mean: Time1=17.678; Time2=17.994). Furthermore, there was a significant interaction of time, study year and self-promotion $(\mathrm{F}=5.316 ; \mathrm{p}=.021)$. That is, senior students were decreasing (Mean: Time1=11.048; Time2=10.749) and junior students were increasing their self-promotion over time (Mean: Time1=10.597; Time2=10.751).

\section{DISCUSSION}

Overall, this study was undertaken to investigate business students' IM styles and tactics over time. More precisely, we aimed (1) to identify the IM styles and tactics mostly applied by business students to influence their teachers, (2) to see whether these are related to teachers' evaluations of students' participation at the beginning and at the end of a shared course, and (3) to find out whether business students' IM differs over time.

Some important findings have emerged from our research. First, we learned that the authentic acting IM style and the IM tactic self-promotion are the most predominant IM behaviors in our sample of business students. The results were not surprising because self-promotion has explicitly the goal to express the image of a competent individual and is therefore most promising in persuading a teacher from one's competence. Further, when an individual's claims do not match his or her abilities, the student may actually create a very bad impression. This speaks for the relevance of an authentic acting IM style in the context of student-teacher interactions, in particular over time. These two IM behaviors in addition the IM tactic of supplication had also significant relationships with students' performance ratings. In contrast to the authentic acting IM style and self-promotion, supplication, evoked, as expected, negative impressions resulting in worse participation ratings.

Moreover, although our findings showed that business students' use of certain IM behaviors influence performance ratings given by their teachers early in a course, this was not given at a later stage. This result is in accordance with theory saying that IM tactics are more likely to affect shortterm outcomes (Tedeschi et al., 1984). Another addition to current knowledge on IM is the finding that students' use of IM does not change over the period of a course. In the following section, we describe a reason why this could be the case. Besides, we showed that certain demographics (gender, nationality, educational experience, and course comprehension) play an important role in business students' IM use.

In general, results of the study point to the importance of examining IM in educational settings and over time. Even though IM has no relation anymore at the end of a course period, it 


\section{CHAPTER 6}

seems important to take IM as a part of performance into account, given its influence on fair performance evaluations i.e. in educational settings.

\section{LIMITATIONS AND FUTURE RESEARCH}

A number of limitations in the current study should be acknowledged. First, despite measuring IM at different times, we conceptualized it in term of static instead of dynamic variables. That is, we demonstrated that there are differences in IM outcome measured at the beginning of a course and at the end of a course, but abandoned the possibility to investigate a "true" process-oriented view of IM. As a result, the results presented here were to some degree correlational and cannot be taken to suggest any causal relations among the variables. However, since students were not informed on their participation grades beforehand, neither before filling in the questionnaires at Time1 nor at Time2, no reversed causality can be assumed. Nevertheless, it would be useful to examine more time periods than were covered here to learn more about the dynamic process of IM.

The generalizability of our results is limited to the characteristics of the sample. This was a study of business students studying at an international university and the focus was on studentteacher relationships. Consequently, future research should replicate our findings with using the same design of the study but with other participants, preferably with consultants and clients.

Further, in this study we have a special situation due to examining student-teacher interactions within group settings. Meaning when students try to influence their teachers, their behavior simultaneously can have an effect on their student colleagues' impressions. This could be a reason why business students' IM styles and tactics did not change over time; there is a second audience which will prove and evaluate their behavior i.e. on its consistency. This issue has not been studied much and needs further attention. For example, future research should include students' colleagues when assessing IM and its outcomes and students should reveal with which IM behavior they try to influence their teachers and with which their student colleagues.

\section{CONCLUSION}

The results of the study provide us with knowledge about IM use and effectiveness in the perception of the relevant IM audience and over time. Results demonstrate that an authentic acting IM style and the IM tactic self-promotion can be effective in a positive and supplication in a negative way - that is increasing or decreasing performance evaluations given by the targets of IM. Moreover, we learned 
that behavior tendencies in IM seem to stay constant over time but not their effectiveness, which diminishes after some time. Further, characteristics as gender, educational experience, nationality and exam grading appear to have a significant influence on IM use.

Altogether, these results demonstrate that IM is an effective strategy to achieve goals in an educational context; however both positive and negative outcomes are possible. Nevertheless, results also show that ultimately the performance rating of a student is not based on the impressions a teacher has from him or her - which may be reassuring for many in the end. 
While fewer and fewer people today are engaged in the production of foodstuffs and even fewer in manufacturing, more and more ... are engaged in generating nothing that is tangible at all, indeed, in generating services, resulting in an entirely new game - one in which man no longer sutures his notion of competence in his struggle with things, but now and in the near future in his ability to impress upon people his or her worth.

- Mark Wexler

"Impression management consists of any behavior by a person that has the purpose of controlling or manipulating the attributions and impressions formed of that person by others" (Tedeschi, 1981: 3). An individual's behavior in interaction with others is described as performance constructed to provide the audience with impressions the actor wants them to develop. While the basics of IM are of a generic nature, the focus of this thesis was on IM in a specific type of service setting: consultancy. Although the literature acknowledges that IM is implied in consultancy, research devoted to a more precise articulation of IM and how it operates in consultancy seemed warranted.

\section{Subject matter and findings}

Overall, this thesis aimed to extend current knowledge on IM by presenting research on IM in organizations, especially on interaction between consultants and clients. Over and above we expect that insights gained are of relevance for IM in general as well. The specific objectives of this $\mathrm{PhD}$ project were:

1. to explain variations in IM performance levels,

2. to identify behavior tendencies in IM,

3. to determine the role of IM competence, and

4. to understand IM processes over time. 


\section{CHAPTER 7}

In the first part of this final chapter we summarize the findings and insights of the overall project. In doing so, we refer to the four objectives and integrate them in two related theoretical perspectives on IM taken in this thesis: the differential and the temporal perspective on IM. The differential perspective concentrates on explaining inter-individual differences, whereas the main focus of the temporal perspective is on understanding intra-individual variations in IM performance. In the second part of the chapter, we describe the main limitation of the current thesis and what future research should consider in attaining an integral picture of IM. The chapter concludes with practical implications of IM in consultancy.

\section{TWO PERSPECTIVES ON IM}

As shown in Figure 1, two perspectives on IM are taken in this thesis to discover and describe factors inside the individual affecting IM performance. The differential perspective focuses mainly on the identification of individual differences in personality (self-monitoring), demographics (age, gender, nationality, job tenure, educational experience, consultancy type, managerial function), IM competence, and their relationships to behavior tendencies in IM (IM styles and tactics) and looks at both to understand why some individuals are successful in their IM attempts and others not. The temporal view on IM includes self-regulation and IM as a process and helps to explain variations over time. In contrast to the differential perspective which has received ample attention in the IM literature, the temporal approach has been given much less consideration. "Most research methodology in the behavioral sciences employs interindividual analyses, which provide information about the state of affairs of the population. However, (...) such analyses do not provided information for, and cannot be applied at, the level of the individual" (Molenaar \& Campbell, 2009: 112). For example, a differential approach helps to distinguish successful from unsuccessful impression managers; however, why even individuals who are generally doing well in their IM attempts fail at times remains unresolved. Further, although differential IM conditions can be used to identify and select good impression managers, they cannot be used to influence IM directly. Here, a consideration of IM competence as well as a process view can help to recognize possibilities to improve general IM effectiveness. Thus, we regard the two approaches as complementary with respect to IM performance, and by integrating them a more complete and realistic model of IM and what determines its performance from inside the individual can be formulated. To integrate the two perspectives in one model, we used the simplest form of Cattell's (1966) well-known data box. It provides an analytical framework across variables, individuals, and time. 


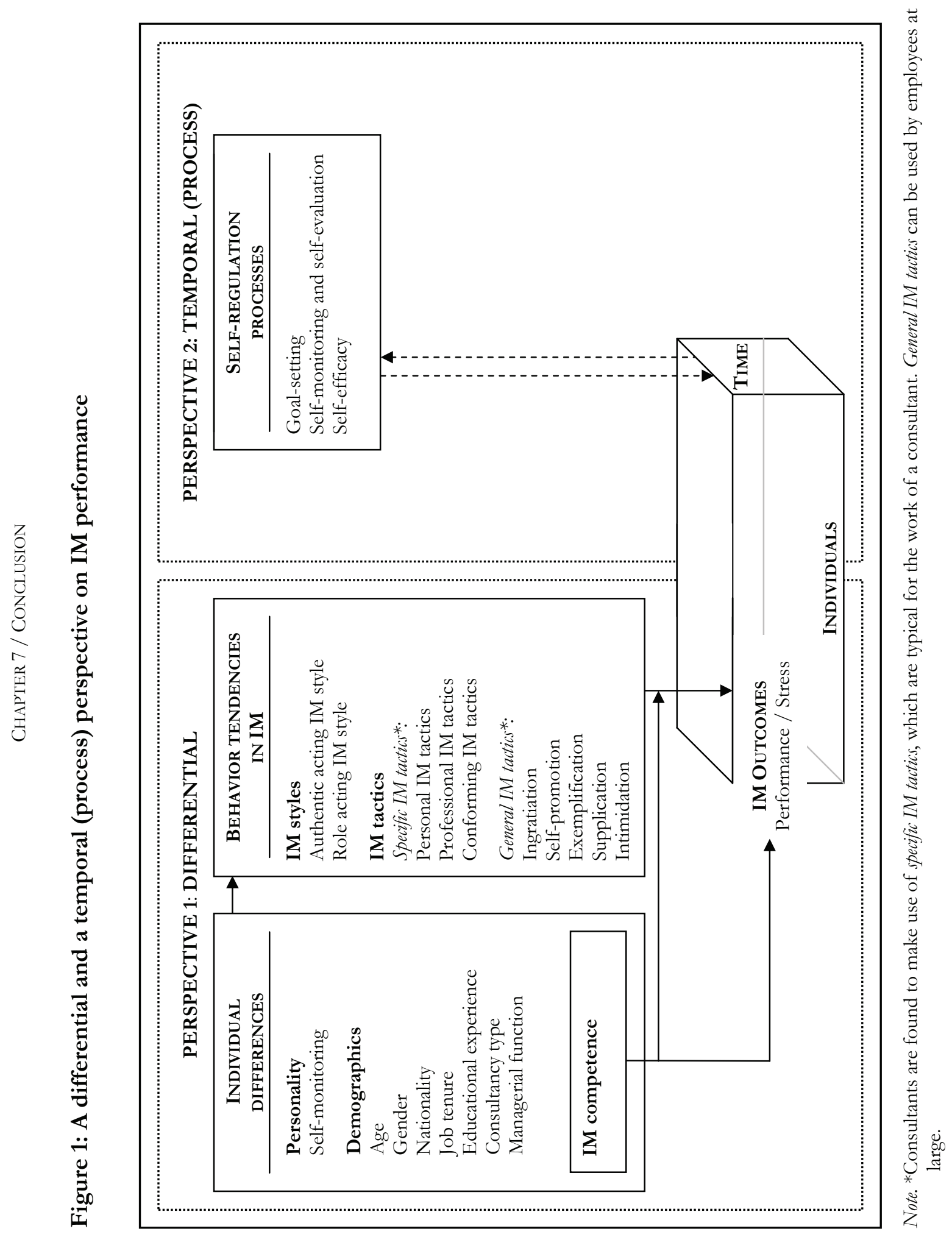




\section{Perspective 1: Differential}

Taking a differential perspective on IM implies that certain factors provide information concerning a person's IM behavior and are therefore useful in understanding and predicting differences in prospective IM performance. At the core of this approach is the notion that individuals differ in their self-monitoring level, their demographics and their competence to perform IM. These individual characteristics relate to diverse behavior tendencies in IM, expressed in IM styles and tactics, which in turn associate differently with IM outcomes.

\section{To explain variations in IM performance levels: Individual differences}

We examined various aspects to account for individual differences. Referring to personality we focused on an individual's self-monitoring level to explain variations in IM performance levels (Chapter 2). High self-monitoring individuals are known to monitor their behavior and the situation, and adapt their performance to create an appearance that fits the current situation. Low selfmonitoring individuals are more cross-situationally consistent and tend to express what they think and feel, rather than tailoring their appearance to fit the situation (Snyder, 1974). These two types of personalities were also mentioned by the respondents in our interview study (Chapter 3). Both consultants and experts described people who match the description of high and low self-monitoring individuals. In Chapter 4 we dealt empirically with self-monitoring and related it to consultants' use of IM tactics. No significant result was found. However, other person and also job-related characteristics assessed by means of demographic variables indeed showed a significant relationship to consultants' IM tactics, eventually resulting in different IM performances. For example, we found age to have a significant impact on IM; consultants older than 51 years used the professional IM tactic more frequently than their younger colleagues at an age between 31 and 40 years. Moreover, consultants with longer job tenure - over 21 years - employed the conforming IM tactic more frequently than consultants with job tenure between 6 to 10 years. In Chapter 6, which investigates the IM behaviors of business students in interaction with their tutors, we further discovered that gender, educational experience, nationality and exam grading had significant relations with IM behaviors. For example, female students made less use of IM tactics than their male student colleagues; junior students acted less authentically than senior students and employed more supplication and intimidation tactics than seniors. Concerning nationality, we discovered that Dutch students in comparison to German students and students from other nationalities performed most 
authentically in their IM behaviors and most frequently used ingratiation as an IM tactic. German students employed mostly the self-promotion and the intimidation IM tactics and less the supplication tactic in comparison to other nationalities in our student sample. Finally, we found that students with high grades - between 8.1 and 10 - more often had an authentic acting IM style than students with lower grades. Students who failed the course with grades between 0 and 5.4 employed mostly the IM tactic supplication. Thus, we were able to identify additional person and job-related characteristics determining individual's IM use and performance. Our findings support the differential perspective on IM indicating that not all people are equally effective in their IM attempts due to individual differences. IM competence is another individual difference factor in our model, to be discussed below.

\section{To identify behavior tendencies in IM}

Referring to our goal to investigate IM in consultancy, we specifically wanted to learn how consultants in the context of performing their work roles try to express certain images; that is, which behavior tendencies in IM are evident. In the interviews reported in Chapter 3, consultants described two different IM styles (authentic acting and role acting IM styles) and also helped us to discern three IM tactics specifically used by consultants in order to influence their clients' impressions in a beneficial way (personal, professional, and conforming IM tactics). We adopted the terms IM styles to represent an individual tendency to perform IM in a systematic way, and IM tactics to correspond with particular behaviors, such as self-promotion. In Chapter 4 we investigated the three identified consultants' IM tactics and their relationships with consultants' performance. When used separately, the personal and the professional IM tactics can help to increase the performance evaluation of a consultant. Consultants in our sample employing either the personal or the professional IM tactic thought they would receive better performance evaluations by their clients. Furthermore, we were able to identify three groups of impression managers within our sample: (a) consultants with a versatile profile; they scored high on all three IM tactics; (b) consultants with an impersonal profile; consultants in this group had low scores for the personal IM tactic and below average scores for the professional and the conforming IM tactics; and (c) consultants with a naive profile, naive because they scored moderately high on the personal IM tactic and below average on the professional and the conforming IM tactics. These findings indicate that consultants differ in their IM use. Further, in comparison to consultants with an impersonal or a naïve profile, those with a versatile profile 


\section{CHAPTER 7}

believed that they would receive better performance evaluations from their clients, supporting the idea that the utilization of all three consultants' IM tactics would be most beneficial. In Chapter 5 we considered the two distinct IM styles, the relationships of authentic acting and role acting IM styles with consultants' performance and stress. We found that an authentic acting IM style was negatively related to stress, and a role acting IM style was negatively associated with performance and positively associated with stress. In our last study, described in Chapter 6, we examined the IM styles again in addition to well-known general IM tactics (ingratiation, self-promotion, exemplification, supplication, and intimidation) and their relationships with performance. Concerning IM styles, we found a positive relationship for the authentic acting IM style and performance. In reference to IM tactics, self-promotion was positively related to performance whereas a negative relationship for the IM tactic supplication with performance was found. Both relationships were only found at the beginning of the impression manager-target interaction.

\section{To determine the role of IM competence}

As people may differ in their use of IM in everyday circumstances, we regarded it as important to distinguish between the knowledge and competence of how to behave and the effectiveness of the behaviors typically shown in real-life situations. In Chapter 3, IM competence evolved as a major factor from the interviews. With regard to the interview accounts we defined IM competence as the proficiency to manage others' impressions. In the subsequent two chapters we empirically investigated IM competence. In Chapter 4, IM competence was related to consultants' use of IM tactics. We found that consultants with high IM competence used all IM tactics more frequently in comparison to their colleagues with low IM competence. That is also expressed by the finding that consultants who score high on IM competence had most likely a versatile profile. In Chapter 5, we studied the role of IM competence as a direct and a moderating factor on consultants' performance and stress. IM competence was found to relate positively to performance and negatively to stress. It buffered the negative main effect of a role acting IM style with performance. Unexpectedly, IM competence in interaction with an authentic acting IM style resulted in lower performance. Since IM competence is a new concept in the IM literature, all findings are novel and enrich current knowledge on IM.

Concerning the differential perspective on IM, it is important to note that we do not claim that the identified variables are necessarily the only ones that determine consultants' IM performance. We 
acknowledge that additional factors inside the individual, as other personality traits, are reliable predictors as well. We refer to findings of other studies (see review by Bolino et al., 2008) and more importantly hope for future research to include ours and further variables. As shown in Table 1, all studies in this thesis include aspects of the differential perspective.

\section{Perspective 2: Temporal (process)}

IM has often to be performed over and over again to achieve and maintain a desired image. Further, its dyadic nature characterizes IM as a reciprocal influence process (Ginzel, Kramer, \& Sutton, 2004). Although many definitions of IM take account of its process character, e.g. "impression management is the process by which individuals attempt to control the impressions others form of them" (Leary et al., 1990: 34), process and temporal facets of IM are highly neglected in the current research literature. Therefore, the second perspective on IM performance taken in this thesis focuses on processes constituting IM and its development over time.

\section{To explain variations in IM performance levels: Self-regulation processes}

A self-regulation outlook on IM taken in Chapter 2 argued for the process character of IM. It is described to involve three processes: (1) goal-setting, (2) self-monitoring and self-evaluation, and (3) self-efficacy. That is, IM is portrayed as a continuous cycle of action and reflection, with respective results and experiences in case of success increasing individual's self-efficacy. The psychological selfregulation perspective on IM with a specific focus on three self-regulation processes was particularly helpful in identifying when and why people might fail to manage other people's impressions. Each self-regulation process can go awry, e.g. when people monitor the wrong aspects of behavior or do not believe in their ability to successfully manage the impressions of other people. As a result, IM performance may vary. For this reason, IM outcomes and effectiveness can be forecasted from the extent to which people successfully enact self-regulation processes involved in IM performance. Previous conceptual analyses of IM and determinants of its performance do not distinguish clearly between these facets of IM.

These theoretical findings were conformed by our interview study presented in Chapter 3. Referring to self-regulation processes the descriptions of our interviewees corresponded to the consulted literature in Chapter 2. Both consultants and experts said that mentioned self-regulation processes can fail and interfere with successful IM. 


\section{CHAPTER 7}

\section{To understand IM processes over time}

Existing research tends to treat IM as discrete rather than as dynamic exchanges occurring in personal interactions. Variations in behavior tendencies in IM as well as their potential effects over time are yet largely unexplored.

To learn more about how IM develops over time we performed a longitudinal study. The findings presented in Chapter 6 indicated that while some IM behaviors (authentic acting IM style and self-promotion) are initially effective, they become less so as the impression managers and the audience have spent more time with one another. Moreover, we found that business students representing the impression managers in this study seemed not to substantially change their IM behaviors - neither their IM styles nor their IM tactics - over time. We have to admit that this study is still differential in its analysis. We measured IM with static and not with dynamic variables and therefore were not able to study the IM process and how it unfolds in people's interaction with others.

To summarize, research on IM has mainly taken a differential perspective to address varieties among individuals attempting to influence others' impressions. In this thesis, trait, demographic and competence characteristics are described as major conditions for inter-individual differences in IM performance. However, there are also intra-individual differences which are accounted for by considering self-regulation processes as well as how IM develops over time. Without discounting the value of the differential perspective on IM performance, we want to point at the added value of a temporal and process perspective for advancing our understanding of IM. By combining the two perspectives we can explain both why some individuals are better in IM than others and why one individual can be successful in his or her IM attempts at one time, but unsuccessful at other times. As shown in Table 1, Chapters 2, 3 and 6 include in addition to the differential perspective on IM, the temporal (process) outlook as well. 


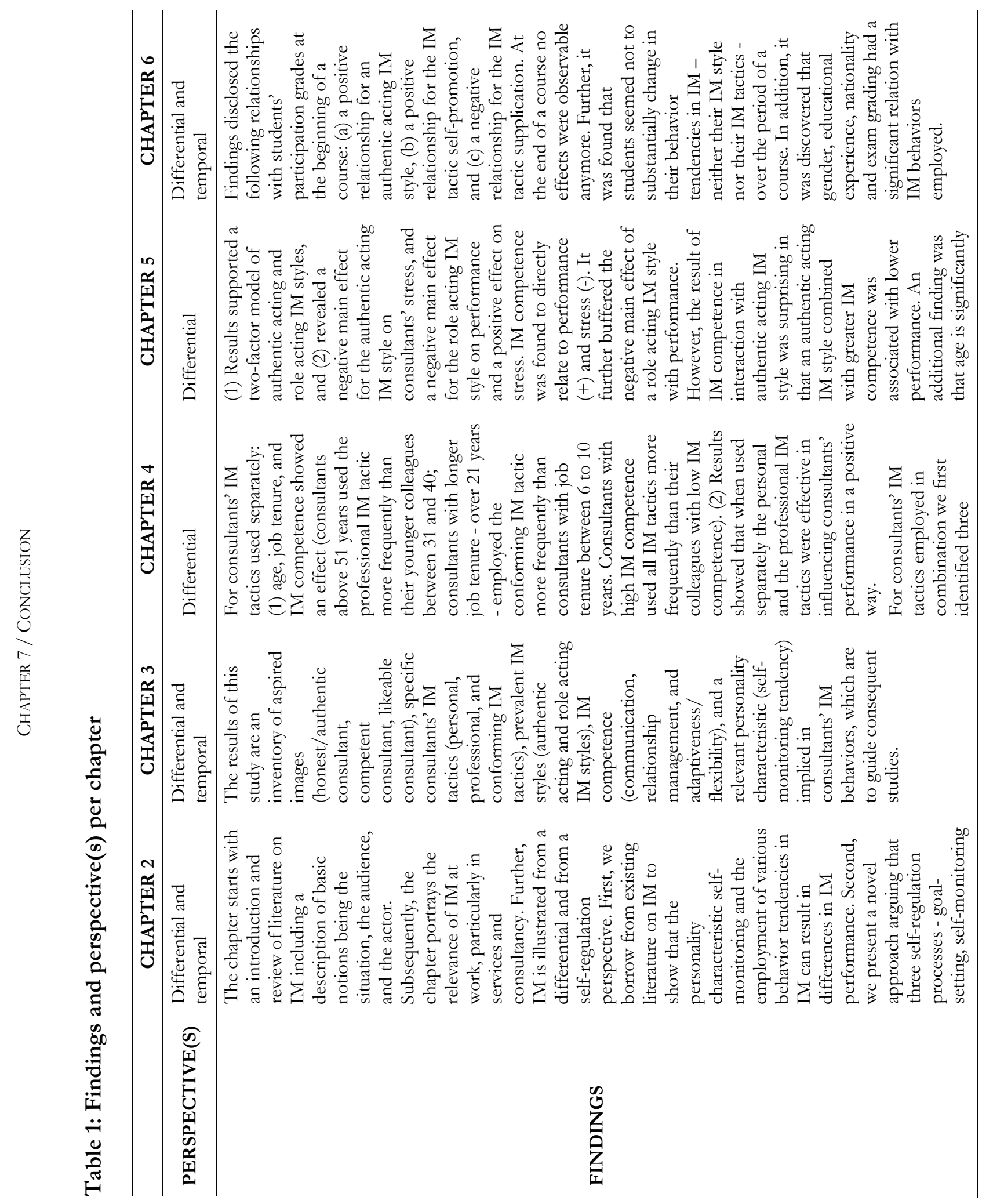




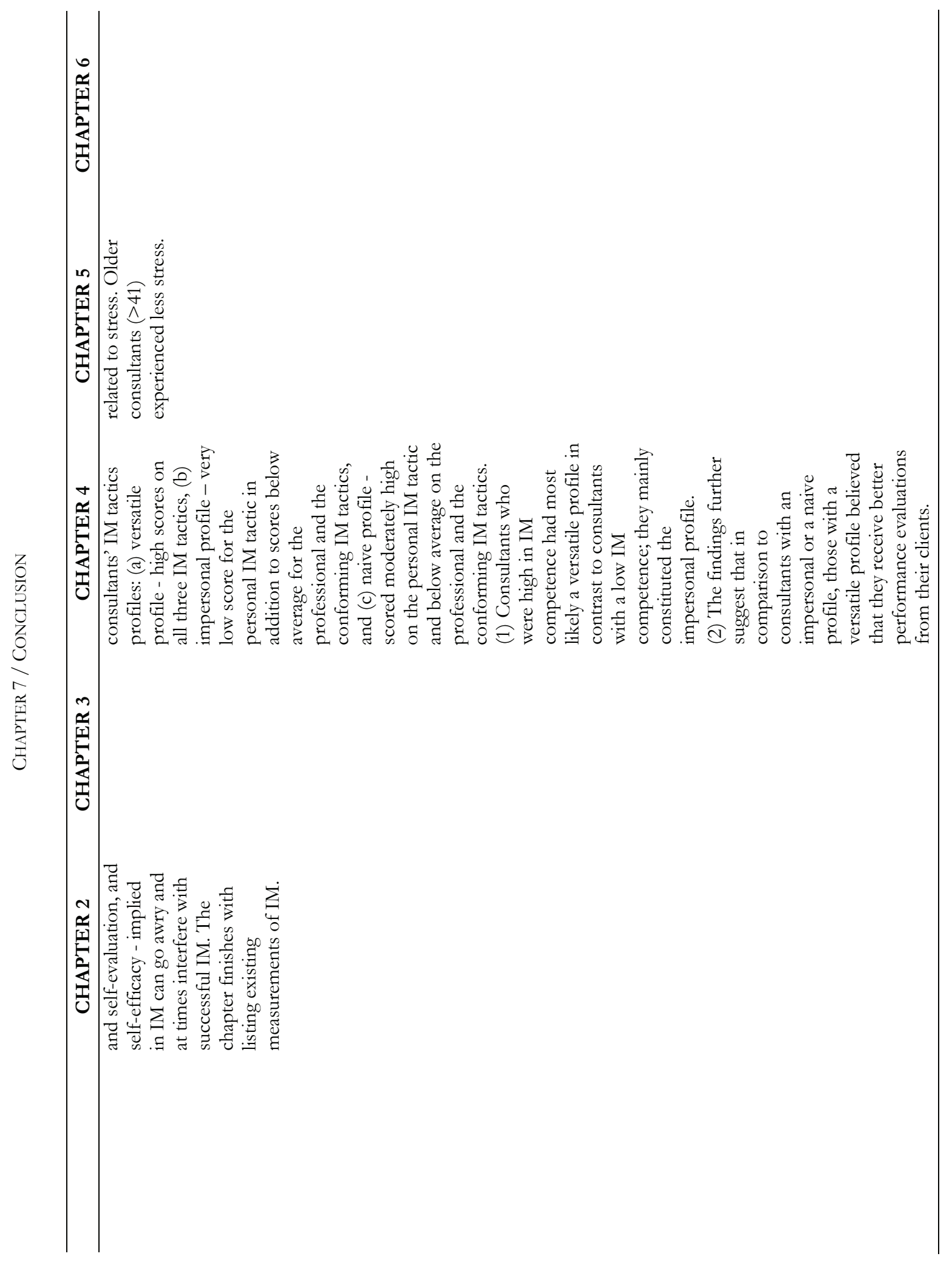




\section{FUTURE RESEARCH DIRECTIONS}

We identified a number of IM tactics (personal, professional and conforming IM tactics), IM styles (authentic acting and role acting IM styles) and IM competence as well as measures of them. These are novel to the literature and we demonstrated their significance for determining consultants' IM performance in the findings of the studies. Newly identified consultants' IM tactics were further examined in combination, which is a new area that has been largely ignored in the past. Moreover, we examined various individual factors and gained a fine-grained understanding of individual differences and the outcomes that result from them. Concerning IM outcomes, we did not only investigate IM's relationship with consultants' performance but also regarded a potential negative output of IM - that of stress. Further, we studied IM over time, which is often demanded in the literature but almost never done. Thereby, the studies in this thesis contribute to the theoretical and methodological field of IM in consultancy.

Despite these strengths, there are a number of limitations and challenges evident in our research. Since specific research limitations and suggestions for future research have been discussed at the end of each chapter, we concentrate here on providing direction for future research in the area of IM in general and in consultancy in particular.

\section{An integral model of IM}

Although we provide a comprehensive model on IM and its performance, in our eyes the most important shortcoming of our research is that mainly factors inside the individual have received our attention. However, IM in organizational life like consultancy warrants a more wide-ranging view of the mix of conditions that are related to its behaviors and outcomes.

As touched upon as basic notions of IM in Chapter 3 and here displayed in Figure 2, two additional broad avenues for future research seem especially compelling. These are factors in relationship to the situation and the audience. We describe their potential impact on IM and why it is so important to consider them in future research on IM. 


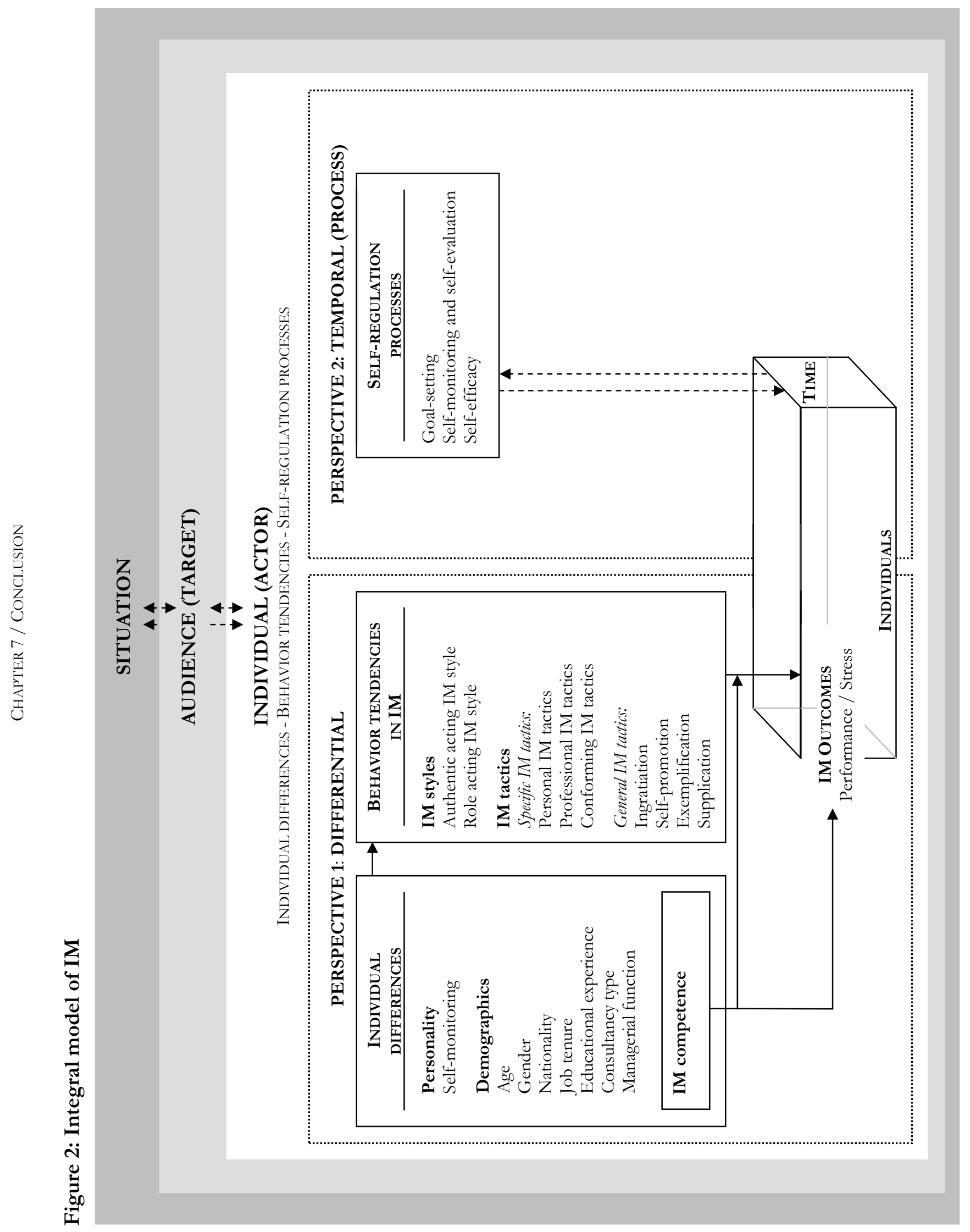




\section{Situation}

An individual's IM behavior is highly responsive to the social aspects of the situation. In Chapter 3 we briefly described the influence of behavior being public, situation-specific roles, and organizational context. For example, research found that the situation may be more likely to elicit IM behaviors when job ambiguity is high (Fandt, 1986), managerial style is authoritarian (Ralston, 1985), and there is either insufficient opportunity to document or externally validate job performance (Schlenker, 1975). Some of these circumstances are described in this thesis as factors boosting IM behavior by consultants.

In addition, one can think of many other situational aspects and how these might influence the IM performance of consultants. For example, the consulting process can be distinguished in three episodes with diverse situational requirements: the qualification stage, the delivery stage, and the closing stage. One could imagine that in the qualification stage, the consultants have to construct an image in the mind of the clients that qualifies them to be the best choice. In the second phase the consultants have rather to maintain their displayed images at work and, if necessary, adjust image impressions. In the closing stage a final stroke is drawn; here the clients form a final impression of the consultants. It can be assumed that consultants use different IM behaviors in order to fulfill the requirements of the different project stages and a temporal perspective can help to investigate the IM process from one stage to the other.

Furthermore, we anticipate that it can make a difference for consultant's IM depending on where the consultant-client interaction takes place, e.g. in an informal setting, as at lunch time in the canteen, or due to formal reasons in a conference room, as for contract negotiations. One could also think of the impact of organizational culture. Since it provides behavioral expectations, it can be expected that clients from a company with an informal organizational culture might need a different handling than those from an organization with rigid norms. These examples could be extended with many different situations implying varying requirements potentially influencing an individual to perform IM by some means or other.

In regard to the different situational requirement, it could be that some consultants perform e.g. better in the qualification stage and others in the delivery phase of a consultancy project, some better in informal and others in formal situations, etc. Here, we get back to what we found in our thesis concerning individual differences: individuals differ in their IM performance and effectiveness. Since this might also be the case for different situations, it would be interesting to see why some individuals perform successfully in certain situations but others not (differential perspective) and what determines individual's effectiveness in IM in some situations but not in others (temporal perspective). 
Although we primarily want to call attention to how the situation can influence individual's IM, the interaction can also go in the reverse direction. Individuals can change the situation by managing others' impressions as well as change situational conditions to influence others' perceptions, e.g. by keeping their office doors open or closed, or by sitting at the head or the side of a table, and so on.

Figure 2 also shows that the situation has an effect on the audience of IM. This is based on the fact that the values and perceptions of people - including those of the impression managers and their targets - are influenced by their surroundings. For example, as briefly mentioned above, the organizational culture of a company will influence which behaviors employees consider as adequate or out of place.

This leads us to the other displayed interaction: the interaction between the individual (impression manager) and the audience (target). In the following, we will describe how the audience acts upon individual's IM and give examples arguing for its inclusion in IM research. The reverse impact will not be discussed; that individuals are able to influence the audience is illustrated throughout the thesis.

\section{Audience}

For IM to happen at least two parties are needed: the actor, the person presenting the information; and the target, the one receiving the information (Goffman, 1959). Unfortunately, a great deal of research, including this thesis, has investigated primarily the actor side of the interaction. Questions answered are i.e. do young consultants use different IM behaviors in comparison to their older colleagues or are females more authentic than males in their IM approach? However, questions concerning targets' characteristics and how they influence the way and the effectiveness of actors' IM are yet open. For example, we do not know whether it makes a difference whether the client is old or young, is from the same age as the consultant or not. We are uninformed about consultants' use and effectiveness of IM behaviors when they interact with female or male clients, with clients from the management board or from the factory floor, and so forth. Thus from a differential perspective there are additional opportunities to develop a better understanding of IM by learning how different targets weigh image concerns instead of just relying on their indicated impression. Thereby, future research may help to uncover which IM behaviors work on which targets, since "audiences (...) may be viewed as templates, each with a different pattern of knowledge and values. Incoming communications must be fitted to these patterns if the actor is to communicate effectively and persuasively" (Schlenker et al., 1992: 155). 
Another interesting question underlining the importance of a temporal perspective on IM is on the timing of IM. It can be assumed that wherever applicable, impression managers wait for optimal conditions to influence their targets' impressions. Here it would be interesting to see e.g. whether consultants wait until their clients are in a good mood before approaching them, interact with them early in the day to avoid any end of the day effect, or rather adapt their IM behavior correspondingly.

A further vital area for future IM research efforts is the examination of simultaneous occurrences of IM behavior in dyadic interactions. Whereas prior research has typically focused on the IM of one party, it is most likely that both parties are using IM, and we need to know more about this process and its outcomes. For example, with regard to self-regulation, research should not only try to investigate whether it makes a difference when the impression manager is e.g. tired or well-rested, angry or happy, but also whether the client's current status accounts for different IM outcomes. Future research should consider both participants in the dyad and in best case simultaneously in order to begin to fully comprehend the interactive nature of IM.

Moreover, it would be interesting to include other audiences beside the individual client. For example, relatively little attention has addressed the role of IM in groups or the effect IM has on bystanders. Due to the fact that "multiple audience problems arise when people find themselves in the awkward position of wanting to present different impressions to two or more people in the same social encounter" we think it is important to consider these audiences as well (Leary, 1995: 109). For example, referring to our study with business students it is likely that teachers value different behaviors than student peer groups. As a result, students might need to alter their IM behavior accordingly in order to make a desired impression on each of the two groups. The same is true in a consultancy context, e.g. consultants may choose different IM behavior when reporting at the supervisor from their own consultant organization than to their clients. For example, when reporting to a supervisor from their own company consultants may use account of how others in their team had not proved the necessary assistance for the project to be completed on time. In the client area, consultants may rather choose a different IM tactic, such as an apology, to lessen the impact of the poor performance without angering the other relevant audience from the client organization.

Finally, it would be interesting to see whether consultants behave differently in IM terms when the client is present or absent. That would include the double-edged quality of IM in service organizations. A useful and everyday way of understanding this so-called front- and backstage behavior of people (Goffman, 1959) is to think of a waiter or waitress at a restaurant. Their main avenue of concern is customer service. Even if a customer is rude, waiters and 
waitresses are expected to be polite as part of their job. That same waiter or waitress speaks differently when going out to their break room. They may complain, mimic and discuss with their fellow peers how rude the customer is. One could think of consultants behaving in similar ways when clients are absent or when their office doors are closed.

All these meaningful yet open issues emphasize the importance of considering all three aspects - the situation, the audience and the individual - when attempting to get an integral picture on IM.

\section{PRACTICAL IMPLICATIONS}

The theoretical elaborations proposed and empirical results obtained have practical implications for consultancies and their members, and suggest some compelling issues for managerial practice.

In today's organizations time is limited and competition for others' attention is intense. That specifically holds in consultancy services. The consulting industry calls for taking a good look at purposeful self-portrayal since employees in the consulting industry represent the organization and coin its image. This seems especially important at present. Triggered by a worldwide economic crisis, the consulting industry might experience dramatic changes. Recession has already affected most companies, and confronted with uncertainty about their earnings and performance they might respond with a reduction of dispensable services, like consulting. It will be much more difficult for the consulting industry to sell its consulting services and so it is crucial for consultants to be able to persuade prospective clients that they will profit from their work.

Due to the fact that concern for impressions is paramount in consultancy services, we drew attention to the fact that organizations and consultants should consider IM as a performance factor - as an integral part of a consultant's work performance - which, when successful, makes interpersonal relations in organizations more effective (Rosenfeld et al., 1994), thereby presumably contributing to overall success. We think that IM is a critical and useful tool for consultants. In case that there is no discrepancy between IM and actual performance, effective IM supposedly translates into positive consequences for the individual and the organization. It is important to note that the information presented should be basically real but adjusted to the public and situation. "In fact, over time, the 'authentic' presentation of self - that is, showing our selves as we believe we really are - is likely to be met by the greatest internal satisfaction and external approval" (Schlenker, 1980: 7). A person who presents him or herself in an inauthentic and non-credible manner is likely to experience negative consequences for wellbeing, relationships and performance. 
To be successful, it is essential for consulting organizations and for consultants to know how to achieve the positive ends and avoid the negative ends. Organizations which better understand reasons for variations in IM performance can focus their efforts on actively helping their employees rather than giving up on them. Adjusting the selection process and facilitating training strategies are seen as ways to increase the chances for IM success and to counter tendencies likely to cause IM failure. IM training is likely to provide the additional benefit of helping people to feel more confident and in control of their interactions. In addition, consultants can improve their IM on a daily basis. An enhanced understanding of IM as well as a regular practice can help them to become better impression managers.

Although our findings have implications for improving consultants' effectiveness, caution is needed in offering guidelines until follow-up research confirms the presented results. Other variables besides the ones tested in this thesis can affect the outcomes of any IM attempt. Moreover, any IM style and tactic can result in resistance if used in an unskillful manner for a request that is illegitimate or unethical.

Wrapping it all up, we believe that, due to its prevalence and implications, IM should occupy a prominent place on the agenda of organizational research and receive augmented managerial attention. We give the last word to the German writer Adolph Freiherr von Knigge (Über den Umgang mit Menschen, On Human Relations, 1788) outlining the "optimal” IM behavior:

"Without condescending oneself to boasting and mean lies one should not miss the opportunity to show favorable aspects of oneself to others. But this should not happen in a rough, even noticeable and vain way, otherwise we will loose much more. But one should help bumans only to conjecture, to notice by themselves, that probably there is somewhat more about us as gleams at first appearance. If one puts a too glittering sign out, so one arouses more exact attention; others recognize small errors, of which no one is free, and so it is at one time over with our luminousness. Show yourself thus with a certain modest consciousness of internal dignity, and first of all with shining consciousness of truth and fidelity! Show sanity and knowledge when you have reason to do so! Not so much as to evoke envy and accounts, not too few, to get over-seen and over-shouted! Make yourself scarce, without others considering you as an eccentric, nor as shy, nor as arrogant." 12

\footnotetext{
12 Original/German version: "Ohne sich zur Prahlerei und zu niederträchtigen Lügen herabzulassen, soll man doch nicht die Gelegenheit verabsäumen, sich von seinen vorteilhaften Seiten zu zeigen. Dies muss aber nicht auf eine
} 
grobe, gar zu merkliche, eitle und auffallende Weise geschehn, den sonst verlieren wir viel mehr dadurch. Sondern man muss die Menschen nur mutmaßen, sie von selbst darauf kommen lassen, dass doch wohl etwas mehr hinter uns stecke, als bei dem ersten Anblicke hervorschimmert. Hängt man ein gar zu glänzendes Schild aus, so erweckt man dadurch die genauere Aufmerksamkeit; andere spüren den kleinen Fehlern nach, von denen kein Erdensohn frei ist, und so ist es auf einmal um unsern Glanz geschehn. Zeige Dich also mit einem gewissen bescheidenen Bewusstsein innerer Würde, und vor allen Dingen mit dem auf Deiner Stirne strahlende Bewussteinsein der Wahrheit und Redlichkeit! Zeige Vernunft und Kenntnisse, wo Du Veranlassung dazu hast! Nicht so viel, um Neid zu erregen und Forderungen anzukündigen, nicht so wenig, um übersehn und überschrien zu werden! Mache Dich rar, ohne dass man Dich weder für einen Sonderling, noch für scheu, noch für hochmütig halte!’. 


\section{GLOSSARY}

\begin{tabular}{|c|c|c|}
\hline $\begin{array}{l}\text { Audience } \\
\text { (also targets, } \\
\text { others) }\end{array}$ & \multicolumn{2}{|c|}{$\begin{array}{l}\text { In the context of IM, an audience is a person or a group of people who encounter the person } \\
\text { performing IM. It is them for whom IM is performed and whose impressions should be } \\
\text { managed. }\end{array}$} \\
\hline $\begin{array}{l}\text { Behavior } \\
\text { tendencies in IM }\end{array}$ & \multicolumn{2}{|c|}{$\begin{array}{l}\text { In this thesis we utilize the terms "behavior tendencies in IM" and "IM behavior" as umbrella } \\
\text { terms for IM styles, tactics and strategies. }\end{array}$} \\
\hline Client & \multicolumn{2}{|c|}{$\begin{array}{l}\text { "The client, in the widest sense of the term, is the organization which employs consulting } \\
\text { services. But there is also a client in a more narrow sense of the term - the person (or group of } \\
\text { persons) in the client organization who initiates the bringing in of the consultant, discusses the } \\
\text { assignment with him, receives reports and so on. He is in a personal relationship with the } \\
\text { consultant" (Kubr, 1976: 21). }\end{array}$} \\
\hline Consultant & \multicolumn{2}{|c|}{$\begin{array}{l}\text { A consultant is someone brought in an organization for a limited time to solve one or more } \\
\text { specific problems. He or she should provide expert knowledge for a fee. }\end{array}$} \\
\hline Consultancy & \multicolumn{2}{|c|}{$\begin{array}{l}\text { Consultancy is a service, which is provided by external consultants in an interactive process with } \\
\text { their clients and which involves the identification, analysis, and solution of economic problems } \\
\text { and the implementation of recommended solutions (Kohr, 2000). }\end{array}$} \\
\hline Image & \multicolumn{2}{|c|}{ Overall impression of a person including various characteristics. } \\
\hline $\begin{array}{l}\text { Impression } \\
\text { management } \\
\text { (IM) }\end{array}$ & \multicolumn{2}{|c|}{$\begin{array}{l}\text { "Impression management consists of any behavior by a person that has the purpose of } \\
\text { controlling or manipulating the attributions and impressions formed of that person by others" } \\
\text { (Tedeschi, 1981: 3). }\end{array}$} \\
\hline IM behavior & \multicolumn{2}{|c|}{ See behavior tendencies in IM. } \\
\hline IM competence & \multicolumn{2}{|c|}{ Proficiency to create favorable impressions in the client. } \\
\hline \multirow{11}{*}{ IM tactics } & \multicolumn{2}{|c|}{$\begin{array}{l}\text { IM tactics correspond with more or less specific behaviors. In this thesis, we distinguish between } \\
\text { specific and general IM tactics. Consultants are found to make use of specific IM tactics, which } \\
\text { are typical for the work of a consultant. General IM tactics can be used by employees at large. }\end{array}$} \\
\hline & \multicolumn{2}{|c|}{ Specific IM tactics: } \\
\hline & $\begin{array}{l}\text { Personal IM } \\
\text { tactic }\end{array}$ & $\begin{array}{l}\text { This consultants' IM tactic consists of personal behaviors. The consultant } \\
\text { wants to appear likeable to the client by using a personal approach of IM. } \\
\text { Particular behaviors that are found to be used by consultants to promote } \\
\text { personal attraction and highlight positive features are: get personal, share } \\
\text { information, act as a partner, flatter, be nice, smile, please the client, and be } \\
\text { honest. }\end{array}$ \\
\hline & $\begin{array}{l}\text { Professional IM } \\
\text { tactic }\end{array}$ & $\begin{array}{l}\text { This IM tactic consists of professional, rather than personal-related, behaviors. } \\
\text { In contrast to the personal tactic, which is used to elicit liking/sympathy, the } \\
\text { professional tactic is used to allure the attribution of competence. The } \\
\text { professional IM tactic is found to be pursued by the following behaviors: self- } \\
\text { promote, rely on references and/or third parties, prepare, and be reliable. }\end{array}$ \\
\hline & $\begin{array}{l}\text { Conforming IM } \\
\text { tactic }\end{array}$ & $\begin{array}{l}\text { This IM tactic is made up of conforming behaviors. The consultant wants to } \\
\text { appear favorable (e.g. likeable/competent) by conforming to formal role } \\
\text { requirements and general conventions as attached to clothing, } \\
\text { communication, and behavior. }\end{array}$ \\
\hline & \multicolumn{2}{|c|}{ General IM tactics: } \\
\hline & Ingratiation & Individuals use flattery or favor-doing in an attempt to be seen as likable. \\
\hline & Self-promotion & Individuals play up their abilities or accomplishments to be seen as competent. \\
\hline & Exemplification & Individuals go above and beyond the call of duty to appear dedicated. \\
\hline & Supplication & Individuals advertise their shortcomings in an attempt to be viewed as needy. \\
\hline & Intimidation & $\begin{array}{l}\text { Individuals seek to appear intimidating or threatening to have others view } \\
\text { them as dangerous. }\end{array}$ \\
\hline
\end{tabular}




\begin{tabular}{|c|c|c|}
\hline \multirow{3}{*}{ IM styles } & \multicolumn{2}{|c|}{ IM styles represent an individual tendency to perform IM in a certain way. } \\
\hline & $\begin{array}{l}\text { Authentic } \\
\text { acting }\end{array}$ & $\begin{array}{l}\text { In case that an individual tends to show to the audience a portrait that is } \\
\text { honestly by him or her believed to be true the individual has an authentic acting } \\
\text { IM style. Hereby, the individual does not hide from nor plays for the audience to } \\
\text { influence their future behavior and thinking. }\end{array}$ \\
\hline & Role acting & $\begin{array}{l}\text { In contrast to an authentic acting IM style, a role acting IM style is defined as a } \\
\text { tendency to influence other's impressions by deflecting from what the individual } \\
\text { believes to be the truth. It is employed to meet the social requirements of a } \\
\text { specific situation irrespective of the real characteristics of the person employing } \\
\text { IM. }\end{array}$ \\
\hline $\begin{array}{l}\text { (IM) } \\
\text { performance }\end{array}$ & \multicolumn{2}{|c|}{$\begin{array}{l}\text { Individuals' behaviors in interaction with others are described as performances constructed to } \\
\text { provide the audience with impressions the actor wants them to develop (Goffman, 1959). }\end{array}$} \\
\hline $\begin{array}{l}\text { (Job) } \\
\text { performance }\end{array}$ & \multicolumn{2}{|c|}{$\begin{array}{l}\text { Includes the actual performance that is the performance of particular working tasks and the } \\
\text { interpersonal dimension of performance that is the behavior towards other people. }\end{array}$} \\
\hline Role & \multicolumn{2}{|c|}{ The social expectations attached to a particular social position or status. } \\
\hline Self-monitoring & \multicolumn{2}{|c|}{$\begin{array}{l}\text { The self-monitoring construct specifies a trait that describes and explains individual differences } \\
\text { in the (self-) control of expressive behavior. According to self-monitoring theory, high self- } \\
\text { monitors tailor their self-presentation for the sake of desired public appearances, whereas low } \\
\text { self-monitors are relatively unlikely to practice such situationally guided IM strategies. }\end{array}$} \\
\hline Self-presentation & \multicolumn{2}{|c|}{$\begin{array}{l}\text { We use the terms IM and self-presentation interchangeably. However, they could be } \\
\text { distinguished by saying that self-presentation deals with impressions about the actor himself, } \\
\text { while IM can also be aimed at controlling the images of objects or events that are only indirectly } \\
\text { self-relevant (Schlenker, 1980). }\end{array}$} \\
\hline Self-regulation & \multicolumn{2}{|c|}{$\begin{array}{l}\text { Self-regulation should be distinguished from self-management (Pintrich, 2000). Kuhl (2000) } \\
\text { stated that self-regulation is largely implicit and that unconscious processes integrate other } \\
\text { processes responsible for action effectiveness. Self-management, on the other hand, usually } \\
\text { emerges when the automatic processes of self-regulation are not sufficient to cope with current } \\
\text { internal or external demands (Goldfried et al., 1973). People who manage themselves consciously } \\
\text { monitor their aims. They plan specific behavior and set up the planned activity at the right time } \\
\text { and in the appropriate situation. They are able to manage their attention and suppress disturbing } \\
\text { stimuli in order to stay with a difficult task (Kuhl \& Fuhrmann, 1998). Self-management is also } \\
\text { described as the process of changing one's own behavior by managing multiple regulations } \\
\text { demands within different situations; it implies the coordination of multiple self-regulation } \\
\text { processes (Baumeister et al., 1994). In order to acknowledge both views, we consider self- } \\
\text { regulation to comprise unconscious as well as conscious processes. Thus, it includes self- } \\
\text { management. Furthermore, self-regulation should also be differentiated from traditional } \\
\text { conceptions of self-control and discipline. It is seen as a process in which action is steered by } \\
\text { integrating various subsystems and processes which together result in performance. Kuhl (2000: } \\
\text { 115) labeled this process "inner democracy", in contrast to the "inner dictatorship" describing } \\
\text { self-control. }\end{array}$} \\
\hline Stress & \multicolumn{2}{|c|}{$\begin{array}{l}\text { Stress is a biological term which refers to the consequences of the failure of a human or animal } \\
\text { body to respond appropriately to emotional or physical threats to the organism, whether actual } \\
\text { or imagined (Wikipedia.com). }\end{array}$} \\
\hline
\end{tabular}




\section{REFERENCES}

Aiken, L. S. \& West, S. G. 1991. Multiple regression: Testing and interpreting interactions. CA: Sage.

Alvesson, M. 1993. Organizations as Rhetoric: Knowledge Intensive Firms and the Struggle with Ambiguity. Journal of Management Studies, 30(6): 997-1019.

Alvesson, M. \& Johansson, A. W. 2002. Professionalism and Politics in Management Consultancy Work. In Clark.T. \& R. Finchham (Eds.), Critical Consulting: New Perspectives on the Management Advice Industry: 228-246. Oxford: Blackwell Publishers Ltd.

Andrews, M. C. \& Kacmar, K. M. 2001. Impression Management by Association: Construction and Validation of a Scale. Journal of Vocational Behavior, 58: 142-161.

Arkin, R. 1981. Self-presentation styles. In J. T. Tedeschi (Ed.), Impression Management and Social Psychological Research: 331-333. New York: Academic Press.

Arkin, R. M., Lake, E. A., \& Baumgardner, A. H. 1986. Shyness and Self-Presentation. In W. H. Jones \& J. M. Cheek \& S. R. Briggs (Eds.), Shyness: Perspectives on Research and Treatment: 189-204. New York: Plenum.

Arkin, R. M. \& Sheppard, J. A. 1989. Self-Presentation Styles in Organizations. In R. A. Giacalone \& P. Rosenfeld (Eds.), Impression Management in the Organization: 125-140. Hove and London: Lawrence Erlbaum Associates.

Arvey, R. D. \& Murphy, K. R. 1998. Performance Evaluation in Work Settings. Annual Review Psychology, 49: 141-168.

Ashforth, B. E. \& Humphrey, R. H. 1993. Emotional labour in service roles: the influence of identity. Academy of Management Review, 18: 88-115.

Avolio, B. J., Gardner, W. L., Walumbwa, F. O., Luthans, F., \& May, D. R. 2004. Unlocking the mask: A look at the process by which authentic leaders impact follower attitudes and behaviors. The Leadership Quarterly, 15: 801-823.

Avolio, B. J. \& Gardner, W. L. 2005. Authentic leadership development: Getting to the root of positive forms of leadership. The Leadership Quarterly, 16: 315-338.

Baldwin, M. W. 1992. Relational Schemas and the Processing of Social Influence. Psychological Bulletin, 112: 461-484.

Bandura, A. 1977. Self-efficacy: Toward a Unifying Theory of Behavioral Change. Psychological Review, 84(2): 191-215.

Bandura, A. 1982. The Self and Mechanisms of Agency. In J. Suls (Ed.), Psychological perspectives on the self, Vol. 1: 3-40. London: Lawrence Erlbaum Associates. 
Bandura, A. 1986. Social foundations of thought and action: A social cognitive theory. New Jersey: Englewood Cliffs, Prentice Hall Inc.

Bandura, A. 1997. Self-Efficacy: The Exercise of Control. New York: W.H. Freeman and Company.

Baumeister, R. F. 1982. A self-presentational view of social phenomena. Psychological Bulletin, 91: 3-26.

Baumeister, R. F. 1989. Motives and Costs of Self-Presentation in Organizations. In R. A. Giacalone \& P. Rosenfeld (Eds.), Impression management in the organization. New Jersey: Lawrence Erlbaum Associates.

Baumeister, R. F., Hutton, D. G., \& Tice, D. M. 1989. Cognitive Processes during Deliberate Self-Presentation: How Self-Presenters Alter and Misinterpret the Behavior of Their Interaction Partners. Journal of Experimental Social Psychology, 25: 59-78.

Baumeister, R. F., Heatherton, T. F., \& Tice, D. M. 1994. Losing control: How and why people fail at self-regulation. San Diego: Academic Press.

Baumeister, R. F. 1999. The Self in Social Psychology. Philadelphia: Psychology Press.

Beard, J. W. 1996. Impression Management and Information Technology: New Perspectives on Individual and Organizational Computing. In J. W. Beard (Ed.), Impression Management and Information Technology: 1-6: Greenwood Publishing Group.

Benard, B. 1995. Fostering resiliency in urban schools. In B. Williams (Ed.), Closing the achievement gap: A vision to guide change in beliefs and practice. IL: Oak Brook.

Bentler, P. M. \& Bonett, D. G. 1980. Significance Tests and Goodness of Fit in the Analysis of Covariance Structures. Psychological Bulletin, 88(3): 588-606.

Bentler, P. M. 1990. Comparative fit indexes in structural models. Psychological Bulletin, 107: 238-246.

Bessom, R. \& Jackson, J. 1975. Service retailing: A strategical marketing approach. Journal of Retailing, 51: 75-84.

Bohra, K. A. \& Pandey, J. 1984. Ingratiation toward strangers, friends, and bosses. The Journal of Social Psychology, 122: 217-222.

Bolino, M. C. 1999. Citizenship and impression management: Good soldiers or good actors? Academy of Management Review, 24(1): 82-98.

Bolino, M. C. \& Turnley, W. H. 1999. Measuring Impression Management in Organizations: A Scale Development Based on the Jones and Pittman Taxonomy. Organizational Research Methods, 2(2): 187-206. 
Bolino, M. C. \& Turnley, W. H. 2003a.Counternormative impression management, likeability, and performance ratings: the use of intimidation in an organizational setting. Journal of Organizational Behavior, 24: 237-250.

Bolino, M. C. \& Turnley, W. H. 2003b. More Than One Way to Make an Impression: Exploring Profiles of Impression Management. Journal of Management, 29(3): 141-160.

Bolino, M. C., Varela, J. A., Bande, B., \& Turnley, W. H. 2006. The impact of impressionmanagement tactics on supervisor ratings of organizational citizenship behavior. Journal of Organizational Behavior, 27: 281-297.

Bolino, M. C., Kacmar, K. M., Turnley, W. H., \& Gilstrap, J. B. 2008. A Multi-Level Review of Impression Management Motives and Behaviors. Journal of Management, 34: 1080-1109.

Bowen, D. E. \& Schneider, B. 1988. Services marketing and management: Implications for organizational behavior. Research in Organizational Behavior, 10: 43-80.

Bozeman, D. P. \& Kacmar, K. M. 1997. A Cybernetic Model of Impression Management Processes in Organizations. Organizational Behavior and Human Decision Processes, 69: $9-30$.

Briggs, S. R., Cheek, J. M., \& Buss, A. H. 1980. An Analysis of the Self-Monitoring Scale. Journal of Personality and Social Psychology, 38(4): 679-686.

Briggs, S. R. \& Cheek, J. 1986. The role of factor analysis in the development and evaluation of personality scales. Journal of Personality, 54: 106-148.

Brislin, R. W. 1980. Translation and content analysis of oral and written material. In H. C. Triandis \& J. W. Berry (Eds.), Handbook of cross-cultural psychology, Vol. 2: 349-444. Boston: Allyn \& Bacon.

Bromley, D. B. 1993. Reputation, Image and Impression Management. Chichester, New York: John Wiley \& Sons Ltd.

Bronson, M. B. 2000. Self-regulation in early childhood: Nature and Nurture. New York: Guildford Press.

Brown, P. \& Levinson, S. 1978. Universal in language use: Politeness phenomena. In E. Goody (Ed.), Questions and Politeness: Strategies in Social Interaction: 56-289. New York: Cambridge University Press.

Browne, M. W. \& Cudeck, R. 1993. Alternative ways of assessing model fit. In K. A. Bollen \& J. S. Long (Eds.), Testing structural equation models: 136-162. Newbury Park: CA: Sage.

Buss, A. H. \& Briggs, S. R. 1984. Drama and the self in social interaction. Journal of Personality and Social Psychology, 47: 1310-1324. 
Byrne, B. M. 1998. Structural equation modeling with LISREL, PRELIS, and SIMPLIS: Basic concepts, applications, and programming. Mahwah, NJ.

Byrne, D. 1961. Interpersonal attraction and attitude similarity. Journal of Abnormal and Social Psychology, 61(713-715).

Caldwell, D. F. \& O'Reilly, C. A. 1982. Boundary spanning and individual performance: The impact of self-monitoring. Journal of Applied Psychology, 67: 124-127.

Cardy, R. L. \& Dobbins, G. H. 1986. Affect and Appraisal Accuracy: Liking as an Integral Dimension in Evaluating Performance. Journal of Applied Psychology, 71(4): 672-678.

Carver, C. S. \& Scheier, M. F. 1981. Attention and self-regulation: A control-theory approach to human behavior. New York: Springer.

Carver, C. S. \& Scheier, M. F. 1985. Aspects of Self and the Control of Behavior. In B. R. Schlenker (Ed.), The Self and Social Life: 146-174. California: Brooks/Cole Publishing Company.

Carver, C. S. \& Scheier, M. F. 1990a. Principles of Self-Regulation: Action and Emotion. In E. T. Higgins \& R. M. Sorrentino (Eds.), Handbook of Motivation and Cognition, Foundations of Social Behavior: 3-52. New York: Guilford Press.

Carver, C. S. \& Scheier, M. F. 1990b. Origins and Functions of Positive and Negative Affect: A Control-Process View. Psychological Review, 97(1): 19-35.

Carver, C. S. \& Scheier, M. F. 1998. On the Self-Regulation of Behavior. Cambridge: Cambridge University Press.

Cash, T. F. \& Wunderle, J. M. 1987. Self-monitoring and cosmetics use among college women. Journal of Social Behavior and Personality, 2: 563-566.

Cattell, R. B. 1966. The data box: Its ordering of total resources in terms of possible relational systems. In R. B. Cattell (Ed.), Handbook of multivariate experimental psychology: 67-128. Chicago: Rand McNally.

Cheek, J. M. \& Hogan, R. 1983. Self-concepts, self-presentations, and moral judgments. In J. Suls \& A. G. Greenwald (Eds.), Psychological Perspectives on the Self, Vol. 2. Hillsdale, NJ: Erlbaum Associates.

Christie, R. \& Geis, F. L. 1970. Studies in machiavellianism. New York: Academic Press.

Cialdini, R. B. \& Richardson, K. D. 1980. Two indirect tactics of image management: Basking and blasting. Journal of Personality and Social Psychology, 39: 406-415. 
Clark, T. 1993. The market provision of management services, information asymmetries and service quality - some market solutions. An empirical example. British Journal of Management, 4: 235-251.

Clark, T. 1995. Managing Consultants: Consultancy as the Management of Impressions. Buckingham - Philadelphia: Open University Press.

Clark, T. \& Salaman, G. 1998. Creating the "Right" Impression: Towards a Dramaturgy of Management Consultancy. The Service Industries Journal, 18(1): 18-38.

Cohen, J. 1988. Statistical power analysis for the behavioral sciences (2nd ed.). Hillsdale, NJ: Erlbaum Associates.

Cohen, S., Kamarck, T., \& Mermelstein, R. 1983. A global measure of perceived stress. Journal of Health and Social Behavior, 24: 385-396.

Colvin, J. W. 2007. Peer tutoring and social dynamics in higher education. Mentoring \& Tutoring, 15(2): 165-181.

Crant, J. M. 1996. Doing more harm than good: When is impression management likely to evoke a negative response? Journal of Applied Social Psychology, 26: 1454-1471.

Czepiel, J. A. 1990. Evaluating the role and place of marketing in service firms. In D. E. Bowen \& R. B. Chase \& T. G. Cummings (Eds.), Service Management Effectiveness: Balancing Strategy Organization and Human Resources, Operations and Marketing: 299-323. San Francisco, CA: Jossey-Bass.

Dawes, P. C., Dowling, G. R., \& Patterson, P. G. 1992. Criteria used to select management consultants. Industrial Marketing Management, 21: 187-193.

Day, D. V., Schleiber, D. J., Unckless, A. L., \& Hiller, N. J. 2002. Self-monitoring personality at work: A meta-analytic investigation of construct validity. Journal of Applied Psychology, 87: 390-401.

Deadrick, D. L. \& Gardner, D. G. 2008. Maximal and typical measures of job performance: An analysis of performance variability over time. Human Resource Management Review, 18(3): 133-145.

Deaux, K. \& Taynor, J. 1973. Evaluation of male and female ability bias works two ways. Psychological Reports, 32: 261-262.

Deci, E. L. 1995. Why we do what we do. New York: Penguin Books.

Deci, E. L. \& Ryan, R. M. 1995. Human autonomy: The basis for true self-esteem. In M. H. Kernis (Ed.), Efficacy, agency, and self-esteem: 31-49. New York: Plenum Press. 
DePaulo, B. M. 1992. Nonverbal behavior and self-presentation. Psychological Bulletin, 11: 203243.

DePaulo, B. M., Lindsay, J. J., Malone, B. E., Muhlenbruck, L., Charlton, K., \& Cooper, H. 2003. Cues to Deception. Psychological Bulletin, 129(1): 74-118.

DeShields, J. O. W., Kara, A., \& Kaynak, E. 1996. Source effects in purchase decisions: The impact of physical attractiveness and accent of salesperson. International Journal of Research in Marketing, 13: 89-101.

DeVellis, R. F. 1991. Scale development: Theory and applications. Newbury Park, CA: Sage.

Duval, S. \& Wicklund, R. A. 1972. A theory of objective self-awareness. New York: Academic Press.

Eisenhardt, K. M. 1989. Building Theories from Case Study Research. Academy of Management Review, 14(4): 532-550.

Elliot, A. 2001. Concepts of the self. Malden: Blackwell Publishers.

Elliott, G. C. 1979. Some Effects of Deception and Level of Self-Monitoring on Planning and reacting to a Self-Presentation. Journal of Personality and Social Psychology, 37(8): 12821292.

Erickson, R. J. 1995. The importance of authenticity for self and society. Symbolic Interaction, 18(2): 121-144.

Ernst, B. \& Kieser, A. 2002. In Search of Explanations for the Consulting Explosion. In L. Engwall \& K. Sahlin-Andersson (Eds.), The Expansion of Management Knowledge: Carriers,

Flows, and Sources: 47-73. Stanford: Stanford University Press.

Falbe, C. M. \& Yukl, G. 1992. Consequences for managers of using single influence tactics and combinations of tactics. Academy of Management Journal, 35(3): 638-652.

Fandt, F. M. 1986. The effects of accountability and ambiguity on information management. Paper presented at the Academy of Management, New Orleans, LA.

Feldman, D. C. \& Klich, N. R. 1991. Impression Management and Career Strategies. In R. A. Giacalone \& P. Rosenfeld (Eds.), Applied Impression Management. How Image-Making Affects Managerial Decisions: 67-80. Newbury Park: Sage.

Fenigstein, A., Scheier, M. F., \& Buss, A. H. 1975. Public and private self-consciousness: Assessment and theory. Journal of Consulting and Clinical Psychology, 43: 522-527. 
Ferris, G. R. \& Judge, T. A. 1991. Personnel/Human Resources Management: A Political Influence Perspective. Journal of Management, 17: 447-488.

Ferris, G. R., Judge, T. A., Rowland, K. M., \& Fitzgibbons, D. E. 1994. Subordinate influence and the performance evaluation process: Test of a Model. Organizational behavior and human decision processes, 58: 101-135.

Filipp, S.-H. \& Freudenberg, E. 1989. Der Fragebogen zur Erfassung dispositionaler Selbstaufmerksamkeit (SAM-Fragebogen). Göttingen: Hogrefe.

Fincham, R. \& Clark, T. 2002. Introduction: The Emergence of Critical Perspectives on Consulting. In T. Clark \& R. Finchham (Eds.), Critical Consulting: New Perspectives on the Management Advice Industry. Oxford: Blackwell.

Fletcher, C. 1981. The influence of candidate's beliefs and self-presentation strategies in selection interviews. Personnel Review, 10: 14-17.

Fletcher, C. 1989. Impression Management in the Selection Interview. In R. A. Giacalone \& P. Rosenfeld (Eds.), Impression Management in the Organization: 269-282. Hove and London: Lawrence Erlbaum Associates.

Flynn, L. R. \& Pearcy, D. 2001. Four subtle sins in scale development: some suggestions for strengthening the current paradigm. International Journal of Market Research, 43(4): 409423.

Ford, M. E. 1985. The concept of competence: Themes and variations. In H. A. Marlowe \& R. B. Weinberg (Eds.), Competence development: 3-49. Springfield: Thomas Publishers.

Friedman, H. S. \& Miller-Herringer, T. 1991. Nonverbal Display of Emotion in Public and in Private: Self-Monitoring, Personality, and Expressive Cues. Journal of Personality and Social Psychology, 61(5): 766-775.

Gangestad, S. W. \& Snyder, M. 2000. Self-Monitoring: Appraisal and Reappraisal. Psychological Bulletin, 126(4): 530-555.

Gardner, W. L. \& Martinko, M. J. 1988. Impression Management in Organizations. Journal of Management Studies, 14(2): 321-338.

Gardner, W. L., Avolio, B. J., Luthans, F., May, D. R., \& Walumbwa, F. O. 2005. "Can you see the real me?" A self-based model of authentic leader and follower development. The Leadership Quarterly, 16: 343-372.

Gergen, K. J. \& Wishnov, B. 1965. Others' self-evaluations and interaction anticipation as determinants of self-presentation. Journal of Personality and Social Psychology, 2(3): 348358. 
Giacalone, R. A. \& Rosenfeld, P. (Eds.). 1989. Impression Management in the Organization. Hove and London: Lawrence Erlbaum Associates.

Giacalone, R. A. \& Rosenfeld, P. 1991. Applied Impression Management: How Image-Making Affects Managerial Decisions. Newbury Park, CA: Sage.

Giles, H., Mulac, A., Bradac, J. J., \& Johnson, P. 1987. Speech accommodation theory: The first decade and beyond. In M. McLaughlin (Ed.), Communication Yearbook 19. Newbury Park, CA: Sage.

Gilmore, D. C. \& Ferris, G. R. 1989. The effects of applicant impression management tactics on interviewer judgments. Journal of Management, 15: 557-564.

Ginzel, L. E., Kramer, R. M., \& Sutton, R. I. 2004. Organizational Impression Management as a Reciprocal Influence Process: The Neglected Role of the Organizational Audience. In M. J. Hatch \& M. Schultz (Eds.), Organizational Identity: 223-261. Oxford: Oxford Management Readers.

Goffman, E. 1959. The Presentation of self in everyday life. New York: Anchor Books.

Goffman, E. 1961. Encounters. Indianapolis.

Goffman, E. 1967. Interaction ritual. New York: Pantheon Books.

Goldfried, M. R. \& Merbaum, M. 1973. Behavior Change through Self-Control. New York: Holt, Rinehart and Winston Inc.

Gordon, R. A. 1996. Impact of ingratiation on judgments and evaluations: a meta-analytic investigation. Journal of Personality and Social Psychology, 71: 54-70.

Grandey, A. A. 2000. Emotion Regulation in the Workplace: A New Way to Conceptualize Emotional Labor. Journal of Occupational Health Psychology, 5(1): 95-110.

Grandey, A. A. 2003. When the Show Must Go On: Surface Acting and Deep Acting as Determinants of Exhaustion and Peer-Rated Service Delivery. Academy of Management Journal, 46(1): 86-96.

Grandey, A. A., Fisk, G. M., Mattila, A. S., Jansen, K. J., \& Sideman, L. A. 2004. Is "service with a smile" enough? Authenticity of positive displays during service encounters. Organizational Behavior and Human Decision Processes, 96: 38-55.

Grandey, A. A., Fisk, G. M., Mattila, A. S., Jansen, K. J., \& Sideman, L. A. 2005a. Is "service with a smile" enough? Authenticity of positive displays during service encounters. Organizational Behavior and Human Decision Processes, 96: 38-55.

Grandey, A. A., Fisk, G. M., \& Steiner, D. D. 2005b. Must "Service With a Smile" be Stressful? The Moderating Role of Personal Control for American and French Employees. Journal of Applied Psychology, 90(5): 893-904. 
Graves, L. M. \& Powell, G. N. 1988. An investigation of sex discrimination in recruiters' evaluations of actual applicants. Journal of Applied Psychology, 73(20-29).

Grayson, K. 1998. Customer responses to emotional labour in discrete and relational service exchange. International Journal of service Industry Management, 9(2): 125-154.

Greenwald, A. G. \& Breckler, S. J. 1985. To whom is the self presented? In B. R. Schlenker (Ed.), The Self and Social Life: 126-145. California: Brooks/Cole Publishing Company.

Grove, S. J. \& Fisk, R. 1989. Impression Management in Services Marketing: A Dramaturgical Perspective. In R. A. Giacalone \& P. Rosenfeld (Eds.), Impression Management in the Organization: 427-438. Hillsdale, New Jersey: Lawrence Erlbaum Associates.

Hair, J. F. J., Anderson, R. E., Tatham, R. L., \& Black, W. C. 1998. Multivariate Data Analysis (Fifth Edition ed.). New Jersey: Prentice-Hall, Inc.

Harris, K. J., Kacmar, K. M., Zivnuska, S., \& Shaw, J. D. 2007. The impact of political skill on impression management effectiveness. Journal of Applied Psychology, 92: 278-285.

Harter, S. 2002. Authenticity. In C. R. Snyder \& S. Lopez (Eds.), Handbook of positive psychology: 383-394. Oxford: Oxford University Press.

Hewitt, P. L., Flett, G. L., \& Mosher, S. W. 1992. The Perceived Stress Scale: Factor Structure and relation to Depression Symptoms in a Psychiatric Sample. Journal of Psychopathology and Behavioral Assessment, 14(3): 247-257.

Hewlin, P. F. 2003. And the award for best actor goes to ...: Facades of conformity in organizational settings. The Academy of Management Review, 28(4): 633-642.

Higgins, C. A., Judge, T. A., \& Ferris, G. R. 2003. Influence tactics and work outcomes: a metaanalysis. Journal of Organizational Behavior, 24: 89-106.

Higgins, E. T. 1992. Achieving 'shared reality' in the communication game: a social action that creates meaning. Journal of Language and Social Psychology, 11(3): 107-131.

Hochschild, A. R. 1983. The Managed Heart: Commercialization of Human Feeling. Berkeley: University of California Press.

Hogan, R. \& Cheek, J. M. 1983. Identity, authenticity, and maturity. In T. R. Sarbin \& K. E. Scheibe (Eds.), Studies in social identity: 339-357. New York: Praeger.

Hu, L. \& Bentler, P. M. 1998. Fit Indices in Covariance Structure Modeling: Sensitivity to Underparameterized Model Misspecification. Psychological Methods, 3(4): 424-453.

Huber, V. L., Latham, G. P., \& Locke, E. A. 1989. The Management of Impressions Through Goal Setting. In R. A. Giacalone \& P. Rosenfeld (Eds.), Impression Management in the Organization: 203-218. Hove and London: Lawrence Erlbaum Associates. 
Huczynski, A. A. 1996. Influencing within Organisations. London: Prentice Hall.

Hull, J. G. 2002. Modeling the Structure of Self-Knowledge and the Dynamics of Self-Regulation. In A. Tesser \& D. A. Stapel \& J. V. Wood (Eds.), Self and Motivation: Emerging Psychological Perspectives: 173-203. Washington: American Psychological Association.

Iddekinge van, C. H., McFarland, L. A., \& Raymark, P. H. 2007. Antecedents of Impression Management Use and Effectiveness in a Structured Interview. Journal of Management, 33(5): 752-773.

Jagacinski, C. M. \& Nicholls, J. G. 1990. Reducing effort to protect perceived ability: "They'd do it but I wouldn't." Journal of Educational Psychology, 82: 15-21.

Jones, E. E. 1964. Ingratiation: A social-psychological analysis. New York: Appleton-CenturyCrofts.

Jones, E. E. \& Berglas, S. 1978. Control of attributions about the self through self-handicapping strategies: The appeal of alcohol and the role of underachievement. Personality and Social Psychology Bulletin, 4: 200-206.

Jones, E. E. \& Pittman, T. S. 1982. Toward a General Theory of Strategic Presentation. In J. Suls (Ed.), Psychological perspectives on the self, Vol. 1: 231-262. London: Lawrence Erlbaum Associates.

Jones, E. E. 1990. Interpersonal perception. New York.

Jones, R. G. \& Jones, E. E. 1964. Optimum conformity as an ingratiation tactic. Journal of Personality, 32: 436-458.

Jordan, J. M. \& Roloff, M. E. 1997. Planning skills and negotiator goal accomplishment: the relationship between self-monitoring and plan generation, plan enactment, and plan consequences. Communication Research, 2(24): 31-63.

Jordon, J. M. \& Roloff, M. E. 1997. Planning skills and negotiator goal accomplishment: The relationship between self-mentoring and plan generation, plan enactment, and plan consequences. Communication Research, 24: 31-63.

Judge, T. A. \& Bretz, R. D. 1994. Political influence behavior and career success. Journal of Management, 20: 43-65.

Juvonen, J. \& Murdock, T. B. 1993a. How to Promote Social Approval: Effects of Audience and Achievement Outcome on Publicly Communicated Attributions. Journal of Educational Psychology, 85(2): 365-376.

Juvonen, J. \& Weiner, B. 1993b. An Attributional Analysis of Students' Interactions: The Social 
Consequences of Perceived Responsibility. Educational Psychology Review, 5(4): 325-345.

Kacmar, K. M., Delery, J. E., \& Ferris, G. R. 1992. Differential effectiveness of applicant impression management tactics on employment interview decisions. Journal of Applied Social Psychology, 22(1250-1272).

Kacmar, K. M. \& Carlson, D. S. 1999. Effectiveness of Impression Management Tactics across Human Resource Situations. Journal of Applied Social Psychology, 29(6): 1293-1314.

Kacmar, K. M., Harris, K. J., \& Nagy, B. G. 2007. Further Validation of the Bolino and Turnley Impression Management Scale. Journal of Behavioral and Applied Management: 16-32.

Kanfer, F. H. 1973. Self-Regulation (Research, Issues, and Speculations). In M. R. Goldfried \& M. Merbaum (Eds.), Behavior Change through Self-Control: 397-406. New York: Holt, Rinehart and Winston Inc.

Kanfer, F. H. 1977. The many faces of self-control, or behavior modification changes its focus. In R. B. Stuart (Ed.), Behavioral self-management: strategies, techniques and outcomes: 148. New York: Brunner/Masel.

Karoly, P. 1993. Mechanisms of self-regulation: A systems view. Annual Review of Psychology, 44: 23-52.

Katz, D. \& Kahn, R. L. 1978. The Social Psychology of Organizations. New York: John Wiley.

Kernis, M. H. 2003. Toward a conceptualization of optimal self-esteem. Psychological Inquiry, 14: $1-26$.

Kieser, A. 1998. Unternehmensberater - Händler in Problemen, Praktiken und Sinn. In H. Glaser \& E. F. Schröder \& A. v. Werder (Eds.), Organisation im Wandel der Märkte: 191-226. Wiesbaden: Gabler.

Kieser, A. 2002. On Communication Barriers between Management Science, Consultancies and Business Companies. In T. Clark \& R. Fincham (Eds.), The Management Advice Industry: Critical Perspectives on Consultants, Gurus and Managerial Knowledge: 206-227. Oxford: Blackwell.

Kilduff, M. \& Day, D. V. 1994. Do chameleons get ahead? The effects of self-monitoring on managerial careers. Academy of Management Journal, 37(4): 1047-1061.

Kipnis, D., Schmidt, S. M., \& Wilkinson, I. 1980. Intraorganizational Influence Tactics: Explorations in Getting One's Way. Journal of Applied Psychology, 65(4): 440-452.

Kipnis, D. \& Schmidt, S. M. 1988. Upward influence styles: relationship with performance evaluations, salary, and stress. Administrative Science Quarterly, 33: 528-542. 
Kirouac, G. \& Hess, U. 1999. Group membership and decoding nonverbal behavior. In P. Philipport \& R. S. Feldman \& E. U. Coats (Eds.), The social context of nonverbal behavior: 182-212. Cambridge: University Press.

Klein, O., Snyder, M., \& Livingston, R. W. 2004. Prejudice on stage: self-monitoring and the public expression of group attitudes. British Journal of Social Psychology, 43(2): 299-314.

Kohr, J. 2000. Die Auswahl von Unternehmensberatungen. Klientenverhalten Beratermarketing. München.

Krippendorff, K. 2004. Content Analysis: An Introduction to Its Methodology (2nd ed.). Thousand Oaks, CA: Sage.

Kristof-Brown, A., Barrick, M. R., \& Franke, M. 2002. Applicant Impression Management: Dispositional Influences and Consequences for Recruiter Perceptions of Fit and Similarity. Journal of Management, 28(1): 27-46.

Kubr, M. 1976. Management Consulting: A Guide To The Profession. Geneva: International Labor Office.

Kuhl, J. \& Fuhrmann, A. 1998. Decomposing Self-Regulation and Self-Control: The Volitional Components Inventory. In J. Heckhausen \& C. S. Dweck (Eds.), Motivation and SelfRegulation Across the Life-Span: 15-49. Cambridge: Cambridge University Press.

Kuhl, J. 2000. A functional-design approach to motivation and self-regulation: The dynamics of personality systems and interactions. In M. Boekaerts \& P. R. Pintrich \& M. Zeidner (Eds.), Handbook of Self-Regulation: 111-169. California: Academic Press.

Kumar, K. \& Beyerlein, M. 1991. Construction and validation of an instrument for measuring ingratiatory behaviors in organizational settings. Journal of Applied Psychology, 76: 619627.

Lalwani, A. K., Shavitt, S., \& Johnson, T. 2006. What is the Relation Between Cultural Orientation and Socially Desirable Responding? Journal of Personality and Social Psychology, 90(1): 165-178.

Leary, M. R. 1989. Self-Presentational Processes in Leadership Emergence and Effectiveness. In R. A. Giacalone \& P. Rosenfeld (Eds.), Impression Management in the Organization: 363374. Hove and London: Lawrence Erlbaum Associates.

Leary, M. R. \& Kowalski, R. M. 1990. Impression Management: A literature review and a two component model. Psychological Bulletin, 107: 34-47.

Leary, M. R. 1995. Self-Presentation: Impression Management and Interpersonal Behavior. Madison, Wisconsin, Iowa: Brown \& Benchmark's. 
Levashina, J. \& Campion, M. A. 2007. Measuring faking in the employment interview:

Development and validation of an interview faking behavior scale. Journal of Applied Psychology, 92(6): 1638-1656.

Locke, E. A. \& Latham, G. P. 1990. A Theory of Goal Setting and Task Performance. New Jersey: Prentice Hall Inc., Englewood Cliffs.

McFarland, R. G. 2003. Crisis of Conscience: The Use of Coercive Sales Tactics and Resultant Felt Stress in the Sales-person. Journal of Personal Selling and Sales Management, 23(4): 311-326.

Mielke, R. 1990. Ein Fragebogen zur Wirksamkeit der Selbstdarstellung. Zeitschrift für Sozialpsychologie, 21: 162-170.

Miles, M. \& Huberman, A. M. 1984. Qualitative data analysis. Beverly Hills, CA: Sage.

Molenaar, P. C. M. \& Campbell, C. G. 2009. The New Person-Specific Paradigm in Psychology. A Journal of the Association for Psychological Science, 18(2): 112-117.

Moss, S. E., Valenzi, E. R., \& Taggart, W. 2003. Are Your Hiding from Your Boss? The Development of a Taxonomy and Instrument to Assess the Feedback Management Behaviors of Good and Bad Performers. Journal of Management Studies, 29(4): 487-510. Mummendy, H. D. 1995. Psychologie der Selbstdarstellung (2 ed.). Göttingen: Hogrefe.

Niedereichholz, C. 1996. Unternehmensberatung (1 ed.). München.

Olds, P. R. \& Crumbley, D. L. 2003. Higher grades = higher evaluations: impression management of students. Quality Insurance in Education, 11(3): 172-177.

Parham, I. A., Feldman, R. S., Oster, G. D., \& Popoola, O. 1981. Intergenerational differences in nonverbal disclosure of deception. The Journal of Social Psychology, 113: 261-269.

Patterson, P. G. 1995. Choice criteria in final selection of a management consultancy service. Journal of Professional Services Marketing, 11(2): 177-188.

Paulhus, D. L. 1986. Self-deception and impression management in test responses. In A. Angleitner \& J. S. Wiggins (Eds.), Personality assessment via questionnaire: 143-165. New York: Springer-Verlag.

Paulhus, D. L. 1991. Measurement and control of response bias. In J. P. Robinson \& P. R. Shaver \& L. S. Wrightsman (Eds.), Measurement of personality and social psychological attitudes: 17-59. San Diego: Academic Press. 
Peterson, R. A. 1997. Creating Country Music: Fabricating Authenticity. Chicago and London: University of Chicago Press.

Pintrich, P. R. 2000. The role of goal orientation in self-regulation learning. In M. Boekaerts \& P.

R. Pintrich \& M. Zeidner (Eds.), Handbook of self-regulation: 452-494. San Diego: Academic Press.

Price, L. L., Arnould, E. J., \& Deibler, S. L. 1994. Consumers' emotional responses to service encounters. International Journal of Service Industry Management, 6(3): 34-63.

Rafaeli, A. \& Sutton, R. I. 1987. Expression of Emotion as Part of the Work Role. The Academy of Management Review, 12(1): 23-37.

Rafaeli, A. \& Sutton, R. I. 1989. The Expression of Emotion in Organizational Life. Research in Organizational Behavior, 11: 1-42.

Rafaeli, A. \& Pratt, M. G. 1993. Tailored Meanings: On the Meaning and Impact of Organizational Dress. The Academy of Management Review, 18(1): 33-55.

Rafaeli, A. \& Harness, A. 2002. Validation of self-presentation: Theory and findings from letters of application for employment. Advances in Qualitative Organization Research, 4: 1-37.

Ralston, D. A. 1985. Employee ingratiation: The role of management. Academy of Management Review, 10: 477-487.

Riggio, R. E. \& Friedman, H. S. 1983. Individual Differences and Cues to Deception. Journal of Personality and Social Psychology, 45(4): 899-915.

Riggio, R. E. 1986. Assessment of Basic Social Skills. Journal of Personality and Social Psychology, 51(3): 649-660.

Roberts, L. M. 2005. Changing Faces: Professional Image construction in diverse organizational settings. Academy of Management Review, 30(4): 685-711.

Roe, R. 2008. Time in Applied Psychology: The Study of "What Happens" Rather than "What is". European Psychologist, 13(1): 37-52.

Roe, R. A. 2002. Competenties - Een sleutel tot integratie in theorie en praktijk van de A\&Opsychologie (Competences - A key towards integration in theory and practice in W\&O Psychology). Gedrag \& Organisatie, 15(4): 203-224.

Rosenfeld, P., Giacalone, R. A., \& Riordan, C. A. 1995. Impression Management in Organizations. London: Routledge.

Rosenfeld, P., Giacalone, R. A., \& Riordan, C. A. 2002. Impression Management: Building and Enhancing Reputations at Work. London and New York: Routledge. 
Roth, D. L., Snyder, C. R., \& Pace, L. M. 1986. Dimensions of Favorable Self-Presentation. Journal of Personality and Social Psychology, 51(4): 867-874.

Rudman, L. A. 1998. Self-promotion as a Risk Factor for Women: The Costs and Benefits of Counterstereotypical Impression Management. Journal of Personality and Social Psychology, 74(3): 629-645.

Ryan, R. M. \& Deci, E. L. 2003. On assimilating identities to the self: A self-determination theory perspective on internalization and integrity within cultures. In M. R. Leary \& J. P. Tangney (Eds.), Handbook of self and identity: 253-272. New York: Guilford.

Sackett, P. R. 2007. Revisiting the Origins of the Typical-Maximum Performance Distinction. Human Performance, 20(3): 179-185.

Salovey, P. \& Mayer. 1990. Emotional Intelligence. Imagination, Cognition, and Personality, 9(3): $185-211$.

Schaefer, A. D. \& Pettijohn, C. E. 2006. The relevance of authenticity in personal setting: is genuineness an asset or liability? Journal of Marketing Theory and Practice, 14(1): 25-35.

Schlenker, B. \& Weigold, M. F. 1990. Self-consciousness and self-presentation: Being autonomous versus appearing autonomous. Journal of Personality and Social Psychology, 59: 820-828.

Schlenker, B. R. 1975. Self-Presentation: Managing the Impression of Consistency When Reality Interferes with Self-Enhancement. Journal of Personality and Social Psychology, 32(6): $1030-1037$.

Schlenker, B. R. 1980. Introduction: Foundations of the Self in Social Life. In B. R. Schlenker (Ed.), Impression Management: The Self-Concept, Social Identity, and Interpersonal Relations: 1-28. California: Brooks/Cole Publishing Company.

Schlenker, B. R. \& Leary, M. R. 1982. Social Anxiety and Self-Presentation: A Conceptualization and Model. Psychological Bulletin, 92(3): 641-669.

Schlenker, B. R. 1985. Identify and Self-Identification. In B. R. Schlenker (Ed.), The self and social life: 65-100. New York: McGraw-Hill Book Company.

Schlenker, B. R. \& Weigold, M. F. 1992. Interpersonal processes involving impression regulation and management. Annual Review of Psychology, 43: 133-168.

Schlenker, B. R., Britt, T. W., \& Pennington, J. 1996. Impression regulation and management: Highlights of a theory of self-identification. In R. M. Sorrentino \& E. T. Higgins (Eds.), Handbook of motivation and cognition, Vol. 2: 118-147. New York: Guilford. 
Schlenker, B. R. 2003. Self-presentation. In M. R. Leary \& J. P. Tangney (Eds.), Handbook of self and identity: 492-518. New York: Guilford Press.

Schneider, D. J. \& Eustis, A. C. 1972. Effects of ingratiation motivation, target positiveness, and revealingness on self-presentation. Journal of Personality and Social Psychology, 22: 142155.

Selchert, M. 1997. Organisationsstrukturen und Professionalität. Formen und Funktionen professioneller In-house Dienstleistungen (1 ed.). Hamburg: Verlag Dr. Kovac.

Singh, V. \& Vinnicombe, S. 2001. Impression Management, Commitment and Gender: Managing Others' Good Opinions. European Management Journal, 19(2): 183-194.

Singh, V., Kumra, S., \& Vinnicombe, S. 2002. Gender and Impression Management: Playing the Promotion Game. Journal of Business Ethics, 37: 77-89.

Snyder, M. 1974. Self-Monitoring of Expressive Behavior. Journal of Personality and Social Psychology, 30(4): 526-537.

Snyder, M. \& Cantor, N. 1980. Thinking about ourselves and others: self-monitoring and social knowledge. Journal of Personality and Social Psychology, 39: 222-234.

Snyder, M. \& Campbell, B. H. 1982. Self-Monitoring: The Self in Action. In J. Suls (Ed.), Psychological perspectives on the self, Vol. 1: 185-208. London: Lawrence Erlbaum Associates.

Snyder, M. \& Gangestad, S. 1986. On the nature of self-monitoring: matters of assessment, matters of validity. Journal of Personality and Social Psychology, 51: 125-139.

Snyder, M. 1987. Public Appearance/Private Realities. New York: W.H. Freeman and Company. Solomon, M. R., Surprenant, C., Czepiel, J. A., \& Gutman, E. G. 1985. A Role Theory Perspective on Dyadic Interaction: The Service Encounter. Journal of Marketing, 49: 99111.

Starbuck, W. H. 1992. Learning by Knowledge-Intensive Firms. Journal of Management Studies, 29: 713-740.

Staute, J. 1998. Der Consulting-Report. Vom Versagen der Manager zum Reibach der Berater. Frankfurt am Main: Heyne.

Stevens, C. K. \& Kristof, A. L. 1995. Making the right impression: A field study of candidate impression management during job interviews. Journal of Applied Psychology, 80(587606). 
Tashakkori, A. \& Teddlie, C. 1998. Mixed Methodology. Thousand Oaks: Sage Publications. Tedeschi, J. T. 1981. Impression Management Theory and Social Psychological Research. New York: Academic Press.

Tedeschi, J. T. \& Riess, M. 1981. Verbal strategies in impression management. In C. Antaki (Ed.), The psychology of ordinary social behaviour: 271-309. London: Academic Press.

Tedeschi, J. T. \& Melburg, V. 1984. Impression management and influence in the organization. In S. Bacharach \& P. Bamberger \& T. P. \& D. Torres \& E. J. Lawler (Eds.), Research in the sociology of organizations, Vol. 3: 31-58. Greenwich/London: Jai Pr., Inc.

Tedeschi, J. T. \& Norman, N. 1985. Social Power, Self-Presentation, and the Self. In B. R. Schlenker (Ed.), The Self and Social Life: 293-322. California: Brooks/Cole Publishing Company.

Tetlock, P. E. 1980. Explaining Teacher Explanations of Pupil Performance: A Self-Presentation Interpretation. Social Psychology Quarterly, 43(3): 283-290.

Thacker, R. A. \& Wayne, S. J. 1995. An Examination of the Relationship Between Upward Influence Tactics and Assessments of Promotability. Journal of Management, 21(4): 739756.

Thomas, A. B. \& Al-Maskati, H. 1997. Contextual influences on thinking in organizations: Learner and tutor orientations to organizational learning. Journal of Management Studies, 34(6): 852-870.

Thorndike, E. L. 1920. A constant error in psychological ratings. Journal of Applied Psychology, 4: 25-29.

Thorndike, R. L. \& Hagen, E. 1961. Measurement and evaluation in psychology and education (2nd ed.). New York.

Toris, C. \& DePaulo, B. M. 1985. Effects of Actual Deception and Suspiciousness of Deception on Interpersonal Perceptions. Journal of Personality and Social Psychology, 47(5): 10631073.

Turnley, W. H. \& Bolino, M. C. 2001. Achieving desired images while avoiding undesired images: Exploring the role of self-monitoring in impression management. Journal of Applied Psychology, 86: 351-360.

Urdan, T., Midgley, C., \& Anderman, E. M. 1998. Role of Classroom Goal Structure in Students' Use of Self-Handicapping Strategies. American Educational Research Journal, 35(1): 101 122. 
Vandenberg, R. J. \& Lance, C. E. 2000. A Review and Synthesis of the Measurement Invariance Literature: Suggestions, Practices, and Recommendations for Organizational Research. Organizational Research Methods, 3(1): 4-70.

Vilela, b. B., González, J. A. V., Ferrín, P. F., \& del Río Araújo, M. L. 2007. Impression management tactics and affective context: influence on sales performance appraisal. European Journal of Marketing, 41(5): 624-639.

Villanova, P. \& Bernardin, H. J. 1991. Performance Appraisal: The Means, Motive, and Opportunity to Manage Impressions. In R. A. Giacalone \& P. Rosenfeld (Eds.), Applied Impression Management. How Image-Making Affects Managerial Decisions: 81-96. Newbury Park: Sage.

Vohs, K. D. \& Ciarocco, N. J. 2004. Interpersonal Functioning Requires Self-Regulation. In R. F. Baumeister \& K. D. Vohs (Eds.), Handbook of Self-Regulation. Research, Theory, and Applications: 392-410. New York: The Guilford Press.

Vohs, K. D., Baumeister, R. F., \& Ciarocco, N. J. 2005. Self-Regulation and Self-Presentation: Regulatory Resource Depletion Impairs Impression Management and Effortful SelfPresentation Depletes Regulatory Resources. Journal of Personality and Social Psychology, 88(632-657).

Wall, J. A. J. 1991. Impression Management in Negotiations. In R. A. Giacalone \& P. Rosenfeld (Eds.), Applied Impression Management. How Image-Making Affects Managerial Decisions: 133-156. Newbury Park: Sage.

Walumbwa, F. O., Avolio, B. J., Gardner, W. L., Wernsing, T. S., \& Peterson, S. J. 2008. Authentic Leadership: Development and Validation of a Theory-Based Measure. Journal of Management, 34(1): 89-126.

Watt, J. D. 1993. The Impact of the Frequency of Ingratiation on the Performance Evaluation of Bank Personnel. The Journal of Psychology, 127(2): 171-177.

Wayne, S. J. \& Ferris, G. R. 1990. Influence tactics, affect and exchange quality in supervisorsubordinate interactions: A laboratory experiment and field study. Journal of Applied Psychology, 75: 487-499.

Wayne, S. J. \& Kacmar, K. M. 1991. The effects of impression management on the performance appraisal process. Organizational Behavior and Human Decision Processes, 48: 70-88.

Wayne, S. J. \& Liden, R. C. 1995. Effects of impression management on performance ratings: A longitudinal study. Academy of Management Journal, 38(1): 232-260. 
Wayne, S. J., Liden, R. C., Graf, I. K., \& Ferris, G. R. 1997. The role of upward influence tactics in human resource decisions. Personnel Psychology, 50: 979-1006.

Webb, W. M., Marsh, K. L., Scheiderman, W., \& Davis, B. 1989. Interaction between selfmonitoring and manipulated states of self-awareness. Journal of Personality and Social Psychology, 56(1): 70-80.

Weiner, B. 2003. The classroom as a courtroom. Social Psychology of Education, 6: 3-15.

Weiss, B. \& Feldman, R. S. 2006. Looking Good and Lying to Do it: Deception as an Impression Management Strategy in Job Interviews. Journal of Applied Social Psychology, 36(4): 10701086.

Westphal, J. D. \& Stern, I. 2006. The other pathway to the boardroom: Interpersonal influence behavior as a substitute for elite credentials and majority status in obtaining board appointments. Administrative Science Quarterly, 51: 169-204.

Wharton, A. S. 1993. The Affective Consequences of Service Work. Managing Emotions on the Job. Work and Occupations, 20(2): 205-232.

Zeidner, M., Boekaerts, M., \& Pintrich, P. R. 2000. Self-regulation: Directions and Challenges for future research. In M. Boekaerts \& P. R. Pintrich \& M. Zeidner (Eds.), Handbook of selfregulation.: 749-768. San Diego: Academic Press.

Zimmermann, B. J. 2000. Attaining self-regulation: A social cognitive perspective. In M.

Boekaerts, Pintrich, P.R. and Zeidner, M. (Ed.), Handbook of Self-Regulation.: 13-39.

California: Academic Press.

Zivnuska, S., Kacmar, K. M., Witt, L. A., Carlson, D. S., \& Bratton, V. K. 2004. Interactive effects of impression management and organizational politics on job performance. Journal of Organizational Behavior, 25: 627-640.

Zuckerman, M., DePaulo, B. M., \& Rosenthal, R. 1981. Verbal and nonverbal communication in deception. In L. Berkowitz (Ed.), Advances in experimental social psychology, Vol. 14. New York: Academic Press. 


\section{APPENDICES}

\section{APPENDIX A: CHAPTER 2}

\section{Definitions of IM Behaviors}

\begin{tabular}{|c|c|}
\hline BEHAVIOR & DEFINITION \\
\hline & Actors ... \\
\hline Accounts & $\begin{array}{l}\text { provide explanations for a negative event to escape disapproval; excuses and } \\
\text { justifications are specific types of accounts. }\end{array}$ \\
\hline Apologies & $\begin{array}{l}\text { accept responsibility for a negative event, offer to make things right, and promise to do } \\
\text { better in the future; a form of defensive IM. }\end{array}$ \\
\hline Assertive IM & $\begin{array}{l}\text { proactively manage impressions about themselves, typically by means of enhancements, } \\
\text { ingratiation, self-promotion, exemplification. }\end{array}$ \\
\hline Blaring & publicly minimize their connections with unfavorable others; a form of self-focused IM. \\
\hline Blurring & $\begin{array}{l}\text { blur their connections with favorable others by way of strategic omissions; a form of } \\
\text { self-focused IM. }\end{array}$ \\
\hline Boasting & boast about their positive connections with favorable others; a form of self-focused IM. \\
\hline Burying & conceal their connections with unfavorable others; a form of self-focused IM. \\
\hline Defamation & attempt to harm the reputation of the target. \\
\hline Defensive IM & $\begin{array}{l}\text { reactively manage impressions about themselves, typically by means of apologies, } \\
\text { excuses, justification, and self-handicapping. }\end{array}$ \\
\hline Demonstrative IM & provide facts or details regarding the organization's specific activities. \\
\hline Enhancement & $\begin{array}{l}\text { claim that positive outcomes for which they are responsible are more valuable than } \\
\text { generally believed; a form of assertive, self-focused IM. }\end{array}$ \\
\hline Excuses & deny responsibility for negative behavior or outcomes; a form of account; defensive IM. \\
\hline Exemplification & $\begin{array}{l}\text { do more or better than is necessary to attempt to appear dedicated or superior; a form } \\
\text { of assertive IM. }\end{array}$ \\
\hline Favor rendering & help others or do favors for them; a form of ingratiation. \\
\hline Illustrative IM & focus on things like pictures or broad generalizations. \\
\hline Ingratiation & use flattery and favor rendering to attempt to appear likeable; a form of assertive IM. \\
\hline $\begin{array}{l}\text { Intentionally decrease } \\
\text { performance at work }\end{array}$ & $\begin{array}{l}\text { work at less-than-full potential, withdraw, display a bad attitude, looking bad or broadcast } \\
\text { limitations to look bad or incompetent. }\end{array}$ \\
\hline Intimidation & threaten or harass to attempt to appear dangerous and powerful; a form of assertive IM. \\
\hline Job-focused IM & Manipulate job performance information for their own benefit; similar to self-promotion. \\
\hline Justifications & $\begin{array}{l}\text { accept responsibility for negative outcomes but not the negative implications, that is, } \\
\text { there is an external cause for their action; a form of account; defensive IM. }\end{array}$ \\
\hline Nonverbal & alter facial expressions, posture, and so on to attempt to manage impressions. \\
\hline Opinion conformity & speak or behave in ways consistent with the target; form of ingratiation. \\
\hline Other-enhancement & compliment or flatter targets; form of ingratiation. \\
\hline Other-focused IM & $\begin{array}{l}\text { behave in ways intended to make the target perceive them as likable or attractive; } \\
\text { a form of ingratiation. }\end{array}$ \\
\hline
\end{tabular}




\begin{tabular}{ll}
\hline BEHAVIOR & DEFINITION \\
\hline $\begin{array}{l}\text { Self-enhancement } \\
\text { Self-focused IM }\end{array}$ & $\begin{array}{l}\text { make their best characteristics salient to targets; a form of ingratiation. } \\
\text { behave in ways intended to make the actor seen as nice and polite by acting like a } \\
\text { "model" employee or working hard when results will be seen by others; similar to } \\
\text { exemplification. } \\
\text { behave so as to provide an external explanation for poor performance; a form of } \\
\text { defensive IM. } \\
\text { communicate abilities and accomplishments to attempt to appear competent; a form of } \\
\text { self-focused IM. } \\
\text { Self-promotion }\end{array}$ \\
engage in favor rendering, opinion conformity, and other forms of ingratiation that is \\
targeted toward supervisors. \\
pupplication
\end{tabular}

Source: Bolino, M.C., Kacmar, M., Turnley, W.H., and Gilstrap, J.B. 2008. A Multi-Level Review of Impression Management Motives and Behaviors. Journal of Management, 34: 1080-1109.

\section{APPENDIX B: CHAPTER 3}

\section{Contact Summary: Consultants (C1-C5)}

\begin{tabular}{|c|c|c|}
\hline SUBJECTS & BACKGROUND & \\
\hline \multirow{5}{*}{ C1 } & Age & 37 \\
\hline & Gender & Female \\
\hline & Educational level & Certified biologist \\
\hline & Current job & Consultant \\
\hline & Work tenure (in years) & 5 \\
\hline \multirow{5}{*}{$\mathrm{C} 2$} & Age & 33 \\
\hline & Gender & Male \\
\hline & Educational level & Economist \\
\hline & Current job & Consultant \\
\hline & Work tenure (in years) & 4 \\
\hline \multirow{5}{*}{ C3 } & Age & 53 \\
\hline & Gender & Male \\
\hline & Educational level & School leaving certificate \\
\hline & Current job & Senior consultant \\
\hline & Work tenure (in years) & 24 \\
\hline \multirow{5}{*}{ C4 } & Age & 35 \\
\hline & Gender & Male \\
\hline & Educational level & Graduate Industrial Engineer \\
\hline & Current job & Senior consultant \\
\hline & Work tenure (in years) & 7 \\
\hline
\end{tabular}




\begin{tabular}{lll}
\hline SUBJECTS & BACKGROUND & \\
\hline & Age & 48 \\
& Gender & Male \\
C5 & Educational level & Master Degree in German, Philosophy, and Theater Sciences \\
& Current job & Freelance consultant \\
& Work tenure (in years) & 18 \\
\hline
\end{tabular}

\section{Contact Summary: Experts / Trainers (E1-E5)}

\begin{tabular}{|c|c|c|}
\hline SUBJECTS & BACKGROUND & \\
\hline \multirow{3}{*}{ E1 } & Gender & Male \\
\hline & Job position & Freelancer \\
\hline & Job description & $\begin{array}{l}\text { Trainer/coach for interaction with a major focus on voice behavior and } \\
\text { body language. }\end{array}$ \\
\hline \multirow{3}{*}{ E2 } & Gender & Female \\
\hline & Job position & HR Officer \\
\hline & Job description & Responsible for recruiting and HR \\
\hline \multirow{3}{*}{ E3 } & Gender & Male \\
\hline & Job position & Chief Programme Development and Operations Group \\
\hline & Job description & Responsible inter alia for recruiting and HR \\
\hline \multirow[b]{3}{*}{ E4 } & Gender & Female \\
\hline & Job position & Freelance consultant \\
\hline & Job description & $\begin{array}{l}\text { The interviewee has a multiple industry background in retailing, banking and } \\
\text { hospitality. She worked for the Shangri-La group, which is headquartered in } \\
\text { Hong Kong and presently operates } 36 \text { luxury hotels throughout Asia. The } \\
\text { Shangri-La group employs over 25,000 employees. Her role was to facilitate } \\
\text { the company's corporate culture change initiatives as well as oversee the } \\
\text { group's human resources strategies. Prior to joining the Shangri-la group, } \\
\text { she was the Senior Vice President of Service Quality \& Human Resources } \\
\text { for Bank of America, Hawaii where she led the banks service quality } \\
\text { initiative as well as a merger and acquisition. Prior to the bank, she was } \\
\text { Regional Director of Human Resources for over } 10 \text { Sheraton Hotels in } \\
\text { Hawaii and Japan. Lately she worked on a consulting project in Tokyo } \\
\text { handling the largest international hospitality joint venture in Japan. }\end{array}$ \\
\hline \multirow{4}{*}{ E5 } & Gender & Male \\
\hline & Job position & $\begin{array}{l}\text { Senior Vice President, General Manager of WJM Associates, Inc. } \\
\text { (Enhancing Executive and Organizational Effectiveness) }\end{array}$ \\
\hline & Job description & $\begin{array}{l}\text { WJM Associates, with headquarters in New York, provides a broad range of } \\
\text { customized human resources consulting services. These include executive } \\
\text { coaching, assessment and recruitment; organizational effectiveness; and } \\
\text { corporate governance consulting. The firm employs a faculty of } \\
\text { psychologists and consultants, including many former senior business } \\
\text { executives, to meet clients' unique requirements. }\end{array}$ \\
\hline & & $\begin{array}{l}\text { WJM Associates is a recognized leader in the fields of executive and } \\
\text { organizational development. They assist Fortune } 500 \text { and mid-sized } \\
\text { companies in achieving continuous and measurable improvement in their } \\
\text { people's performance. }\end{array}$ \\
\hline
\end{tabular}




\section{Interview Scheme: Consultants - "Work as a Consultant"}

\begin{tabular}{ll}
\hline TOPICS & QUESTIONS \\
\hline Introduction & $\mathbf{1 .}$ How would you describe a typical consultant? \\
& 2. What is the image of a consultant? \\
3. How do you describe yourself as a consultant? As a private person? \\
$\mathbf{4 .}$ Which image of a consultant would you like to express? \\
5. What made you become a consultant? \\
$\mathbf{6 .}$ What is included in the work of a consultant? \\
7. What does it take to be successful as a consultant? \\
$\mathbf{8 .}$ Do you behave differently at work than in privacy? \\
$\mathbf{9 .}$ What do you think when you hear this statement: There are two major aspects to any consulting- \\
\\
10. client relationship: (1) the analysis and solution of the problem, and (2) the relationship between consultant
\end{tabular}

10. When do you recognize that the relationship to the client is important?

IM use $\quad$ 1. Do you try to influence the impressions you make on the client?
2. Do you behave differently when the client is absent?
3. What do you do to obtain information from the client?
4. How far goes the cooperation with the client?
5. Do you recognize a difference of these behaviors in the different stages of a project?

\begin{tabular}{lll}
\hline IM behavior & 1. & Can you describe the nature and outcomes of two or three specific situations in which you \\
& encountered colleagues in your organizations employing IM behavior? \\
2. How can you influence the impressions of other people (with which behavior)? \\
3. Please give examples of how you try to influence the impressions of the client. \\
4. What are the appropriate clothes for a consultant? \\
5. What about verbal behavior? \\
6. What about nonverbal behavior? \\
IM & 1. What are your strengths and weaknesses? \\
& 2. What do you think is needed to be an effective performer in consultancy services? \\
& 3. Do you think you are successful in your performance independent of other impact factors \\
& 4. Which competence, do you think, do you need to influence other people's impressions?
\end{tabular}

IM hindrances 1. What do you think could be personal reasons for failure in performing?

2. Which fears accompany you as a consultant (in regard to the desire to leave a particular impression)?

3. What do you think could be reasons for failing the making the desired impression on the client?

4. What are you doing to work on the reasons?

5. Do you have the conscious goal to influence client's impressions?

6. Do you monitor and evaluate your and client's behavior and adjust your behavior accordingly?

7. Do you belief in your ability to influence client's impressions? 
IM hindrances 8. Consider yourself in the following situation: you and your colleague are working together in your office. You are very busy and concentrated because in one hour you have to give a presentation and the presentation is still to be prepared. Two people enter the room, what do you do? Why?

9. Consider yourself in the following situation: after the presentation, which unfortunately did not work very well but okay, you go back to the hotel. You feel tired and want to go directly to your hotel room. On the way to your hotel room you meet one of your clients. What do you do? Why? Are you effective considering your personal conditions?

10. In the next morning you get a call by your office, telling you that your supervisor has to talk to you. In the days of huge layoffs you get nervous and emotionally aroused. However, you have to moderate a workshop for client's employees today and since it is the first workshop of this type it is very important to make a good impression. Considering your emotions and feelings how do you think would you perform? Why?

11. After the workshop you feel very tired, you couldn't sleep that good last night and therefore you just want to go to bed. On your way out you meet some colleagues from the client's company and they ask you if you would like to go out with them tonight. What do you do? Why?

12. Consider your personal self-image to be more introverted and actually you are not eager to go out with your colleagues, at least not on that day. What could be a reason for the decision to go out? What would be the reason for rejection? How do you feel in these situations?

IM effectiveness
1. Can you think of colleagues who are were/are successful in creating a particular image at the client's place?

2. What do you think how the clients feel then?

3. How are these behaviors evaluated by your company?

4. Do you feel appropriately evaluated?

5. Do you think you are successful when you try to influence the client's impressions? Please give an example of a successful experience and an unsuccessful one.

\section{Interview Scheme: Experts / Trainers}

\begin{tabular}{ll}
\hline TOPICS & QUESTIONS \\
\hline IM use & 1. What are your thoughts on IM? \\
& 2. What do you think are the goals behind IM behavior in the consultancy context? \\
& 3. What images do consultants aim for? \\
\hline IM & 1. What are required competences for effective IM behavior? \\
competence & 2. Of all the competences mentioned, which one do you think is the most necessary one? \\
& 3. Which competences are important for what kind of behavior? \\
\hline IM hindrances & 1. What are personal hindrances for effective IM behavior? \\
& 2. Of all the personal hindrances mentioned, which one do you think is most destructive? \\
& 3. Of all the personal hindrances mentioned, which one do you think is less destructive?
\end{tabular}


THEMES \& (SUB-)

CATEGORIES

REPRESENTATIVE STATEMENTS

\section{THEME 1: CONSULTANTS IMAGES}

\begin{tabular}{|c|c|}
\hline Authentic / honest consultant & $\begin{array}{l}\text { - I want to be perceived as honest. [C1] } \\
\text { - Only when my counterpart believes what I tell or how I behave, I have a } \\
\text { chance to influence him according to my conception. [C2] } \\
\text { - A great level of honesty. [C3] } \\
\text { - I am prepared to say, I do not understand but I know somebody who will. } \\
\text { Then I ask somebody for advice or present him or her at the client and say, } \\
\text { he or she is able to do it. That is well received by clients. [C3] }\end{array}$ \\
\hline Competent consultant & $\begin{array}{l}\text { - The main image is competence, professional as well as human. Here also } \\
\text { social competence and emotional intelligence count. [C3] } \\
\text { - I want to be known as an expert. [C4] } \\
\text { - Professional competence, however I have the opinion, if you want to } \\
\text { impress that is not enough. [C4] }\end{array}$ \\
\hline Likeable consultant & $\begin{array}{l}\text { - How the clients like the consultants, how they appeal to them. Not the } \\
\text { expertise but really how they get along with the client is important. [C1] } \\
\text { - You cannot carry the project effectively out, if you do not get along with the } \\
\text { clients. [C3] } \\
\text { - You play the "Please-like-me-act". [C4] }\end{array}$ \\
\hline
\end{tabular}

\section{THEME 2: IM BEHAVIORS - STYLES AND TACTICS}

\section{IM STYLES}

Authentic IM style

Acting IM style
- I cannot fundamentally dissimulate, there are no fundamental differences. I am Mr. X who performs at the client and that person I am also at home. [C2]

- As a consultant I am not different than as a private person. [C3]

- I do not care about a particular consultant-image. I do try to conform to a specific picture of a consultant. [C3]

- No, I do not change my behavior in interaction with the client. Also not in interaction with my colleagues. I do not know it different. I am not an actor, I do not do that. [C3]

- You can exaggerate but it has to be me. [C4]

- You run the risk to come across ridiculous, because you are not authentic anymore and then the image which I like to present, the good-tempered and nice guy, would not be there anymore. That would personally affect me. Therefore, I try to keep my self-image. My perception has to be positive and my self-image should not be contrary to the one presented to the outside. They cannot differ on 180 degree, they can go in different directions, but not be entirely different. [C4]

- I am happy that I do not necessarily have to carry to two different characters to do the job I like to do and to live my life as I want. [C5]

- I am not an actor and I do not want to be. I want to reach my aim effectively and therefore I use my communication, including facial expression and gesture. Whereupon, my facial expression and gesture rest on my natural competence. [C5]

- I recognize insincere behaviors by colleagues, in particular by those, which I know on a private basis. They jump into a consultant-costume, which they disrobe after the end of work, and then they are fully normal. [C4] 
- You are in the spotlight. The clients ask: what do you think; I mean you are the consultant; we spend a lot of money for you? Therefore, you have to be able to sell yourself. Sometimes you do not have the knowledge and then you have to pretend it and therefore you sell yourself. [C4]

- There are often topics, about which I have not clue. However, it is expected from you, that you can talk about these, even though I have no or little knowledge about it. Then you inevitably have to play act and thereby conceal my lack of knowledge. [C4]

\section{CONSULTANTS' IM TACTICS}

Personal IM tactic

Professional IM tactic
- I try to get on a personal level. That helps a lot. [C2]

- There are some factors of kindness and affection, you have to ensnare the client, listen how it is going, invite for dinner, and try to get in personal conversation. That belongs to it, if the client is responsive. [C2]

- It strikes that having a good relationship with the client is definitely project elongating, it depends how good you can deal with people. [C5]

- I give them information from which they think they normally do not get that kind of information. Then they think, hey he is telling me something, and then I will do so too. That is a good method, when you try to elicit them by given them information they normally do not get and thereby express: I trust you. [C2]

- You have to give the client the feeling, to have you as a partner on his side that you specifically stand up for him. [C3]

- Flattery. That belongs to it. [C4]

- To be nice is just a part of the game. [C2]

- Really successful you can only be, when you bring authenticity, and you optimize the tools you have. [C5]

- To create trust, you have to be honest, do not exaggerate and do not put your knowledge in the background, but also admit that there are others which are better than I. [C3]

- In discussions I try to specifically express what I have done. (...) You point at: I am awesome. [C2]

- When I have to present somewhere, I would like to express, that I have competence on the field. I try to underline this with references. [C2]

- When I can really confirm that we already did this at clients and it worked well, then the readiness of the client to book us for a similar project will be much bigger. [C2]

- Of course I try to influence the client by saying: We can do that, we already did this. However, with such stories you have to be careful, that you only say what you can prove. You can fib but not lie. [C2]

- Through a number of various projects I made experiences in different areas, which I can point out and thereby make a competent impression. [C5]

- If you know that a contract depends on central persons who can report to others: these are good boys; that is even more important for the significance of a project. [C2]

- I think you need the skill to imagine with whom you are dealing. Here an old seller-wisdom should be applied to get as much information about the other as possible. [C5]

- When I want to consult a company (...) I have to prepare for it, what kind of people are there, how do they proceed, how do they think, according to which criteria do they decide, that is the essential thing: I have to prepare. Through this preparation I unconsciously adjust to the situation. So, the first essential information is information over the other, this you have to collect, and then adjust the impression you want to achieve. [C5]

- Starting on time, I think is important, and finishing on time is also important. Because these are things that people remember. [C5] 
- The image of a consultant is the suit, the shirt and the SLK, which make the image. That is surely an indicator, they can dress appropriately, if he drives such a car, which is not cheap, he earns a lot, then he also must perform well, he must do good work. [C2]

- I consciously consider what I wear. [C2]

- I think from a well-tended appearance you can associate an ordered brain and thinking. [C3]

- We are also in a system, where how you appear counts. Obviously when you come in jeans or shorts that will shape very negative impressions in the beginning. There is a minimum in the demand that we have, so the way you appear and the initial message that you convey, these are the ingredients that construct or make an impression, a good or bad one. [C4]

- I dress more conservative and elegant when I meet clients for the first time. [C4]

- We are better dressed than the client. [C4]

- In particular phases it is important that you come in the office appropriately dressed and it happens that you are overdressed, that you stand out of the crowd. That is not a problem. Important is, that you are always noticeable as a contact person, so that you do not develop any timidness in the other. We look out, not only on our performance but also on our clothing. This also has to be accomplished in another setting that means when I carry on with people who work in a factory floor I have to take care, that I can get dirty, und I can also work if necessary. And it is also important to recognize, where the suit is important. That means that you should not have a fixation on a specific working image but that you use it goal-oriented. [C5]

- You choose the language differently. Of course, I speak different with friends. Then I speak in my dialect. I also speak different with an area manager than with the CEO or with a colleague of the client who is in my project. [C3]

- I try to express myself more eloquently and I recognized that you can achieve respect with it. [C4]

- You express yourself better when you take the client's argumentation and lead him to something. [C4]

- You have to make clear, yes, I am all ears that means I am with you and your problems. That you show, yes, I have time, I bring understanding and I am really actively interested, e.g. by taking notes or by asking additional questions to develop understanding, that the clients thinks, yes that is what I said, he understood it. To feel I can deal with him, he knows what I want, that is a very essential point, that you make this impression in communication. [C4]

- I behave more politely and reticent at the client's place. [C2]

- When you know that you want to impress a person, you will do everything necessary to achieve that. You will behave differently in a discussion, e.g. you speak more eloquent. Yes, I do that. Yes, also with ingratiation. Further, when the client says something which supports his argumentation, you sometimes will make a fist in your pocket, because you think it will serve the project. [C4] 


\section{THEME 3: REQUIREMENTS AND OBSTACLES FOR EFFECTIVE IM}

IM competence
- That is also a component of our occupational image; you have to be able to talk with everyone. [C3]

- I would not pat on the back of management. I would also not do it with employees of the client. Of course, I wouldn't do that. I do with my tennis buddies, but otherwise certainly not. No, that is absolutely conscious behavior. I also would not have any reason to get so close. [C3]

- I worked with a colleague; he manipulated others with his face. Very strong with his eyes and the way he looked at others. He rewarded people with a smile or penalized them with a harsh expression. [C4]

- Ability to communicate is a crucial base, which you should have. Active listening is also a component of it. [C5]

- Questioning through specific questions and statements, which actually only allow one answer. [C2]

- That you are an attentive partner, that you recognize the situation of the other, and that you draw the right conclusion for the client out of this perception, that is an essential thing. [C5]

- To create confidence in the client's mind (...) they (consultants) have not only to show that they understand the topic matter, but also that they have the wisdom and the judgment to understand that the formula doesn't necessarily work in all circumstances, that they are flexible enough to understand what the client wants. [C5]

Self-regulation processes

- I act as I am. Here I have a person, and I want to influence him/her in this or that direction; that is not how I calculate. [C1]

- During a presentation I recognize that I have my hands in my pocket, but I do not take it out, because I do not know what I should do with it. [C2]

- I think it happens relatively often, that you do not know, how to say it. [C2]

- I think it is not so much disinterest, but more insecurity: how can I say that, how I can work with that, may I say something like that. [C3]

- When I do not like somebody the limits are quickly achieved and I retreat. Behaving against that is exhausting and I have no interest in it. [C4]

- Sometimes you are so occupied with a topic that you have no time left to think about your own behavior. [C4]

- I do not know how I am perceived. [C1]

- I mean, if I would dissimulate, I would not know how I am perceived. Hence, I mean I mostly have another impression then the other, since I am uncertain. [C1]

- Meanwhile I made so many of these activities, that I do not think that much of it. Normally, when I recognize weaknesses during an event, I react on it. [C2]

- I monitor my behavior and the situation is also deciding. When I am quite confident, then I am also able to assess others and to see, how far they go and how far can I go with them. [C4]

- You need feeling to recognize, here I can move closer, und there I have to bare my teeth to create distance. [C4]

- You feel it, and it is a very uncomfortable situation, when you feel that you loose your audience. I monitor my behavior. [C4]

- My own behavior is monitored and tested, what I can do, e.g. to mitigate a situation. The behavior of the other is also monitored e.g. why is he now moping, or so aggressive, or also so open-minded, what did I wrong or well, in order to countersteer and reach a good communicative result. [C5]

- My behaviors are rather spontaneous, and often, unfortunately, emotionally directed. [C3] 
- I even do not try (to influence others' impressions) because I would presumably fail. [C1]

- My weaknesses lie in the point that I find it difficult to sell. That is not really my nature; it is a weakness, because it belongs to the job, that you can display your performance and that you display yourself as sellable. But I always give in that weakness, because I act on the assumption, that I am not good in it. [C1]

- I know there are things I should address, but I avoid them and try to escape from that situation. Out of it result failures that is obvious. [C5]

Self-monitoring

- I act as I am. [C1]

- I can press a button and say: Show-time! [C4]

- (Quotations from "self-regulation processes" match with different selfmonitoring tendencies as well)

\section{Experts' and trainers' quotations}

THEMES \& (SUB-) CATEGORIES

THEME 3: REQUIREMENTS AND OBSTACLES FOR EFFECTIVE IM
IM competence
- Be expressive, it is only possible when you start to be expressive, expressive means use your voice and all expressive parts, you show your body in all his parts, and you show face, and these three you have to connect with your way of thinking and behavior. At that moment, you can talk about being nice, being awful, being shy. [E1]

- I think impression is also a balance between the body impression and the knowledge impression, I think you use them both, sometimes more from this part, sometimes more from that part.(...) But they are all the time in interaction. [E1]

- Obviously it is the way you talk. You have to know what you are talking about. That is the first step. The way of talking is extremely important, it is even more important in the context like ours, because how convincing your are in the way you state what your are saying; so this is one factor that I consider as important in shaping the impressions that people have. [E3]

- Definitely, body language does count, when you are someone, like myself, who tries to impress by insisting with my hands on some points I want to make, that is my way of conveying it. It may work or it may backfire, but what really counts are your presentation skills that make the difference. [E3]

- I think a lot of it depends on the individual ability to communicate, some are better at it, some are not. Sometimes I wonder why they choose that job, you know, because they cannot communicate, on the other hand they might be great thinkers or something like that, but gosh, I can not help to believe that the impression, the first initial impression, the first three minutes is so critical (...). [E4]

- When you do not have the ability to communicate your thought it will not get you anywhere. And even when you have done that, if you do not have the ability to listen it will not get you anywhere. I think they are equally important. [E4]

- You really have to sit there and listen to what they are saying so then you can be in the same tempo as I say and the same nuance, but no matter what a consultant should always listen, with their eyes, with their ears. They should always listen, no matter what. [E4] 
- Speaking loudly enough so that people can understand you. [E5]

- The ability to develop relationships, but that is part of the interpersonal skill. But I think it is a gift, I do not know whether it is a skill, some people have the ability, because they are able to create a relationship all over sudden and you feel really good at it. [E4]

- Some people are more adaptable than others, but basically people should have a minimum ability to cope. [E2]

- To create confidence in the client's mind (...) they (consultants) have not only to show that the understand the topic matter, but also that they have the wisdom and the judgment to understand that the formula doesn't necessarily work in all circumstances, that they are flexible enough to understand what the client wants (...). [E4]

- When somebody comes in dressed looking really good, really well, very much in line with our standard it is like an automatic $20 \%$ buying versus if somebody comes in not in line with our standards or with something that is totally different from our image, we get the feeling they do not understand our business. So a lot of it, you must understand what is the client's business, what is the client's environment like, and then create your visual image. [E4]

- I think it is so important for consultants to adapt, you know, when you are going as a consultant to the W-hotels, you should be somehow cheerful dressed, when you are going to GE, this will be different or when you going to Microsoft. [E4]

IM trainable?

- I mean some people are gifted, they are born like this. They have it. Some people are better at it; they have better communication abilities than others. But maybe with a training people can improve their communication competence, and usually nowadays most of the organizations have some training on communication. I think that helps. I mean each person knows his weakness. When I have a weakness in communication skills I will attend training, read books. I always say you can improve in life, you cannot change $100 \%(\ldots)$, but you can always improve. Some people learn how to control themselves a bit more, other people learn how to be more extraverts, and other people learn how to address an audience, learn how to talk in front of people. You know this comes with training. [E2]

- I think that presentations skills are very much learnable, and there are some where it comes more naturally to and they are probably better than those that aren't. But I do think that it is very, very learnable. I have seen it in our own practice, where we got people to be good in giving presentations, who weren't good at it before. And part of that is that they learn some techniques, they develop some more confidence, they get a positive response, then it is easier to do in the next time, you know, they will prepare, the presentation is frozen and appropriate in a technical manner and when they feel better about it, like in anything, when you get some coaching and you get some practice, you get better at it, and you feel better at playing. [E5] 
Self-regulation processes
- I have a consultant friend and I have been able to see him now and then. I know him as very personal, and he is such a sweet and nice person and I have seen him in situations where is he like under the gun, where all over the sudden he is different. Everybody understands that he acts different, but I think that impression is how you react when other people try to disturb you. People understand when you are busy, you can go like: oh I am sorry, sorry or you can go: Don't bother me. I think it depends on your behavior. Your true personality comes up, when your value system on how you want to relate to others is not important. (...) in situations where people have to be, they don't want to be (...) it depends on their value system, how important is impression management and how important is your relationship with others. [E4]

- You need to develop all the time, you need self-reflection, to realize how to handle the body, because the body is all the time changing when you are $14,21,30,50$ years. I can behave myself now in a completely other way then 15 years ago. [E1]

- When you do not know, who you are, by sound, by the way your face is looking, by how your shoulders are: high or low, when you do not realize your own behavior, you are not able to recognize the reactions. [E1]

- I think it is important for consultants to realize the moments when you are really true, and manage how much do you give of yourself, and how to you use your voice, and what is your behavior and what I really played, what I was wearing at that time. [E1]

- I think, when you make an impression it is more interesting to realize your own situation, than to make an impression. To realize what the other person's situation is much harder. Therefore, look through your head and your emotions. [E1]

- Recognize for yourself your true part, your being part. What is my truth in this moment, what is the situation, and then I can use that part to be or not to be. [E1]

- So, be constantly aware of your behavior, of your words, it is kind of being an actor or an actress to some degree. [E4]

- I think eye contact is incredibly important, measuring what is going on with the audience, whether you got them or if you do not have them. [E5]

- I had one person one day, and he kept moving on his chair, and you could feel it with him, but they do not recognize, because for them it is automatic, impulsive, it is from inside, they feel it inside, it is reflected outside, but they do not realize it. [E2]

- May be it comes impulsive, or they are not aware that this could impact negatively. May be they think it is what they are. And may be they believe that it should be like this. [E2]

- When you are going into consultancy and you have a problem of selfefficacy it does not help to form a good impression. That is lack of selfcontrol, and a lack of confidence is not positive for forming positive impressions. It can lead to an impression of instability and that does not help. [E3]

- I think for the most people it is about confidence and how you feel about yourself. [E5]

Self-monitoring

- I mean some people are gifted, they are born like this. They have it (the ability to make an impression). [E2]

- It could be linked to personality, whether people have it (the ability to make an impression) or not really. [E3]

- It differs from individual to individual, some people can have it (the ability to make an impression) real fast and other people, what is the sense of bothering, they never be, they, you know, they do not want to do it. Some people are terrified to get up in front of others, it is one of the highest rated fear-thing that human beings have. Some people never get in front of others and you can not make them. [E5] 


\section{APPENDIX C: CHAPTER 4}

\section{Project description for participating companies}

\section{Background}

Impression Management is defined as a basic human inclination and a fundamental feature of social interaction. At this conjuncture, the own behavior is planned and adapted to make a positive impression on another person in order to influence his/her future thinking and behavior. Impression Management is seen as a crucial component of consultancy service, due to the fact that business success in consultancy depends mainly on performance evaluations given by clients.

\section{Topic of Investigation}

At this point, the here described research project applies. At Maastricht University, a questionnaire was developed that investigates IM in consultancy. In particular, the questions refer to the following aspects:

Identification of Impression Management tactics applied by the consultants.

Identification of factors determining consultants' use of Impression Management tactics.

Identification of an Impression Management effect on consultants' performance.

\section{Effort}

Consultants are asked per e-mail - incl. link to questionnaire - to participate in the study. The completion of the questionnaire takes ca. 10-15 minutes.

\section{Benefits}

In case that your company supports the survey among your consultants, the following benefits can be noted:

At first, there is the possibility to develop an Impression Management company profile. This includes an identification of Impression Management tactics applied by your consultants in interaction with the client.

In addition, the ascertainment of factors that influence consultants' performance is of vital importance. With the gained information your company is more able to understand consultants' performances, to utilize advantages more effectively, and to minimize weaknesses.

Given the assumption that effective Impression Management is not alone the result of talent, but learnable and improvable, the results provide inter alia the basis for the development of adequate trainings. 


\section{Questionnaire}

\section{Self-monitoring scale}

The following statements ask about your personal reactions in various situations. Please indicate your agreement with the following statements.

\begin{tabular}{|c|c|c|c|c|c|c|}
\hline Nr. & Description & $\begin{array}{l}\text { Totally } \\
\text { Agree }\end{array}$ & $\begin{array}{c}\text { Partially } \\
\text { Agree }\end{array}$ & $\begin{array}{l}\text { Neither } \\
\text { Agree or } \\
\text { Disagree }\end{array}$ & $\begin{array}{l}\text { Partially } \\
\text { Disagree }\end{array}$ & $\begin{array}{c}\text { Totally } \\
\text { Disagree }\end{array}$ \\
\hline 1 & $\begin{array}{l}\text { I find it hard to imitate the behavior of } \\
\text { other people. (reverse item) }\end{array}$ & O & O & O & O & O \\
\hline 2 & $\begin{array}{l}\text { At parties and social gatherings, I do not } \\
\text { attempt to do or say things that others will } \\
\text { like. (reverse item) }\end{array}$ & O & O & O & O & O \\
\hline 3 & $\begin{array}{l}\text { I can only argue for ideas which I already } \\
\text { believe. (reverse item) }\end{array}$ & O & ○ & O & O & O \\
\hline 4 & $\begin{array}{l}\text { I can make impromptu speeches even on } \\
\text { topics about which I have almost no } \\
\text { information. }\end{array}$ & O & O & $\mathrm{O}$ & O & O \\
\hline 5 & $\begin{array}{l}\text { I guess I put on a show to impress or } \\
\text { entertain people. }\end{array}$ & O & ○ & O & O & O \\
\hline 6 & I would probably make a good actor. & O & O & O & O & O \\
\hline 7 & $\begin{array}{l}\text { In a group of people I am rarely the center } \\
\text { of attention. (reverse item) }\end{array}$ & O & O & O & O & O \\
\hline 8 & $\begin{array}{l}\text { In different situations and with different } \\
\text { people, I often act like very different } \\
\text { persons. }\end{array}$ & O & ○ & O & O & O \\
\hline 9 & $\begin{array}{l}\text { I am not particularly good at making other } \\
\text { people like me. (reverse item) }\end{array}$ & O & O & O & O & O \\
\hline 10 & I'm not always the person I appear to be. & 0 & O & O & 0 & O \\
\hline 11 & $\begin{array}{l}\text { I would not change my opinions (or the } \\
\text { way I do things) in order to please } \\
\text { someone or win their favor. (reverse item) }\end{array}$ & O & O & O & O & O \\
\hline 12 & I have considered being an entertainer. & O & O & O & O & O \\
\hline 13 & $\begin{array}{l}\text { I have never been good at games like } \\
\text { charades or improvisional acting. (reverse } \\
\text { item) }\end{array}$ & O & O & O & O & O \\
\hline 14 & $\begin{array}{l}\text { I have trouble changing my behavior to } \\
\text { suit different people and different } \\
\text { situations. (reverse item) }\end{array}$ & O & O & O & O & O \\
\hline 15 & $\begin{array}{l}\text { At a party I let others keep the jokes and } \\
\text { stories going. (reverse item) }\end{array}$ & O & O & O & O & O \\
\hline 16 & $\begin{array}{l}\text { I feel a bit awkward in company and do } \\
\text { not show up quite as well as I should. } \\
\text { (reverse item) }\end{array}$ & O & O & O & O & ○ \\
\hline 17 & $\begin{array}{l}\text { I can look anyone in the eye and tell a lie } \\
\text { with a straight face (if for a right end). }\end{array}$ & O & O & O & O & O \\
\hline 18 & $\begin{array}{l}\text { I may deceive people by being friendly } \\
\text { when I really dislike them. }\end{array}$ & 0 & 0 & 0 & 0 & 0 \\
\hline
\end{tabular}




\section{APPENDICES}

\section{Consultants' IM tactics scales}

Impression management is the process by which you control and adapt certain aspects of your behavior with the goal of making a positive impression (e.g. a likeable or competent one) on the client. Please indicate how often the following statements apply to you.

Personal IM tactic scale

\begin{tabular}{|c|c|c|c|c|c|c|}
\hline Nr. & Description & $\begin{array}{l}\text { Very } \\
\text { often }\end{array}$ & Often & $\begin{array}{c}\text { Some- } \\
\text { times }\end{array}$ & Rarely & Never \\
\hline \multicolumn{7}{|c|}{ As a consultant I perform the following behavior in order to make a likeable impression on the client: } \\
\hline 1 & I compliment my client. & O & O & O & O & O \\
\hline 2 & I take interest in my client's personal life. & O & O & $\bigcirc$ & $\bigcirc$ & O \\
\hline 3 & $\begin{array}{l}\text { I praise my client for his or her } \\
\text { accomplishments. }\end{array}$ & O & O & $\bigcirc$ & O & O \\
\hline 4 & I do personal favors for my client. & $\mathrm{O}$ & $\bigcirc$ & $\bigcirc$ & $\bigcirc$ & O \\
\hline 5 & I share personal information with the client. & O & O & 0 & 0 & 0 \\
\hline 6 & I smile. & O & $\bigcirc$ & O & O & O \\
\hline 7 & $\begin{array}{l}\text { I try to give the client the impression that what I } \\
\text { display outwards is authentic. }\end{array}$ & 0 & 0 & 0 & 0 & 0 \\
\hline 8 & I try to create trust. & O & O & O & O & O \\
\hline 9 & I try to be perceived as honest. & $\bigcirc$ & O & O & $\mathrm{O}$ & 0 \\
\hline 10 & $\begin{array}{l}\text { I try to convey to the client that I stand bebind him or } \\
\text { her. }\end{array}$ & 0 & 0 & 0 & 0 & 0 \\
\hline
\end{tabular}

Professional IM tactic scale

\begin{tabular}{|c|c|c|c|c|c|c|}
\hline Nr. & Description & $\begin{array}{l}\text { Very } \\
\text { often }\end{array}$ & Often & $\begin{array}{c}\text { Some- } \\
\text { times }\end{array}$ & Rarely & Never \\
\hline \multicolumn{7}{|c|}{ As a consultant I perform the following behavior in order to make a competent impression on the client: } \\
\hline 1 & $\begin{array}{l}\text { I talk proudly about my experience or } \\
\text { education. }\end{array}$ & O & O & O & O & O \\
\hline 2 & $\begin{array}{l}\text { I make my client aware of my talents and } \\
\text { qualifications. }\end{array}$ & O & O & ○ & O & O \\
\hline 3 & $\begin{array}{l}\text { I let my client know that I am valuable to the } \\
\text { organization. }\end{array}$ & ○ & O & ○ & O & O \\
\hline 4 & I make my client aware of my accomplishments. & O & O & O & O & O \\
\hline 5 & $\begin{array}{l}\text { For a presentation I am always very well- } \\
\text { prepared. }\end{array}$ & O & O & O & O & O \\
\hline 6 & $\begin{array}{l}\text { I mention my references to convey my experiences and } \\
\text { performances. }\end{array}$ & O & O & ○ & O & O \\
\hline 7 & $\begin{array}{l}\text { I mention third-parties to show that I know } \\
\text { important people. }\end{array}$ & O & O & O & O & 0 \\
\hline 8 & $\begin{array}{l}\text { I am always on time to underscore that I am } \\
\text { reliable. }\end{array}$ & O & O & ○ & O & $\bigcirc$ \\
\hline
\end{tabular}


Conforming IM tactic scale

\begin{tabular}{|c|c|c|c|c|c|c|}
\hline Nr. & Description & $\begin{array}{l}\text { Very } \\
\text { often }\end{array}$ & Often & $\begin{array}{l}\text { Some- } \\
\text { times }\end{array}$ & Rarely & Never \\
\hline \multicolumn{7}{|c|}{ As a consultant I perform the following behavior in order to make a positive impression on the client: } \\
\hline 1 & $\begin{array}{l}\text { I attach great importance on my outward } \\
\text { appearance, such as my clothing. }\end{array}$ & O & O & ○ & ○ & O \\
\hline 2 & $\begin{array}{l}\text { I try to adjust my outward appearance to my client } \\
\text { and my task. }\end{array}$ & O & O & O & O & O \\
\hline 3 & $\begin{array}{l}\text { I try to adjust my communication style to match the } \\
\text { client's. }\end{array}$ & O & O & O & O & O \\
\hline 4 & I adopt the arguments of the client. & O & 0 & 0 & 0 & 0 \\
\hline 5 & I try to speak eloquently. & O & O & O & O & O \\
\hline 6 & $\begin{array}{l}\text { In a conversation I do not speak about } \\
\text { myself, but try to limit the conversation to } \\
\text { the topic of the client. }\end{array}$ & O & O & O & O & O \\
\hline 7 & $\begin{array}{l}\text { I show the client that I listen and thereby I } \\
\text { emphasize my understanding and my interest } \\
\text { for his or her problem. }\end{array}$ & O & $\bigcirc$ & O & O & O \\
\hline 8 & I am polite. & O & O & O & O & O \\
\hline 9 & I am reticent. & 0 & O & 0 & 0 & 0 \\
\hline
\end{tabular}

Note. Italic $\Rightarrow$ Shortened versions of personal, professional, and conforming IM scales.

\section{IM competence scale}

The following statements refer to some of your personal competences in interaction with the client. Please indicate your level of agreement with the following statements.

\begin{tabular}{|c|c|c|c|c|c|c|}
\hline Nr. & Description & $\begin{array}{l}\text { Totally } \\
\text { Agree }\end{array}$ & $\begin{array}{l}\text { Partially } \\
\text { Agree }\end{array}$ & $\begin{array}{l}\text { Neither } \\
\text { Agree or } \\
\text { Disagree }\end{array}$ & $\begin{array}{l}\text { Partially } \\
\text { Disagree }\end{array}$ & $\begin{array}{l}\text { Totally } \\
\text { Disagree }\end{array}$ \\
\hline 1 & $\begin{array}{l}\text { When I speak with the client, I am able to } \\
\text { keep eye contact. }\end{array}$ & O & O & O & O & O \\
\hline 2 & $\begin{array}{l}\text { My communication with the client is } \\
\text { comprehensible and clear. }\end{array}$ & O & O & O & O & O \\
\hline 3 & I can listen to the client. & O & ○ & O & O & ○ \\
\hline 4 & I do not interrupt the client in a conversation. & O & O & O & O & O \\
\hline 5 & $\begin{array}{l}\text { I can ask the client in a way that I practically } \\
\text { govern his or her answer. }\end{array}$ & O & O & O & O & O \\
\hline 6 & $\begin{array}{l}\text { It is nearly impossible for clients to hide their } \\
\text { true feelings from me. }\end{array}$ & O & ○ & O & O & O \\
\hline 7 & $\begin{array}{l}\text { At client meetings, I can instantly tell if } \\
\text { someone is interested in my opinion. }\end{array}$ & O & O & O & O & O \\
\hline 8 & $\begin{array}{l}\text { People often tell me that I am a sensitive and } \\
\text { understanding person. }\end{array}$ & O & O & O & O & O \\
\hline 9 & I can put myself in the client's place. & O & O & O & O & O \\
\hline 10 & I recognize my client's feelings. & O & O & O & O & O \\
\hline 11 & I try to socialize with clients. & 0 & O & 0 & 0 & 0 \\
\hline
\end{tabular}




\begin{tabular}{llccccc}
\hline Nr. & Description & $\begin{array}{c}\text { Totally } \\
\text { Agree }\end{array}$ & $\begin{array}{c}\text { Partially } \\
\text { Agree }\end{array}$ & $\begin{array}{c}\text { Neither } \\
\text { Agree or } \\
\text { Disagree }\end{array}$ & $\begin{array}{c}\text { Partially } \\
\text { Disagree }\end{array}$ & $\begin{array}{c}\text { Totally } \\
\text { Disagree }\end{array}$ \\
\hline $\mathbf{1 2}$ & $\begin{array}{l}\text { I find it very easy to play different roles at } \\
\text { different times. }\end{array}$ & 0 & $\bigcirc$ & 0 & 0 & 0 \\
13 & $\begin{array}{l}\text { I can fit in with all types of clients. } \\
\text { I } \text { am flexible in my behaviors if required for } \\
\text { project success. }\end{array}$ & 0 & 0 & 0 & 0 & 0 \\
15 & $\begin{array}{l}\text { I am able to conform well to new demands } \\
\text { and new clients. }\end{array}$ & 0 & 0 & 0 & 0 & 0 \\
\hline
\end{tabular}

\section{Performance scale}

The following statements investigate how you are evaluated by the client. Please indicate your level of agreement with the following statements.

\begin{tabular}{llccccc}
\hline Nr. & Description & $\begin{array}{c}\text { Totally } \\
\text { Agree }\end{array}$ & $\begin{array}{c}\text { Partially } \\
\text { Agree }\end{array}$ & $\begin{array}{c}\text { Neither } \\
\text { Agree or } \\
\text { Disagree }\end{array}$ & $\begin{array}{c}\text { Partially } \\
\text { Disagree }\end{array}$ & $\begin{array}{c}\text { Totally } \\
\text { Disagree }\end{array}$ \\
\hline $\mathbf{1} \quad \begin{array}{l}\text { The client views me as superior to } \\
\text { consultants he or she has worked with } \\
\text { before. }\end{array}$ & 0 & 0 & 0 & 0 & 0 \\
$\mathbf{2} \quad \begin{array}{l}\text { The client observes my overall level of } \\
\text { performance as excellent. }\end{array}$ & 0 & 0 & 0 & 0 & 0 \\
$\mathbf{3}$ & $\begin{array}{l}\text { The client considers me as highly effective. } \\
\text { The client feels that I have been effectively } \\
\text { fulfilling my role and responsibilities. } \\
\text { The client will spread positive words about } \\
\text { me. }\end{array}$ & 0 & 0 & 0 & 0 & 0 \\
$\mathbf{5}$ & 0 & 0 & 0 & 0 & 0 \\
\hline
\end{tabular}

\section{Controls}

\begin{tabular}{rlcc}
\hline Nr. & Description & Yes & No \\
1 & $\begin{array}{l}\text { I work/worked as a consultant in direct } \\
\text { contact with the client }\end{array}$ & O & O \\
\hline Nr. & Description & Female & Male \\
2 & Gender & 0 & 0 \\
\hline Nr. & Description & & \\
3 & Age & - & \\
\hline Nr. & Description & & \\
4 & Job tenure & - & \\
\hline Nr. & Description & & \\
5 & Consultancy type (e.g. IT-Consultancy, or & - & \\
\hline Nr. & Description & Yes & No \\
6 & Managerial function & 0 & 0 \\
\hline
\end{tabular}




\section{APPENDIX D: CHAPTER 5}

\section{Project description for participating companies}

\section{Background}

Impression Management is defined as a basic human inclination and a fundamental feature of social interaction. At this conjuncture, the own behavior is planned and adapted to present a favorable image to another person in order to influence his or her future thinking and behavior. Impression Management is seen as a crucial component of consultancy service, due to the fact that business success in consultancy depends mainly on how consultants' performance is evaluated by clients. At the same time, it is acknowledged that there are individual differences in Impression Management style and in persons' possession of necessary competences resulting in varying performance or even stress. Regarding the style of presenting a favorable image, individuals either act authentically - that is in accord with the true self - and involve personal emotions, needs, preferences or beliefs with a focus to express oneself in order to impress the client as opposed to role acting, which is merely performed to please others by expressing conformity to role conditions irrespective of the truth.

\section{Topic of Investigation}

At Maastricht University, a questionnaire was compiled that investigates the impact of two Impression Management styles - authentic acting and role acting - on consultants' performance and stress. The core aspects to be investigated can be summarized by the following research questions:

To what degree does consultants' performance and stress depend on their Impression Management style?

To what degree do Impression Management competences have an impact on consultants' performance and stress?

\section{Effort}

Consultants are contacted via e-mail including a link to an online-questionnaire to participate in the study. The estimated time for completing the questionnaire is $10-15$ minutes.

\section{Benefits}

In case that your company supports the survey among your consultants, the following benefits can be noted:

Your cooperation has the opportunity to develop an Impression Management company profile. This includes an identification of the Impression Management style mostly applied by your consultants and their views on its outcome (measured in performance and stress). With the information obtained your company will be able to gain an improved understanding of the Impression Management behavior of your consultants, to utilize advantages more effectively, and to minimize weaknesses.

Given the assumption that effective Impression Management is not solely the result of talent, but learnable and improvable respectively (e.g. through better Impression Management competences), the results can provide a basis for the development of effective employee trainings. 
APPENDICES

\section{Questionnaire}

\section{MIMSS (Maastricht Impression Management Styles Scales)}

Authentic acting IM style scale

The following statements ask how you behave as a consultant to influence clients' impressions. Please indicate your level of agreement with the following statements.

\begin{tabular}{|c|c|c|c|c|c|c|}
\hline Nr. & Description & $\begin{array}{l}\text { Totally } \\
\text { Agree }\end{array}$ & $\begin{array}{l}\text { Partially } \\
\text { Agree }\end{array}$ & $\begin{array}{l}\text { Neither } \\
\text { Agree or } \\
\text { Disagree }\end{array}$ & $\begin{array}{l}\text { Partially } \\
\text { Disagree }\end{array}$ & $\begin{array}{l}\text { Totally } \\
\text { Disagree }\end{array}$ \\
\hline 1 & $\begin{array}{l}\text { In dealing with clients I rarely mask my true thoughts } \\
\text { and feelings. }\end{array}$ & O & O & O & O & O \\
\hline 2 & As a consultant I express my true self. & O & O & 0 & 0 & O \\
\hline 3 & $\begin{array}{l}\text { I express what I feel when I am excited about something } \\
\text { at work. }\end{array}$ & O & O & O & O & O \\
\hline 4 & $\begin{array}{l}\text { I only make small talk with clients about topics } \\
\text { I care about. }\end{array}$ & O & O & O & O & O \\
\hline 5 & $\begin{array}{l}\text { I compliment clients only when I think they are } \\
\text { worth it. }\end{array}$ & O & O & O & O & O \\
\hline 6 & I do not pretend to be someone else at work. & O & O & O & O & O \\
\hline 7 & $\begin{array}{l}\text { I express my interest in a client's personal life } \\
\text { only when I actually care. }\end{array}$ & O & O & O & O & O \\
\hline 8 & $\begin{array}{l}\text { I only agree with clients when I share their } \\
\text { opinion. }\end{array}$ & O & O & O & O & O \\
\hline 9 & I don't change my view just to please a client. & O & O & O & 0 & O \\
\hline 10 & My behavior towards the client is genuine. & O & O & O & 0 & O \\
\hline 11 & $\begin{array}{l}\text { My behavior as a consultant is usually an expression of } \\
\text { my true feelings, attitudes and beliefs. }\end{array}$ & O & O & O & O & O \\
\hline 12 & At work I do not lie even if I am unlikely to be caught. & O & O & O & O & O \\
\hline 13 & $\begin{array}{l}\text { I do not put a good face on a bad matter at } \\
\text { work. }\end{array}$ & 0 & 0 & 0 & 0 & 0 \\
\hline
\end{tabular}

Note. Italic $\Rightarrow$ Shortened version of authentic IM scale.

Role acting IM style scale

The following statements ask how you behave as a consultant to influence clients' impressions. Please indicate your level of agreement with the following statements.

\begin{tabular}{|c|c|c|c|c|c|c|}
\hline Nr. & Description & $\begin{array}{l}\text { Totally } \\
\text { Agree }\end{array}$ & $\begin{array}{l}\text { Partially } \\
\text { Agree }\end{array}$ & $\begin{array}{l}\text { Neither } \\
\text { Agree or } \\
\text { Disagree }\end{array}$ & $\begin{array}{l}\text { Partially } \\
\text { Disagree }\end{array}$ & $\begin{array}{l}\text { Totally } \\
\text { Agree }\end{array}$ \\
\hline 1 & I feel like an actor in my work. & O & $\mathrm{O}$ & $\mathrm{O}$ & $\mathrm{O}$ & O \\
\hline 2 & $\begin{array}{l}\text { At work I talk about topics on which I have almost } \\
\text { no information. }\end{array}$ & 0 & 0 & O & O & O \\
\hline 3 & $\begin{array}{l}\text { I look the client in the eye and tell a lie with a } \\
\text { straight face. }\end{array}$ & O & O & O & O & O \\
\hline 4 & I conceal my true feelings from the client. & 0 & 0 & 0 & 0 & 0 \\
\hline
\end{tabular}




\begin{tabular}{|c|c|c|c|c|c|c|}
\hline Nr. & Description & $\begin{array}{l}\text { Totally } \\
\text { Agree }\end{array}$ & $\begin{array}{l}\text { Partially } \\
\text { Agree }\end{array}$ & $\begin{array}{l}\text { Neither } \\
\text { Agree or } \\
\text { Disagree }\end{array}$ & $\begin{array}{l}\text { Partially } \\
\text { Disagree }\end{array}$ & $\begin{array}{l}\text { Totally } \\
\text { Agree }\end{array}$ \\
\hline 5 & $\begin{array}{l}\text { In situations with different clients I act like different } \\
\text { persons. }\end{array}$ & O & O & O & 0 & O \\
\hline 6 & $\begin{array}{l}\text { I deceive clients by acting friendly when I actually } \\
\text { dislike them. }\end{array}$ & 0 & 0 & 0 & O & 0 \\
\hline 7 & $\begin{array}{l}\text { At work I tend to maintain a calm exterior, } \\
\text { even when I am upset. }\end{array}$ & 0 & 0 & 0 & 0 & 0 \\
\hline 8 & I flatter clients even when they do not deserve it. & 0 & 0 & 0 & 0 & 0 \\
\hline 9 & $\begin{array}{l}\text { The way I interact with clients does not } \\
\text { personally affect me. }\end{array}$ & O & O & O & O & O \\
\hline 10 & $\begin{array}{l}\text { I do personal favors for the client even when I do not } \\
\text { feel like. }\end{array}$ & 0 & 0 & 0 & O & 0 \\
\hline 11 & $\begin{array}{l}\text { What I say or do as a consultant is not necessarily a } \\
\text { reflection of what I really think or feel. }\end{array}$ & 0 & 0 & 0 & 0 & 0 \\
\hline 12 & I smile to the client even when I am bad-tempered. & O & O & ○ & O & O \\
\hline 13 & I tell clients what they want to hear. & 0 & 0 & 0 & 0 & 0 \\
\hline
\end{tabular}

Note. Italic $\Rightarrow$ Shortened version of authentic IM scale.

\section{IM competence scale}

The following statements refer to some of your personal competences in interaction with the client. Please indicate your level of agreement with the following statements.

\begin{tabular}{|c|c|c|c|c|c|c|}
\hline Nr. & Description & $\begin{array}{l}\text { Totally } \\
\text { Agree }\end{array}$ & $\begin{array}{c}\text { Partially } \\
\text { Agree }\end{array}$ & $\begin{array}{l}\text { Neither } \\
\text { Agree or } \\
\text { Disagree }\end{array}$ & $\begin{array}{l}\text { Partially } \\
\text { Disagree }\end{array}$ & $\begin{array}{l}\text { Totally } \\
\text { Disagree }\end{array}$ \\
\hline 1 & $\begin{array}{l}\text { When I speak with the client, I am able to keep } \\
\text { eye contact. }\end{array}$ & O & O & O & O & O \\
\hline 2 & $\begin{array}{l}\text { My communication with the client is } \\
\text { comprehensible and clear. }\end{array}$ & O & O & O & O & O \\
\hline 3 & I can listen to the client. & O & 0 & O & O & O \\
\hline 4 & I do not interrupt the client in a conversation. & O & O & O & O & O \\
\hline 5 & $\begin{array}{l}\text { I can ask the client in a way that I practically } \\
\text { govern his or her answer. }\end{array}$ & O & O & O & O & O \\
\hline 6 & $\begin{array}{l}\text { It is nearly impossible for clients to hide their } \\
\text { true feelings from me. }\end{array}$ & O & O & O & O & O \\
\hline 7 & $\begin{array}{l}\text { At client meetings, I can instantly tell if } \\
\text { someone is interested in my opinion. }\end{array}$ & O & O & O & O & O \\
\hline 8 & $\begin{array}{l}\text { People often tell me that I am a sensitive and } \\
\text { understanding person. }\end{array}$ & O & O & O & O & O \\
\hline 9 & I can put myself in the client's place. & 0 & O & O & 0 & O \\
\hline 10 & I recognize my client's feelings. & O & O & O & 0 & 0 \\
\hline 11 & I try to socialize with clients. & O & 0 & O & O & O \\
\hline 12 & $\begin{array}{l}\text { I find it very easy to play different roles at } \\
\text { different times. }\end{array}$ & O & 0 & O & O & O \\
\hline
\end{tabular}




\begin{tabular}{llccccc}
\hline Nr. & Description & $\begin{array}{c}\text { Totally } \\
\text { Agree }\end{array}$ & $\begin{array}{c}\text { Partially } \\
\text { Agree }\end{array}$ & $\begin{array}{c}\text { Neither } \\
\text { Agree or } \\
\text { Disagree }\end{array}$ & $\begin{array}{c}\text { Partially } \\
\text { Disagree }\end{array}$ & $\begin{array}{c}\text { Totally } \\
\text { Disagree }\end{array}$ \\
\hline $\mathbf{1 3}$ & $\begin{array}{l}\text { I can fit in with all types of clients. } \\
14\end{array}$ & 0 & 0 & $\bigcirc$ & $\bigcirc$ & $\bigcirc$ \\
$\begin{array}{l}\text { I am flexible in my behaviors if required for } \\
\text { project success. }\end{array}$ & 0 & 0 & 0 & 0 & $\bigcirc$ \\
15 & $\begin{array}{l}\text { I am able to conform well to new demands and } \\
\text { new clients. }\end{array}$ & 0 & 0 & 0 & 0 & $\bigcirc$ \\
\hline
\end{tabular}

\section{Performance scale}

The following statements investigate how you are evaluated by the client. Please indicate your level of agreement with the following statements.

\begin{tabular}{|c|c|c|c|c|c|c|}
\hline Nr. & Description & $\begin{array}{l}\text { Totally } \\
\text { Agree }\end{array}$ & $\begin{array}{c}\text { Partially } \\
\text { Agree }\end{array}$ & $\begin{array}{l}\text { Neither } \\
\text { Agree or } \\
\text { Disagree }\end{array}$ & $\begin{array}{l}\text { Partially } \\
\text { Disagree }\end{array}$ & $\begin{array}{l}\text { Totally } \\
\text { Disagree }\end{array}$ \\
\hline 1 & $\begin{array}{l}\text { The client views me as superior to consultants } \\
\text { he or she has worked with before. }\end{array}$ & O & O & O & O & O \\
\hline 2 & $\begin{array}{l}\text { The client observes my overall level of } \\
\text { performance as excellent. }\end{array}$ & O & O & O & O & O \\
\hline 3 & The client considers me as highly effective. & O & O & O & O & O \\
\hline 4 & $\begin{array}{l}\text { The client feels that I have been effectively } \\
\text { fulfilling my role and responsibilities. }\end{array}$ & O & O & O & O & O \\
\hline 5 & The client will spread positive words about me. & 0 & 0 & 0 & 0 & 0 \\
\hline
\end{tabular}

\section{Perceived distress scale}

With these questions, we would like to find out more about how you felt and thought about yourself in the last month. Please indicate your level of agreement with the following statements.

\begin{tabular}{llcccc}
\hline $\mathbf{N r} . \quad$ Description & $\begin{array}{c}\text { Very } \\
\text { often }\end{array}$ & Often & $\begin{array}{c}\text { Some- } \\
\text { times }\end{array}$ & Rarely & Never \\
\hline $\mathbf{1} \quad \begin{array}{l}\text { In the last month, how often have you been } \\
\text { upset because of something that happened } \\
\text { unexpectedly at your work place? }\end{array}$ & 0 & 0 & 0 & 0 & 0 \\
$\mathbf{2} \quad \begin{array}{l}\text { In the last month, how often have you felt that } \\
\text { you were unable to control the important things } \\
\text { at work? }\end{array}$ & 0 & 0 & 0 & 0 & 0 \\
$\mathbf{3} \quad \begin{array}{l}\text { In the last month, how often have you felt } \\
\text { nervous and stressed? }\end{array}$ & 0 & 0 & 0 & 0 & 0 \\
$\mathbf{4} \quad \begin{array}{l}\text { In the last month, how often have you felt that } \\
\text { things with the client were not going your way? }\end{array}$ & 0 & 0 & 0 & 0 & 0 \\
$\mathbf{5} \quad \begin{array}{l}\text { In the last month, how often have you found } \\
\text { that you could not cope with all the things that } \\
\text { you had to do at work? }\end{array}$ & 0 & 0 & 0 & 0 & 0 \\
$\mathbf{6} \quad \begin{array}{l}\text { In the last month, how often have you been } \\
\text { angered because of things that happened at } \\
\text { work that were outside of your control? }\end{array}$ & 0 & 0 & 0 & 0 & 0 \\
\hline
\end{tabular}




\section{Controls}

\begin{tabular}{|c|c|c|c|}
\hline Nr. & Description & Female & Male \\
\hline 1 & Gender & 0 & 0 \\
\hline Nr. & Description & & \\
\hline 2 & Age & _ & \\
\hline Nr. & Description & & \\
\hline 3 & Job tenure & - & \\
\hline Nr. & Description & & \\
\hline 4 & $\begin{array}{l}\text { Consultancy type (e.g. IT-Consultancy, or } \\
\text { Management Consultancy, etc.) }\end{array}$ & - & \\
\hline Nr. & Description & Yes & No \\
\hline 5 & Managerial function & 0 & 0 \\
\hline
\end{tabular}


APPENDICES

Rotated factors and loadings for the shortened IM scales (Authentic acting IM style and Role acting IM styles scales) on the two separate samples

\section{Snowball sample}

\begin{tabular}{lcc}
\hline ITEMS & FACTOR 1 & FACTOR 2 \\
\hline 1. Authentic acting IM style & .620 & -.039 \\
2. Authentic acting IM style &. .030 \\
3. Authentic acting IM style & .782 & .066 \\
4. Authentic acting IM style & .658 & -.415 \\
5. Authentic acting IM style & .493 & -.358 \\
6. Authentic acting IM style & .651 & -.291 \\
7. Authentic acting IM style & .784 & -.250 \\
1. Role acting IM style & .571 \\
2. Role acting IM style & -.055 & $\mathbf{. 6 2 9}$ \\
3. Role acting IM style & -.268 & $\mathbf{. 6 6 4}$ \\
4. Role acting IM style & -.222 & .724 \\
5. Role acting IM style & -.071 & .713 \\
6. Role acting IM style & .141 & .476 \\
7. Role acting IM style & -.557 & .538 \\
8. Role acting IM style & -.270 & .463 \\
\hline
\end{tabular}

Note. $\mathrm{N}=130$

\section{Companies sample}

\begin{tabular}{|c|c|c|}
\hline ITEMS & FACTOR 1 & FACTOR 2 \\
\hline 1. Authentic acting IM style & .175 & -.221 \\
\hline 2. Authentic acting IM style & .481 & -.393 \\
\hline 3. Authentic acting IM style & .626 & .245 \\
\hline 4. Authentic acting IM style & .674 & -.250 \\
\hline 5. Authentic acting IM style & .827 & -.083 \\
\hline 6. Authentic acting IM style & .800 & -.183 \\
\hline 7. Authentic acting IM style & .638 & -.166 \\
\hline 1. Role acting IM style & -.178 & .612 \\
\hline 2. Role acting IM style & -.252 & .581 \\
\hline 3. Role acting IM style & -.334 & .567 \\
\hline 4. Role acting IM style & -.113 & .726 \\
\hline 5. Role acting IM style & .081 & .687 \\
\hline 6. Role acting IM style & -.238 & .556 \\
\hline 7. Role acting IM style & .103 & .640 \\
\hline 8. Role acting IM style & -.079 & .570 \\
\hline
\end{tabular}

Note. $\mathrm{N}=103$ 


\section{APPENDIX E: CHAPTER 6}

\section{Questionnaire for students}

\section{MIMSS (Maastricht Impression Management Styles Scales)}

\section{Authentic acting IM style scale}

The following statements ask how you behave in interaction with the teacher in order to make a particular impression on $\mathrm{him} /$ her. Please indicate your level of agreement with the following statements.

\begin{tabular}{|c|c|c|c|c|c|c|}
\hline Nr. & Description & $\begin{array}{l}\text { Totally } \\
\text { Agree }\end{array}$ & $\begin{array}{c}\text { Partially } \\
\text { Agree }\end{array}$ & $\begin{array}{l}\text { Neither } \\
\text { Agree or } \\
\text { Disagree }\end{array}$ & $\begin{array}{l}\text { Partially } \\
\text { Disagree }\end{array}$ & $\begin{array}{l}\text { Totally } \\
\text { Disagree }\end{array}$ \\
\hline 1 & $\begin{array}{l}\text { In dealing with the teacher I rarely mask my } \\
\text { true thoughts and feelings. }\end{array}$ & 0 & 0 & 0 & 0 & 0 \\
\hline 2 & As a student I express my true self. & O & O & O & ○ & O \\
\hline 3 & $\begin{array}{l}\text { I express what I feel when I am excited about } \\
\text { something in class. }\end{array}$ & O & O & O & ○ & O \\
\hline 4 & I do not pretend to be someone else in class. & O & O & ○ & O & O \\
\hline 5 & My behavior towards the teacher is genuine. & O & O & ○ & ○ & O \\
\hline 6 & $\begin{array}{l}\text { My behavior as a student is usually an } \\
\text { expression of my true feelings, attitudes and } \\
\text { beliefs. }\end{array}$ & O & O & $\bigcirc$ & O & O \\
\hline 7 & $\begin{array}{l}\text { In class I do not lie even if I am unlikely to be } \\
\text { caught. }\end{array}$ & O & O & O & O & O \\
\hline
\end{tabular}

Role acting IM style scale

The following statements ask how you behave in interaction with the teacher in order to make a particular impression on $\mathrm{him} /$ her. Please indicate your level of agreement with the following statements.

\begin{tabular}{|c|c|c|c|c|c|c|}
\hline Nr. & Description & $\begin{array}{l}\text { Totally } \\
\text { Agree }\end{array}$ & $\begin{array}{l}\text { Partially } \\
\text { Agree }\end{array}$ & $\begin{array}{l}\text { Neither } \\
\text { Agree or } \\
\text { Disagree }\end{array}$ & $\begin{array}{l}\text { Partially } \\
\text { Disagree }\end{array}$ & $\begin{array}{l}\text { Totally } \\
\text { Disagree }\end{array}$ \\
\hline 1 & $\begin{array}{l}\text { In class I talk about topics on which I have } \\
\text { almost no information. }\end{array}$ & O & 0 & 0 & 0 & 0 \\
\hline 2 & $\begin{array}{l}\text { In situations with different teachers I act like } \\
\text { different persons. }\end{array}$ & O & 0 & O & 0 & 0 \\
\hline 3 & $\begin{array}{l}\text { I deceive the teacher by acting friendly when } \\
\text { I actually dislike him/her. }\end{array}$ & O & O & 0 & 0 & O \\
\hline 4 & $\begin{array}{l}\text { I flatter the teacher even when he/she does } \\
\text { not deserve it. }\end{array}$ & O & O & O & 0 & 0 \\
\hline 5 & $\begin{array}{l}\text { I do personal favors for the teacher even } \\
\text { when I do not feel like. }\end{array}$ & O & O & O & 0 & $\bigcirc$ \\
\hline 6 & $\begin{array}{l}\text { What I say or do as a student is not } \\
\text { necessarily a reflection of what I really think } \\
\text { or feel. }\end{array}$ & 0 & 0 & O & 0 & $\bigcirc$ \\
\hline 7 & $\begin{array}{l}\text { I smile to the teacher even when I am bad- } \\
\text { tempered. }\end{array}$ & 0 & 0 & 0 & 0 & 0 \\
\hline
\end{tabular}




\begin{tabular}{llccccc}
\hline Nr. Description & $\begin{array}{c}\text { Totally } \\
\text { Agree }\end{array}$ & $\begin{array}{c}\text { Partially } \\
\text { Agree }\end{array}$ & $\begin{array}{c}\text { Neither } \\
\text { Agree or } \\
\text { Disagree }\end{array}$ & $\begin{array}{c}\text { Partially } \\
\text { Disagree }\end{array}$ & $\begin{array}{c}\text { Totally } \\
\text { Disagree }\end{array}$ \\
\hline $\mathbf{8}$ & I tell the teacher what he/she wants to hear. & 0 & 0 & 0 & 0 & 0 \\
\hline
\end{tabular}

\section{IM tactics}

Please indicate how often you perform the following behaviors in order to make a particular impression on the teacher.

\begin{tabular}{|c|c|c|c|c|c|c|}
\hline Nr. & Description & $\begin{array}{l}\text { Very } \\
\text { often }\end{array}$ & $\begin{array}{c}\text { Fre- } \\
\text { quently }\end{array}$ & $\begin{array}{l}\text { Occa- } \\
\text { sionally }\end{array}$ & Seldom & Never \\
\hline \multicolumn{7}{|c|}{ Ingratiation } \\
\hline 1 & $\begin{array}{l}\text { I praise my teacher for his/her efforts so that } \\
\text { he/she will consider me a nice person. }\end{array}$ & O & O & O & O & O \\
\hline 2 & $\begin{array}{l}\text { I compliment my teacher so that he/she will see } \\
\text { me as likeable. }\end{array}$ & O & O & O & O & O \\
\hline 3 & $\begin{array}{l}\text { I do personal favors for the teacher to show } \\
\text { him/her that I am friendly. }\end{array}$ & 0 & 0 & 0 & 0 & 0 \\
\hline 4 & $\begin{array}{l}\text { I take an interest in the personal life of a } \\
\text { teacher to show him/her that I am friendly. }\end{array}$ & 0 & 0 & 0 & 0 & 0 \\
\hline \multicolumn{7}{|c|}{ Self-promotion } \\
\hline 1 & $\begin{array}{l}\text { I make the teacher aware of my talents or } \\
\text { qualifications. }\end{array}$ & 0 & 0 & O & O & 0 \\
\hline 2 & $\begin{array}{l}\text { I make the teacher aware of my unique skills } \\
\text { and abilities. }\end{array}$ & 0 & 0 & 0 & 0 & 0 \\
\hline 3 & $\begin{array}{l}\text { I let the teacher know that I am a valuable } \\
\text { member of the group. }\end{array}$ & 0 & 0 & 0 & 0 & O \\
\hline 4 & $\begin{array}{l}\text { I talk proudly about my past accomplishments } \\
\text { which might help to make this course } \\
\text { successful. }\end{array}$ & 0 & 0 & O & 0 & 0 \\
\hline \multicolumn{7}{|c|}{ Exemplification } \\
\hline 1 & $\begin{array}{l}\text { I let the teacher know how hard I have been } \\
\text { working for this course. }\end{array}$ & 0 & 0 & 0 & 0 & 0 \\
\hline 2 & $\begin{array}{l}\text { I let the teacher know that I have been putting } \\
\text { in a lot of time in this course. }\end{array}$ & O & O & 0 & 0 & 0 \\
\hline 3 & $\begin{array}{l}\text { I take on more than my fair share of course } \\
\text { work so that the teacher will see that I am } \\
\text { dedicated. }\end{array}$ & 0 & 0 & 0 & 0 & 0 \\
\hline 4 & $\begin{array}{l}\text { I try to appear like I have been very busy } \\
\text { working on my part of the course work. }\end{array}$ & O & O & O & O & 0 \\
\hline 5 & $\begin{array}{l}\text { I arrive at group meetings on time in order to } \\
\text { look dedicated. }\end{array}$ & 0 & 0 & O & 0 & 0 \\
\hline \multicolumn{7}{|c|}{ Supplication } \\
\hline 1 & $\begin{array}{l}\text { I act like I know less than I really do so that the } \\
\text { teacher will help me out. }\end{array}$ & O & 0 & O & O & O \\
\hline 2 & $\begin{array}{l}\text { I try to gain assistance or sympathy from the } \\
\text { teacher by appearing needy in some area. }\end{array}$ & 0 & 0 & O & 0 & 0 \\
\hline
\end{tabular}




\begin{tabular}{|c|c|c|c|c|c|c|}
\hline Nr. & Description & $\begin{array}{l}\text { Very } \\
\text { often }\end{array}$ & $\begin{array}{c}\text { Fre- } \\
\text { quently }\end{array}$ & $\begin{array}{c}\text { Occa- } \\
\text { sionally }\end{array}$ & Seldom & Never \\
\hline \multicolumn{7}{|c|}{ Supplication } \\
\hline 3 & $\begin{array}{l}\text { I act like I need assistance on my part of the } \\
\text { course work so that the teacher will help me } \\
\text { out. }\end{array}$ & O & O & O & 0 & O \\
\hline 4 & $\begin{array}{l}\text { I pretend not to understand how to do } \\
\text { something in order to avoid having to work on } \\
\text { an undesirable part of the assignments. }\end{array}$ & 0 & 0 & O & 0 & O \\
\hline 5 & $\begin{array}{l}\text { I disclose my weakness in a particular area so } \\
\text { that I can avoid an unpleasant part of } \\
\text { assignments. }\end{array}$ & O & O & 0 & 0 & O \\
\hline \multicolumn{7}{|c|}{ Intimidation } \\
\hline 1 & $\begin{array}{l}\text { I am intimidating with the teacher when it is } \\
\text { necessary for the good of the course. }\end{array}$ & 0 & O & O & 0 & O \\
\hline 2 & $\begin{array}{l}\text { I use intimidation to get the teacher to do } \\
\text { his/her work. }\end{array}$ & O & 0 & 0 & 0 & 0 \\
\hline 3 & $\begin{array}{l}\text { I speak strongly or forcefully to get the teacher } \\
\text { to agree to do the course the way I think it } \\
\text { should be done. }\end{array}$ & O & 0 & 0 & 0 & O \\
\hline 4 & $\begin{array}{l}\text { I deal strongly or aggressively with the teacher } \\
\text { if he/she is not contributing enough. }\end{array}$ & 0 & 0 & ○ & O & O \\
\hline 5 & $\begin{array}{l}\text { I let the teacher know that I am not willing to } \\
\text { be pushed around or dictated to. }\end{array}$ & O & O & O & O & O \\
\hline
\end{tabular}

\section{Controls}

\begin{tabular}{rlcc}
\hline Nr. & Description & Female & Male \\
1 & Gender & $O$ & 0 \\
\hline Nr. & Description & & \\
2 & Nationality & - & \\
\hline Nr. & Description & 1 Year & 3 or 4 Year \\
3 & Study year & 0 & 0 \\
\hline
\end{tabular}




\section{SUMMARY}

Impression management (IM) is defined as any behavior by a person that has the purpose of controlling the impressions formed of that person by others. Due to the fact that an organization is very much a social setting, where people interact on a daily basis this thesis started from the assumption that IM is a crucial component of employee behavior and performance. This particularly applies to consultancy services where business success depends largely on performance vis-à-vis clients, and clients often judge the quality of consultancy services in terms of the images created by the consultant. Because IM may positively as well as negatively contribute to consultants' effectiveness we considered the study of IM in consultancy as very important.

By means of five studies we investigated IM in consultancy. In manifold ways of research (literature review, qualitative and quantitative empirical studies), we aimed specifically for a clarification of reasons and a demonstration of variations in IM performance levels, an identification of behavior tendencies in IM and respective outcomes, a determination of the role of IM competence, and an advanced understanding of IM processes over time.

A literature review described in Chapter 2 revealed that IM plays a crucial role in services, in particular for consultancy, in that IM can be seen as an integral part of consultants' work performance. Further, we focused on finding explanations for variations in IM performance. One the one hand, we showed that individual differences, mainly expressed in an individual's selfmonitoring level, might account for variations in IM performance levels. People low on selfmonitoring are characterized as insensitive to others' reactions while those high on self-monitoring actively respond to others' reactions to obtain favorable outcomes. We also discussed behavior tendencies in IM, making a clear distinction in IM styles and tactics in subsequent chapters. On the other hand, we presented a new insight on variations in IM performance by examining a selfregulation perspective on IM, arguing for failures in self-regulation processes (goal-setting, selfmonitoring and -evaluation, self-efficacy) as sources for IM ineffectiveness. These two perspectives helped to shed light on the questions why individuals vary in their motivations and abilities to manage others' impressions, and why some fail in their IM attempts at certain occasions, but succeed at other times. We closed the chapter with a review of existing methods of IM measurement in general and organizational settings.

As described in Chapter 3, we interviewed consultants, trainers and experts in the area of IM and/or consultancy to learn how consultants, in the context of performing their work roles, try to 
express particular images, which abilities are required and what could hinder them to effectively manage clients' impressions. The results of this study were an inventory of images aimed for, behavioral tendencies in IM (IM styles and tactics), prerequisites and impediments to effective IM (IM competence, self-regulation and self-monitoring), which guided subsequent studies.

In Chapter 4 we empirically explored consultants' IM, in particular three specific IM tactics (personal, professional, and conforming IM tactics) and their potential relationships with consultants' performance. We distinguished between IM tactics used one by one and in combination. Concerning IM tactics used in combination, we used cluster analysis to identify three groups in our sample of 80 consultants having a similar approach in their IM tactics utilization. The identified IM tactics profiles were: (1) versatile profile - high scores on all three IM tactics, (2) impersonal profile - low score for the personal IM tactic and scores below average for the professional and the conforming IM tactics, and (3) naive profile - moderately high score on the personal IM tactic and below average on the professional and the conforming IM tactics. In regard to performance, more specifically, with consultants' perception of how clients evaluate them, we found that when used separately the personal and the professional IM tactics showed a positive relation with consultants' performance. Concerning the IM tactics profiles, the findings suggested that consultants with a versatile profile have the best performance. In addition, we discovered that age, job tenure, and IM competence related to the frequency of IM tactics employed.

In Chapter 5 we explored the two IM styles (authentic acting and role acting IM styles) which evolved from the interviews as behavior tendencies in IM. In the first part of the chapter, a factor analysis of the data provided by 223 consultants supported a 2 -factor structure of the authentic acting and role acting IM styles. In the second part of the chapter, we aimed for an identification of relationships of the two IM styles with potential IM outcomes. In addition to performance we also addressed stress as a potential effect. Moreover, we investigated whether IM competence plays a direct or indirect role in the model proposed. The findings revealed a negative main effect for the authentic acting IM style on consultants' stress, and a negative main effect for the role acting IM style on performance and a positive effect on stress. We found that IM competence related positively to performance and negatively to stress. It further buffered the negative main effect of a role acting IM style with performance. However, the result of IM competence in interaction with authentic acting IM style was unexpected in that an authentic acting IM style combined with greater IM competence was associated with lower performance. Additionally, we found that age was significantly related to stress; older consultants seem to experience less stress. 
In Chapter 6 we investigated IM over time. More precisely, we measured the IM attempts of 726 business students at the beginning and at the end of a course period ( 7 weeks). Their behavior tendencies in IM were measured by their IM styles in addition to five general IM tactics (ingratiation, self-promotion, exemplification, supplication, and intimidation) well-known in the IM literature. To determine IM effectiveness, we received students' participating grades at the beginning and the end of a course. We found that at the beginning of a course an authentic acting IM style and the IM tactic self-promotion related positively to students' performance and that supplication associated in a negative way with students' performance. At the end of a course any IM attempt lost its effect. Further, we found that students did not substantially alter their behavior tendencies in IM over the period of a course. In addition, we discovered that gender, educational experience, nationality and exam grading had a significant relation with IM behaviors employed.

The final chapter is divided in two parts. In the first part, we summarized the findings per chapter by integrating them in two related theoretical perspectives on IM taken in this thesis. These two approaches deal with factors inside the individual potentially determining IM performance. The differential perspective addresses individual differences in personality, behavioral tendencies, and IM competence in clarifying variance in IM performance. The temporal approach has a processorientation and focuses on understanding how IM develops over time. In the second part, we gave suggestions for future research by focusing on aspects not being sufficiently considered by IM research and our thesis: the inclusion of the situation and the audience. A discussion of practical implications completes the last chapter.

This dissertation aimed to contribute to an enhanced theoretical understanding of IM by explaining reasons for variations in IM performances, identifying behavior tendencies in IM, addressing the impact of IM competence, and by learning how IM develops over time. On a practical level, consultancy organizations can profit from this knowledge by taking advantage of the benefits of IM and by preventing the potential drawbacks. 


\section{SAMENVATTING}

Impression management (IM) wordt gedefinieerd als het gedrag van een persoon dat is bedoeld om de impressies die door anderen over die persoon worden gevormd, te beheersen. Aangezien in organisaties mensen dagelijks met elkaar interacteren nemen we in dit proefschrift aan dat IM een cruciale component van werknemersgedrag en -prestaties is. Dit geldt in het bijzonder voor de consultancy dienstverlening, waar succes voor een groot deel afhankelijk is van prestaties bij klanten. Deze klanten beoordelen de consultancy dienstverlening vaak in termen van het beeld dat door de consultant wordt gecreëerd. Omdat IM zowel positief als negatief bijdraagt aan de effectiviteit van consultants is de studie van IM in deze branche van groot belang.

Dit proefschrift over IM in consultancy bestaat uit vijf studies. Gebruik makend van verschillende methoden (literatuuroverzicht, kwalitatieve en kwantitatieve empirische studies) hebben wij in het bijzonder gezocht naar variatie in IM-prestatieniveaus. Hoe is de variatie te verklaren? Hoe manifesteert zich de variatie? Verder hebben wij gedragstendenties in IM proberen te identificeren, evenals hun uitkomsten. Ook hebben wij de rol van IM-competentie trachten te bepalen. Ten slotte hebben wij ons begrip van IM-processen over de tijd willen verdiepen.

Het literatuuroverzicht in hoofdstuk 2 bracht aan het licht dat IM een cruciale rol speelt in dienstverlening, in het bijzonder in consultancy. IM kan worden gezien als een integraal onderdeel van de werkprestatie van de consultant. De bestaande IM-literatuur richt zich vooral op het verklaren van variatie in IM-prestaties. Daarbij neemt individuele zelfmonitoring (self-monitoring) een vooraanstaande plaats in. Wie laag op zelfmonitoring scoort is ongevoelig voor de reacties van anderen; wie hoog scoort beantwoordt de reacties van anderen op een actieve wijze, in de hoop gunstige resultaten te boeken. We presenteren ook een nieuw perspectief op variaties in IM-prestaties door zelfregulering (self-regulation) in ogenschouw te nemen. We kijken vooral naar het falen van zelfreguleringprocessen, tekortkomingen in: zelfmonitoring, zelfevaluatie, zelfwerkzaamheid (selfefficacy), het stellen van doelen (goal-setting), als oorzaak voor IM-ineffectiviteit. Deze twee perspectieven - zelfmonitoring en zelfregulering - helpen licht te werpen op de vraag waarom individuen verschillen in motivatie en bekwaamheid om andermans impressies te beïnvloeden, en waarom sommige mensen op bepaalde momenten in hun IM falen terwijl ze op andere momenten slagen. Het hoofdstuk sluit met een overzicht van de bestaande methoden om IM te meten, zowel IM in het algemeen als IM in de context van organisaties.

In hoofdstuk 3 hebben wij consultants, trainers en experts op het gebied van IM en/of consultancy geïnterviewd. We wilden te weten komen hoe consultants bij het uitvoeren van hun 


\section{SAMENVATTING}

werkrollen proberen bepaalde impressies teweeg te brengen, welke bekwaamheden ze vereist achten en wat in hun ogen de hinderpalen zijn om effectief de impressies van de klanten te beheersen. Deze studie leverde een inventaris van gewenste impressies, gedragstendenties binnen IM (IM-stijlen en tactieken), voorwaarden en hinderpalen met betrekking tot effectieve IM (IM-competentie, zelfregulering en zelfmonitoring) op, die richting gaf aan de volgende studies.

Hoofdstuk 4 is een empirische verkenning van het IM van consultants, in het bijzonder van drie IM-tactieken: persoonlijke, professionele, en conformerende IM-tactieken, en hun mogelijke relaties met prestaties. Wij hebben een onderscheid gemaakt tussen IM-tactieken die afzonderlijk en IM-tactieken die in combinatie worden gebruikt. Met betrekking tot de gecombineerde IM-tactieken hebben we een clusteranalyse uitgevoerd die leidde tot de identificatie van drie profielgroepen in onze steekproef van 80 consultants. De geïdentificeerde profielen van IM-tactieken profielen zijn: (1) het versatiel profiel - hoge scores op alle drie IM-tactieken, (2) het onpersoonlijk profiel - lage score op de persoonlijke IM-tactiek en scores onder het gemiddelde op de professionele en conformerende IM-tactieken, en (3) het naïef profiel - gematigd hoge score op de persoonlijke IM-tactiek en beneden gemiddeld op de professionele en conformerende IM-tactieken. Met betrekking tot prestaties - meer specifiek: de percepties van de geïnterviewde consultants over hoe klanten hen evalueren - vonden we dat de persoonlijke en professionele IM-tactiek, indien separaat gebruikt, een positieve relatie lieten zien met de prestaties van consultants. Het versatiel profiel leverde de beste prestaties. Ten slotte vonden we dat leeftijd, duur van de huidige betrekking (job tenure) en IMcompetentie samenhingen met de frequentie waarmee de IM-tactieken werden aangewend.

In hoofdstuk 5 hebben wij twee IM-stijlen verkend: de authentiek acterende IM-stijl (authentic acting IM style) en de rol acterende IM-stijl (role acting IM style), die uit de interviews naar voren kwamen als gedragstendenties in IM. Een factoranalyse van data verstrekt door 223 consultants leverde duidelijke steun op voor een tweefactor-structuur van de authentieke acteer en rol acteer IMstijlen. We hebben geprobeerd de relaties van de twee stijlen met potentiële IM-uitkomsten te identificeren. Daarbij keken we ook naar stress als een potentieel effect. Bovendien hebben we onderzocht of IM-competentie een directe of indirecte rol in het voorgestelde model speelt. De bevindingen tonen een negatief hoofdeffect voor de authentiek acterende IM-stijl op stress en een negatief hoofdeffect van de rol acterende IM-stijl op prestaties en een positief effect op stress. IMcompetentie blijkt direct positief gerelateerd te zijn aan prestaties en negatief aan stress. Verder tempert IM-competentie het negatief hoofdeffect van een rol acterende stijl op prestaties. IMcompetentie in interactie met de authentiek acterende IM-stijl levert echter een onverwacht resultaat 
op. Een authentiek acterende IM-stijl in combinatie met een grotere IM-competentie is geassocieerd met lagere prestaties. Een extra bevinding is dat leeftijd significant is gerelateerd met stress; oudere consultants lijken minder stress te ervaren.

In hoofdstuk 6 hebben we IM over de tijd onderzocht. We hebben de IM pogingen van 726 universitaire bedrijfskunde studenten gemeten, zowel aan het begin als aan het einde van hun cursusperiode (zeven weken). Hun gedragstendenties in IM werden gemeten via hun IM-stijlen, alsmede via vijf uit de literatuur bekende, algemene IM-tactieken: vleierij (ingratiation), zelfpromotie (self-promotion), voorbeeldgedrag (exemplification), smeken (supplication), en intimidatie (intimidation). Om IM-effectiviteit te meten keken we naar de cijfers voor actieve participatie in de groepsdiscussies van studenten aan het begin en aan het einde van de cursus die ze volgden. Aan het begin hingen een authentieke acteer IM-stijl en de IM-tactiek zelfpromotie positief samen met studentenprestaties en de IM-tactiek smeken was daar negatief aan gerelateerd. Aan het einde van de cursus verliest elke poging tot IM haar effect. Verder vonden wij dat studenten hun gedragstendenties niet substantieel veranderen gedurende de duur van een cursus. Geslacht, opleiding, nationaliteit en verstrekte examencijfers lieten een significante relatie met IM-gedrag zien.

In het laatste hoofdstuk vatten wij de bevindingen per hoofdstuk samen door ze te integreren in twee gerelateerde theoretische modellen die de door ons gekozen perspectieven op IM representeren. Het differentiële perspectief bestudeert het effect van individuele verschillen in persoonlijkheid, gedragstendenties en IM-competentie op variatie in IM-prestaties. Het temporele perspectief hanteert een procesoriëntatie en probeert te begrijpen hoe IM zich ontwikkelt over de tijd. Een indicatie van de beperkingen, suggesties voor toekomstig onderzoek - in het bijzonder naar de rol van de situatie en het publiek - en een bespreking van praktische implicaties completeren hoofdstuk 7.

Dit proefschrift wil een bijdrage leveren aan een beter theoretisch begrip van IM door oorzaken van variatie in IM-prestaties te verklaren, gedragstendenties in IM te identificeren, het effect van IM-competentie te adresseren en door te kijken naar hoe IM zich over de tijd ontwikkelt. Op een praktisch niveau kunnen consultancybedrijven van deze kennis profiteren door de voordelen van IM te incorporeren en de potentiële schaduwzijden van IM te voorkomen. 


\begin{abstract}
ABOUT THE AUTHOR
Sara Safay was born on March 6, 1975 in Tehran, Iran. In 1985 she started her high school education at the Ritzefeld-Gymnasium in Stolberg, Germany, where she obtained her gymnasium degree in 1994. After high school, she started studying International Economic Studies at Maastricht University. In 1995 she decided to switch to International Business Studies at Maastricht University where she graduated in August 2000. After her graduation she decided to first collect (work) experience in the industry and then return to the university to obtain a doctoral degree. In October 2000 she started as a consultant at PricewaterhouseCoopers (later IBM Business Service Consulting), where she worked till the end of 2002. In May 2003, she started her PhD research at the Department of Organization and Strategy at Maastricht University on impression management in consultancy. Since August 2009, Sara is working as a lecturer for the department of Organization \& Strategy at Maastricht University.
\end{abstract}

